ALDEN

UNIVERSITY

A higher degree. A higher purpose.

Walden University ScholarWorks

2015

\title{
Underserved Patients' Perspectives on How the EHR Impacts Their Health
}

Marie Mirna Lexima

Walden University

Follow this and additional works at: https://scholarworks.waldenu.edu/dissertations

Part of the Health and Medical Administration Commons, and the Public Health Education and Promotion Commons

This Dissertation is brought to you for free and open access by the Walden Dissertations and Doctoral Studies Collection at ScholarWorks. It has been accepted for inclusion in Walden Dissertations and Doctoral Studies by an authorized administrator of ScholarWorks. For more information, please contact ScholarWorks@waldenu.edu. 


\title{
Walden University
}

\author{
College of Health Sciences
}

This is to certify that the doctoral dissertation by

\author{
Marie Mirna Lexima
}

has been found to be complete and satisfactory in all respects, and that any and all revisions required by the review committee have been made.

\section{Review Committee}

Dr. Ronald Hudak, Committee Chairperson, Health Services Faculty

Dr. Eric Oestmann, Committee Member, Health Services Faculty

Dr. John Oswald, University Reviewer, Health Services Faculty

\section{Chief Academic Officer \\ Eric Riedel, Ph.D.}

Walden University

2015 


\begin{abstract}
Underserved Patients' Perspectives on How

the EHR Impacts Their Health

by

Marie Mirna Lexima
\end{abstract}

MSN, George Mason University, 2002

BSN, Hunter College of the City University of New York, 1995

\author{
Dissertation Submitted in Partial Fulfillment \\ of the Requirements for the Degree of \\ Doctor of Philosophy \\ School of Health Sciences
}

Walden University

December 2015 


\begin{abstract}
Our modern health care system requires technology that can deal with multidisciplinary and complex processes, operations, and situations. The EHR, by far, is one of the greatest health information technology innovations that satisfy these requirements because of its efficiency and the effectiveness of its features. This study sought to develop an in-depth understanding of how underserved patients' perspectives about their health and illness, can contribute to greater use of the EHR. It also sought to improve their health outcomes and maintain sustainable change in the lives of the underserved. A quantitative non-experimental design study was conducted over a 6week period outside of three different internal medicine clinics, one in the Northwestern and the two others in the Southeastern regions of Washington, DC. Surveys were distributed directly to patients coming out of these health clinics, and participants sent their responses via mail. Data collection included 215 surveys out of 560, but, only 155 fit the overall study categories. A strong level of significance in the relationships between clinical outcome measures and the EHR was identified at a $95 \%$ confidence interval. There were considerable health determinants that demonstrated the essence of patients' perspectives and the need for its incorporation into health outcomes measures for the underserved populations. The study also identified sets of environmental health predictors which acted as facilitators and contributors to a holistic health management model designed to contribute to the needs of the underserved communities. The holistic health model and the individual care plan model derived from the study are applicable at the level of the underserved population. It can help achieve sustainable health outcomes that will save lives and promote better health.
\end{abstract}




\section{Underserved Patients' Perspectives on How}

the EHR Impacts Their Health

by

Marie Mirna Lexima

MSN, George Mason University, 2002

BSN, Hunter College of the City University of New York, 1995

Dissertation Submitted in Partial Fulfillment

of the Requirements for the Degree of

Doctor of Philosophy

School of Health Sciences

Walden University

December 2015 


\section{Dedication}

I thank God first for his love and blessings and for granting me the wisdom, strength, and desire to go on. This dissertation is mainly dedicated to my mom and dad, although not alive today, who have been essential in my upbringing. They made sure their children understood and believed that education was a powerful tool to lead and to serve others; even though they had almost none. My dad always completed his first day of the year speech to us children by saying "Apart from education, I have nothing else to give you." And my mom would finish, saying "we love you; remember that education allows you to do great things." That has always been my inspirational theme; and you bet, it has been carried on to my children.

I would also dedicate this dissertation to my three children: Gaelle, Geoffrey, and Jonathan. There are my reminders, my clock, and my calendar that helped me balance my daily multitasked activities and kept me from procrastinating with my assignments. My children would say to me at times, "Mom, take a break; you act like you are a piece of steel". Of course not, but I was always looking forward for the next academic project.

I could not also do this without the moral support of my brothers and sisters who always understood when I missed a family function, especially our yearly family reunion. Through it all, I learned about strength, resilience, and besides all, the power of prayers. I pray God that I continue to go on and to deliver great things where and when it matters and to bring about change where it matters. 


\section{Acknowledgments}

I would like to thank God for giving me the opportunity to choose Walden University and to have great and wonderful faculty instructors and other faculty affiliated individuals during my academic years. The flexibility of the programs offers open doors for people like me with incredible life challenges and experiences.

I would like to acknowledge my wonderful Mentor and Chair, Dr. Ronald Hudak. The first thing he did was to introduce himself as my Mentor and my KAM Assessor before school started. He emailed me right after his resume to see if his background matched my prospective academic needs as a Walden student, and he asked me to send him my resume as well. It felt that I was already on the road with my new academic endeavors; I thought right then that I was ready to go on. I contacted Dr. Hudak more than I did with my Advisor and he always had an answer, to me he played both advisor and mentor. KAM I was such a challenge, whether grammar, organizational, scholarly writings, or APA citations challenges, he never gave up on me and would write instead, "I look forward to your corrections". It was very important for me to get some encouragement and to know that he was looking forward to seeing more academic progress because I needed that kind of moral booster to push myself to do better. I knew it worked because KAMs II and III got much easier. Dr. Hudak still took the decision to be my Chair; to tell you the truth, I was very reluctant to ask because of all my challenges with KAMs; but asking was the best thing I did. He gave me clear directions and did it professionally, and in the most encouraging way possible. He always looked forward to my corrections. Today, I reached the end point of this wonderful learning experience, and I can say that I was blessed to learn and achieve this great deal of accomplishment under your guidance, Dr. Hudak. 
I would also like to acknowledge my Methodologist, Dr. Eric Oestmann. Dr. Oestmann was the first Faculty to answer my request to join my Research Committee. It was such a great relief having Dr. Oestmann on my Committee team because every other Faculty member I checked already had other projects. I was told good luck in my search each time I had that conversation with someone, something that told me each time that my search for a methodologist was going to be difficult. Dr. Oestmann, thank you for taking this challenging road with me. Your advice and guidance were of great help and benefits to my research and the results of my research. My original sample plan would have been endless if it was not for your advice on finding the minimum acceptable returned sample size for my study.

I would like to thank the University Research Reviewer Dr. Andreea Creanga for accepting to be the Reviewer role for the committee. Without doubt and exaggeration, I think I had the best team in place. I could not ask for more.

I also must give credit to the University Writing Center team and the Library team. There were both on point and because of them, I went home from Residencies three and four with lots of resources that enable me to develop more writing skills from grammar to APA for my dissertation and research project. It was such great hands-on experience and practice. These resources were valuable and easily accessible especially for me with English as the secondary language. And finally, I would like to thank the Research Center for making sure students have all necessary resources available to make their research project possible. 


\section{Table of Contents}

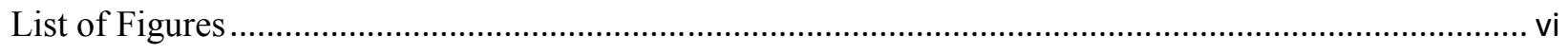

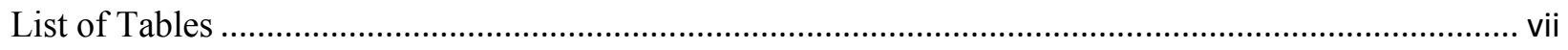

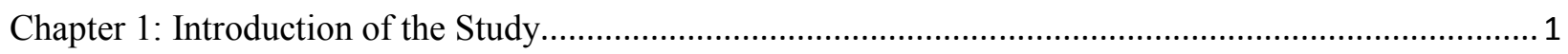

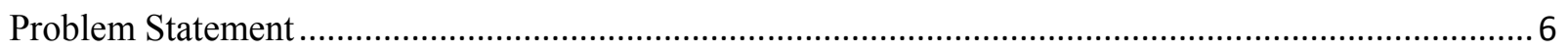

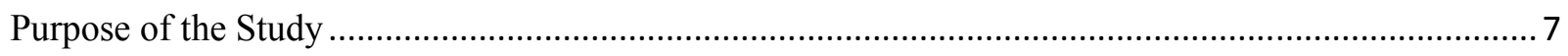

Research Questions and Hypotheses.................................................................................... 8

Research purpose and objectives …………………………………………………………10

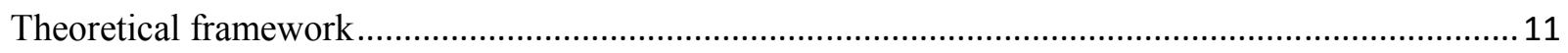

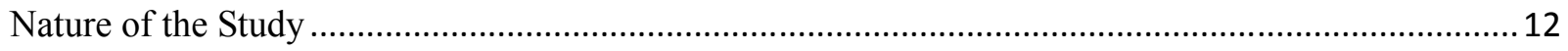

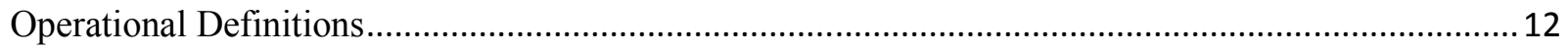

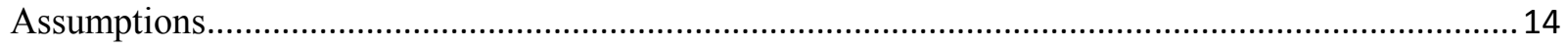

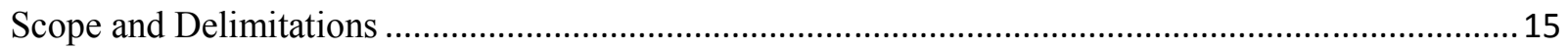

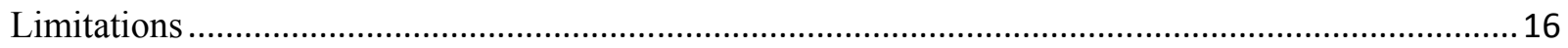

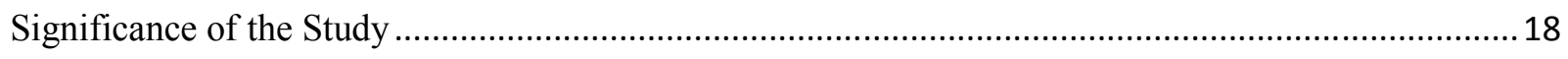

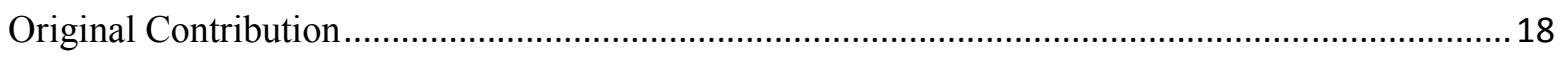

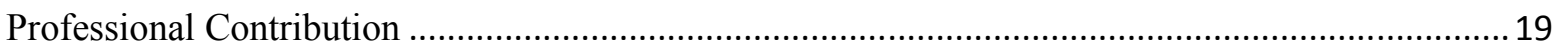

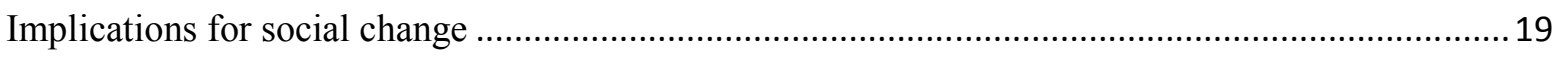

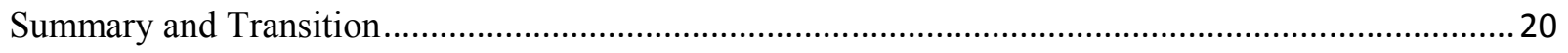


Introduction

Modeling and Simulation in Health Sciences (Banks, \& Sokolowski (2011)

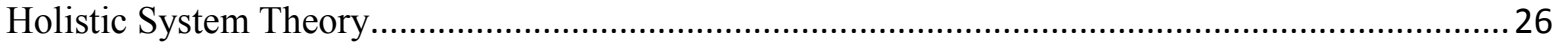

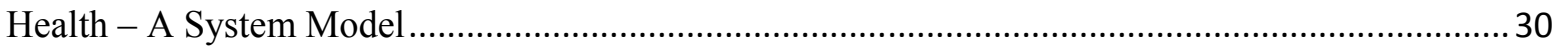

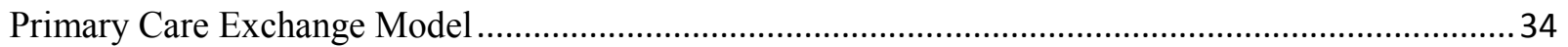

The perspectives of Patients in Health Delivery Care Model ............................................................ 36

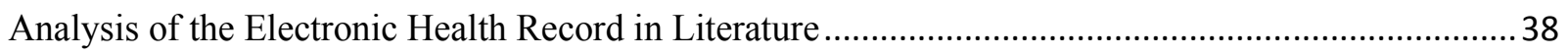

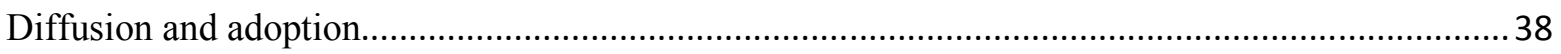

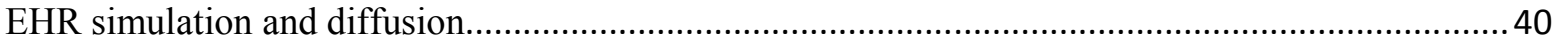

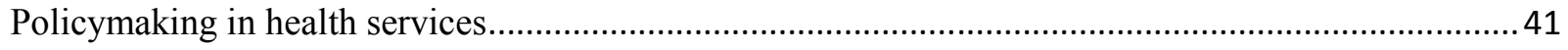

The New Age of Medical and Clinical Practice......................................................................... 43

Clinical innovations and diffusion in primary care practice ..................................................... 44

Analysis of Clinical Health Technology in Literature …................................................................... 50

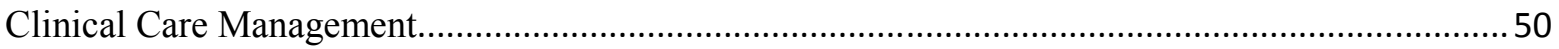

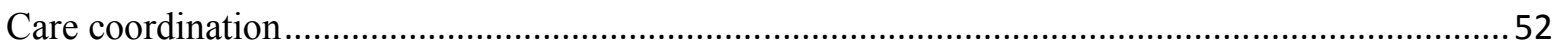

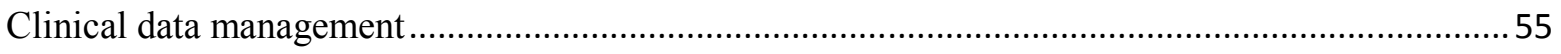

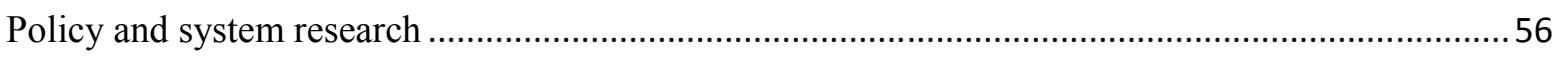

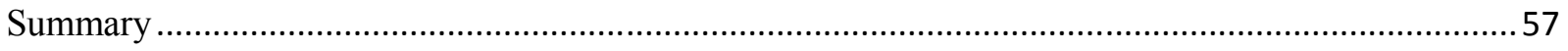

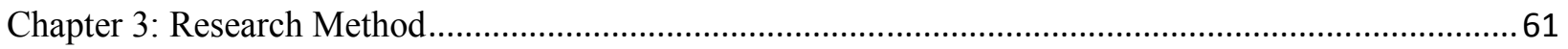


Introduction

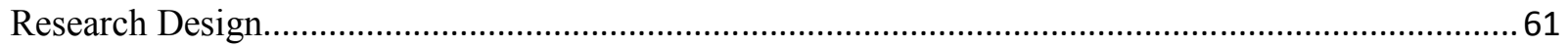

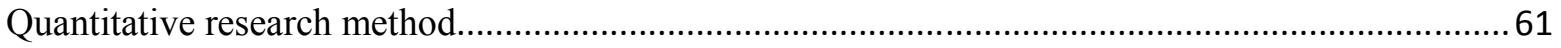

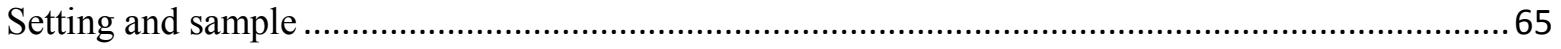

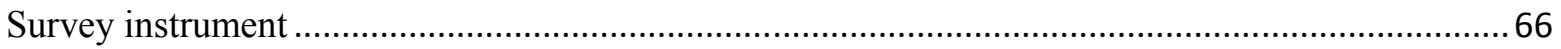

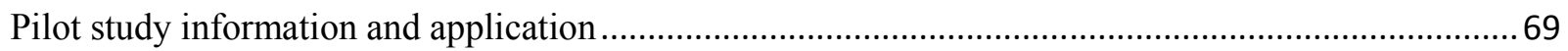

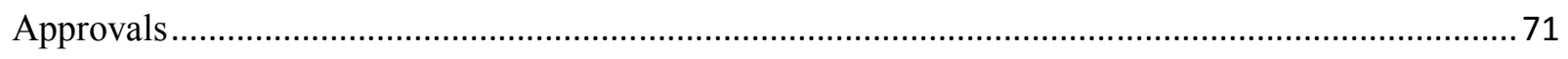

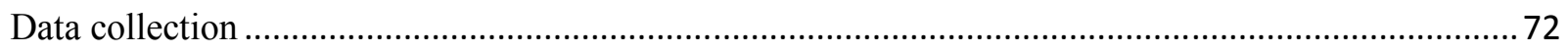

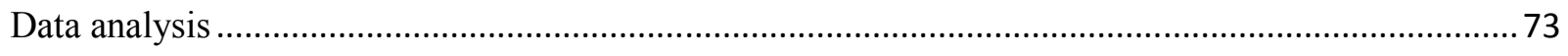

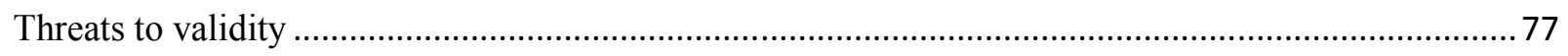

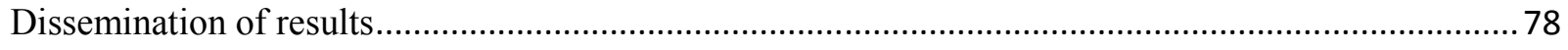

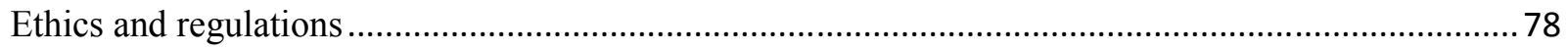

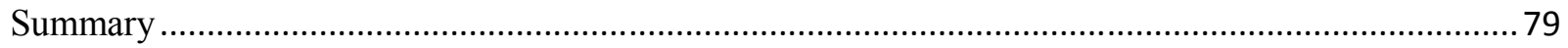

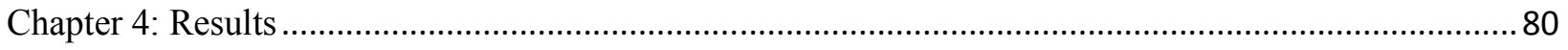

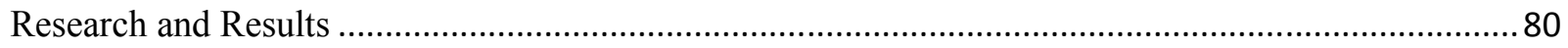

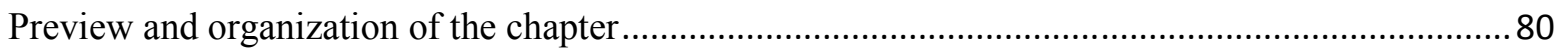

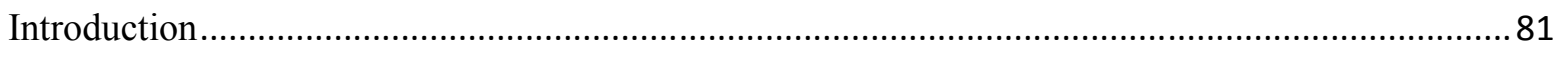

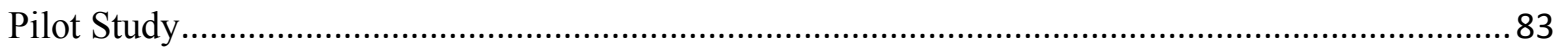

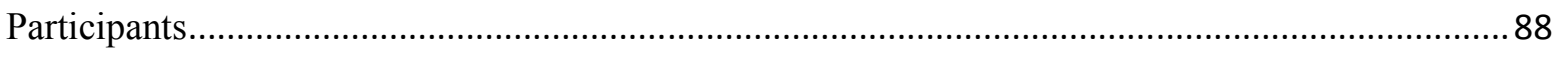

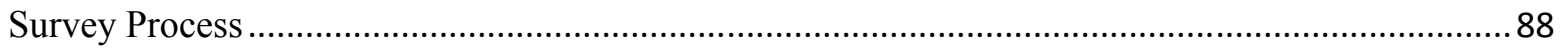


Data organization and analysis

Treatment / Intervention Fidelity. 102

Results. .103

Sample characterization 103

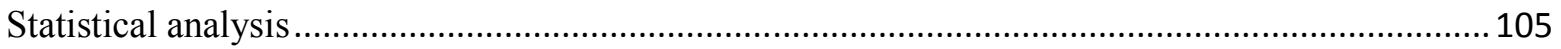

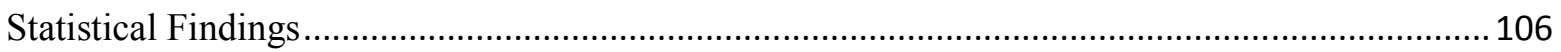

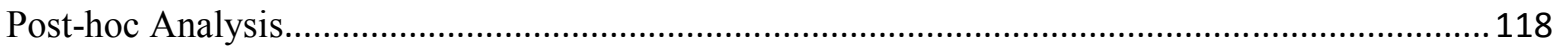

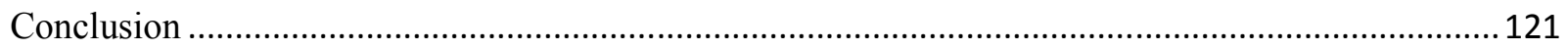

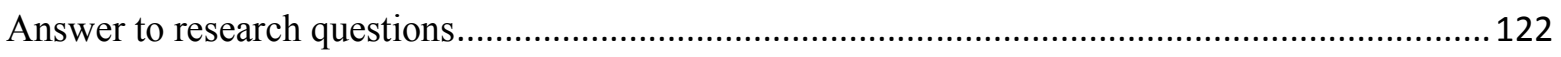

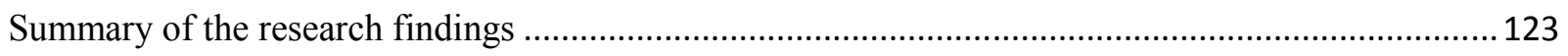

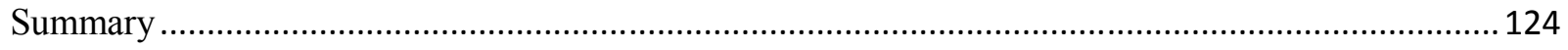

Chapter 5: Discussion, Conclusions, and Recommendations ….................................................... 126

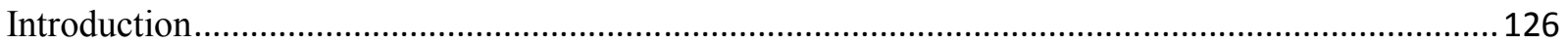

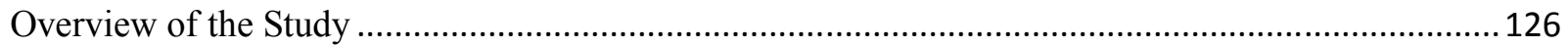

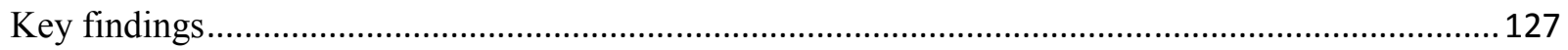

Discussions and interpretations of the research findings ........................................................ 128

Theoretical and Conceptual concept of the findings................................................................. 129

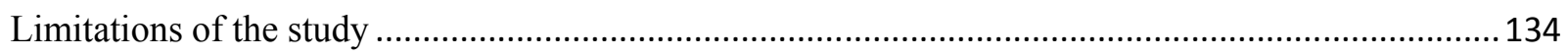

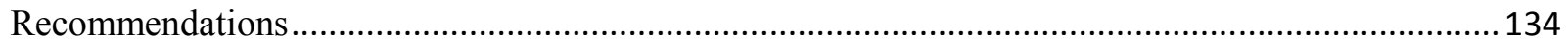

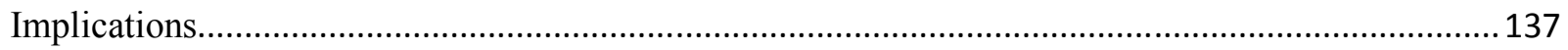


Implications for social change

Implications for future research

Conclusion

References.

Appendices.

.161

Appendix A: Literature Search Engine.

.161

Appendix B: Letter of invitation to Pilot Study.

Appendix C: Pilot Study instrument

Appendix D: Partial survey instrument for the pilot study

Appendix E: Letter of invitation- Main study .175

Appendix F: Research Survey instrument 176

Appendix G Permission for using SF-36 survey 180

Appendix H: Descriptive statistics. 180

Appendix I: Table 1 .187

Appendix J: Descriptive Statistics .197

Appendix K: One Way ANOVA 198

Appendix L: The Bootstrap for coefficients ...... .201

Appendix M: Holistic Health Integration Care Plan Model 202 


\section{List of Figures}

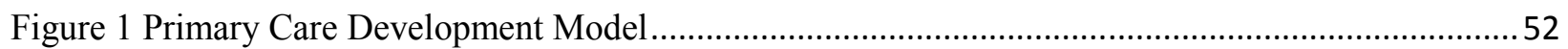

Figure 2 Variables map using a holistic framework. ................................................................... 76

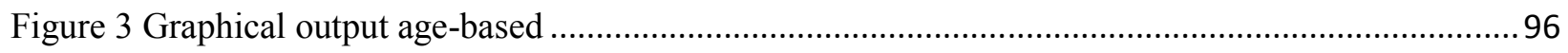

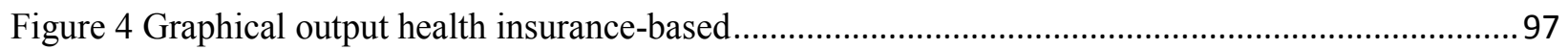

Figure 5 Graphical Output diagnosis-based ............................................................................. 98

Figure 6 Graphical Output disease management-based .............................................................. 99

Figure 7 Graphical Output health care needs-base ..................................................................... 100

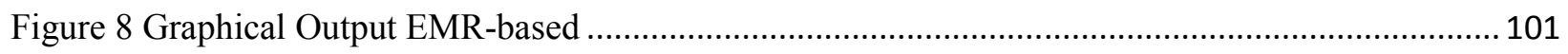

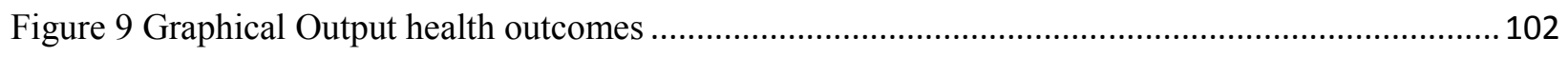

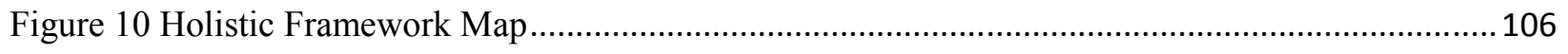

Figure 11 Holistic System Theory Application .......................................................................... 107

Figure 12. Graphical Output health improvement-based ............................................................. 112 


\section{List of Tables}

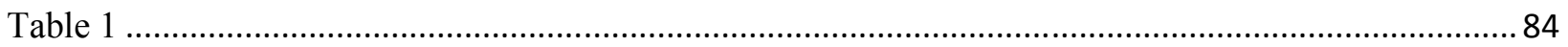

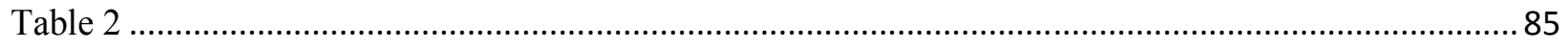

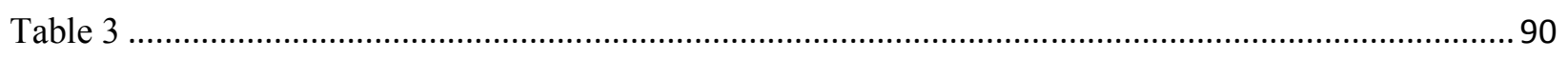

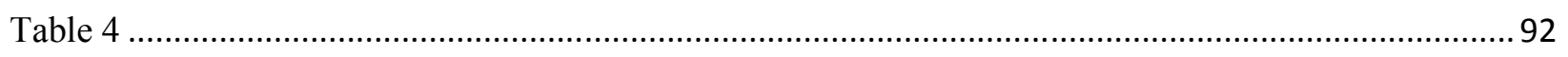

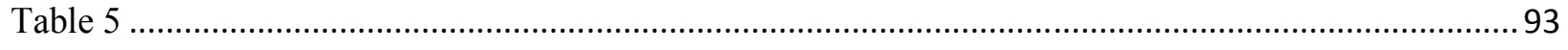

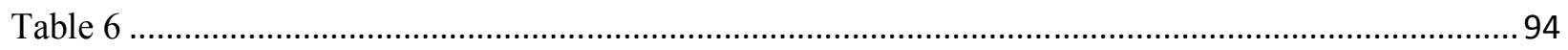

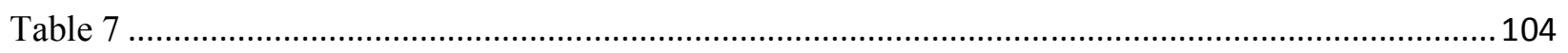

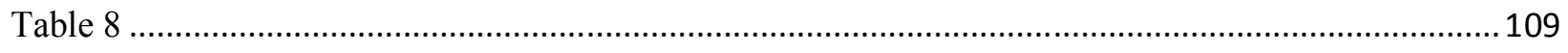

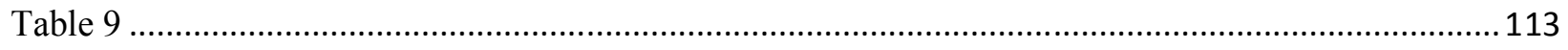

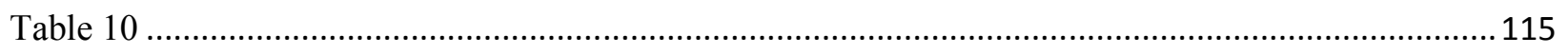

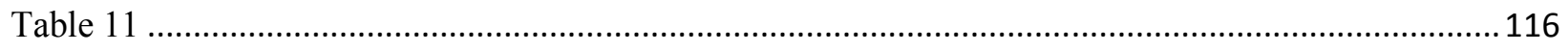

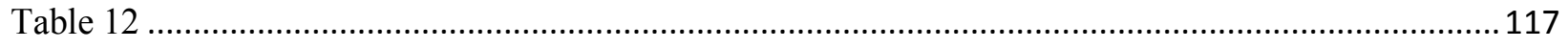

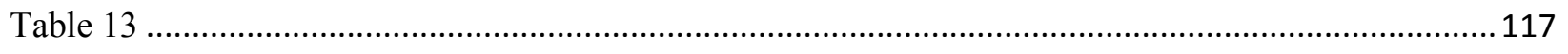

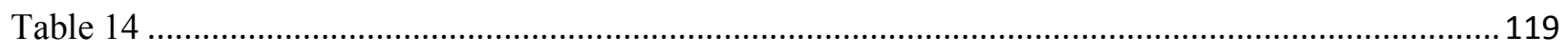

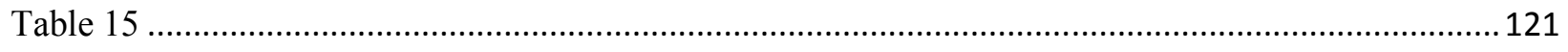

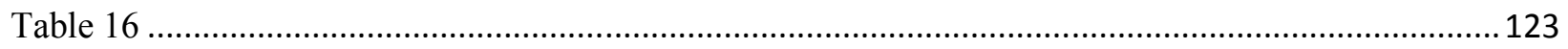




\section{Chapter 1: Introduction of the Study}

The U.S. healthcare system has been under tremendous debate (Brown, 2013), (Harmon, 2013) since the health care reform policy endorsed by President Barack Obama in 2010. Three major components were found to be essential components of the reform: access, quality, and cost (Huntington, et al., 2011). But thus far, there have been too few convincing approaches to changing the way the U.S. health system has been advancing toward the population health improvement (Moreno-Serra \&Smith, 2012). According to Porter (2009), EHRs could facilitate both delivery restructuring and outcome measurement. Orszag (2010) wrote that an independent payment advisory board for providing up-to-date information on controlling costs and creating dynamics should enable consistencies and outcome improvements. Fisher, McClellan et al., (2009) suggested the need for greater integration of accountability with a focus on value and performance. Porter's (2010) perspective offered a high-value achievement for patients to help reduce cost by reducing the needs of others. Kitson (2009) summarized it best when he posited that the health care system is a very complex entity where technologies, practices and processes are to be conceptualized using experimental, evidence-based practices for creating improvement, and effective innovations.

Health information technology has become an essential element in modern health care system operations; it is evolving at a rapid pace in the health industry. One major innovation in health care technology is the EHR, also referred to as the electronic medical record (EMR), an innovative technology system that has been universally adopted since 
the health care reform, although implementation has not been moving at a fast pace (Weiss \& Nunes, 2013). The EHR is one effective communication tool that allows Webbased communication tools across the health industry and it allows doctors to navigate patients' health records at any given time through remote Internet access, for example, in order to prescribe or renew prescriptions. Furthermore, doctors can also address new social media tools such as text memory, email, and alerts. These instant tools are becoming paramount because they continue to provide substantial means to re-engineer health and health care through providers', patients', and families' interactions and communications.

This study sought to determine the relevancy of underserved patients' perspectives for understanding all significant elements affecting the patients' social, cultural and psychological needs for implementing strategies that will not only improve their health but sustain ongoing health improvement for the underserved population. Two theories, diffusion of innovation and holistic health, served respectively, as the theoretical foundations for understanding health information technology processes and for analyzing its interconnectivity with health improvement. These theories enabled solid, supportive, and comprehensive health management solutions that tailor the needs of underserved patients' health, health policies, and health decision making processes. A quantitative, non-experimental survey was conducted to determine the perspectives of these patients on how the EHR improves their health.

There is a growing challenge for the U.S. health care system to demonstrate sustainable health improvement for all Americans (Schiller et al., 2012). The 2012 
edition of United Health Foundation of America's health rankings survey results demonstrated the importance of community and environment and their influence on not only the individual's health but also the population (unitedhealthfoundation.org). Major disparities were found between States and different regions within the States. The effects of these national health concerns are also reflected in the World Health Organization's (WHO) World Health Statistics 2012, where the U.S. was seen lagging behind other developed countries ([WHO], 2012). Major system innovations are in demand so that organized care can be stronger and more efficient. Many agree about reengineering primary care infrastructure in order to improve the nation's health outcomes (Porter, Pabo, \& Lee, 2013); (Grant \& Green, 2012). Others argue against the dominant fragmentation of the health system to achieve universal coverage (Porter, 2009). The strategic value that has been consistent with the debate about the U.S. health care reform is the use of health information technology to secure health delivery through efficient service coordination and care management (Shomaker, 2011).

There is no doubt that an EHR is critical to establish efficient coordination of care in ambulatory care settings (Frimpong et al., 2013). Besides, one of the overarching goals of the Department of Health and Human Services (HHS) Healthy People 2020 is to help individuals of all ages increase quality and years of healthy life, achieve health equity, and to eliminate disparities among segments of the population (Jamoon et al., 2011). Also, one of the leading health indicators focused specifically on health communication and on health information technology that used evidence-based data tracking outcomes and that engaged multidisciplinary and multi-sectorial stakeholders in order to meet the 
goals and objectives set for Healthy People 2020 (HHS, 2012). Many previous studies have demonstrated the benefits of EHR as a great resource to health care providers for coordinating care but that focus little on the patients' perspectives, especially those of the underserved (DesRoches, et al., (2008), Kazley \& Oscan (2008), Ludwick \&Doucette (2009) and Terry et al., 2012). Therefore, determining underserved patients' perspectives on how the EHR impacts their health will be vital to authenticate their needs, their knowledge, and their participation. This is critical not only for clinical decision making process, but also for predicting and preempting undesirable health outcomes (DankwaMullen et al., 2010) that provide comprehensive health services that meet the underserved populations' needs and to remain consistent with improving their health outcomes. This study will explore how the EHR can facilitate broader health improvement while putting value on patients, both community-based care and services.

Background

The American Recovery and Reinvestment Act (ARRA) of 2009, the Health Information Technology for Economic and Clinical health (HITECH) and the Patient Protection and Affordable Care Act of 2010 (PPACA) all emphasized the use of technology to improve care coordination, communication, accountability, and the quality of care. Among these mandates are value-based purchasing and meaningful use mandates that apply not only to billing and reimbursement, but also applicable data demonstrating health outcomes improvement. The EHR was found to be ideal to respond to these mandates (Shih, 2008). Considering the challenge from the numerous visits in ambulatory care over the last few years, 1 billion visits to physician offices, 96 million 
visits to hospital outpatient departments, and 136 million visits to hospital emergency departments ([CDC], 2010), underserved area clinics and community health centers struggle to provide effective health management and coordinate care. Therefore, the EHR should support these clinics to deliver more efficient care and should help providers create more accessible and convenient care for these underserved populations.

Many research studies evaluated the use of the EHR in ambulatory care settings (Lanham, Leikum, \& McDaniel, 2012) but very few demonstrated interests in the patients' perception of the effects of the EHR on their health (Manary et al., 2013). DesRoches et al. (2008) found some association between EHR and quality of care when compared to the dimensions of quality care and physician satisfaction. Zhi et al. (2008), in contrast, found no association in regard to quality care. Garg et al. (2005) suggested equal positive and negative results in regard to quality, safety and patient-provider relations. But in a study similar to Garg et al (2005) by Frimpong et al. (2013), which focused on the quality of care in federally qualified health centers in regard to health information technology capacity in other ambulatory care sites, the authors suggested the need for greater use of technology that directly influences health outcomes and not just the quality of care.

The ambivalence demonstrated in these results triggered the need for this research, which questioned the use of EHR from a patient's perspective and determined its relationships to health outcomes and patients' self-care response. Since patients are recipients of the health services provided to them, it would be important to determine their perspectives on the use of the EHR, not only to evaluate its contribution, but 
primarily to understand patients' concept of health, illness, and health determinants associated with the delivery of care. It would also be important to examine how the EHR may be put to greater use not simply to improve patients' health outcomes but to also maintain a sustainable change in the health of underserved populations.

\section{Problem Statement}

Coordination of care in outpatient settings has always been a challenge even more so since the PPACA shifted the focus to disease prevention and treatment. It is estimated that ambulatory care will see an increased flow of patients with enactment of the PPACA, which may lead to serious needs for care coordination and for management in outpatient settings, especially in areas where health access is scarce (Shomaker, 2011). Policymakers have developed great interest in health information technology since the Health Information Technology for Economic and Clinical Health Act enacted under Title XIII of the American Recovery and Investment Act of 2009. The EHR was found to be an ideal technology that offers care coordination and management to improve health (Shih, 2008). In fact, the Act authorized Medicare and Medicaid services to provide monetary incentives for achieving specified improvement in health care delivery (cms.gov, 2010). Hall et al. (2012) emphasized the crucial need for using collaboration, cooperation, and continuity of services with committed engagement from researchers and community partners to disseminate research findings to the scientific communities as a substantive approach to eliminate health disparities among the vulnerable populations. The lack of efficient and accessible care and commitment to eliminate health disparities among the underserved populations found in the research literature serves as the basis for 
this research study for examining the relationship between patient's perspective and the use of EHRs in underserved area clinics, for examining the patients' response to treatment, self-care, and use of health services, and for exploring its associations and its objectives on health and on the improvement outcomes among underserved populations. In summary, the problem is that it is essential to provide accessible and suitable health services to the underserved population and to explore how EHRs can help meet these needs in order to increase self-health engagement and achieve sustainable health improvement.

\section{Purpose of the Study}

As EHRs continue to get recognition in the health care industry for improving quality of care, it is appropriate to question its relevancy and impact on underserved area clinics and health centers and to examine its association with the overall health services and delivery of care. The purpose of this quantitative research study was to determine the underserved patients' perspective about the effects of EHRs on their health outcomes with respect to care coordination and health management and to examine its relationship to patient's overall improvement in health. These dependent, independent and covariates were explored to determine their relationships and interconnectivity.

With regards toward significant change, this study has the potential to contribute to the major U.S. health reform to decrease cost, improve quality, and promote good health by increasing underserved patients' self-care engagement and self-participation in health related activities through direct digital health information, communication, and promotion. This study advocates for increasing patient's autonomy by allowing them to 
understand and help them make suitable choices toward healthy and achievable goals. This study also has the potential to contribute to building a stronger primary care infrastructure through better coordinated care and service deliveries and better relationships between providers and between providers and patients throughout the US health system in order to improve the overall population health status and ranking.

\section{Research Questions and Hypotheses}

This quantitative study collected data to answer the following research questions and hypothesis:

$H 0=$ Null hypothesis

$H \mathrm{a}=$ Alternative hypothesis

How does the holistic system theory explain the relationship between EHR and patient's health related outcomes?

$H 0$ : Holistic system theory has no significant effect in explaining the relationship between patients' health and their health related outcomes.

Ha1: Holistic system theory has a major role in explaining the relationships between patients' health and their health related outcomes.

\section{H1: $H 0$ different from $H a 1$}

What best clinical or set of clinical outcomes should be measured to determine the effectiveness of EHR for the underserved population?

H0: There will be no clinical outcome measures that determine the effectiveness of EHR on the health of the underserved population. 
There will be significant clinical outcome measures that determine the effectiveness of EHR on the health of the underserved population.

\section{$H 1: H 0$ different from $H a 2$}

How can patients' perspectives be integrated in outcome calculations?

$H 0$ : There is no reason for patients' perspectives to be integrated in outcome calculations. Ha3: Patients' perspectives will be significantly integrated in patient's health outcome calculations.

H1: $H 0$ different from $H a 3$

What characteristics of patients view EHR as beneficial to their health?

H0: There is no difference in the characteristics of patients who view EHRs as beneficial to their health.

Ha4: The characteristics of patients who view EHRs as beneficial to their health will be significant.

\section{$H 0$ different from $\mathrm{Ha} 4$}

How can EHR be utilized to facilitate better relations between providers-providers, and patient-providers; increase patient self-care engagement; and facilitate ongoing health improvement activity measures?

H0: Utilization of EHR has no effects on relationships between providers and patients, patient self-care engagement, and health care related activities.

Ha5: EHR can be significantly utilized to improve relationships among providers and patients, patient self-care engagement, and ongoing health relayed activities. .

$H 0$ different from $H a 5$ 


\section{Research purpose and objectives}

The purpose of this quantitative research study was to determine the underserved patients' perspectives about the effects of EHRs on their health outcomes with respect to care coordination and health management and to examine its relationship to patient's overall improvement in health. These dependent, independent, and covariates were explored to determine their relationships and interconnectivity. This study utilized patients' perspectives and clinical technology innovations to provide a collaborative interdisciplinary health model for underserved populations. There were also several objectives associated with this study:

To understand how patients' perspectives on the effects of EHR may influence clinical decision-making and health outcomes in primary care clinics in underserved areas To explore how the EHR may be put to greater use to address underserved patients health issues

To implement dynamic logistical processes to tailor underserved populations' needs To provide strategies to sustain the transformational change environment following adoption and implementation of EHRs

To inform policy makers on interventions specifically pertaining to underserved populations and to generate venues for facilitating more funds and investments for continuous health improvement 


\section{Theoretical framework}

The theoretical base for determining how patients understand innovation through EHR and their perception on how it improves their health relies on the application of two theories: the diffusion of innovation theory and the holistic system theory. These two theories guided the research questions and objectives of the study. A more detailed philosophical approach and more in-depth explanations about the connection of the research variables to these two theories are presented and supported in the literature review in Chapter 2.

The theory of innovation diffusion describes and provides processes for adaptation, influences, and changes to existing values and needs; in addition, it allows for demonstration of treatment application. It also influences changes in clinical behaviors with respect to promoting and improving health outcomes (Samson-Fisher, 2003). The theory will provide groundwork for exploring the role of EHRs as and how they may be put to greater use to facilitate care coordination and health management for underserved populations.

The theory of holistic systems and thinking provides a uniform platform for coordinating care and managing health (Zott \& Amit, 2009; Pourbohloul \& Kieny, 2011). It also offers a holistic structure that supports influential behaviors and achievement (Senge, 1990; Caldwell, 2012). The same concept supports the provision of comprehensive care management and coordination to allow value and full attention on the patient's health. This includes the patient's physical, physiological, mental, economic, social, and psychological factors to be considered by the entire health care team and 
services to identify areas for empirical examination and improvements (Frimpong et al., 2013). The theory of holistic thinking will be the guiding theory behind understanding the significance of underserved patients' perspectives on their health outcomes and their association with EHRs within the techno-health environment.

These two theories supplement each other to provide a much more in-depth explanation in exploring the current technological environment in underserved areas, for example, clinics and health centers, to determine their effects on this population's health outcomes with respect to their views and needs. The two theories provided the foundation for developing the survey instrument and also offered guidelines for the analytical data, discussions and argument in later chapters.

\section{Nature of the Study}

This was a quantitative, non-experimental study. A research survey was conducted to determine patients' responses and understanding of the effects of the EHRs on their health. A Likert scale was used to measure the patients' judgment, attitude, knowledge, and satisfaction with the effects of EHR on their health and health outcomes. The survey was distributed just outside of the health clinic sites and the survey responses were collected via mail. More detailed information and explanations are provided in Chapter 3.

\section{Operational Definitions}

Health information technology refers to a "conglomeration of technologies such as EHRs, which include computerized provider order entry (CPOE), electronic clinical 
decision support tools, and clinical documentation such as physician notes and discharge summaries; personal health records (PHRs); technology for the management of chronic conditions (such as the use of e-mail, text messaging, or remote monitoring); population health tools (such as patient disease registries, and telemedicine); and data warehouse tools" (Lopez et al., 2011, p.437).

Outpatient EHR: "a functional EHR with four domains: recording patient's clinical and demographic data, viewing and managing results and laboratory tests and imaging, managing order entry including electronic prescriptions and supporting clinical decisions including warnings about drug interactions or contraindications" ( DesRoches et al., 2008). Other components include the "ability to exchange data electronically across organizations or to collect data for disease surveillance" (Jha et al., 2006). Innovation is defined as "an idea, practice, or object that is perceived as new by an individual or other unit of adoption" (Rogers, 2003, p. 12).

Diffusion is defined as "the process in which an innovation is communicated through certain channels over time among the members of a social system” (Rogers, 2003, p. 5) Holistic health comprises physical/physiological health, psychological/emotional/mental health, and socio-psychological/social health and means a comprehensive health defined by the World Health Organization (WHO) (Lee et al., 2012).

Health centers or rural health clinics or safety net clinics or federally qualified health centers are community health centers that provide primary care services to vulnerable and underserved populations in rural and urban areas (Frimpong et al., 2013). 
Interdisciplinary collaboration involves continuous interaction between two or more professionals or disciplines, organized into a common effort to solve or to explore common issues with the best possible participation of the patient (Nolte, 2012). Underserved populations or special populations are defined as "population groups at a higher-than-average risk of death, disease, and disability" Fridel et al., 2001). These include those with economic, cultural, and linguistics barriers (HRSA, 2009), with reduced access to health services, and with lower quality of care when they do have access (Li \& West-Strum, 2010).

Sustainability is defined as continuation of a service beyond its initial pilot funding that makes no judgments about fidelity to original intent (Graham et al., 2012).

\section{Assumptions}

This research study was based on a series of assumptions.

- It was assumed that the EHR would improve the delivery of health care and therefore improve the health outcomes of patients.

- The underserved area health clinics could benefit the most from EHR since these clinics tend to handle more complex and chronic disease patients.

- The EHR has the potential to increase access to care, improve quality care if put to a much greater use to benefit the underserved populations and therefore contribute to better disease management and improve the health status of this population. 
- The EHR was the most appropriate health information technology that would establish change in the US health system while contributing to the elimination of the disparities in the U.S. health care system.

This study can be a step forward to redesign health to meet the goal of universal healthcare - good health for all Americans. If the policies suggested in this study were introduced, there should be a more sustainable change for the underserved population through health maintenance and health outcome improvement. This change should improve the ranking of the U.S. population's health in the future global health surveys administered by the WHO.

\section{Scope and Delimitations}

The scope of the research study entailed distributing as many surveys as possible within the time frame permitted to conduct the research and the ability to reach out to as many patients and collect as many survey responses as possible for a maximum effect size toward generalization of the results. Nevertheless, a minimum survey response can also produce a strong enough interpretation toward generalization of the findings if the correct t-value is used for the selected alpha level. According to Kotrlik and Higgins (2001), an alpha level of 0.5 is acceptable for most research, therefore, was considered an acceptable alpha level for this study. The survey response met above the minimum expectations; there were no needs to expand the research boundaries.

Delimitations for this study also involved the development of the survey instrument and its validity. The theoretical concepts used in Chapter 2 also served as guidance for developing and formulating the survey instrument; few survey instruments 
will be compiled to develop the intended survey instrument. An expert panel consisting of three panelists with different background and who are very knowledgeable about this specific population assessed the appropriateness and the language of the survey instrument. A pilot study was conducted to ensure validity and reliability of the instrument before engaging in the research survey. There was no restriction for conducting the survey since the survey questionnaire was delivered exclusively to adult internal medicine patients attending three underserved areas health clinics. Minors were strictly prohibited from completing the survey.

\section{Limitations}

Several criteria contributed to the limitations of this research study. The first one involved the concept of generalizability of the findings mainly because this research was limited to adult internal medicine underserved patients only; the second anticipated limitation involved the effectiveness of the sample size; and the third from using limited health care centers or clinics sites. It was estimated that the survey response rate would be lower than $100 \%$, to deal with this issue, Kotrlik \& Higgins (2001) suggested increasing the sample size by $40-50 \%$ to account for lost mail and uncooperative subjects. Cochran's (1977) sample size method spoke of the importance of incorporating vital items into the sample size determination. Patients' perspectives, care coordination, and patient's engagement were all used as the founding variables of measure for a decisive sample size for this study. According to Hashim (2010), the minimum returned sample size for a given population, based on Kotrlik \& Higgins' (2001) table, ranges from 55 to 119 for a population size range from 100 to 10,000 considering a margin of error of 0.3 and a 
statistical power of alpha 0.5 and $t$ of 1.96 for continuous data; $80-370$ for a population size range from 100 to 10,000 for categorical data with 0.5 margin of error. Because the survey was voluntary, all efforts to collect survey responses were considered to have at least the minimum sufficient returned sample size. In addition to self-stamped addressed envelope for returning the survey responses, a locked box was provided at the health centers for collecting the survey response. Also, flyers were placed inside and outside of the health centers.

Another potential weakness of the study was the use of the researcher's own data collection tool for this research study. One major issue with self-measured tool is demonstrating its validity and reliability. Therefore to ensure validity, supporting evidence that the instrument measures the variable it was designed to measure (FrankfortNachmias \& Nachmias, 2008) was authentically verified using an expert panel and a pilot study. Another reason for demonstrating validity was because the instrument would have influence on the validity of the conclusions after testing the hypotheses and this concept is strongly embedded in quantitative research (Patton, 2002). To address these issues, the content of the instrument included most relevant information appropriate to investigate the research question and was tested before its application in order to demonstrate the instrument's empirical value. 


\section{Significance of the Study}

\section{Original Contribution}

Underserved populations are defined as populations living in specific geographic areas who face economic, social, cultural or linguistic barriers to health care, and who reside in areas with limited access to primary care services (DC Department of Health [DOH], 2012). These populations are also referred to as medically underserved or medically under-privileged populations. One of the major objectives from the Healthy People 2010 summary report is to help individuals of all ages increase quality and years of healthy life and to eliminate disparities among segments of the population (US Department of Health and Human Services [HHS], 2010). Besides, a well-functioning system should exhibit productive efficiency, meaning that health care resources are put to the best use possible and produce as much health as possible with its share of resources (Baicker, Chandra \& Skinner, 2012).

The concept of EHR in a medical or clinical setting has been explored mostly to look at the relationship between EHR and quality care and also to determine the level of adaptation and likeability of the EHR system among providers and other staff members. However, this study made an original contribution by focusing on the underserved patients to determine their perspectives about whether their health has improved since EHR implementation in their respective health clinics. The findings should contribute to the design, development, and should help implement necessary strategies with supportive information pertinent to identifying and tailoring health improvement efforts and activities for the underserved populations. The findings should also facilitate 
implementations of best practices that aim at obstructing undesirable health outcomes to maintain consistency in the improved health outcomes of the underserved populations.

\section{Professional Contribution}

This study aimed at raising awareness of the importance of understanding patient's' perception of response to treatment, compliance, and self-care management. The underserved patient's perspectives are relevant for understanding ramifications and interconnections between all elements affecting the patient's' social, cultural, and psychological needs for implementing strategies for greater use of EHR. This research study also sought to provide a framework for professional practices, physicians, and practitioners to develop reasonable and practical processes and health interventions while taking into account all possible health determinants pertinent to the underserved community.

\section{Implications for social change}

This study should offer understanding and strategic approaches for dealing constructively and holistically with the underserved community while using the EHR to detect information for tackling and responding to health determinants specific to underserved patients. This study is also expected to support efforts to use innovative approaches to implementing best practices that provide quality and holistic care for all patients; to help develop new processes to improve treatment outcomes, and to promote an avenue for eliminating health disparities in underserved communities. This study sought to enlighten government agencies, policy makers, and health institutions about 
current determinants of health issues that the underserved communities face on a day to day basis. It aimed to facilitate more grant opportunities for underserved area clinics and safety net clinics to provide necessary health coverage and to increase access to care in the underserved community.

\section{Summary and Transition}

The EHR has received major recognition since the Patient Protection and Affordable Care Act was instituted. It has been considered as the best health information technology tool that can improve health through efficient care management and coordination in primary care medicine. Federal recognition of the HITECH law has advanced its diffusion profusely among the primary care network by providing a considerable amount of funding and incentives. A large percentage of primary care clinics have already adopted the EHR or plan to implement an EHR system within the next few years, a major contribution to the adoption and diffusion of the EHR in primary care and health services.

As previous scholars have noted, it is conceivable that EHR facilitates better management and coordination of patient care and health. There is abundant evidence of increased safety, quality service delivery, and access improvement (as reflected in the literature review). Some examples of safety with drug administration, prescription, clinical procedures, and results - in terms of care management, treatment, and clinical decisions- are supported in the literature. More comprehensive exploration is considered in Chapter 2. There is also other rich evidence that demonstrates more accurate information during interdisciplinary and interdepartmental exchange; more detailed 
collaborative exchange is given in the next chapter. It is inconceivable to see that with all the features that the EHR offers and the high cost associated with the health care spending - over $\$ 750$ billion (United Health Foundation, 2012) that our health system remain unpredictable and the U.S. population health ranks still at a level below that of some developed countries'. This implies that the underserved population's health is to be improved as it also has effects on the US population's health ranking and the EHR system implementation ought to be explored to assist with improving the health of the underserved population.

This study, grounded in holistic system and diffusion of innovation theories, was designed to determine the underserved patients' perspectives about the effects of the EHR on their health. It was crafted to explore how the EHR could be put to greater use in order to improve the health outcomes of the underserved communities who have been demonstrated most health care needs and also to bring sustainable change for this population. The holistic theoretical framework discussed in the literature review section in Chapter 2 indicates how collaborative interdisciplinary exchange can produce comprehensive communication that tackles the patient's entire health which considers the patient's physical, physiological, mental, and psycho-social environment. Both theories provide understanding, care coordination, and management associated with the EHR within the primary care network. The gaps demonstrated in different scholars' studies supported the need for this study and further research development in that area. Chapter 3 is dedicated to the study design and methodology for the research application. In Chapter 4, the data analysis will describe important points and discuss the findings. Chapter 5 will 
present conclusive remarks about the study and the findings and potential needs for further research. 


\section{Chapter 2: Literature Review}

\section{Introduction}

Health information technology has been given extensive consideration within the last decade in the delivery of quality health services and the assurance of cost-saving and containment. Its adoption has been widely diffused throughout the national and global health care system. Literature engaging in the progressive impact of EHR on health service delivery and particularly on patient's' health has not slowed down in the face of exploration of this great innovation. This literature review continues, in the same respect, to examine the influence of health information technology, and particularly the EHR, from its nascent state to the most recent clinical innovations, models, and simulation affiliated with health care services. This literature review offers an in-depth understanding of the concept of holistic health and care based on the work of many scholars. The majority of the works cited are within five years, except the work of scholars or philosophers who described the origin, or path, or evolution of the holistic system theory.

An analysis of various bodies of literature contributes to the theoretical value and practical work of previous and current scholars in the field of health information technology that features the EHR. This chapter emphasizes service delivery models, operational processes, clinical decision-making, and health outcomes through health management and care coordination; it also highlights gaps in the literature that prompted this research toward the perspectives of patients - the recipients of health services - 
toward a much more suitable, collaborative, and interdisciplinary model. to improve the health of the underserved populations and sustain continuous improvement in that direction.

The list of journals used is compiled below. More details are given in Appendix

\begin{abstract}
A.
\end{abstract}
Journal of the American Medical Informatics Association

MIS quarterly

Annual Review of Economics

Health Expectations

New England Journal of Medicine

Social Science \& Medicine

New England Journal of Medicine.

Health Affairs

Annals of Internal Medicine

British Medical Journal

Canada Family Physician

Implementation Science

Management Science

Journal of the American Medical Informatics Association

IDS Bulletin

Italian Journal of Public Health

Annual Review of Public Health

Journal of the American Medical Informatics Association: JAMIA 
American journal of preventive medicine.

International Journal of Technology Assessment in Health Care

ONC Data brief

The Annals of Family Medicine

The LSE Companion to Health Policy

American Journal of Preventive Medicine

Joint Commission Journal on Quality and Patient Safety,

Critical Public Health

Journal of Health and Social Behavior

Tufts Managed Care Institute

Hospitals \& Health Network, Academic Search Complete database

Journal of Psychiatric services

Social Work Practice Research

Quality and Safety in Health Care

BMC medical informatics and decision making

Journal of Counseling \& Development

Medical journal of Australia

Journal of medical Internet research

Journal of General Internal Medicine

Journal of the American Medical Informatics Association

International Journal for Equity in Health:

Journal of the American Medical Informatics Association

National Center for Health Statistics 
American Health Information Management Association

Journal of Health Care for the Poor and Underserved

Canadian Family Physician Journal

Health Expectations

International journal of technology assessment in health care

BMC Health Services Research

Health Policy and Planning

Health Services Management Research

WHO Bulletin

Long Range Planning

Journal of Inter-professional Care

Journal of Nursing Informatics

International journal of environmental research and public health,

Information Systems Research

BMC Family Practice

Canadian Medical Association Journal

\section{Modeling and Simulation in Health Sciences (Banks, \& Sokolowski (2011)}

\section{Holistic System Theory}

The Aristotelian paradox of understanding the parts and relationships between them is still justified today when exploring the fundamentals behind a system and its operations (De Savigny \& Adam, 2009). The principles for understanding the dynamics in a functioning system are manifested impressively in Von Bertalanffy's logical approach for any regulatory network (Bertalanffy, 1973). This notion of general system 
theory brought up models, laws, principles that are pertinent to wholeness and sum that imply logic relationships between forces within the system (Bertalanffy, 1947). Von Bertalanffy (1972) strongly emphasized that order or organization of a whole or system can be justified through observation of a living organism, a social group, or even an atom. This strong emphasis was revealed in other philosophers such as Descartes and Darwin explaining the principles of biological phenomenon in molecular genetics and biology (Overton, 2013). The principle of the whole symbolized a much broader thinking in von Bertalanffy statement when he wrote, "if we know the ensemble of the elements and the relationships existing between them, then the higher levels are derivable from the components" (1973, p. 411).

The principles applying to general system theory have developed into a much more interdisciplinary and collaborative ideas and models that appear to be consistent with the evolutionary and innovative approaches such as the integration of electronic information systems seen in today's health care delivery system (Pourbohloul \& Kieny, 2011). In fact, the value of the general system theory can be shared today in the paradigm of the newly adopted care coordination model mandated by our health care system reform. General system theory is not new and has been widely employed; it has also become a classical tool for understanding the complexity of modern technology in many industries and society, including the health industry. The general system conceptual model sets the ground for deeper reasoning for structural correlation and processes that inform the holistic thinking to be manifested in the health information technology within the health industry. The concept fosters collective and interdisciplinary understanding 
that supports sound decision making over hierarchical or linear thinking and methods. Von Bertalanffy's legendary philosophical beliefs and practice are lived today in modern technology and logistic practices.

Another influential thinker in the realm of understanding system perspective method is Peter Senge (Kim \& Senge, 1994). When explaining how the system influences its own behaviors, Senge (1990) believed that systems perspective looks beyond individual mistakes, personalities, events, and bad luck to understand problems; creates conditions that will shape individual actions into structural and efficient influential behaviors and achievements. The concept of generalized thinking remains strongly as a supportive connection to the holistic thinking strategy. The five disciplines are registered in the following order: personal mastery, mental models, team learning, shared vision and systems thinking with personal mastery as a meditative practice using mind-body system; the mental models bring new systemic insights; team training offers collective knowledge; shared vision adds a common sense and purpose; and as for systems thinking, it adds a feedback structure to the holistic structure (Caldwell, 2012). This method will be necessary for understanding patient's perspectives toward achieving better results with greater use of technology.

Dimensional views of system thinking compel us to reason and think of the world holistically through relationships and seek understanding to why things are shaped a certain way and their impact on each other and their ramifications (Daniels \& Walker, 2012). This also compels us to consider the ideas for behavioral modifications, causes and rationales for behaviors, the effects and results on people and society in general. 
Holistic thinking lays out the system activities and embeds all ongoing projects at different levels of the organization from high levels of aggregation to the lowest level of aggregation. In fact, Zott and Amit (2009) affirmed that "activity system perspective encourages systemic, holistic thinking instead of concentrating on isolated choices" ( $\mathrm{p}$. 8). Best and Saul (2011) believed that system thinking represents the model of choice for understanding complex situations. They emphasized on the importance of understanding the problem and they explored alternatives for knowledge creation, synthesis, and application methods; understanding the context to build flexibility to allow for contextual differences; re-conceptualizing science to create new models that aim at solutions with problem-based inquiry and with focused-solution (Best \& Saul, 2011). This is particularly convincing in the case of the underserved population in pursuing problembased and solution-focused strategies pertaining to successful health outcomes. Technology can be integrated to provide methods and to facilitate the logistics of communication throughout all the different components of the system including the patients and family units.

Finally, this concept of holistic thinking compels us to look beyond the obvious and to seek understanding of a more complex world where systems' interplay causes unimaginable effects on the overall team. The same reasoning leads to believe that by taking a more holistic systemic approach with managing or coordinating underserved patients care comprehensively, new models and methodological approaches that implement a full scope of services to these patients can create a real impact on them and their families. 


\section{Health - A System Model}

It has been noticeable that cultural and biological origins in the search of better understanding of social determinants of disease or health have gotten high interest in the field of social sciences. Evidence demonstrates existing extraordinary link between early life events that manifest later during adulthood. Halfon (2009) life course trajectory model showed a convincing strategy on how health is a developmental process that evolves throughout the life span. Power and Hertzman (1997) study a pathways' model demonstrating the strong association of early life events and diseases occurring during late adulthood and also the influence of the early life conditions on adult health. Conroy, Sundel, and Zukerman (2010) argued on the connectivity of childhood social-economic status to adult health. This life course trajectory influences the overall understanding of why some populations are more health flourishing than others.

The concept of health has gotten much broader attention over the last few years (Haffner \& Shiffman, 2013). Vashist, Schneider, \& Luong (2014) posited the evolution of technology plays a tremendous impact on how health is described through the eyes of health professionals, the health industry, and individuals. Jessen (2008) defines health where patients, physicians, providers, and payers use competition at the medical condition level over the full cycle of care as a catalyst for improving safety, efficiency, and quality of health care delivery. Maun (2009) argued that health should be broadly defined as interactive applications, services, and tools that are Web-based services for health care consumers, caregivers, patients, and health professionals while SarashonKhan (2007) understood health as a social movement that uses social software that 
empowers, engages, and educates consumers and providers in health care. However the idea of health is embraced, the technology surge seems to be very significant for understanding the importance of transformation of the health industry through a holistic thinking strategy throughout the health system exchange supporting health and delivery of care to maintain good health.

The notion of holistic care and thought supports the provision of a comprehensive management of care, allowing the entire focus on the patient from the entire health care team and services. Literature supporting health system exchange emphasized on relationship management taking in consideration a broader understanding in the context of trust, commitment, background, shared values, communication, behavior, satisfaction, adaptation, and cooperation. In fact, Sun and Collins (2009) agreed with the literature supportive of strong consideration of the system external environment to bring a holistic approach during exchange and control.

It is reasonable to believe that cognitive and personal determinants exist in even the most simplex system that account for the dynamics in problem solving or even inference driven solutions. Obstacles such as service provision, logistics, stewardships, and management issues can keep a system stagnant. Other issues such as engagement, knowledge, human behaviors, and information may interfere with the system flow. System interventions should be designed to satisfy the overall provision of health while targeting health conditions and diseases or problem particular in order to mobilize all parts inherent to strengthen the whole system. De Savigny and Adam (2011) argued about the imperativeness to know not only what works but for whom and under what 
circumstances as investments in health are expanded and as funders increasingly support broader initiatives for system strengthening.

Understanding the logistics in health care systems allows for better understanding of the connection between system thinking and health. A typical public health model is the social-ecological model where various levels of influence such as individual, family, interpersonal, organizational, community, and public policy, can elicit behaviors with integrated effect to the whole system (Glanz \& Bishop, 2012). The ecological model provides a framework to guide healthy community initiatives to include not only individuals and families, but also institutions, systems, and the social and physical environments of a community (Glanz \& Bishop, 2012). The same can be established from a holistic care approach for underserved communities.

In this approach, philosophy of the holistic system serves as the foundation for considering health as a complete system, featuring all the parts and sub-parts in the system: health, patient, providers, treatment, environment, patient's social network, and other ancillary care services. Pourbohloul and Kieny (2011) posited that a holistic framework is needed to capture disparate diseases and health conditions and their intricate relationships into a unified platform. Atun et al (2010) analyzed the holistic system approach in their research study to the benefit of informing the policymaking process for integrating critical elements that affect adoption, diffusion and assimilation of health interventions. A holistic contribution was also considered in Creswell, Worth, and Shiek (2009) when investigating the integration and complexity of technology in health care. The dynamic of the holistic system theory was exploited to understand the 
interconnectivity associated with health, its social determinants, and patients' views of their health conditions to develop and to change the decision making process to one that offers comprehensive care management, that includes patients' perspectives in decision making, and that collaborates with activities that involve patients' health and care.

It is suggested that ill-health and social problems are interconnected in the sense that historical patterns in a poor society shows how living standards differ not only through the course of social and economic development but also through the health distribution that is also affected by many other determinants of many aspects of life (Wilkinson \& Pickett, 2009). The concept of good health may need to be understood at all levels in order to determine best strategies to improve the population's health. Based on the complexity and variability of these determinants of health, community-based focused projects may be ways to invest and tackle one or few problems at a time and one community at the time with the communities heavily connected and supported. It is ethical that the health reform is justified through all health services delivered throughout the nation.

The issue of privacy has been a primary concern by many users and also by patients. EHR is significantly advanced and it has the ability to share, to process, and to communicate while other different parties are involved (Angst \& Agarwal, 2009). Perceptions and concerns over privacy and confidentiality need to be addressed openly with or between all parties involved including the patient. A range of issues of privacy and confidentiality goes beyond sharing medical information in underserved communities. Other points of interests such as fear to get caught up or reported to local 
authorities such as the police, immigration, social services, APS or CPS (adult/child protected services), are among the issues of privacy concerns among many underserved community patients when it comes to information sharing with EHR. This alone creates reluctance to seek medical care and proper follow up care. Besides, EHR is accessible via remote access through the internet. Although the website may be secured, underserved people need to have assurance that all efforts are made to insure confidentiality of their health information exchange. While the digitization plays a significant role in improving our health system, direct and customized care reminders, including lab and tests results through digital phones, emails, and text messages are also at risks of privacy violation and may need to have regulatory reviews. More in depth study may be needed to inform on secured digital health information management.

\section{Primary Care Exchange Model}

The concept of primary care is widely utilized. It provides the basis and entry point to the health care system, and also continuity for patients and families (Schoen et al., 2009). Provider and patient relationships are more dominant and individualized in a primary care setting than in out-patient care setting. Although the length of visits is limited, patients displayed possessive tone where they refer to their care provider as "my doctor", an eloquent way of showing some bonding, connection, and some trust. Most health issues are discussed at the primary care office and most health decisions are subject to take course or finalized in the office. The idea of keeping primary care at the heart of our health care system is no brainier but definitely requires not only leadership, communication, teamwork, and metrics, but also a sense of responsibility for cost quality 
and service (Gill \& Bagley, 2013) to maintain a holistic care environment with efficient care coordination, process management, and information exchange. While the opportunity for primary responsibility to lead the health care system suits well, this transformative process needs to be consistent with the values that embrace a holistic care approach.

Health information technology has transformed primary care while primary care is transforming the delivery of care. In their research study, Ancker, Kern, Abramson, \& Kaushaul (2011) are convinced about mutual transformation that health IT creates in primary care technology alters clinical workflow, staffing levels, and user perceptions and attitudes; conversely health care providers and health care organizations have to customize technologies to support specific organizational priorities and clinical goals, such as quality measurement or patient safety.

An essential factor in the rebuilt or transformation of primary care is the idea of patient centered care, a health service model that puts expertize of each health care professional to be used wisely and efficiently with an infrastructure building around the patient's health. While this model continues to be recognized and adopted, the rate of adoption suggested lack of feasibility in efficient service delivery and lack of access to usable data (Rosenberg et al., 2012). In their strategic vision for reinventing primary care, Porter, Pabo, and Lee (2013) recommended to put the value on patients by organizing care around groups and subgroups of patients with similar needs, placing the primary care as the crucial player in the health care system. While this model offers a good alternative in the prospective of reforming primary care, it lacks a robust foundation to meet the 
challenges of the constant emerging social, cultural, and economical resources for the changing population and emerging community needs (Gill \& Bagley, 2013). This study sought to provide a much more collaborative and contributive interdisciplinary model that values and engages patients in the health system transformation process.

Information exchange in primary care settings are an essential component that requires trust, and that incorporates the use of resources to fulfill segmented communication channels involving in shared decision-making. Under the new primary care model, the primary care physician has become the ultimate primary care coordinator of the treatment plan for the patient and the patient's family. Inter-professional information exchange has to lead to a mutual idea of responsibility, respect, and consensus toward activities pertinent to patient's health outcomes, in order to produce collective and sound decision on behalf of patients. Mutual understanding and collaboration are critically valued in inter-professional and interdisciplinary clinical practice decision-making. Legare et al., 2011 study emphasized on developing technologies that support information and deliberation to help mapping the process for larger decision making that occurs over time. The goal should be targeted to the delivery of optimal medical outcomes rather it's individualized care, or a group-based care, or population-based care.

\section{The perspectives of Patients in Health Delivery Care Model}

The immensity of the operational transformation behind the health care reform makes it impossible to have a full review of all the successes and barriers affecting 
improvement in care delivery. The health information for economic and clinical health act (HITEHC) authorized not only adoption on the EHR but meaningful use with a multiyear incentives through the Centers for Medicare and Medicaid Services (CMS) with particular requirements for health care practices and hospitals to abide by, including electronic reporting data on the quality of care (Blumenthal \& Tavenner, 2010). Literature supporting the EHR is relevant to Department of Health and Human Services (DHHS) commitment of the electronic driven medical care in support of improving health of the nation. This obvious benefit of the EHR is that it addresses the complexity of the health exchange and coordination throughout the health care delivery system. The new frontier in the US health care delivery must integrate the patient's perspectives with sustainable programs that promote patient and families with the ability to expand care beyond treatment and clinical performances. The fact is that patient situation around their health conditions is unique, changing, evolving, and deserving holistic attention to maintain good health.

In their study analyzing health and medicine concepts in the health industry, van de Belt, Engelen, Berben, and Schoonhoven (2010) elaborated on the changing role of patients and health professionals within the health care industry. Patients were found to be active contributors, active and responsible partners, a level that was seen consistent with stakeholders, a concept that has been considered to improve collaboration between patient and health care providers. This suggests profound consideration of the changing patient-provider relationship and the changing culture of health and medicine toward recognizing patient's perceptions in this health care changing environment. In such 
emerging patient and technology- driven health care system, it becomes obligatory to highlight the dynamics behind the dual characteristics in defense of sustainable development while establishing a supportive, vigilant, and reassuring committed relationship between the two. It is crucial that patients understand the role of information technology in health care and their role as recipients of care.

The literature supporting EHR implementation in primary care already shows a tremendous increase attention but, the development of information technology tools that interface with patients, according to Lopez et al (2011), must be established with patient input and continued feedback using user and patient-centered design processes that closely involve end-users in the implementation process; this should occur during the design and development phase and in the testing stage, in which cultural and linguistic needs can be matched with the technology using end-user focus groups and individual indepth interviews. These in depth interviews should include risks and needs assessments that promote the initiation of a trusted relationship between the health care team and the patient and an invitation to the patient to be involved with participatory engagement while promoting health knowledge and self-care while eliminating daunting barriers to compliance and interest in self-care.

\section{Analysis of the Electronic Health Record in Literature}

\section{Diffusion and adoption}

Over the last few years, the American Academy of Family Physician's (AAFP) 2008 survey noted nineteen commercial vendors of EHR that are available with office- 
based physicians' products. These ranged from AllScripts Professional to Care Revolution, from e-Clinical Works to NextGen EHR, and from Epic Care Ambulatory to e-MDs to e-Prescribing for citing a few. Adoption of the EHR nearly double during the first 2 years period, ranging from 9.3\% in 2006 National Ambulatory Medical Care survey to $14 \%$ in AAFP survey (DesRoches et al., 2008) compare to US hospitals 1.5 to 7.6\% over the same period (Jha et al., 2012). It was anticipated that diffusion would be at a more rapid rate. Since the PPACA enactment, more hospitals and ambulatory care organizations had undergone some type of partial or full adoption. It was anticipated a much higher adoption rate, and to promote successful and significant adoption, a portion of the ARRA of 2009 allowed an unprecedented stimulus package of $\$ 19$ billion under the HITECH bill to promote the adoption and use of health information technology (HIT) and especially EHRs (EHRs) throughout the health care system (Blumenthal, 2009). It is predicted that EHR will reach its maximum market share by 2024 in small practice settings (Ford, Menachemi \& Phillips, 2006).

As health information technology continues to spread, more ideas and concerns evolved around EHR. Many adopters embraced the notion of change without reservation, however many other users found EHR to be a disruptive change (Ford, Menachemi, \& Phillips), others considered it as a digitization of health care (Angst \& Agarwal, 2009). Regardless of the opinions, it is impossible to go back to paper; it requires good collaboration, communication, and understanding to move forward. The ability to exchange data across health care organizations has become necessary as chronic disease management continues to pose encumbrance and defiance among providers and patients 
alike. Many studies demonstrated the importance of EHR for facilitating quality care improvement, achieving greater flexibility with care coordination and care management, increasing safety in treatment procedures although capital requirements and high maintenance costs (Jha et al., 2009).

\section{EHR simulation and diffusion}

Technological innovations are very much influential in organizational systems whether it's for enhancing communication or developing social connections or understanding organizational behavior through analytical construct. This becomes very apparent in the various interdependencies of advanced technology embedded in our health care system, which balances and benefits the interests of the entire system. In this context, understanding the interplays of individuals and collective judgments would be relevant to the entire system to enhance values, responsibilities, and commitment and to diffuse conflicts.

Technology in holistic system thinking brings transdiciplinary and collaborative approaches to most rational elements within the health system that allow increase information about ideas on change, development, and improvements. This idea is very much noticeable in the domains of finance, personnel, scheduling and resource management that embraced the advantages offered by technology within health services exchange in practice management within and outside the health services. The notion of a collaborative approach to produce efficient and sustainable health services through care management and care coordination has been exemplified in the literature. 
When holistic systemic structure is clearly understood, the entire technological process makes interconnections favorable to produce collaborative support to collective reflections and behaviors to produce useful and meaningful solutions for development (Ortiz, 2009). This is also true in health care system where technology helps us understand the concept of function for defining relationships that may lead to discussions such as issues relevant to patients, problem solving, shared meanings, activities, expectations and results. It is apparent that the conditions of technology are more likely to be appreciated as applicable and practical science with most fixations on engineering science.

Holistic system thinking allows a much broader thinking as technology influences general intellectual knowledge and provides opportunities that certainly lead to sustainable change in health services, particularly in primary care or ambulatory health services. Structural health organizational model seems to adopt this broader thinking approach to bring contextual change and innovative resolutions that become fundamental for transforming and adapting to the values placed in the health reform. As with any process of transformation, a clear departure point and a clear structural process are important for avoiding chaotic implications during knowledge transfer within the systemic transformation.

\section{Policymaking in health services}

It was apparent that the rapid market share would trigger lawmakers to review the benefits and barriers relevant to EHR adoption. Blumenthal (2010) emphasized on the provision of the HITECH act as part of the American Recovery and Reinvestment Act of 
2009. He highlighted the providers' technical and logistic problems with health information technology and the commitment from the government investment under the HITECH act to extend HIT to primary care and clinics and maintenance of EHR and to assist with meaningful use. The HITECH bill covers not only adoption, but also the "meaningful use" objectives and criteria set by the HHS to achieve significant improvement in health care processes and outcomes.

According to Blumenthal and Tavenner (2010), the meaningful use requirements include providing patients with electronic versions of their health information, performing drug-formulary checks, incorporating clinical laboratory results into EHRs, providing reminders to patients for needed care, identifying and providing patientspecific health education resources, employing EHRs to support the patient's transitions between care settings or personnel, and quality data reporting. Improving the health and well-being of patients is a very significant characteristic of the bill but it needs to take in consideration the wider health, social needs, and clinically complex of behavioral and psychological problems faced by individuals and families.

Political commitment has a significant role in facilitating a sustainable comprehensive health reform. It will be hard for any country to promote good health without laws and policies that support all elements of good health including holistic health promotion activities. The state government has the responsibility to ensure the good health of the people. In the light of the health care reform, a strong link between all the elements of the health system needs to be tightened by the laws to avoid a disjointed system. It is evident that collaboration and partnerships between health providers, 
communities, local health officials, opinion and religious leaders, capitalize on the capacity of dynamics of the services to coalesce all the components of the health care governance within the health care system.

\section{The New Age of Medical and Clinical Practice}

New conceptual thinking emerged considerably in the US and abroad within the last few years since the Affordable Care Act, the World Health Organization framework for action of 2007, and the United Nations Millennium Declaration in 2010. This new conceptual thinking about a phenomenon may be the fundamental of the matter in all development processes in organizations; it is highly likely that the new way of thinking which appears to be in the fields of health management and coordination, has also brought the systemic way of thinking into the spotlight (Johanessen, Olaisen, \& Olsen, 1999). The collective consensus clearly elaborates on the need for applying a system perspective and method for improving people's health and doing systemic evaluation for improving individual and population-based health outcomes.

A very emerging example of complex system deals with population preventive health where health disparities and determinants of health are dynamically interconnected and cannot be resolved in a linear system approach. Exploration of system complexity will help understand the reality of general system thinking for conceptualizing, strategizing, and implementing organizational change that will certainly have high impact on health and society in general. This concept will certainly optimize the essential functions of the health system with the integration of interdisciplinary collaboration within the system (Pourbohloul \& Kieny, 2011). In light of the growing resource and 
functionality of the EHR, this paper hopes to contribute to a broader delivery of health services with a focus on building collaboration and sustained partnerships via physical and electronic means that not only offers efficiency, quality, access to care but also provides structural conditions and infrastructure in the delivery of health care to the underserved communities.

\section{Clinical innovations and diffusion in primary care practice}

The theoretical framework underlying the value and meaningful strategies for methods of clinical innovations and diffusion in primary care can be understood in diffusion of innovation theory. Diffusion of innovation theory describes the process through which new innovations and ideas become diffused and adopted within wider social networks (Rogers, 2003 \& Murray, 2009). Roger's (1983) diffusion of innovation theory introduced five elements that determine diffusion in the theory application for the health care setting: relative advantage, compatibility, complexity, trial ability, and observability. Murray (2009) utilized the diffusion of innovation theory framework for addressing the gap between research and practice in the counseling profession. Nicol et al (2011) applied the diffusion of innovation theory concepts to identify problems and develop innovative strategies for rapid quality improvement. Dearing (2009) explored the applicability of the diffusion of innovation theory while concentrating on external validity and looked at several ideas: interventions, demonstration projects, societal sectors, adaptation, and leadership. This paper intends to apply the guiding principles of the diffusion of innovation theory in the pursuit of understanding and determining how patients perceive the use of the EHR on their health and how the EHR can be of greater 
use for providing holistic care in consideration of the health determinants associated with the underserved communities.

According to the diffusion of innovations theory, early adopters are the quicker adopters followed by the early majority adopters and late majority adopters; others who resist the adoption are laggards (Vedel et al., 2012). Although adoption in primary care has been accelerated over the last few years, there are many challenges to be considered. Galloway and Ghosal (2012) studied the determinants of adoption to investigate primary care clinics in regard to adoption throughout the major States in the U.S. and found that the adoption probabilities vary considerably by the particular type of clinic, size, geographic location urban versus rural counties, distinction in State-specific laws in respect to information privacy, medical malpractice and state initiatives, and market competitive forces are things that play significant role in adoption though the diffusion rate continues to be vastly increasing.

According to Roger (2003), there are four principles in the process of the adaptive diffusion strategies: innovations, communication channels, time, and social system. These principles are essential to understand the adopters' perceptions in their adoptive decisions in relation to values, needs, and meaningfulness. Therefore, needs, values, and even meaningfulness may be structurally, economically, and socially different for urban health clinics as opposed to rural health clinics and more specifically, underserved area or safety net clinics. Rogers (2003) also asserted that multiple approaches be used to diffuse the innovations within relevant social networks to increase their immediate benefits. In 
this context, this paper explores all possible strategies that may increase the benefits of the use of EHR in improving the health of underserved communities.

While late adopters are viewed as being laggards, many late adopters such as health centers, underserved area clinics, and solo practices are not laggards by choice but are sometimes caught in the complex operational determinants and economic factors associated with costs, qualifications, budgetary pressures, and maintenance of the transformation incurred with health information system implementation. Many of them rely on government support and on grants for adoption as the EHR is outrageously expansive and demands extensive preparation. The American Recovery and Reinvestment Act of 2009 has certainly raised the interest of policymakers into health information technology adoption. A portion of the bill authorized incentive payments to providers through Medicare and Medicaid services seems to booster adoption even more by primary care physicians for achieving criteria-based meaningful use requirements that improve health care delivery services in the U.S. (Hsiao, Hing, Esther, Socey, \& Cai, 2010).

According to the National Ambulatory care Survey, there is a consistent increase in adoption from year 2009, 2010 and in the preliminary report of 2011 from $14.2 \%$, $46.4 \%$, and 54\% respectively (Jamoom et al., 2012). While the study demonstrated great progress toward adoption, there are still $46 \%$ of non-adopters and an increase concern about sustainability post EHR implementation in primary care. Graham et al., (2012) study addressed challenges from service innovations following initial funding and implementation that interfere with securing long-term sustainability. Their research 
findings suggested a non -stagnant situation with a moving goal, in which clinically led development are to be compatible with the need to respond to changing expectations and priorities from external stakeholders. This can evidently be demonstrated by a healthily adaptable, patient-focused system that is capable of responding to changing needs and expectations (Graham et al., 2012). Sheridan (2012) argued that while everyone involved with the EHR is a winner, the barriers of knowledge need to be overcome to secure sustainability.

The concerns about sustainability of EHR are globally shared. Hernandez-Avila et al (2013) argued that operating funds and most importantly political commitment are the most identified difficulties in their case study of the public health system in Mexico. EHR implementation across Canada also presented tremendous challenges with sustainability. The consensus is to shift toward a decentralized approach (Millar, 2012; Grrenhalgh, 2010; \& Webster, 2011). While the idea of sustainability revealed an overarching issue for considering EHR implementation, there is still cloudiness that impedes the success of EHR and continued progress. This paper asserts that patients' perspective may play a significant role in developing strategic processes that sustain growth and successful implementation.

It is necessary to recognize the patients as the ultimate recipients of the care delivery and any change in the process of care delivery should take consideration of the patients understanding, knowledge, and even the most complicated situational determinants in the transformation process. The idea of one size fits all does not work as it has been experienced before with the national smoking cessation and obesity programs. 
Ancker, Kem, Abramson, and Kaushal (2011) a triangle model that identified structurelevel predictors and characteristics such as technology, provider, organizational setting, and the patient population with integrated perspectives from both health services research and biomedical informatics, and examples from evaluations of electronic prescribing; but lack itself from patients' perspectives although the design affirmed patient-centered care. While this paper supports patient- centered care, the structural process involving the health and care delivery has to be essentially in alignment with the patient's ultimate needs in order for care to be effective, goals to be sustainable, and health to be satisfied and promoted.

Today, the analysis in providing holistic care impels us to believe that the reason for complete health and delivery of care can be more efficient through technology used and also through learning from the patients themselves about their needs, the socioeconomic factors influencing these needs, the cultural background, and personal experience and understanding of self-conditions and self-care that provide beneficial and sustainable results in our health system delivery. This is particularly in alignment with Bombard, Abelson, Simeonov, and Gauvin's (2011) findings in their mixed design study in which they used an interactive participatory approach to elicit ethical, social, and cultural values to inform the health technology assessment in Ontario, Canada and to explore the feasibility of a participatory approach of cores conditions for universal access, choice, and quality care.

There has been a noticeable increase in the literature pursuing the development of health technology used during the era of our health system reform. Baicker, Chandra, and 
Skinner (2012) posited that health care systems be designed to foster innovation and promote its use in patients for whom high health benefits will accrue without incurring government debt. Realistically, health care will have to incur expense and debt if it has to be transformed to offer better health and better access to care. Baicker, Chandra, \& Skinner (2012) proposal toward a complete view on the US health care spending with the emphasis on a substantial costs redistribution associated with transferring resources and inefficient use of health care resources may sound intriguing, it is hard to predict that technology will reduce costs and challenge slow growth while the system and its maintenance and training cost a fortune. It is reasonable to assume, however, that better health or better care leads to a better return of investment if health outcomes and change in health improvements are reproducible and sustainably consistent with the population's health.

The variables in determining health around the individual are also circumstantial and require profound attention, especially in underserved populations. Bodenheimer (2007) strongly believed that care coordination was virtually impossible without a strong primary care foundation to the health care system for which he suggested a medical home for each person and family. The dual functionality of the primary care physician or provider as generalist and coordinator calls for a thorough understanding of the practicality in the essence of ramifications, interconnections, and interrelations in system application in a patient centered environment (Honore et al., 2011). Consensus has been incoherent at different levels during delivery of service. A lack of partnerships, collegiality, and collaboration alone with lack of clarity on responsibility and 
accountability at the point of care exchange or transition among health care providers are often the reasons. Leadership and all key players in our health care system are needed to improve collaboration at the point of transition to help providers think of working better together and decrease the fragmentation at the point of care transition (Clauser et al., 2011).

\section{Analysis of Clinical Health Technology in Literature}

\section{Clinical Care Management}

It is necessary to understand the primary care environment in the context of this paper. The primary care system includes physicians' offices (POs), hospital outpatient departments (OPDs), community clinics, and community health centers. Health centers are primary care safety-net providers because they aim to meet the needs of underserved populations in the United States, including the poor, uninsured, homeless, and minority populations. Studying the relevancy of underserved patients' perspectives in primary care clinics about the beneficial contribution of the EHR on their health may provide very valuable insights in the long run in dealing effectively and sustainably in the provision of eliminating health disparities facing by underserved communities.

It is evident that the health care reform mandates comprehensive improvement in the way health care services are delivered to patients. Sometimes, sharing true stories may help understand difficulties commonly encountered in underserved area health clinics or centers. This particular actual story is a typical example of involves a patient within the primary care network. This particular patient had four different chronic 
diseases, including extreme obesity; she missed all her appointments because her conditions had become too much a burden on her family and even transportation was a challenge as she had to be fitted in only particular vans with a lift to get her in and out of her bed and home. Her insurance would not cover a visiting nurse but only a part time home health aide that she claimed is not even regular because her neighborhood was too unsafe. The health agency itself had difficulty handling her case; it was a challenge keeping a steady home health aide just because of the neighborhood she lives in. She encountered the same problem with all other services that were recommended to her such as physical and occupational therapy, as well as the home nursing care and treatment. At thirty eight, she was praying that she gets enough support to regain her mobility and autonomy with self-care. Her primary care physician would not renew her medications because she has not been seen for a while. Although she had referrals to other specialists, she could not make her appointments because of difficulties with self-care, mobility, and transportation issues. This points out the need to look at diseases and treatment differently and to re-invent the health and treatment in the twenty-first century to offer the holistic understanding of health, the skills, passion and commitment required to be the core of a social movement which advocates for new healthy, equitable and sustainable economic and social structures (Baum, 2008).

Primary care is at the heart of the health care services to ensure preventive services and health management services are delivered accordingly. Unfortunately the health care delivery system is so sectored that it almost impossible to achieve consistent health management and provide universal health. The literature in Public Health 
emphasizes considerably on the social and environmental determinants of health as critical indicators for disparities or inequities seen in mortality, morbidity and mental illnesses. Awareness of these indicators needs to be increasingly promoted in community health for decision making in health practices and for making policy recommendations.

\section{Care coordination}

Care coordination has been defined as "function that helps ensure that the patient's needs and preferences for health services and information sharing across people, functions, and sites are met over time" (Bodenheimer, 2007). The EHR makes that process possible, bringing the divide existing between in-patient, out-patient, specialty, and sub-specialty care and the social network surrounding the individual's health in our health service delivery system. A primary care development model as shown below is strongly needed in light of improving health and care coordination.

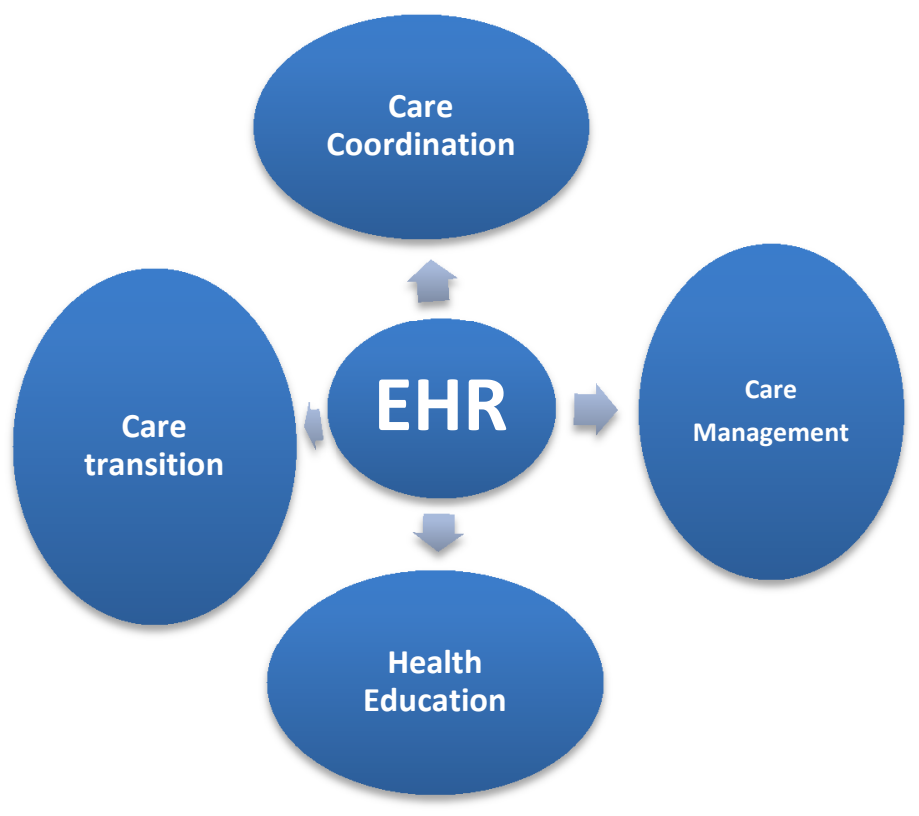

Figure 1 Primary Care Development Model 
One of the primary characteristics of care coordination lies in the referral management process. Successful referral requires significant coordination and interactive communication between patient, provider, and the specialty and sub-specialty care (Hysong et al., 2011; Foy et al., 2010). For this reason, e-referral has been given a lot of recognition in the light of health care technology implementation in primary care. It provides a development of responsibility for a caring patient among multiple services and requires accountability of each individual service. In their study, Hysong et al (2011) posited that e-referral policies to standardize roles and responsibilities and adequate resource for patient transition need to bring clarity to role and responsibilities across the referral-processing practice to ensure a successful process. It is hopeful that health information continues to evolve in that direction as its widespread adoption continues to grow within the primary care system.

The impact of EHR on medical and clinical management has been well studied. Ancker, Kern, Abramson, \& Kaushal, (2012) assessed the impact of information technology on health care quality and safety and other health information technology applications to health. The electronic prescribing was used to demonstrate how eprescribing technology reduced prescription errors and improves safety. Ancker, Kern, Abramson, \& Kaushal, (2012) evaluated the impact of information technology on health care quality and safety and other health information technology applications to health. The electronic prescribing was used to demonstrate how e-prescribing technology reduced prescription errors and improves safety. 
In people with more complex care needs, EHR was not put in use to respond to individuals' situations. McCullough, Christianson, \& Leerapan (2013) conducted a cross sectional analysis to estimate the impact of EMR effectiveness on health outcomes in diabetes patients. The results of their study showed minimal significance in the adoption of EMR and health outcomes of patients with diabetes. The results also showed no significant improvement in individual measure. In their analysis demonstrating the actual function of technology, Cutis (2012) general findings suggested there is a net consumption benefit associated with efficient health care delivery and that issues of equity tend be toward health care technology used for younger populations. Health expenditure in the United States tends to be drenched from chronic disease management and other degenerative diseases. The notion of improving care coordination is to balance cost and quality services while reducing hospitalizations with efficient care management which represents a challenge for primary care from lock of resources.

Another component of care coordination in primary care is medication management. Because chronic care requires multiple medications from different disciplines, chronic care management and clinical decision making are challenged. Cardiovascular disease alone accounts for 2 million heart attacks and is associated with more than 800,000 deaths in the United States with a medical expensed and productivity losses for about 450 billion annually (Frieden \& Berwick, 2011). It is estimated that the EHR will reduce health care cost and increase security. In fact Zlabek, Wickus, and Mathiason (2011) study results about EHR impact on the cost of care and safety, found significant reduction in hospitalization, transcription costs, medication errors, and 
medication events associated with medication errors from $66 \%$ to $55 \%$, demonstrating rapid improvement in cost and safety post inpatient EHR implementation. A recent study on the impact of ambulatory EHR adoption on cost by Milstein et al (2013) also showed slow ambulatory cost growth post implementation. Among other functional features such as e-prescriptions and e-test orders are considered in the cost analysis of EHR in primary care, e-prescription is the electronic prescription data exchange between primary care physicians and the pharmacists. Forty per cent of all prescriptions are transmitted electronically to pharmacies since the incentive programs (Grossman, Cross, Boukus, \& Cohen, 2012). Data infrastructure in e-prescribing system includes patient demographics such as telephones, email address where patients can be easily sent reminders via text or email. This method has been proven to increase adherence in medication management (Hufstader, Swain, \& Furukawa, 2012).

\section{Clinical data management}

Clinical data management is considered one of the best features in clinical and medical technology. EHR has the prospective to increase access to health care, reduce medication errors, and improve administrative efficiency and quality of care (Blumenthal et al. 2006; Chaudhry et al. 2006; Amarasingham et al. 2009, Li \&West-Strum, 2012). A study by Garrido et al (2012) of Kaiser Permanente health care system supported this assertion. Their study showed improvement in productivity, increased work flow and efficiency. This data was compared and used as evidence-based to help advance other clinics within the system that had difficulties after their EHR implementation. Tracking the health of the population is essentially convenient and practical for adopters to provide 
evidence based research or to contribute to scientific study to better manage the health of their patient. EHR has the capacity of collecting and handling large volume of data relatively quickly at the practice level (Terri et al., 2012).

\section{Policy and system research}

Policy makers rely heavily on health system research to enact, promote, and defend health care laws. The role of health policy is influenced by many different health care variables when it comes to public health service delivery, health care management and administration, and public health education, and requires all levels government attention to deliver sound policies, methodologies, and other goods to the public. Such health variables may include the physical environment where people live and work, their biology and behavior, social-economic factors, and access to health services (Komro, O'Mara, \& Wagenaar, 2012). For these reasons and others, significant attention has been given to new policies and innovations associated with the health of the public to address all social and physical determinants of health (Wallace, 2012).

Social determinants of health have been given some attention in the literature. There is also strong evidence that supports actions to tackle the social determinants of health and health inequalities, but interventions need to be not only effective but also for whom should they be tailored and to whom information should be disseminated (Bambra et al., 2009). The World Health Organization (WHO) Commission on Social Determinants of Health (CSDH) brought together global data as a way to reduce health inequities, or inequalities, justifying the role of economic and social policy in improving health and health equity (Friel \& Marmot, 2011). It is in the same perspectives that this 
study hopes to inform health policy the demands for population specific characteristics that should influence health technology innovations in order to see consistent health results with the underserved communities and increase overall population's health.

It is imperative that the electronic health system is acquiescent to different populations if it's going to be the tool to help resolve our public health issues, especially the underserved areas populations. Frimpong et al., (2013) conducted an extensive research that focused on the quality of care in federally qualified health centers and its association in regard to health information technology capacity. The results of their study suggested the need for greater utilization of technology that directly influences health outcomes and not just the quality of care. López, Green, Tan-McGrory, King, \& Betancourt (2011) research study strongly emphasized on the crucial need to address health disparities during system implementation, so the system is designed to support information that is pertinent to identifying data and tailoring development efforts. They also identified possible gaps and high need for empirical study of EHR that focused on the needs of diverse communities. A collaborative interdisciplinary design as indicated in the goals and objectives for this study should provide policymakers with suitable tools to influence future health technology innovations and to update current innovations and develop various paths for adoptions.

\section{Summary}

An abundant analysis of literature from numerous fields was identified and discussed in this chapter. There has been sufficient evidence to support the incredible progress made throughout the health care system over the last few decades, from evidence based- 
practice to quality improvement and more particularly to technology and scientific research and studies. However there are also a lot of gaps to be addressed and conceptualized into applied science more precisely within the primary care network.

There is no doubt that the US health system is extremely big, complicated, and expansive. For this reason, the health care industry has been under tremendous challenge to find best appropriate measures to improve the community health and control cost. Health policy in the other hand banks on quantitative and qualitative research studies to advise law makers on their decision making process. Various diffusion of technology paradigms have been developed over the last decade in the health care industry and it continues to impact the health service deliveries as it transforms in and outpatient services. Literature supporting primary care transformation emphasized on reconceptualization of primary care in order to achieve sound and consistent health results and build up a stronger and healthier communities.

The concept of the whole noted in holistic theory embraced not only a philosophical understanding for analyzing and exploring health and its determinant variables but also added reasoning to the most complex health situations in the pursuit of delivering ultimate care. This is very significant in rural health services or in underserved areas health centers or clinics, as they striving to accomplish more with less. As noted earlier in this chapter, the concept of holistic care set the tone for considering all subsidiary health determinants if extensive care or treatment is to be delivered. The logistics are essentially important to allow all branches of the health system to interconnect internally and externally in order to deliver efficient and adequate services. The EHR provides the 
logistics to facilitate the communication within the system. Many scholars believed that it would be worth exploring the EHR for greater use, a scientific ideal that this study seeks to examine with the underserved community. It is evident that this is also an area where health outcome research will need to explore further.

The literature review supported a growing acceptance for evidence-based practice medicine and a growing interest in EHR, but robust adoption and implementation are not sufficient enough for policy decisions in primary care. There are still weak collaboration and minimal inter-relationships between providers and a lack of accountability during care transition or transfers at decision making process or in determining responsibilities. It is anticipated that the findings of the study will contribute to the development of a new comprehensive collaborative interdisciplinary model that will be suitable for primary care, to move beyond quality measures and interventions, to implement along with the EHR, efficient care coordination and health management for the underserved communities. While the anticipated extensive collaborative interdisciplinary model is obvious for a complete transformation of primary care, it will require direct impact on policymaking and decision making process at local, state, and national levels, at public and private health services as well. The research study seeks to provide all these necessary benefits. Therefore, great emphasis will be put on developing and establishing purposeful relationships through better understanding of patients' perspectives in the clinical and non-clinical environment while using the EHR as a conduit to arrive to sustainable health improvements for the underserved population. 
The methodology for conducting the research study, the survey instrument, and all the associated requirements such as the validation of the non-existing instrument are discussed in the next chapter and are detailed in the appendix sections of the proposal. 


\section{Chapter 3: Research Method}

\section{Introduction}

In Chapter 1, I identified the problem" determining and examining the relationship between patients' perspectives and the use of the EHR in underserved area clinics to examine its association and its objectives for improving health outcomes among underserved populations. The intent is also to use community-based research to make a significant contribution to health policy and health outcome research that help underserved communities. This chapter is dedicated to the research design and methodology that will be used for the study. The research survey instrument, the data collection and analysis, the validity of the methodology used, and the dissemination of the results are discussed. Data will be gathered to explore the EHR, to examine any relationships using the environmental, social and economic, and psychological contexts of the patient to identify knowledge and relationships between variables, to cultivate insights, and to analyze for the development of a comprehensive collaborative interdisciplinary care model, not only for the underserved populations but one that will help any other population.

\section{Research Design}

\section{Quantitative research method}

The design chosen for the study is a non-experimental quantitative research design. A research survey will be conducted to determine patients' perspectives and 
response about the effects of the EHR on their health and to examine any association with their health outcomes. Major determinant variables and moderate variables will be characterized in the form of care coordination and care management, will be recognized, and examined to determine cause and effects and relationships. The literature revealed how survey research has been used extensively by local and national governments, and for global research. There are several reasons for choosing to conduct a research survey for this study. One of the strengths of the survey design is that it's more economical and it has more rapid turnaround in data collection (Creswell, 2009), which makes this study method and design more appropriate based on the time available and planned to conduct the research. Another excellent feature of the survey design is that it has less bias since the participants are not affected by the interviewer; it's anonymous and the respondents are not forced to respond, which give them time to think about the questions and their answers (Frankfort-Nachmias \& Nachmias, 2008).

Survey research has been used widely by local and national governments as well as for research. One of the strengths of the survey design is that it is more economical and has a more rapid turnaround for data collection (Creswell, 2009). The survey design also has less bias because the participants are not affected by the interviewer it is anonymous and respondents are not forced to answer, they have time to think about their questions and their responses (Frankfort-Nachmias \& Nachmias, 2008). Originally, pre- and postEMR implementation surveys were to be conducted, using a Likert scale survey instrument for both pre- and post-implementation surveys; however, due to the time constrained, the pre-implementation survey of the clinics may be used for comparison 
later, but this study will focus on the post-EHR implementation. The survey was administered at three different community health centers and clinics in Washington DC, providing care to underserved population living in DC and the Metropolitan areas surrounding the District. The survey was administered strictly to patients attending these health clinics. A post implementation survey will also be administered to the health care providers of the same sites to determine if any connections in patient-provider relations, as well as to compare physicians and patients perceptions about the effects of EHR on health outcomes. The post-implementation tool includes questions that assess the spreading characteristics of the EHR implementation. Although post implementation evaluation will not be the focus of this study, it may provide some valuable information to new system updates or new electronic health system implementation.

The Likert scale is the scale of choice for this study. According to FrankfortNachmias and Nachmias (2008), scaling techniques transform qualitative variables into a series of quantitative variables. This may be done by determining the power to discriminate among a random sample of respondents expressing different dimensions toward the items being measured (Frankfort-Nachmias \& Nachmias, 2008). The bivariate correlation, Pearson's $r$, will be used to show the higher overall total correlation or the statistic correlation Cronsbach's alpha can also be used to indicate the tight connection of the items in the scale (p. 424). The split-half reliability test and the test-retest method are the most common methods to estimate the reliability of the scaling method and will be utilized to demonstrate evidence and generalizability based on likeness, differences of conditions, and measures (p.157). 
Another reason for choosing the Likert scale for this study is for its flexibility and its proven reliability for evaluating customers' survey. In Dawes' (2008) study was to evaluate how the Likert type scale influences the resultant data, the result suggested that a 5- to 7-point Likert scale was more likely to produce higher mean scores relative to the highest possible achievable score compared to the 10-point scale. The result also demonstrated that indicators of customer sentiment may be partially dependent on the choice of the scale format. Another study by Latham, Fay and Saari (2006) on behavioral observation scales showed the advantage of the Likert scale over the BES scale. The Likert scale is also known for its consistency and is easier to use to measure attitude.

A 5-point Likert scale will measure a broad range of attitudes using fixed alternative expressions such as strongly agree, agree, neither agree nor disagree, disagree and strongly disagree with an ordinal ranking scale. According to Frankfort-Nachmias and Nachmias (2008), Likert scaling requires the researcher to compile a list of all potential scale items, administer them to a random sample of respondents, compute a total score, and determine the discriminative power contributing to increase the efficiency as well as the validity of the research. The Likert scale is a simple tool to assess judgment in term of set ordered categories; the average may be estimated of all possible split-half reliability coefficients where a high alpha indicates that the items in the scale are significantly connected (pp. 424-425). This scale may be useful as part of the evaluation of care coordination and health outcomes since the EHR implementation to measure patient experience and patient satisfaction. 


\section{Setting and sample}

The literature supporting sampling stands behind the principles of theoretical saturation or theoretical sampling with regard to build and refine theory or hypothesis. This concept, according to Carlsen and Glenton (2011), requires that data collection through recruiting, interviewing and analysis, is conducted as an iterative process. There are numerous mixed ideas and rationale addressing the numeric component of sampling. In fact, Carlsen and Glenton's (2011) study on examining how researchers explain the number in focus groups they carried out in their qualitative study, suggested lack of clear, evidence-based guidance about deciding about how researchers can achieve optimal sample size. In this quantitative study, the goal was to collect a satisfactory survey response that was convincing enough to yield toward generalizing the research findings or to present a sound argument in favor of generalization of the findings.

The study focused on adult internal medical medicine patients attending underserved area clinics or health centers in rural areas of Washington DC, specifically in the Northwest and Southeast regions. A randomized sample will be ideal for this study as it provides ability to generalize to a population (Creswell, 2009). Different characteristics such as background (work status, source of income, education, age, and gender), health status and medical condition, health services, special determinants (homelessness, substance abuse, violence, immigration, and language barrier) will be used to stratify the population. A maximum of 4 to 6 weeks period with daily administration of the survey will be devoted to meet the study objectives. It is estimated that a target size from about 750-1000 will be appreciated for such a short period of time. The target sample size is 
based on an approximate of $7,700(2500 ; 2000 ; 3200)$ adult internal medicine patients who are actively registered respectively in all tree health centers for the fiscal year 20122013. Cohen (1992) lower standard medium effect size of 0.3 criterion of significance suggested a 69 percentile of the portion of the population where Cohen's $d$ value of 0.3 corresponds to a Pearson's $r$ value of .148 or $9 \%$ or a minimal sample size of $68-90$ based on the target sample size. Based on Cochran's (1977) formula, Kotrick \& Higgins' (2001) table for minimal returned sample size determination of 0.3 margin of error corresponds to a sample size of 92 to 106 for alpha of 0.5 for continuous data; a sample size of 0.5 margin of error to a sample size of 190 to 272 for categorical data. Based on these statistical measures, it would be acceptable to consider a minimum returned sample size of 200 for this study.

Determining the discriminative power will help discriminate among the individual expressing different attitudes toward the attitude being measured (Frankfort-Nachmias \& Nachmias, 2008). A bivariate correlation, Pearson's $r$ will be used to show the higher overall total correlation or the statistic correlation Cronsbach's alpha may also be used to show the tight link of the items on the scale (p. 424). The split-half reliability test and the test-retest method are the most common methods to determine the reliability of the scaling method and may be used for evidence and generalizability based on likeness, variations of conditions, and measures (p.157).

\section{Survey instrument}

Creswell (2009) provided a handy checklist for designing a survey instrument, which will be considered for improving the survey instrument for this study. Many 
existing survey instruments have been considered for this study including the National Ambulatory Medical Care (NAMC) survey, the Medical Group Management Association (MGMA) survey on EHR adoption. Although these survey instruments are very well designed survey instruments and have been used on a national level, they may not reflect all the questionnaires that reflect these research objectives into specific questions (Frankfort-Nachmias \& Nachmias, 2008). According to Rudestam and Newton (2007), modification of an existing instrument is perfectly acceptable and there has been considerable borrowing among various authors, but the reliability and validity of the instrument need to be demonstrated in its revised form. They believe that the use of multiple measures of a single concept can be useful, because in the new instrument fails; the old standard can be used in its place (p.100).

Care coordination, care management, and patient engagement are essential elements in a holistic framework, as it has been noted in chapter 2; a realistic survey instrument for this research would be one that includes these relevant variables categories for collecting specific data for testing the hypothesis formulated for this study, therefore, both survey instruments will be modified for formulating and developing a new instrument. Manary, Boulding, Staelin \& Glickman (2013) recommended to use or to develop instruments that focus on how to improve patient experiences through care coordination and engagement activities. They believed that these kinds of activities are more likely to be connected with both satisfaction and outcomes, and can at the same time, evaluate the effects of new care-delivery models on patients' experiences and 
outcomes, develop robust measurement approaches that provide timely and actionable information to facilitate organizational change (p. 203).

Although the preferred survey instrument is an existing instrument with established validity, as mentioned earlier in this chapter, unfortunately, not all the questions fit the design of the study. The survey instrument will rather be a modified survey instrument using portion of the SF-36 heath survey questionnaire for determining relationships between clinical and social interventions and the Health Research and Educational Trust integration and care coordination survey instrument for determining relationships between care management and coordination services and patient engagement and health outcomes. Both survey instruments have been utilized nationwide in community-based participatory research, in health and policy development research, and in innovative health research. The conceptual knowledge built from the holistic system theory will serve as guidance in the construction of the survey questionnaire for this study. The new survey instrument or tool will be called the "Wholistic Health Integration Power Tool” questionnaire.

Since this survey instrument has not been tested and validated before or used by any other studies, a pilot study will be done to test the reliability and the validity of the new instrument before conducting the study. According to Rudestam and Newton (2007), it is necessary to add to the body of literature by reporting the reliability and validity of the instrument as evidence of the new sample. The pilot participants will be asked questions about difficulty and any confusing terms about the instrument. A written description about the structure, scoring, and administration of the instrument will be 
included in the appendix of the dissertation as recommended by Rudestam and Newton (2007, p. 96). The purpose for the pilot study is to justify the validity of the survey instrument for the main study. Nearly $74 \%$ of the instrument is from existing validated survey questions and $26 \%$ of the researcher's created survey questions. Only the author's created portion of the instrument will be used for validation. Any confusing terms will be clarified and the instrument modified, based on the feasibility criteria, before administering the main study survey instrument. Also an expert panelist of five judges will be used to rate the instrument for its content and its wording. Poorly rated items may be modified or eliminated.

\section{Pilot study information and application}

Pilot studies are carried out for testing, evaluating, or examining new protocols, treatment, interventions, or methods and procedures for later use on a larger scale study (Everitt, 2006; Thabane et al., 2010). There are considerable reasons for conducting this pilot study. One of the primary objectives for this pilot is to assess the feasibility of the survey instrument by determining if there is sufficient understanding of the questionnaire, and evaluate the success rate of the instrument. The result of the pilot will inform the forecasting of the main study. Because the survey questionnaire is a combination of another well developed and tested instrument and a newly added survey questionnaire, only the untested portion of the survey tool will be piloted to determine if there are a clear understanding and appropriateness of the questions; if these questions are clearly presented and defined; if they do not create confusion and difficulty for any participant who wishes to answer. According to Thalbane et al., (2010), investigators should not 
underestimate the resource issues such as length of time to fill out forms, length of time to process the data that may arise from a pilot etc. Attention to these types of information, during the pilot, may help to deal better with a larger study. All these determinants will be given consideration for better management of the main study.

Literature focusing on pilot studies does not quite emphasize on a fixed sizable sample of a pilot study. However, the $95 \%$ confidence interval method was found to be a general estimate for determining the sample size based on a proportion formula when the sample size is known (Naing, 2006). Julius (2008) demonstrated that research with lack of prior information to base the size of the sample should base the justification of the sample size on the rationale for feasibility; his recommendation is to use a size of 12 per group; however, there are no separate groups in this study design. Cocks and Torgeson (2013) suggested utilizing $9 \%$ of the main study sample size if the sample size is known, but the final sample size is not known yet for this study. In another study determining sample sizes for pilot studies, Hertzog (2008) explained and demonstrated several considerations before deciding or picking a sample size. A sample size of 10 or even fewer was found to be sufficed for adequacy of instrumentation in term of clarity, format, wording or ease of administration (Hertzog, 2008). The later clearly fits the purpose of this pilot study of which a sample of 10 participants will be utilized at the three community health center sites for a total of 30 participants.

The procedure for conducting the pilot study will not be different from the main study. The process will remain the same except the randomized sample will be smaller. The same population is considered for this pilot. The survey instrument package will be 
distributed in an envelope to adult patients entering the health centers during their clinic visit. The pilot study package will include an invitation letter, the survey instrument, a short questionnaire using the Likert scale to determine the adequacy, clarity, and understanding of the main study's survey instrument, and a stamped envelope. Participants can choose to return their response while exiting the health center, or via mail using the stamped envelope included in the package. Since the pilot study is also voluntary, and no personal identifications will be used, a consent form will not be needed. A copy of the invitation letter for the pilot study and the evaluation tool are included in the Appendix section of this proposal.

Reliability and validity of the pilot is necessary to move to the next phase to conduct the main study in question. Much of the literature about reliability and validity of a pilot study focused rather on feasibility. According to Thabane (2010), a success rate of $70 \%$ or more, signals that criteria for feasibility are met and a rate of $50-69 \%$ that feasibility is possible. Any feasibility rate under $50 \%$ is considered not met. In the case of this pilot study, $70 \%$ or more of understanding rate of the tool will confirm the feasibility of the survey instrument. An outcome of potential feasibility (50-69\%) will require no modifications in the survey instrument, but to monitor closely the survey response, an outcome with no feasibility $(<50 \%)$ will require modifications before proceeding to the main research study. The same rating criteria will be utilized for the expert panelist.

\section{Approvals}

Appropriate permission was obtained from each organization before the use of any existing, or partial sections of an existing instrument. All ethical considerations will 
be reviewed and followed as recommended by the Investigative Review Board (IRB) on research protocols. All permission letters are included in the appendix section of the dissertation. All collected data was handled professionally and was only used for the purpose of the study.

\section{Data collection}

In preparation for the data collection, a separate cover letter explaining the purpose of the study and the rationale for the study along with the survey instrument and the choice of a pencil to answer the survey questions was distributed to the patients at the door steps of the clinic. The survey was completely voluntary and patients may fill out the survey while waiting to be seen at their visit or later using a stamped envelope via local mail service. The survey instrument was a self-administered questionnaire that will be handed out directly to the patients as they enter or leave the health center for their appointment. The Spread Assessment Tool survey may be administered in writing or online to the health providers using the internet survey monkey to capture as many participants as possible.

The survey responses were collected at the sites if patients are able to respond while waiting at the clinic to be seen by their physician (usually, the waiting time may take from 30 minutes to an hour and the time may be adequate for some people to respond to the survey) or later by mailing he response in the stamped envelope provided with the survey. A large sealed envelope or locked box was posted at different locations in the clinics for patients who wish to return their survey response right away upon completion. All collected data was protected. The survey was strictly anonymous, 
therefore it is expected that no identifiable information such as name, date of birth were obtained. The survey was also e completely restricted to children up to eighteen years of age.

\section{Data analysis}

The steps involved in analysis of the data will be presented for a complete discussion about the study. Addressing the research questions and hypotheses helped with the selection of the appropriate analytical tests after collecting the data. As noted in Chapter 1:

This study will analyze the following research questions:

RQ1

How does the holistic system theory explain the relationship between EHR and patient's health related outcomes?

$H 0$ : Holistic system theory has no significant effect in explaining the relationship between patients' health and their health related outcomes.

Ha1: Holistic system theory has a major role in explaining the relationships between patients' health and their health related outcomes.

$H 1: H 0$ different from $H 1$

RQ2

What best clinical or set of clinical outcomes should be measured to determine the effectiveness of EHR for the underserved population? 
H0: There will be no clinical outcome measures that determine the effectiveness of EHR on the health of the underserved population.

There will be significant clinical outcome measures that determine the effectiveness of EHR on the health of the underserved population.

H1: H0 different from $\mathrm{H} 2$

RQ3

How can patients' perspectives be integrated in outcome calculations?

$H 0$ : There is no reason for patients' perspectives to be integrated in outcome calculations. Ha3: Patients' perspectives will be significantly integrated in patient's health outcome calculations.

$H 1: H 0$ different from $H a 3$

RQ4

What characteristics of patients view EHR as beneficial to their health?

H0: There is no difference in the characteristics of patients who view EHRs as beneficial to their health.

Ha4: The characteristics of patients who view EHRs as beneficial to their health will be significant.

$H 0$ different from $\mathrm{Ha} 4$

RQ5

How can EHR be utilized to facilitate better relations between providers-providers, and patient-providers; increase patient self-care engagement; and facilitate ongoing health improvement activity measures? 
H0: Utilization of EHR has no effects on relationships between providers and patients, patient self-care engagement, and health care related activities.

Ha5: EHR can be significantly utilized to improve relationships among providers and patients, patient self-care engagement, and ongoing health relayed activities. .

$H 0$ different from $H a 5$

The variable map below demonstrates the relationships between variables while using a holistic framework approach. This map will be modified based on the research findings to create a final framework or model that will illustrate the effects of relationships between variables on the final outcomes. 

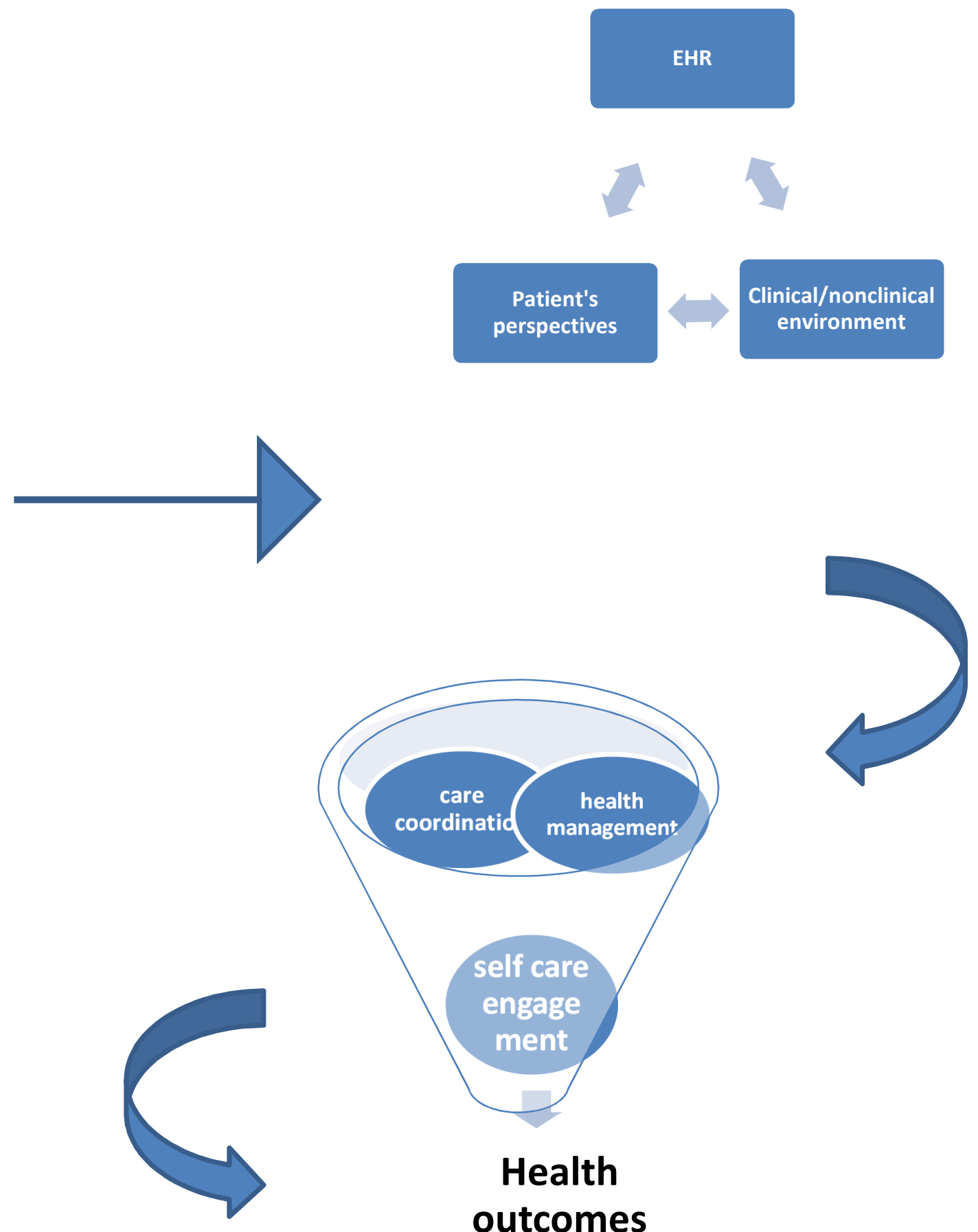

\section{Health outcomes}

Figure 2 Variables map using a holistic framework. 
Detailed descriptive items will be tabulated with descriptions for identifying the survey respondents and non-respondents. Any bias will be clarified; weekly average responses will be determined. A descriptive analysis will be given for all variables. The SPSS statistical computer program will be used to analyze the data, to draw inferences, comparing groups, and establish comprehensive diagrams and graphs. The research hypotheses 1,2 , and 3 , as noted in chapter 1, on the importance of patients' perspectives on health outcomes and the relations between the variables will be examined using a onetailed t test. Hypotheses 4 and 5 on the significance of benefit and contribution comparisons will be examined differently by using the analysis of variance (ANOVA). Multiple regression analysis will be used for non-mediated relationships such as social, economic, educational, and environmental factors to examine direct and indirect effects between central and moderate variables. All results will be analyzed, interpreted, and reported along with any implications for practice and recommendations for future research.

\section{Threats to validity}

One major threat to internal validity is with the self-measured instrument survey. To ensure validity, supporting evidence will be provided to demonstrate that the instrument measures the variable it was designed to measure (Frankfort-Nachmias and Nachmias, 2008). One primary reason for demonstrating validity is because the instrument will have influence on the validity of the conclusions after testing the hypotheses. This concept is strongly embedded in quantitative research. For this reason, it 
is imperative that the content of this survey instrument includes most of the relevant information appropriate to investigate the research questions to demonstrate that the instrument has empirical value that leads to the research findings.

\section{Dissemination of results}

Dissemination of the study results will be necessary to spread the knowledge about the study and raise awareness about all essential and relevant issues. The results of the study will be shared with all the participated health centers and clinics and also with the participants who want to follow up on the study. It is my wish to be able to publish this research study and findings in any major professional journals; I have particular interest in the following journals Health Affairs, The New England Journal of Medicine, and the Journal of Public health Management for demonstrating serious interest in medicine, health care, and health care policy. I will also seek opportunity to present the study at professional health conferences and at any other applicable local health and community health functions.

\section{Ethics and regulations}

Ethics and regulations have a very dominant role in health care. They ensure that research studies are in alignment with all ethical and regulatory standards. They influenced all aspects of health care including policies, programs, technologies, and procedures to protect, inform, and to create properly right decisions and optimum solutions on behalf of society. As this quantitative study is concerned, the following ethical and regulatory characteristics are being considered: age, education, social and 
economic status, religion, background, risks, benefits, provision of care, confidentiality, and privacy. It is a non-invasive study and is strictly prohibited to children; and totally voluntary. The report will be anonymous; no name, date of birth, or address will be needed on the survey response. An informed consent will not need to be provided to the participants. However, the cover lever will include information about who is conducting the investigation, the time commitment for completing the survey, purpose, and benefits of the study. Appropriate permission for conducting the research study will be obtained from Walden University IRB and for the modified survey instrument. A permission letter to utilize the survey instrument from the other organizations will be sent to them for before conducting the pilot study. All precautions were taken to eliminate all possible biases.

\section{Summary}

The rapid development and adoption of health information technology has certainly increased the political, social, cultural, and economic demand for efficiency, quality, and digital integration in our primary care system. Patients are able to access health resources, make virtual visits, on-line scheduled appointment, and access their health information at their convenience. In chapter 2, I discussed the benefit of a general system application using a holistic system approach to focus on the patient's whole health. A full spectrum in the context of EHR was also given. Pursuing the goal of the research study in chapter 1 , this chapter covered the comprehensive research design and methodology to conduct the investigation; it also addressed the relevant ethical issues of concerns and the plan to 
handle these issues. Chapter 4 and 5 will present the results of the study and the discussion about the findings respectively.

\section{Chapter 4: Results}

\section{Research and Results}

\section{Preview and organization of the chapter}

The dynamic hypotheses established in the previous chapters are evident in this chapter. The results are scrutinized to determine any cause and effect relationships existing between variables, covariates, and extraneous variables. Causal relationships that emerged from the analysis are also discussed to determine new strategies, structures and to address possible influence and effect on the health outcomes of the underserved populations and its relationships to the EHR. This study used comprehensive standard statistical calculations; tables and graphics from the data output results are presented in this chapter and extended in the appendices.

This chapter is organized as follow:

Pilot study result of the research instrument including tables

Data collection process

Research Participants information including demographic tables

The research findings including tabular and graphical outputs

Statistical analyses of the findings

Conclusion 


\section{Introduction}

In the previous chapters, it has been recognized the problem that this research study is pointing to address. Chapter 3 introduced the development of the dynamic hypotheses through causal relationships and analysis of the holistic framework. This chapter describes the survey process that includes the overall study through data collection, the findings, and the descriptive analysis that contribute to the interpretation of the results. It also includes tabulation, graphics scenarios that detail the data collection, the findings, and the statistical analyses and inferences contributing to the relationships and interpretation of the results.

The purpose of this quantitative research study was to determine the underserved patients' perspectives on the effects of the EHR (EHR) on their health outcomes with respect to care coordination and health management. Moreover, to examine its relationship to the patient's overall health improvement. This study aims to utilize patients' perspectives and clinical technology innovations to provide a collaborative approach and an interdisciplinary health model. It also aims to develop a care plan for the management of people with chronic diseases, more specifically for the underserved population.

The following five research questions along with their hypotheses were the focus of the study:

RQ1

How does the holistic system theory explain the relationship between EHR and patient's health related outcomes? 
H0: Holistic system theory has no significant effect in explaining the relationship between patients' health and their health related outcomes.

Ha1: Holistic system theory has a major role in explaining the relationships between patients' health and their health related outcomes.

H1: $H 0$ different from $H 1$

RQ2

What best clinical or set of clinical outcomes should be measured to determine the effectiveness of EHR for the underserved population?

H0: There will be no clinical outcome measures that determine the effectiveness of EHR on the health of the underserved population.

There will be significant clinical outcome measures that determine the effectiveness of EHR on the health of the underserved population.

H1: H0 different from $\mathrm{H} 2$

RQ3

How can patients' perspectives be integrated in outcome calculations?

$H 0$ : There is no reason for patients' perspectives to be integrated in outcome calculations. Ha3: Patients' perspectives will be significantly integrated in patient's health outcome calculations.

H1: $H 0$ different from $H \mathrm{a} 3$

RQ4

What characteristics of patients view EHR as beneficial to their health? 
$H 0$ : There is no difference in the characteristics of patients who view EHRs as beneficial to their health.

Ha4: The characteristics of patients who view EHRs as beneficial to their health will be significant.

$H 0$ different from $H a 4$

RQ5

How can EHR be utilized to facilitate better relations between providers-providers, and patient-providers; increase patient self-care engagement; and facilitate ongoing health improvement activity measures?

H0: Utilization of EHR has no effects on relationships between providers and patients, patient self-care engagement, and health care related activities.

Ha5: EHR can be significantly utilized to improve relationships among providers and patients, patient self-care engagement, and ongoing health relayed activities. .

$\mathrm{H} 0$ different from $\mathrm{Ha} 5$

The dynamics of the research hypotheses developed in chapter three were established to bring understanding of causal relationships existing between the EHR and patients' health outcomes and to evaluate the overall impact of technology on the population's health. All the research hypotheses will be discussed, debated, and analyzed against the findings of the study.

\section{Pilot Study}

The pilot study, as noted in chapter three, was deemed appropriate not only to evaluate the clarity of the self-prepared survey instrument, but also to evaluate the 
wordiness and the level of understanding and difficulty of the survey questionnaire. The pilot sample consisted of thirty random participants of the same research population who were challenged to test the survey questionnaire and to grade it based on their level of understanding, clarity, and their level of difficulty. The pilot questionnaire was simple, short, and based on likely response to clarity, understanding, and wordiness ranging from agree, mostly agree, very much agree, to disagree. Two other questions were based on the level of difficulty and understanding ranging from minimal to very minimal and appropriate to mostly appropriate respectively. The participants were adult patients from the underserved neighborhood clinics and health centers. All participants answered the pilot questions. Table 1 shows the frequency table for each variable factor.

Frequency Table

Table 1

\section{Wordiness too difficult to understand}

\begin{tabular}{|ll|c|c|c|c|}
\hline & Frequency & $\%$ & Valid \% & Cumulative \% \\
\hline \multirow{4}{*}{ Valid } & disagree & 20 & 66.7 & 66.7 & 66.7 \\
& mostly disagree & 9 & 30.0 & 30.0 & 96.7 \\
& very much disagree & 1 & 3.3 & 3.3 & 100.0 \\
total & 30 & 100.0 & 100.0 & \\
\hline
\end{tabular}

\section{Overall level of understanding}

\begin{tabular}{|c|c|c|c|c|c|}
\hline & Frequency & $\%$ & Valid \% & Cumulative $\%$ \\
\hline \multirow{4}{*}{ Valid } & appropriate & 14 & 46.7 & 46.7 & 46.7 \\
\hline & mostly appropriate & 11 & 36.7 & 36.7 & 83.3 \\
\hline & very much & 5 & 16.7 & 16.7 & 100.0 \\
\hline & total & 30 & 100.0 & 100.0 & \\
\hline
\end{tabular}

Overall level of difficulty

\begin{tabular}{|l|c|c|l|} 
Frequency & $\%$ & Valid $\%$ & Cumulative $\%$ \\
\hline
\end{tabular}




\begin{tabular}{|ll|c|c|c|c|}
\hline \multirow{2}{*}{ Valid } & minimal & 12 & 40.0 & 40.0 & 40.0 \\
& mostly minimal & 11 & 36.7 & 36.7 & 76.7 \\
& very much minimal & 7 & 23.3 & 23.3 & 100.0 \\
total & 30 & 100.0 & 100.0 & \\
\hline
\end{tabular}

A descriptive statistic for quantitative variables is used to compute the score defining the validity of the survey instrument for this research study. Table 1 presents the means and the standard deviations of the wordiness, level of clarity, and level of understanding of the survey questionnaire. The means and standard deviations of the survey instrument level of clarity and understanding were relatively significant and conclusively acceptable on the average with all participants. A one- sample $t$ test was also conducted to evaluate the significance of the mean. The accepted mean for the level of difficulty of the survey questionnaire is not significantly different for the level of clarity, difficulty, and understanding. The $95 \%$ confidence interval for the mean range shows no significance difference in the score distribution. The result supports the conclusion that the participants agree that the survey instrument is appropriately fit to be used as the research instrument for the study.

Table 2

One-Sample Statistics

\begin{tabular}{|l|r|r|r|c|}
\hline & N & Mean & $\begin{array}{c}\text { Std. } \\
\text { Deviation }\end{array}$ & $\begin{array}{c}\text { Std. Error } \\
\text { Mean }\end{array}$ \\
\hline $\begin{array}{l}\text { Wordiness too } \\
\text { difficult to } \\
\text { understand } \\
\begin{array}{l}\text { Overall level of } \\
\text { difficulty }\end{array}\end{array}$ & 30 & 11.8333 & 2.78027 & .50760 \\
\hline
\end{tabular}




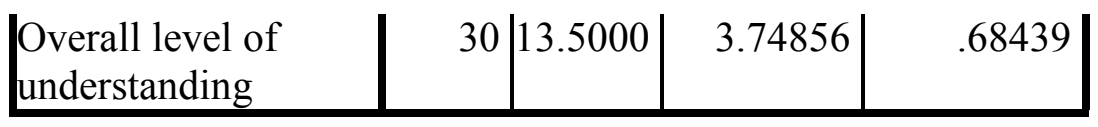

One-Sample Test

\begin{tabular}{|c|c|c|c|c|c|c|}
\hline & \multicolumn{6}{|c|}{ Test Value $=0$} \\
\hline & \multirow[t]{2}{*}{$\mathrm{t}$} & \multirow[t]{2}{*}{ df } & \multirow[t]{2}{*}{$\begin{array}{l}\text { Sig. (2- } \\
\text { tailed) }\end{array}$} & \multirow[t]{2}{*}{$\begin{array}{c}\text { Mean } \\
\text { Difference }\end{array}$} & \multicolumn{2}{|c|}{$\begin{array}{l}95 \% \text { Confidence } \\
\text { Interval of the } \\
\text { Difference }\end{array}$} \\
\hline & & & & & Lower & Upper \\
\hline $\begin{array}{l}\text { Wordiness too } \\
\text { difficult to } \\
\text { understand }\end{array}$ & 23.312 & 29 & .000 & 11.83333 & 10.7952 & 12.8715 \\
\hline $\begin{array}{l}\text { Overall level of } \\
\text { difficulty }\end{array}$ & & 29 & .000 & 14.16667 & 12.6890 & 15.6444 \\
\hline $\begin{array}{l}\text { Overall level of } \\
\text { understanding }\end{array}$ & 19.726 & 29 & .000 & 13.50000 & 12.1003 & 14.8997 \\
\hline
\end{tabular}

The pilot study result qualified the survey instrument to be suitable for use as the research survey instrument for the study. Therefore, no modifications were required to the research survey instrument. Although the pilot study dictated no change requirement to the survey instrument, the pilot study had contributed to a much better understanding of the logistics and preparation of data collection for the research survey. Much consideration was given to the mailing response timeframe due to the limited time set to accomplish the study. It was clear from the pilot that the response time was going to be a challenge with the change made toward the mailing response instead of direct data collection at the sites as planned in the third chapter for the main research.

Besides the pilot study, the survey instrument has also undergone a review by an expert panel of five panelists: three medical providers, a community health nurse, and a community outreach coordinator. The panelists were chosen for their knowledge, work 
experience, and contribution to the underserved areas health centers and clinics. All five panelists were in agreement with the survey content, clarity, and wordiness. The five panelists universally agreed on the authenticity of the survey instrument for the research study.

\section{Data Collection}

This research study involves data collection and analysis of the perceptions of the underserved patients on the impact of the EHR on their health. The research surveys were distributed over a three week period using only public places near health centers and clinics within the underserved communities; participants were given a complete survey envelop including a stamped addressed mailing envelop to mail their response back.

Initially, the surveys were to be distributed directly from the three different clinical sites as noted in chapter 3 , but the plan was later changed to using the public places adjacent or closed to the same sites within the same communities as it has been confirmed over the phone prior to conducting this research, that these sites have been using the EHR for at least two years post implementation. The data collection lasted over a few weeks more than anticipated which may be due to the later change and also weather change at the end of the winter season. A total of 400 surveys were distributed; 215 surveys or about $53 \%$ were returned but only 155 surveys or $72 \%$ of the total returned responses were patients from internal medicine discipline and were fully completed. According to Cohen's (1992) lower standard medium effect size of 0.3 criterion of significance, Cochran's (1977) formula, and Kotrick \& Higgins' (2001) table for minimal returned sample size determination of 0.3 margin of error, a sample size of 92 to 106 for 
alpha of 0.5 for continuous data satisfies the criteria for the minimal returned sample size for this research. Although the returned sample size of 215 met the criterion set in chapter 3 , the 155 participants' responses from internal medicine alone still met the minimal returned sample size determination under Cochran's (1997) formula and Kotrick \& Higgins' (2001) table and therefore, was kept to meet the time limit set for this study.

\section{Participants}

Participants were adult patients age 18 and over who attended underserved areas and rural health clinics in the Northwestern and Southeastern regions of Washington DC. Selected participants are those utilizing internal medicine clinics located in these areas and with two or more chronic health conditions. Only 155 survey responses out of 215 returned survey responses were selected for fitting the study categories. The pilot study participants are not included in the study. This number of participants is relatively small compare to the general population or the entire underserved community in Washington DC; however it represents above 145 patients per 400- 500 monthly visits of the approximate active clinics internal medicine patient population as described in the Ambulatory Care 2010 Survey Report (cdc.gov, 2013).

\section{Survey Process}

The survey envelop packages were simply given to patients going to and coming from their clinic appointment. The survey envelops were handed to them while working on the nearby sidewalks of each research location. The participants returned their responses upon completion of the survey. A stamped addressed envelope was enclosed in 
the survey envelop for convenience. These sites were chosen after confirming that their EHR system was fully established and active. While this process for collecting data was acceptable for this study, some discrepancies were inevitable during this process. Daily on site survey distribution had to be revised and put on hold because of new administrative protocol put in place right before data collection at two of the three research sites; daily data collection was also deferred. To avoid this prolonged process and to maintain consistency of the process, it was realistically more appropriate and cheaper to accomplish this study by using nearby public places while maintaining the same population. The effect size, although adequate for this study, was estimated to be smaller than the previous process and therefore might compromise the generalization of the findings.

\section{Data organization and analysis}

Research data were organized and analyzed using the computer statistical system SPSS. Table 3 from the statistical frequencies shows all the demographic characteristics of the research participants and the population percentage. The majority of the participants are black or African American who had Medicaid and HMO's as insurance carriers with four or more diagnoses. Nearly half of the participants rely on some form of transportation; whether it's public, special transportation, or simply a walk to their doctor's appointment. Interestingly, every participant has some sort of digital access through ownership of cell phones, desktop computers, or laptops via basic means of call, texts, and even email. The table below shows the different demographic characteristics 
with value and percentage based on race, source of income, health insurance, number of chronic diagnoses, mode of transportation, and digital access.

Table 3

\section{Demographic}

\begin{tabular}{|l|c|c|c|c|}
\hline Patient race & Frequency & Percent & Valid Percent & Cumulative Percent \\
\hline 11.00 & 2 & 1.3 & 1.3 & 1.3 \\
4.00 & 3 & 1.9 & 1.9 & 3.2 \\
$\quad$ Hispanics/Latino/Spanish & 8 & 5.2 & 5.2 & 8.4 \\
Valid & origin & 6.5 & 6.5 & 14.8 \\
White & 10 & 85.2 & 85.2 & 100.0 \\
Black & 132 & 100.0 & 100.0 & \\
Total & 155 & & & \\
\hline
\end{tabular}

\begin{tabular}{|l|c|c|c|c|}
\hline Source of income & Frequency & Percent & Valid Percent & Cumulative Percent \\
\hline homeless & 4 & 2.6 & 2.6 & 2.6 \\
live with family/friend & 13 & 8.4 & 8.4 & 11.0 \\
Valid not working & 49 & 31.6 & 31.6 & 42.6 \\
working & 89 & 57.4 & 57.4 & 100.0 \\
Total & 155 & 100.0 & 100.0 & \\
\hline
\end{tabular}

\begin{tabular}{|l|c|c|c|c|}
\hline Health insurance & Frequency & Percent & Valid Percent & Cumulative Percent \\
\hline 8.00 & 1 & .6 & .6 & .6 \\
7.00 & 3 & 1.9 & 1.9 & 2.6 \\
self-pay & 4 & 2.6 & 2.6 & 5.2 \\
Valid HMO/CHIPS & 12 & 7.7 & 7.7 & 12.9 \\
Medicare & 25 & 16.1 & 16.1 & 29.0 \\
private & 47 & 30.3 & 30.3 & 59.4 \\
Medicaid & 63 & 40.6 & 40.6 & 100.0 \\
Total & 155 & 100.0 & 100.0 & \\
\hline
\end{tabular}

\begin{tabular}{|l|c|c|c|c|}
\hline Number of diagnoses & Frequency & Percent & Valid Percent & Cumulative Percent \\
\hline Valid 7.00 & 1 & .6 & .6 & .6
\end{tabular}




\begin{tabular}{|l|c|c|c|c|}
\hline 5.00 & 3 & 1.9 & 1.9 & 2.6 \\
4.00 & 7 & 4.5 & 4.5 & 7.1 \\
6 or more & 27 & 17.4 & 17.4 & 24.5 \\
2 or more & 54 & 34.8 & 34.8 & 59.4 \\
4 or more & 63 & 40.6 & 40.6 & 100.0 \\
Total & 155 & 100.0 & 100.0 & \\
\hline
\end{tabular}

\begin{tabular}{|l|c|c|c|c|}
\hline Transportation & Frequency & Percent & Valid Percent & Cumulative Percent \\
\hline by arrangement only & 1 & .6 & .6 & .6 \\
6.00 & 1 & .6 & .6 & 1.3 \\
7.00 & 3 & 1.9 & 1.9 & 3.2 \\
Valid walk to appointment & 5 & 3.2 & 3.2 & 6.5 \\
special transportation & 15 & 9.7 & 9.7 & 16.1 \\
public transportation & 52 & 33.5 & 33.5 & 49.7 \\
own car & 78 & 50.3 & 50.3 & 100.0 \\
Total & 155 & 100.0 & 100.0 & \\
\hline
\end{tabular}

\begin{tabular}{|l|c|c|c|c|}
\hline Digital access & Frequency & Percent & Valid Percent & Cumulative Percent \\
\hline laptop & 1 & .6 & .6 & .6 \\
internet service & 1 & .6 & .6 & 1.3 \\
8.00 & 1 & .6 & .6 & 1.9 \\
Valid computer & 18 & 11.6 & 11.6 & 13.5 \\
cell phone & 60 & 38.7 & 38.7 & 52.3 \\
all & 74 & 47.7 & 47.7 & 100.0 \\
Total & 155 & 100.0 & 100.0 & \\
\hline
\end{tabular}

A simple univariate analysis of variance (ANOVA) test was also conducted to assess the relationships of different variables determining the effects of digitalization on patients' health management. One-way ANOVA, according to Green and Salkind (2011), assumes equality of population variances. Table K1 (Appendix K) examines the 
significance of one-way ANOVA $F$ test including the means, the standard deviations, and the homogeneity of variances between subjects.

The Levene's Test of Equality of Error Variances as shown in table 4 below, resulted in $p<.001$ is less than the $p$ value of significance $p=.05$. The Levine test result confirmed that the underlying assumption for the ANOVA homogeneity of variances has been met. The standard deviation from the means ranges from 0.00 to 5.8354 . The ANOVA test $F$ shows that there is significant differences when $F(83,70)=2.624, p<$ .001 . This result suggested that there was a strong relationship among the variables supporting the impact of digital access on patient's health management.

Table 4

Levene's Test of Equality of Error Variances

Dependent Variable: Digitalization access

\begin{tabular}{|c|c|c|c|}
\hline $\mathrm{F}$ & $\mathrm{df1}$ & $\mathrm{df2}$ & Sig. \\
\hline 2.624 & 83 & 70 & .000 \\
& & & \\
\hline
\end{tabular}

Since the ANOVA $F$ test was significant, other covariates were added to evaluate the homogeneity of variances among their means. Table 5 (Appendix J) detailed the pairwise relationships among the covariates. The standard deviations among the groups ranged from 0.00 to 2.91 and the variances ranged from 0.00 to 2.00 which signaled that pairwise comparisons are still significant. The results suggested that there are substantial relationships between the EHR and the management of patients' health. The homogeneity of the variances among the covariates suggested significant relationships between 
patient's demographic and care management and also between the EHR and patient's health improvement. The $95 \%$ confidence intervals for the test of homogeneity of variances also suggested very significant relationships among the covariates except for patient age and health insurance where the test was no significant for $p=.13$ and .43 respectively.

Considering the influence of the environment and health determinants on health outcomes, careful examination was given about how relationships between variables may be combined or extracted in the analysis determining patients' perspectives on the impact of the EHR on their health. Table 5 (Appendix J) and Table 6 (Appendix H) addressed the descriptive statistics that characterized the sample population. Patients' perception and digital access are depicted in table 6 (Appendix H) to help understand the correlations existing between variables in this study. The homogeneity of variances with the Levene Statistic below in table 6.1 addressed the relative significance between the variances $F(3,149)$ with a $p$ range $.01>p<.45$; a valid indication that more than one single variables are to be measured in establishing relationships between patients' perspectives and the EHR.

\section{Table 6.1}

\section{Test of Homogeneity of Variances}

\begin{tabular}{|l|r|r|r|r|}
\hline & Levene statistic & df1 & df2 & Sig. \\
\hline Patient age & $1.881^{\mathrm{a}}$ & 3 & 149 & .135 \\
Health insurance & $.916^{\mathrm{b}}$ & 3 & 149 & .435 \\
Number of health conditions/diagnosis & $4.754^{\mathrm{c}}$ & 3 & 149 & .003 \\
Disease management & $2.959^{\mathrm{d}}$ & 3 & 148 & .034 \\
The care team addresses my health care needs differently & $3.764^{\mathrm{e}}$ & 3 & 149 & .012
\end{tabular}


\begin{tabular}{|l|l|l|l|l|} 
EMR helps me manage my care better & $3.188^{\mathrm{f}}$ & 3 & 149 & .026 \\
$\begin{array}{l}\text { My overall health has improved since the clinic started } \\
\text { with the EHR }\end{array}$ & 5.6719 & 3 & 149 & .001 \\
\hline
\end{tabular}

a. Groups with only one case are ignored in computing the test of homogeneity of variance for Patient age.

b. Groups with only one case are ignored in computing the test of homogeneity of variance for Health insurance.

c. Groups with only one case are ignored in computing the test of homogeneity of variance for Number of health conditions/diagnosis.

d. Groups with only one case are ignored in computing the test of homogeneity of variance for Disease management.

e. Groups with only one case are ignored in computing the test of homogeneity of variance for The care team addresses my health care needs differently.

Another ANOVA test was conducted to evaluate the homogeneity between and within groups as noted in Table 6.2 below. This helps to determine which strategy produces significant output on the contribution, benefit, and comparison for hypotheses 4 and 5 as discussed in Chapter 3. The mean square ranged from 1.45 to 3.54 between groups and from .6 to 3.00 within groups. The ANOVA $F$ test ranged from $F(5,149)=$ $.482, p=.79$ to $F(5,149)=3.68, p=.004$. The $95 \%$ confidence interval between and within groups ranged from .004 to .79. Although $p$ is not consistently significant, the mean square variances suggested that contributory relationships may exist between and within the variables and the covariates. This will be discussed further in chapter 5 when reviewing the research questions.

Table 5.2

ANOVA

\begin{tabular}{|ll|r|r|r|r|r|}
\hline & & $\begin{array}{c}\text { Sum of } \\
\text { Squares }\end{array}$ & df & \multicolumn{1}{c|}{$\begin{array}{c}\text { Mean } \\
\text { Square }\end{array}$} & F & Sig. \\
\hline Patient age & Between & 7.268 & 5 & 1.454 & 1.754 & 126 \\
& $\begin{array}{l}\text { Groups } \\
\text { Within }\end{array}$ & 123.506 & 149 & .829 & & \\
Health insurance & $\begin{array}{l}\text { Groups } \\
\text { Total }\end{array}$ & 130.774 & 154 & & & \\
& Between & 15.305 & 5 & 3.061 & 1.871 & .103 \\
& Groups & & & & &
\end{tabular}




\begin{tabular}{|c|c|c|c|c|c|c|}
\hline & $\begin{array}{l}\text { Within } \\
\text { Groups }\end{array}$ & 243.792 & 149 & 1.636 & & \\
\hline & Total & 259.097 & 154 & & & \\
\hline & $\begin{array}{l}\text { Between } \\
\text { Groups }\end{array}$ & 17.695 & 5 & 3.539 & 3.680 & .004 \\
\hline \multirow[t]{3}{*}{ Number of health conditions/diagnosis } & $\begin{array}{l}\text { Within } \\
\text { Groups }\end{array}$ & 143.298 & 149 & .962 & & \\
\hline & Total & 160.994 & 154 & & & \\
\hline & $\begin{array}{l}\text { Between } \\
\text { Groups }\end{array}$ & 9.971 & 5 & 1.994 & 3.405 & .006 \\
\hline \multirow[t]{3}{*}{ Disease management } & Within & 86.685 & 148 & .586 & & \\
\hline & $\begin{array}{l}\text { Groups } \\
\text { Total }\end{array}$ & 96.656 & & & & \\
\hline & Between & 13.647 & 5 & 2.729 & 1.177 & .323 \\
\hline \multirow{4}{*}{$\begin{array}{l}\text { The care team addresses my health care } \\
\text { needs differently }\end{array}$} & Groups & 315553 & & & & \\
\hline & Groups & נטעם דים & (14) & 2.015 & & \\
\hline & Total & 359.200 & 154 & & & \\
\hline & $\begin{array}{l}\text { Between } \\
\text { Groups }\end{array}$ & 7.148 & 5 & 1.430 & .482 & .789 \\
\hline \multirow[t]{4}{*}{ EMR helps me manage my care better } & Within & 442.052 & 149 & 2.967 & & \\
\hline & $\begin{array}{l}\text { Groups } \\
\text { Total }\end{array}$ & 449.200 & 154 & & & \\
\hline & $\begin{array}{l}\text { Between } \\
\text { Groups }\end{array}$ & 13.241 & 5 & 2.648 & .985 & .429 \\
\hline & Within & 400.669 & 149 & 2.689 & & \\
\hline \multirow{2}{*}{$\begin{array}{l}\text { My overall health has improved since the } \\
\text { clinic started with the EHR }\end{array}$} & Groups & & & & & \\
\hline & Total & & & & & \\
\hline
\end{tabular}




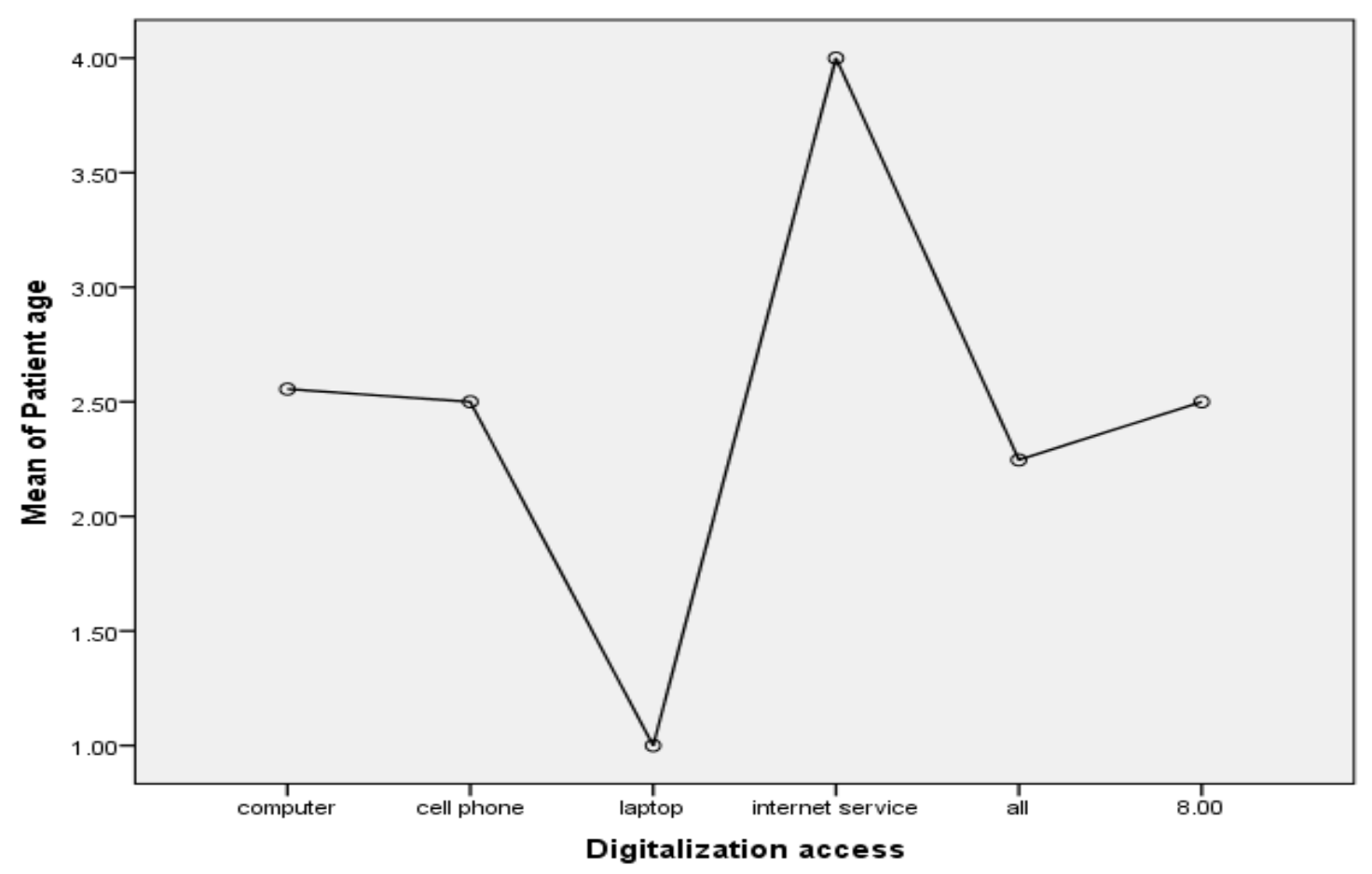

Figure 3 Graphical output age-based

In trying to understand why certain variables may have more or less influence than another, the graphical outputs depicted a much more visual understanding of the similarities and differences among variables and its relative effect on the final result. Graphic output figure 3, for instance, showed the affinity exiting between digital access and patient age. A great percentage of the participants have digital access or internet service through their cell phone compared to the small percentage of participants that claimed to have a laptop. Does the kind of access makes a difference in the way patients engage in accessing their EHR? 


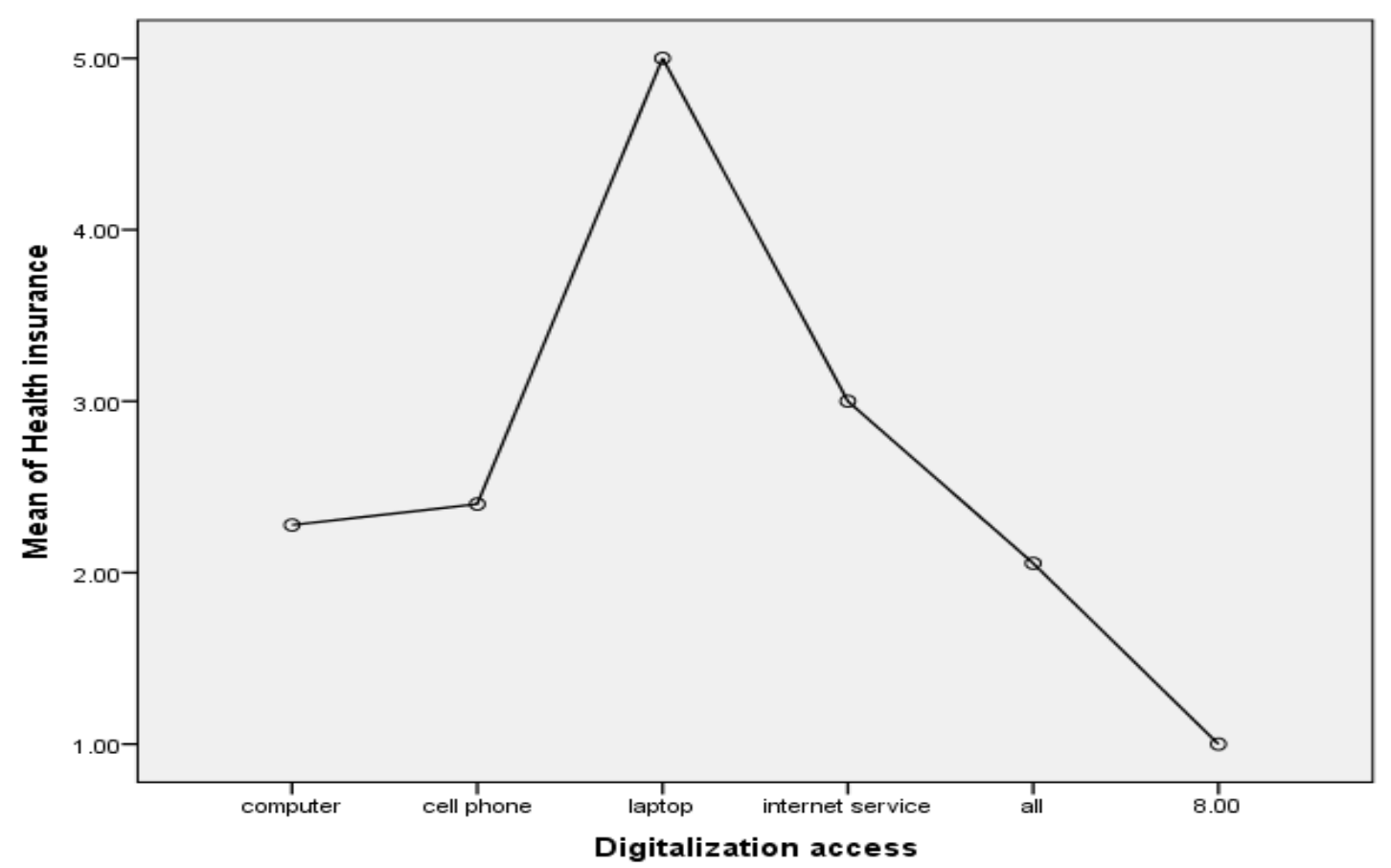

Figure 4 Graphical output health insurance-based

Graphical output figure 4 illustrated the correlations between participants with digital access and the health insurance access. Those with laptops are those with health insurance other than Medicaid or related HMOs while those with cell phone and desktop access are those affiliated with Medicaid and Medicaid HMOs. This output also suggested that participants with all access are those with desktop computers and cell phone access while those with no access or non-applicable access are those with less on no access through health insurance. This graphical output will probably help understanding patients' perspectives about their self- health maintenance and engagement. Similar relations are depicted in graphical output figure 5 below. Stronger relations are shown between higher number of health conditions and patients with desktop computer access. 
Similar correlations are also depicted in output graphic figure 5 below showing correlations between disease management and digital access. An interesting factor is that the participants with access through their laptop have one or more chronic conditions, an inverse proportion of those with three or more chronic diseases and with source of internet access. Source of internet access for this study meant access through local community resources such as churches, libraries, supermarkets, and schools. The frequency of digital health access was not included in the survey questionnaire. This raised further research questions examining, perhaps, the lack of digital health access and self-care health education and management.

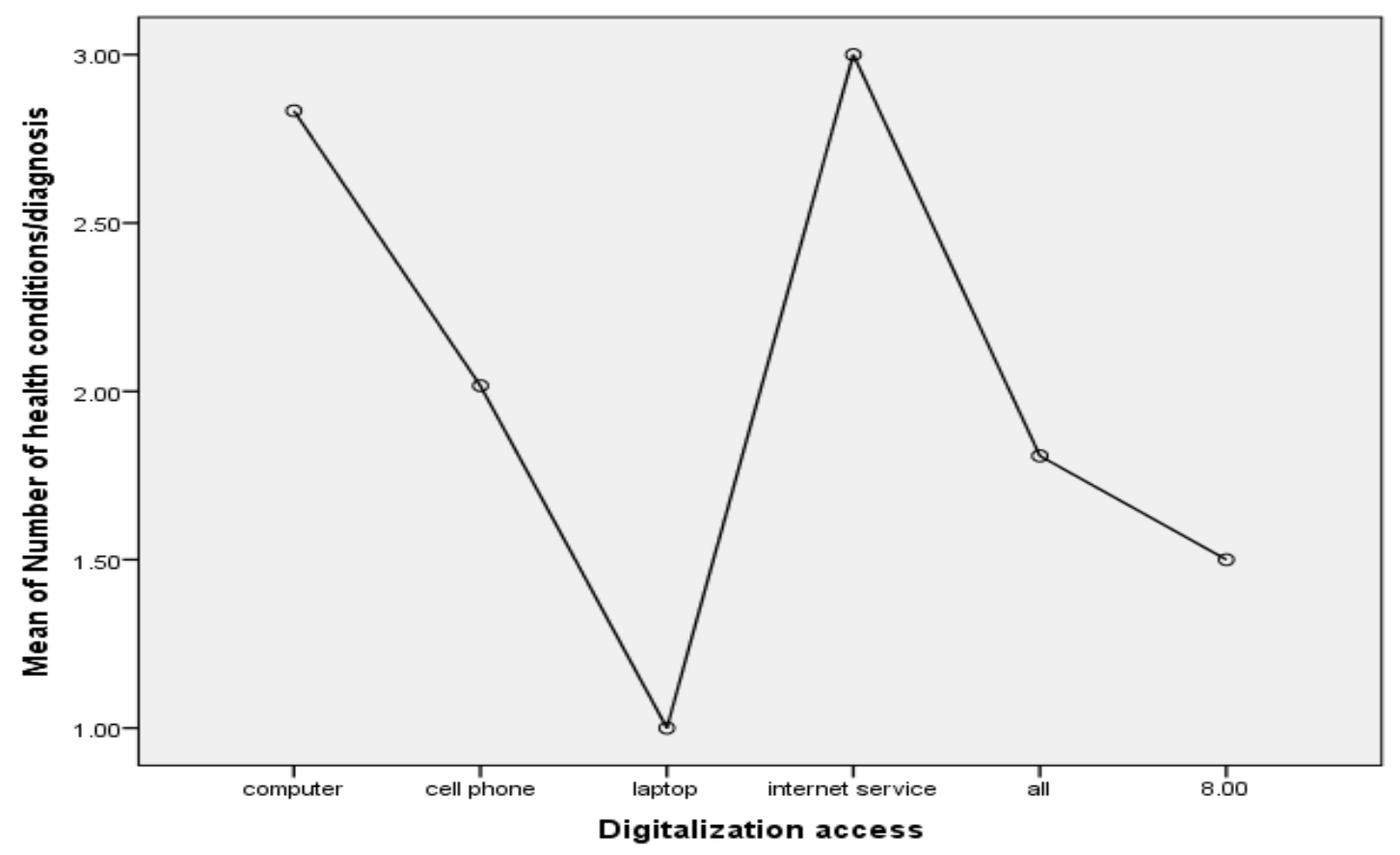

Figure 5 Graphical Output diagnosis-based

Disease management is one of the core variables in pursuing this study. It is obvious to believe from the previous chapters that suitable health care outcomes require 
at least a minimum of good and consistent disease management. Health information technology diffusion found its niche and was declared one of the greatest technology inventions for its greatest benefits of re-engineering capability (Davenport, 2013) and its cross industry facilitation (Hardash et al., 2015). While there is abundant research and literature to prove such, it is also unknown and useless for those with limited and no access to this great innovative resource. This fact is reflected in graphical output figure 6 below:

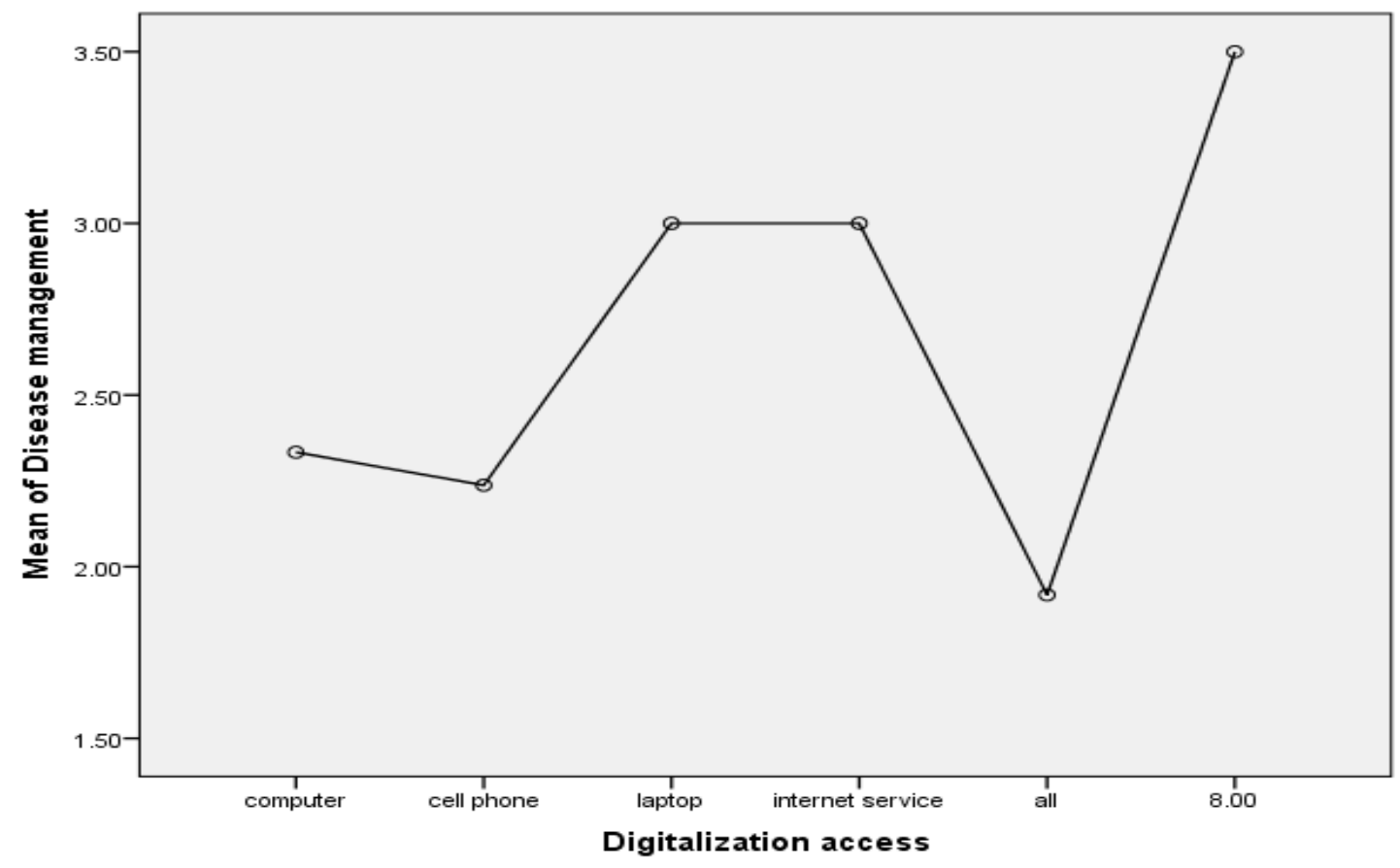

Figure 6 Graphical Output disease management-based

It illustrated the correlation between disease management and digital access among the participants in this study. The participants with limited access or no access are correlated with those with three or more chronic diseases. This graph also reveals that benefits of 
access cannot be limited to the health care organizations or the health care sites but to provide means of access to those with needs of disease management.

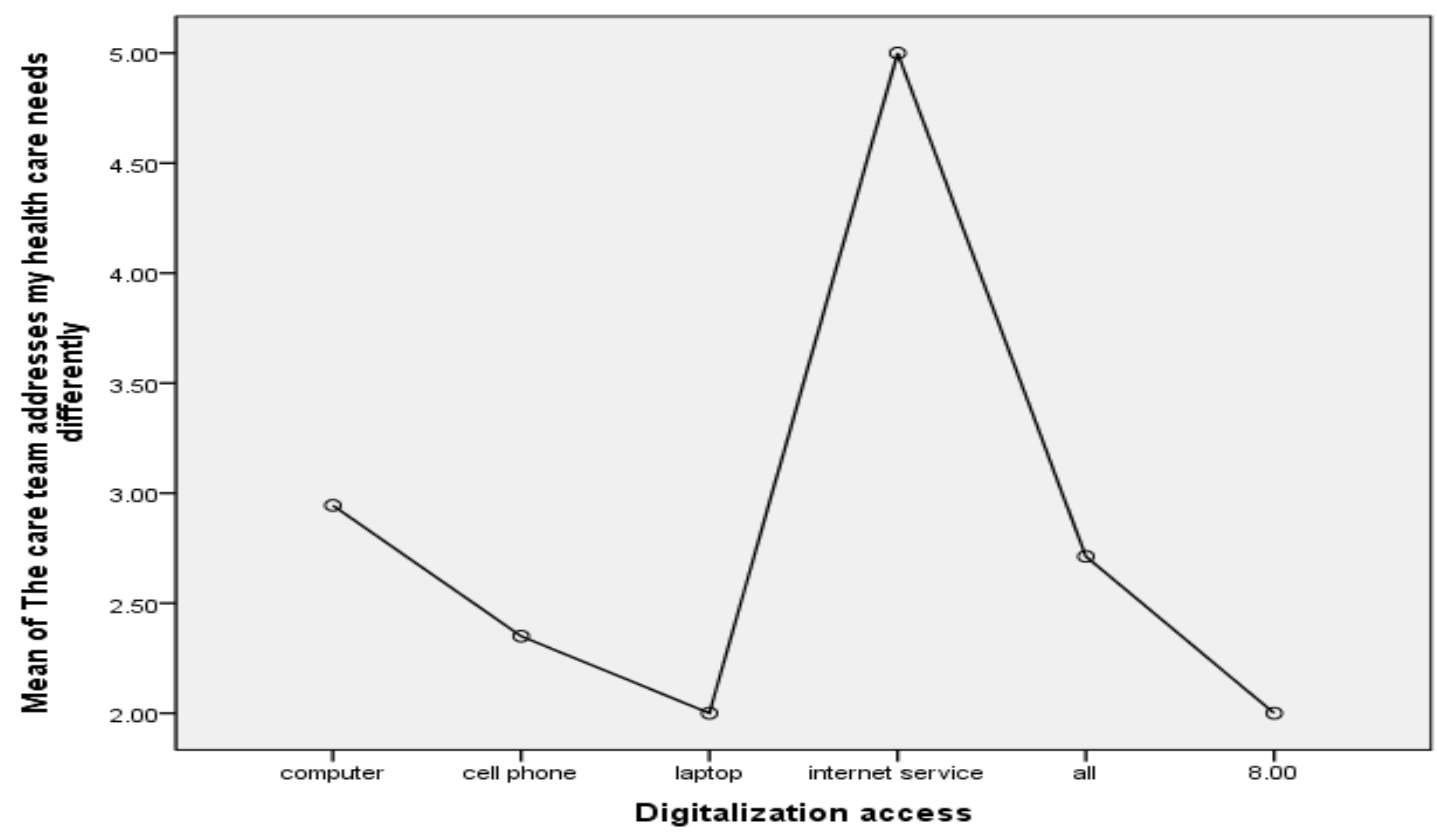

Figure 7 Graphical Output health care needs-base

There is lack of awareness among the participants who claimed having access via their home computers, phones, and laptops and among those with no access; however, there is more awareness from the participants with internet access from community resources as illustrated in graphical output figure 7 above. One possible reason may be due to limited service access or limited communication from the health services sites. It is noted that the spread of diffusion and adoption is lacking among the health centers and those with EHRs may still be in learning curve and with limited access such as patient portal which is an extra cost to these local health care organizations. 


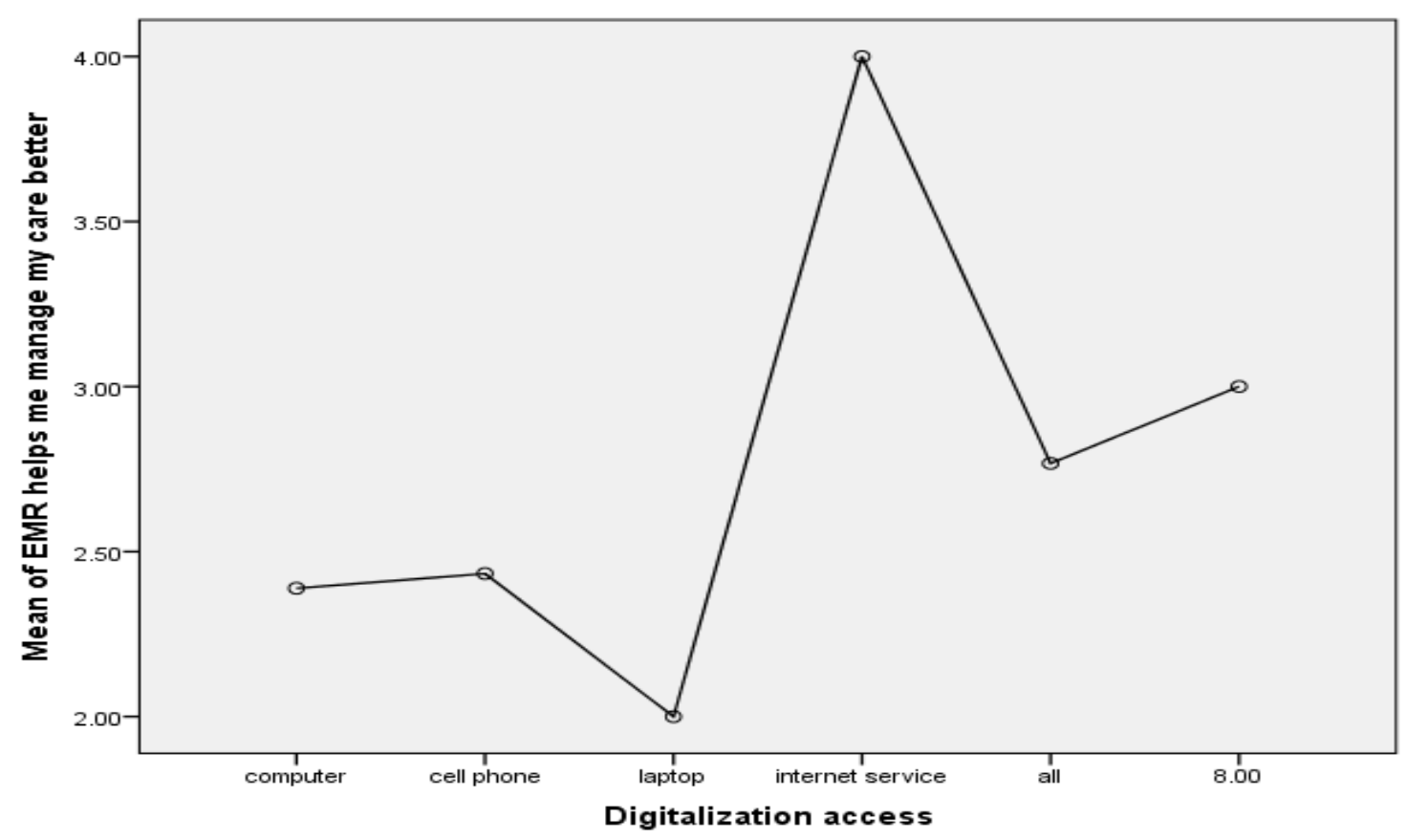

Figure 8 Graphical Output EMR-based

The correlation between digital access and the EHR support to self-manage care is a very important one as it can help understand and analyze the patient's perspectives. The impact of the EHR on their health should be as it pertains to them based on the EHR contribution to their health outcomes. Figures 8 and 9 addressed the correlations between digital access and self-care management and health improvement respectively. Figure 7 shared a similarity of results in terms of means of access and participants who are in synch with the electronic health care program at their respective health care services sites.

It is reasonable to believe that there is a correlation between health improvement and the accessible means of digital services. The lack of access to self-care management is inversely correlated with the lack of awareness of the health care team to the health services participants. However, the health care team including health organizations, 
physicians, nurses, medical statisticians, and others may have different perspectives. As one may note, the EHR was primarily created to fit the professional team needs, not the people that it intends to address and manage care.

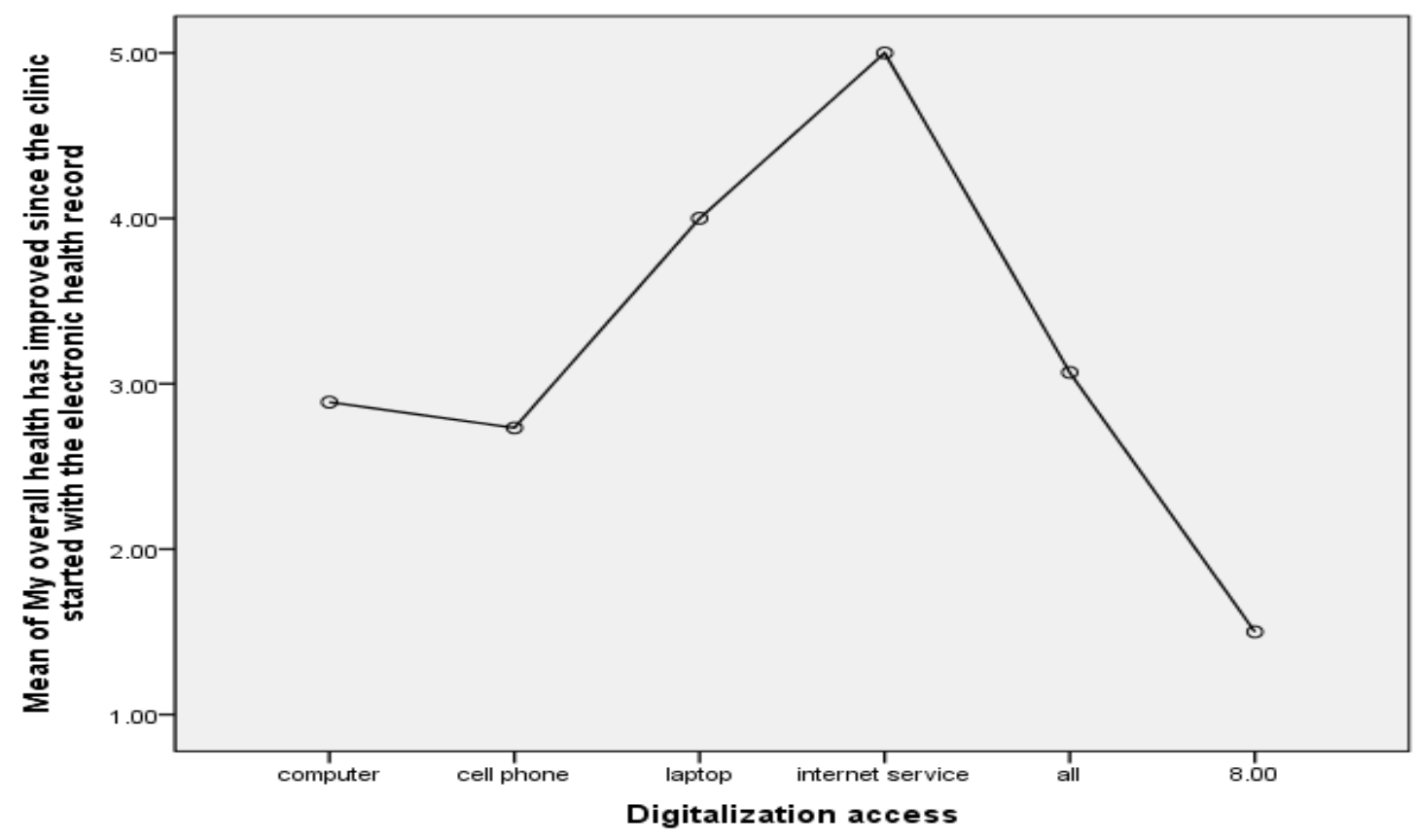

Figure 9 Graphical Output health outcomes

\section{Treatment / Intervention Fidelity}

The research data collection intervention deviated from its original design.

Originally three health care settings were chosen not only for their specific locations but also for their active use of EMR. Research survey distribution and collection were to be administered on sites as patients present to their appointments. Several administrative operational changes took place at two of the sites which required longer procedural approval. I had to use another alternative to continue to move on with the project and complete the research in a reasonable time that fits my educational needs. The survey distribution went well; however, the data collection took much longer time than 
anticipated. This caused serious consequences on the limitation of the sample size and the time allotted to complete the research. In order to reach the maximum sample size effect for this research as planned in chapter 3, at least a minimum of six months or more would need to be allocated for data collection alone. For this reason, the minimum returned sample size value was kept for this research as supported by Cochran's (1997) formula and Kotrick \& Higgins' (2001) formulary table.

\section{Results}

\section{Sample characterization}

The demographic structure of the population sample for this study is very crucial in determining the internal validity of the results. Each variable is considered, compared, and explored for their relationships and their typical behavioral patterns that may impact the results of the study. This research considers the facts that the population is underserved, with low health literacy, low income or unemployed, and with minimal education. Comparative analysis expressed in figures 3 to figures 9 above explained the marginal deficits and setbacks within the study parameters.

One major issue depicted from most graphical outputs illustrated from figures 3 to

9 , is the lack of home and community digital access to respond to the demand imposed by the health reform. Although every household may not be equipped with internet services, providing means for digital access in communal gathering places such as libraries, supermarkets, grocery stores, barbershops, and local restaurants such as McDonald, Burger King, whichever are the most accessible within the underserved communities, can 
create a recovered sense of community outreach, caring, and engagement. The EHR is cost-intensive and needs to be put to use in a more ubiquitous way by extending and even customizing its service to fit the needs of the underserved population. Optimization of the EHR to benefit the health of the underserved community will certainly result in better and sustainable health outcomes. Table 8 depicts the sample population and its characteristics.

Table 6

Descriptive Statistics

\begin{tabular}{|c|c|c|c|c|c|c|c|}
\hline & \multirow{2}{*}{\begin{tabular}{|c}
$\mathrm{N}$ \\
Statistic
\end{tabular}} & \multirow{2}{*}{\begin{tabular}{|l|} 
Minimum \\
Statistic
\end{tabular}} & \multirow{2}{*}{\begin{tabular}{|l} 
Maximum \\
Statistic
\end{tabular}} & \multirow{2}{*}{\begin{tabular}{|l} 
Mean \\
Statistic
\end{tabular}} & \multirow{2}{*}{$\begin{array}{c}\text { Std. } \\
\text { Deviation }\end{array}$} & \multicolumn{2}{|c|}{ Kurtosis } \\
\hline & & & & & & Statistic & $\begin{array}{l}\text { Std. } \\
\text { Error }\end{array}$ \\
\hline Patient race & 155 & 1.00 & 11.00 & 1.3613 & 1.27353 & 41.780 & .387 \\
\hline Patient income & 155 & 1.00 & 4.00 & 1.6194 & .89204 & 1.699 & .387 \\
\hline Patient age & 155 & 1.00 & 4.00 & 2.3871 & .92151 & -.908 & .387 \\
\hline Citizenship status & 155 & 1.00 & 4.00 & 1.1484 & .43832 & 14.887 & .387 \\
\hline Health insurance & 155 & 1.00 & 8.00 & 2.2258 & 1.29709 & 4.433 & .387 \\
\hline $\begin{array}{l}\text { Number of health } \\
\text { conditions/diagnosis }\end{array}$ & 155 & 1.00 & 7.00 & 2.0065 & 1.02245 & 3.458 & .387 \\
\hline $\begin{array}{l}\text { Environmental exposure or } \\
\text { habit }\end{array}$ & 155 & 1.00 & 7.00 & 4.8839 & 2.13187 & -1.077 & .387 \\
\hline Digitalization access & 155 & 1.00 & 8.00 & 4.3355 & 2.64152 & -1.942 & .387 \\
\hline Health service utilization & 155 & 1.00 & 5.00 & 1.8839 & .83709 & .949 & .387 \\
\hline $\begin{array}{l}\text { Transportation access } \\
\text { Valid N (list wise) }\end{array}$ & $\begin{array}{l}155 \\
155\end{array}$ & 1.00 & 7.00 & 1.8258 & 1.21756 & 6.306 & .387 \\
\hline
\end{tabular}




\section{Statistical analysis}

The first research question focuses on how the holistic system theory explains the relationship between EHR and patient's health related outcomes. The research survey was very necessary in evaluating technology in health care to account for all possible social, ethical, and environmental factors that should be accountable for reliable system thinking and system communication that is grounded in the explanation of the holistic system theory. Existing literature, empirical data, research, and case studies as noted in chapter 2 demonstrated great influence of theoretical formation for understanding large and complicated systems such as health care. Involvement of primary care providers, ancillary services, referred specialty services; stakeholders, medical personals, policy makers, patients and family, appropriate education or training, medical labs, patients' surroundings, equipment, treatment and tests are theoretically influenced under the holistic system that facilitates all the systemic interactions to deliver essential care management and care coordination to reach optimal results based on the patient's health care needs.

A one-sample $t$ test was conducted on the Kudi scale scores to appraise whether a significance difference exists between the means and the hypothesis value. The sample mean of $\mathrm{t}(154)(\mathrm{SD}=.75-4.19)$ is different from $\mathrm{t}(153)=14-92.5, \mathrm{p}<.001$. The mean in Kudi score ranged from 2.12 to 4.35 at $95 \%$ confidence interval with a very low authenticity of bias and standard error $<.5$ for nearly all central variables as seen in Table 7.1. The results reject the null hypothesis in research question 1 while supporting effect

of the factors associated with holistic system theory in understanding the complexity and 
the dynamics of the EHR on health management and coordination which lead to the overall patient's health outcomes. This result validated the holistic framework system model below that was initiated in the previous chapter

Holistic Framework Map

EHR

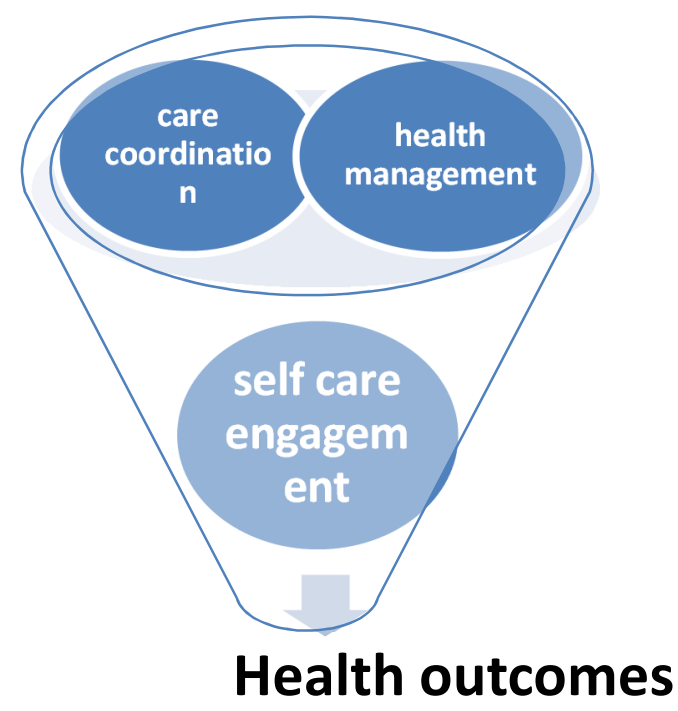

Patient's perspectives

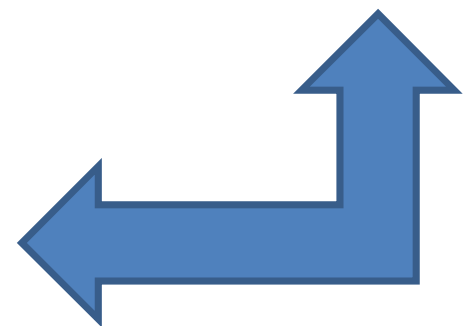

Clinical/nonclinical environment

Figure 10 Holistic Framework Map

\section{Statistical Findings}

The results of the one-sample $t$ test also support the needs to focus on factors that promote a patient centric environment with all subsidiaries working together to the benefits of providing appropriate care that is designed to fit the patients or the community specific needs. Research hypothesis 1 is statistically significant; and therefore, validates the fact that the holistic system theory can be utilized for understanding the complexity 
and the dynamics of the EHR on health. Diagram 3.0 details the theoretical process and logistics involved.

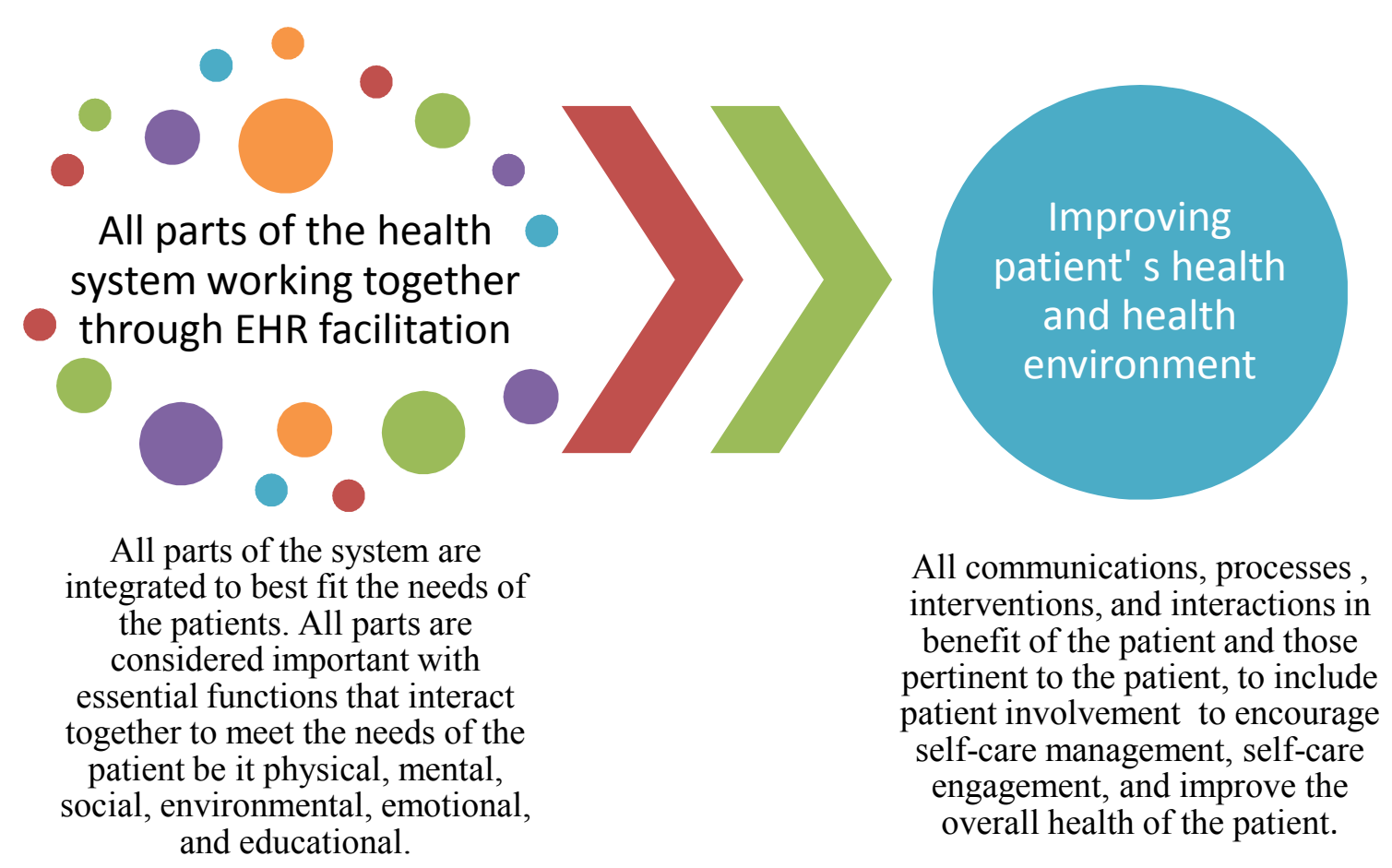

Figure 11 Holistic System Theory Application

RQ2 elaborates on best clinical outcomes for determining the effectiveness of

EHR on the underserved population. The list of clinical outcomes can be countless;

however, the factors contributing to these clinical outcomes can also be very substantial.

Those who are providing direct patient care in the field know for facts that patients may, for example, present with high blood pressure during triage and assessment. However, they do not experience other clinical symptoms as normally expected in a hypertensive case. The opposite may also be true for those with normal blood pressure but may experience many different clinical symptoms of hypertensive nature. This research goes 
beyond addressing only clinical outcomes. It uses other supporting contributors such as social-economic conditions and situations, living conditions, lifestyle, religious belief, past and present experiences, personal circumstances, understanding, self-care knowledge, and self-care engagement instead.

It has been a common belief that underserved population households may lack digital accessibility. It is a mechanism that is necessary to complement the EHR health information to the patient point of access via a portal or simply a text message communication or via a landslide communication. The sample t-test in Table 8 demonstrates the benefits of considering open-ended questions. Health outcomes are depicted using open-ended questions to stimulate comprehensive understanding of patients' self-health and self-care as perceived appropriate and comfortable.

In this research, clinical outcomes were determined based on the patients' perceptions of their health as it pertains to the reality of their everyday life. The sample statistics test in Table 8 showed significant relationships when $p<.05$. This is consistent with the following survey questions: I know more about my health since EMR implementation took place; EMR helps me manage my care better; EMR helps me manage my health better than before; the EMR helps me engage more and have more control of my health; my overall health has improved since the clinic started with the EHR. The one-sample $t$ test on the KUDI depression scale was significantly different when $t(153)=$ ranging from 14.8 to 95.1. $p<.01$ therefore, supporting the research hypothesis over the assumption that clinical outcome measures can significantly contribute to the effectiveness of EHR on the health of the underserved community. 
Table 7

Relationships between variables

\begin{tabular}{|c|c|c|c|c|c|c|}
\hline \multicolumn{7}{|c|}{ One-Sample Test } \\
\hline & \multicolumn{6}{|c|}{ Test Value $=8$} \\
\hline & \multirow[t]{2}{*}{$\mathrm{t}$} & \multirow[t]{2}{*}{ df } & \multirow[t]{2}{*}{$\begin{array}{l}\text { Sig. }(2- \\
\text { tailed) }\end{array}$} & \multirow[t]{2}{*}{$\begin{array}{c}\text { Mean } \\
\text { Difference }\end{array}$} & \multicolumn{2}{|c|}{$\begin{array}{l}\text { 95\% Confidence } \\
\text { Interval of the } \\
\text { Difference }\end{array}$} \\
\hline & & & & & Lower & Upper \\
\hline Digitalization access & $17.132^{-}$ & 153 & .000 & -3.64935 & -4.0702 & -3.2285 \\
\hline Disease management & 91.753 & 153 & .000 & -5.87662 & -6.0032 & -5.7501 \\
\hline general health status & $72.994^{-}$ & 153 & .000 & -5.66883 & -5.8223 & -5.5154 \\
\hline $\begin{array}{l}\text { Limitations from typical } \\
\text { activities }\end{array}$ & $95.130^{-}$ & 153 & .000 & -5.79221 & -5.9125 & -5.6719 \\
\hline $\begin{array}{l}\text { Physical pain during the } \\
\text { last } 4 \text { weeks }\end{array}$ & $56.713^{-}$ & 153 & .000 & -5.68831 & -5.8865 & -5.4902 \\
\hline $\begin{array}{l}\text { The care team addresses } \\
\text { my health care needs } \\
\text { differently }\end{array}$ & 43.726 & 153 & .000 & -5.39610 & -5.6399 & -5.1523 \\
\hline $\begin{array}{l}\text { The health service is better } \\
\text { than before }\end{array}$ & 50.124 & 153 & .000 & -5.78571 & -6.0138 & -5.5577 \\
\hline $\begin{array}{l}\text { I know more about my } \\
\text { health since EMR } \\
\text { implementation }\end{array}$ & 42.027 & 153 & .000 & -5.50649 & -5.7653 & -5.2476 \\
\hline $\begin{array}{l}\text { EMR helps me manage my } \\
\text { care better }\end{array}$ & 39.097 & 153 & .000 & -5.39610 & -5.6688 & -5.1234 \\
\hline $\begin{array}{l}\text { I prefer email for my lab } \\
\text { results, and questions } \\
\text { about my health }\end{array}$ & 14.498 & 153 & .000 & -4.98701 & -5.6666 & -4.3074 \\
\hline $\begin{array}{l}\text { I have multiple health } \\
\text { conditions, I rely on others } \\
\text { to help me }\end{array}$ & 15.472 & 153 & .000 & -4.51948 & -5.0966 & -3.9424 \\
\hline $\begin{array}{l}\text { The emr helps me manage } \\
\text { my health better than } \\
\text { before }\end{array}$ & $14.760^{-}$ & 153 & .000 & -4.98701 & -5.6545 & -4.3195 \\
\hline $\begin{array}{l}\text { The emr helps me engage } \\
\text { more and have more } \\
\text { control of my health }\end{array}$ & $41.710^{-}$ & 153 & .000 & -5.29870 & -5.5497 & -5.0477 \\
\hline $\begin{array}{l}\text { My overall health has } \\
\text { improved since the clinic } \\
\text { started with the EHR }\end{array}$ & 38.352 & 153 & .000 & -5.07792 & -5.3395 & -4.8163 \\
\hline
\end{tabular}


Research hypothesis 3 supports the assumption that patients' perspectives will be significantly valuable if integrated into patient's health outcome calculations. A pairedsample t test as seen in Table 8 above was conducted to evaluate the relationships between variables and covariates. The closed interval between the mean differences ranging from -4.51 to -5.87 and between the mean differences ranging from -3.2 to -.6 is an indication that there are moderate relationships to be considered. It rejects the null hypothesis that negates the reasons for patients' perspectives to be integrated into the health outcome calculations. Indeed, $p<.001$ indicates a strong level of significance in the relationships existing between the clinical outcome measures and the EHR based on patients' perspectives on how the EHR impacts their health to facilitate self-engagement and self-care coordination. The mean response rate showed a below $50 \%$ average response that support EHR having an impact on health outcomes.

The result supports the conclusion that there are acceptable reasons to believe that patients' perspectives should be integrated in health outcomes to determine the impact of the EHR on their overall health. Graphical output figure 8 synchronized with the digital revolution within the underserved communities. Nearly $90 \%$ of respondents have some sort of access to the internet; however, nearly half are undecided about if the EHR has impact on their health. Nearly $60 \%$ believed that the EHR has some impact on their health through standard health care coordination and disease management.

Another convincing graph is figure 6 demonstrating the narrow relationship existing between digital access and disease management. Although only about $20 \%$ of the survey responders have all available points of access to communicate with their health 
care management team, it was a convincing fact demonstrating that patients with better digital access were more likely to have better health communication, better health experience, and better relationship with their health care provider team.

Having an information technology infrastructure for the underserved health centers or rural health clinics is of a great advantage for the simple fact that the underserved areas patients have multiple health needs with several different chronic diseases that require good care coordination and consistency in their disease management process. While the EHR is in great demand, this research results greatly demonstrate the significance of understanding the needs involved with the undertaking from the underserved population to help comprehend the use of the EHR to serve these patients' population in a much more customable approach. If a value is to be put on health care coordination and care management, then the underserved community must be equipped with digital access to facilitate service integration trough care management, care coordination, as well as care transition. EHR overall implementation must satisfy complete and multidimensional services that meet the underserved community's needs.

The graph below as noted in figure 12 shows the positive influence of the EHR on patient's overall health improvement since their clinics started to use the EHR. Although all means of access are counted for, those with internet access seem to demonstrate a much better predictor over the others. Interestingly demonstrated in the graph below is that, even patients with minimal accessible digital means agreed that their overall health has shown some improvement since their clinics started using the EHR. 


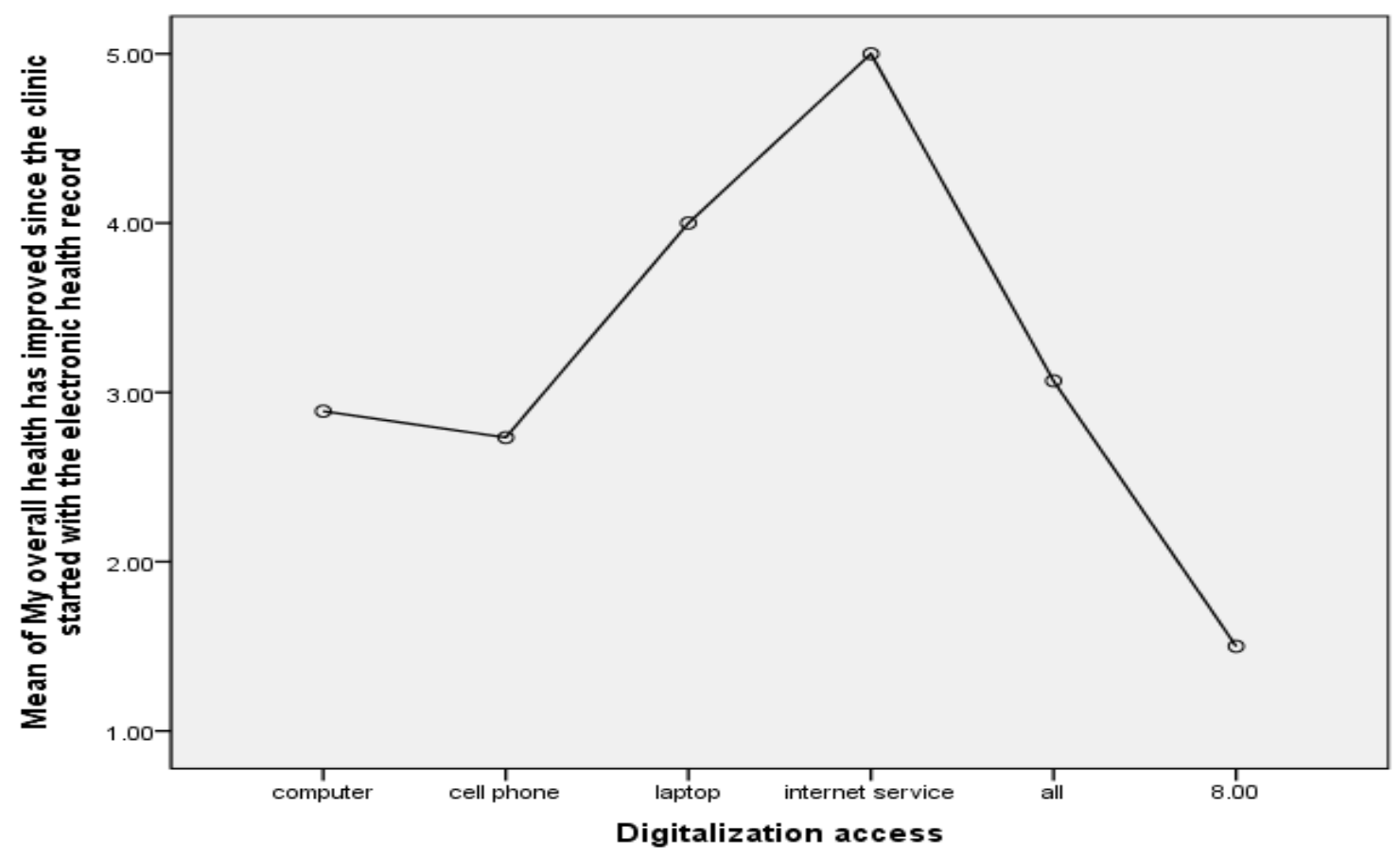

Figure 12. Graphical Output health improvement-based

A multiple regression analysis was conducted to examine research questions 4 and 5 as indicated in chapter 3. RQ4 elaborated on the characteristics of patients who may view the significant benefits of the EHR on their health. Table 9 below shows the computation of correlations between variables within each set and from different sets of variables. The Pearson correlation coefficient indicates the effect size index with a ranging value from -1 to +1 . The statistical result showing in Table 9 was consistent with the correlation coefficient $r$ with $-1>r<+1$; the effect size of the correlation analysis was statistically significant for $.30>r<$ or $=1$.

This research uses the Bonferroni's approach to control bias and standard error across the correlations. This approach involves the chance that at least on test between and within the correlations may be statistically significant (Armstrong, 2014). A $p$ value 
of less than .005 was required to satisfy the statistical significance of the correlations. A one t-tailed test was also statistically significant for $p<.001$ and was consistently demonstrated during all the correlation analyzes, an indicator of strong correlations between the variables and the covariates. It, in fact, rejects the null hypothesis of RQ4 which stated that there is no difference in the characteristics of patients who view EHR beneficial to their health. This linear regression analysis suggested moderate to high predictability between the variables or the set of variables. The correlation between two intervals ranged from .096 to 1.00. Therefore: $r(155)=.094$, sig $p<0.01$, 2-tailed. The statistical output regression as demonstrated in Table 9 below presents the details of the linear relationship between the variables.

Table 8

Regression Tables

Descriptive Statistics

\begin{tabular}{|c|c|c|c|c|c|c|}
\hline & \multirow[t]{3}{*}{ Statistic } & \multicolumn{4}{|c|}{ Bootstrap $^{a}$} \\
\hline & & & \multirow[t]{2}{*}{ Bias } & \multirow[t]{2}{*}{$\begin{array}{l}\text { Std. } \\
\text { Error }\end{array}$} & \multicolumn{2}{|c|}{$\begin{array}{c}95 \% \text { Confidence } \\
\text { Interval }\end{array}$} \\
\hline & & & & & Lower & Upper \\
\hline \multirow{3}{*}{$\begin{array}{l}\text { EMR helps me manage my } \\
\text { care better }\end{array}$} & Mean & 2.6000 & .0050 & .0884 & 2.4129 & 2.7894 \\
\hline & $\begin{array}{l}\text { Std. } \\
\text { Deviation }\end{array}$ & 1.70789 & .00748 & .10994 & 1.52012 & 1.95344 \\
\hline & $\begin{array}{l}\mathrm{N} \\
\text { Mean }\end{array}$ & $\begin{array}{r}155 \\
2.6000\end{array}$ & $\begin{array}{r}0 \\
.0056\end{array}$ & $\begin{array}{r}0 \\
.0775\end{array}$ & $\begin{array}{r}155 \\
2.4645\end{array}$ & $\begin{array}{r}155 \\
2.7484\end{array}$ \\
\hline \multirow[t]{2}{*}{$\begin{array}{l}\text { The care team addresses my } \\
\text { health care needs differently }\end{array}$} & $\begin{array}{l}\text { Std. } \\
\text { Deviation }\end{array}$ & 1.52724 & .00060 & .03299 & 1.45622 & 1.59472 \\
\hline & & $\begin{array}{r}155 \\
2.4903\end{array}$ & $\begin{array}{r}0 \\
.0045\end{array}$ & $\begin{array}{r}0 \\
.0918\end{array}$ & $\begin{array}{r}155 \\
2.3419\end{array}$ & $\begin{array}{r}155 \\
2.6744\end{array}$ \\
\hline \multirow{2}{*}{$\begin{array}{l}\text { I know more about my health } \\
\text { since EMR implementation }\end{array}$} & Std. & 1.62116 & & .12658 & 1.42106 & 1.90734 \\
\hline & $\begin{array}{l}\text { Deviation } \\
N\end{array}$ & 155 & $\begin{array}{r}.00735 \\
0\end{array}$ & 0 & 155 & 155 \\
\hline \multirow{2}{*}{$\begin{array}{l}\text { I communicate better with my } \\
\text { health care team }\end{array}$} & Mean & 2.3935 & .0041 & .0781 & 2.2452 & 2.5419 \\
\hline & $\begin{array}{l}\text { Std. } \\
\text { Deviation }\end{array}$ & 1.48803 & .00261 & .04091 & 1.40607 & 1.55230 \\
\hline
\end{tabular}




\begin{tabular}{|ll|r|r|r|r|r|} 
& $\mathrm{N}$ & 155 & 0 & 0 & 155 & 155 \\
My prescriptions are done & Mean & 1.8065 & .0023 & .0560 & 1.7032 & 1.9167 \\
electronically & Std. & 1.10546 & - & .05437 & .99192 & 1.21926 \\
& Deviation & & .00363 & & & \\
& $\mathrm{~N}$ & 155 & 0 & 0 & 155 & 155 \\
I get texts or email messages & Mean & 2.0645 & .0022 & .0599 & 1.9419 & 2.1806 \\
to remind me my & Std. & 1.28769 & - & .04464 & 1.19526 & 1.36040 \\
appointments & Deviation & & .00135 & & & \\
& $\mathrm{~N}$ & 155 & 0 & 0 & 155 & 155 \\
\hline
\end{tabular}

a. Unless otherwise noted, bootstrap results are based on 155 stratified bootstrap samples

Graphical age output-based and insurance type output-based shown in the ANOVA test results previously are also shown below. In figure 5, the younger population was more likely to carry a laptop or iPod compared to the mid-age population who used a desktop computer and cell phone. The older population had some form of internet access but not necessarily owned. An interesting fact from this graphical output is the mid-aged population with $50 \%$ access and the other $50 \%$ with no access to the digital capability for internet service. Another fact is the non-reliable digital access to allow them to communicate with their health care team readily.

Graphical figure 5.1 addressed the mean of health insurance that puts the earlier graphical result in a much better perspective. The patients with some digital access through computer and phone are those with insurance through Medicaid /Medicare HMOs and those with all digital access reflect the patients with insurance through their work organization. Those with the laptop are few college students with parental insurance and digital service access. Interestingly, this group has better access but with less chronic disease management needs as supported by the other graphic outputs. 
The Bootstrap for Pearson Correlation and Bootstrap for Coefficients are shown in Table I1 and L1 respectively. They were found statistically significant at 95\% interval with a $p$ value ranging from $p<.005$ to $p<$ or $=.009$. The Bootstrap suggested that correlational significance may vary between and within the same or different variables. The correlations of EMR implementation with better self- health management tend to be lower and partially significant. The correlations of appointment reminders via text messages with better self-care management were not significant because of its low negative score. Another variable addressing self-care knowledge correlations with the EMR implementation and care management has the same negative low score.

Table 9

Model Summary

\begin{tabular}{|c|c|c|c|c|}
\hline Model & $\mathrm{R}$ & $\mathrm{R}$ Square & $\begin{array}{c}\text { Adjusted } \mathrm{R} \\
\text { Square }\end{array}$ & Std. Error of the Estimate \\
\hline 1 & $.788^{\mathrm{a}}$ & .622 & .609 & 1.06799 \\
\hline
\end{tabular}

Predictors: (Constant), I get texts or email messages to remind me my appointments, I owe more about my health since EMR implementation, The care team addresses my health care needs differently, My prescriptions are done electronically, I communicate better with my health care team

ANOVA

\begin{tabular}{|c|c|c|c|c|c|c|}
\hline \multicolumn{2}{|c|}{ Model } & $\begin{array}{l}\text { Sum of } \\
\text { Squares }\end{array}$ & $d f$ & $\begin{array}{l}\text { Mean } \\
\text { Square }\end{array}$ & $F$ & Sig. \\
\hline \multirow{3}{*}{1} & Regression & 279.251 & 5 & 55.850 & 48.966 & $.000^{b}$ \\
\hline & Residual & 169.949 & 149 & 1.141 & & \\
\hline & Total & 449.200 & 154 & & & \\
\hline
\end{tabular}


a. Dependent Variable: EMR helps me manage my care better

b. Predictors: (Constant), I get texts or email messages to remind me my appointments, I know more about my health since EMR implementation, The care team addresses my health care needs differently, My prescriptions are done electronically, I communicate better with my health care team

RQ5 addressed the effect of the EHR on the provider-patient relationship and to evaluate how accurate does the EHR predict the provider-patient relationship and how well the set of variables predict the relationship between providers and patients while using the EHR. Table 12 shows the result of a multiple regression test that was conducted to determine the strength associated with the criterion variable, the EMR helps me manage my care better. The strength measure was significantly related to the EMR index. $F(11,143)=22.17, p<.001$. The sample multiple correlation coefficient was .80 representing about $20 \%$ of the variance of the EMR tester in the sample. This can be accounted for by the variable combination indicating the measured strength. Partial correlation strength for each variable is indicated in Table 12 below.

Table 10

Model Summary

\begin{tabular}{|c|c|c|c|c|c|c|c|c|c|}
\hline \multirow[t]{2}{*}{ Model } & \multirow[t]{2}{*}{$\mathrm{R}$} & \multirow{2}{*}{$\begin{array}{c}\mathrm{R} \\
\text { Square }\end{array}$} & \multirow{2}{*}{$\begin{array}{l}\text { Adjusted R } \\
\text { Square }\end{array}$} & \multirow{2}{*}{$\begin{array}{l}\text { Std. Error } \\
\text { of the } \\
\text { Estimate }\end{array}$} & \multicolumn{5}{|c|}{ Change Statistics } \\
\hline & & & & & $\begin{array}{l}\text { R Square } \\
\text { Change }\end{array}$ & $\begin{array}{c}\mathrm{F} \\
\text { Change }\end{array}$ & dfl & $\mathrm{df} 2$ & $\begin{array}{c}\text { Sig. F } \\
\text { Change }\end{array}$ \\
\hline 1 & $.182^{\mathrm{a}}$ & .033 & .001 & 1.70734 & .033 & 1.020 & 5 & 149 & .408 \\
\hline 2 & $.798^{\mathrm{b}}$ & .637 & .609 & 1.06839 & .604 & 39.586 & 6 & 143 & .000 \\
\hline
\end{tabular}

a. Predictors: (Constant), Transportation access , Patient age, Health insurance, Environmental exposure or habit, Patient income

b. Predictors: (Constant), Transportation access , Patient age, Health insurance, Environmental exposure or habit, Patient income, I am aware that the clinic has EMR, I get texts or email messages to remind me my appointments, I know more about my health since EMR implementation, The care team addresses my health care needs differently, I communicate better with my health care team, My prescriptions are done electronically 
Table 11

\begin{tabular}{|c|c|c|c|c|c|c|}
\hline \multicolumn{1}{|c|}{ ANOVA } & Model & Sum of Squares & $\mathrm{df}$ & Mean Square & $\mathrm{F}$ & Sig. \\
\hline \multirow{4}{*}{1} & Regression & 14.862 & 5 & 2.972 & 1.020 & $.408^{\mathrm{b}}$ \\
& Residual & 434.338 & 149 & 2.915 & & \\
& Total & 449.200 & 154 & & & \\
& Regression & 285.972 & 11 & 25.997 & 22.776 & $.000^{\mathrm{c}}$ \\
2 & Residual & 163.228 & 143 & 1.141 & & \\
& Total & 449.200 & 154 & & & \\
\hline
\end{tabular}

Table 12

\section{Coefficients}

\begin{tabular}{|c|c|c|c|c|c|c|c|c|c|c|}
\hline \multirow[t]{2}{*}{ Model } & \multicolumn{2}{|c|}{$\begin{array}{l}\text { Unstandardized } \\
\text { Coefficients }\end{array}$} & \multirow{2}{*}{$\begin{array}{c}\begin{array}{c}\text { Standardized } \\
\text { Coefficients }\end{array} \\
\text { Beta }\end{array}$} & \multirow[t]{2}{*}{$\mathrm{t}$} & \multirow[t]{2}{*}{ Sig. } & \multicolumn{2}{|c|}{$\begin{array}{c}95.0 \% \\
\text { Confidence } \\
\text { Interval for B }\end{array}$} & \multicolumn{3}{|c|}{ Correlations } \\
\hline & B & $\begin{array}{l}\text { Std. } \\
\text { Error }\end{array}$ & & & & $\begin{array}{l}\text { Lower } \\
\text { Bound }\end{array}$ & $\begin{array}{l}\text { Upper } \\
\text { Bound }\end{array}$ & $\begin{array}{l}\text { Zero- } \\
\text { order }\end{array}$ & Partial & Part \\
\hline (Constant) & 2.084 & .554 & & 3.763 & .000 & .990 & 3.179 & & & \\
\hline Patient age & .316 & . 164 & .170 & 1.921 & .057 & -.009 & 641 & 169 & .155 & 155 \\
\hline Patient income & .046 & .184 & .024 & .248 & .804 & -.317 & .408 & .044 & .020 & .020 \\
\hline 1 Health insurance & -.067 & .110 & -.051 & -.614 & .540 & -.284 & .149 & -.018 & -.050 & -.049 \\
\hline $\begin{array}{l}\text { Environmental } \\
\text { exposure or habit }\end{array}$ & -.008 & .067 & -.010 & -.115 & .909 & -.139 & .124 & .026 & -.009 & -.009 \\
\hline $\begin{array}{l}\text { Transportation access } \\
\text { (Constant) }\end{array}$ & $\begin{array}{r}-.068 \\
.035\end{array}$ & $\begin{array}{l}.129 \\
.406\end{array}$ & -.049 & $\begin{array}{r}-.533 \\
.086\end{array}$ & $\begin{array}{l}.595 \\
.932\end{array}$ & $\begin{array}{l}-.323 \\
-.768\end{array}$ & $\begin{array}{l}.186 \\
.838\end{array}$ & -.052 & -.044 & -.043 \\
\hline Patient age & .001 & .107 & .000 & .005 & .996 & -.210 & .212 & .169 & .000 & .000 \\
\hline Patient income & .086 & .116 & .045 & .739 & .461 & -.144 & .316 & .044 & .062 & .037 \\
\hline Health insurance & -.046 & .071 & -.035 & -.653 & .515 & -.186 & .094 & -.018 & -.055 & -.033 \\
\hline $\begin{array}{l}\text { Environmental } \\
\text { exposure or habit }\end{array}$ & .041 & .043 & .052 & .965 & .336 & -.043 & .126 & .026 & .080 & .049 \\
\hline Transportation access & -.008 & .081 & -.005 & -.093 & .926 & -.168 & .153 & -.052 & -.008 & -.005 \\
\hline $\begin{array}{l}\text { The care team } \\
\text { addresses my health } \\
\text { care needs differently }\end{array}$ & -.050 & .072 & -.044 & -.692 & .490 & -.191 & .092 & .317 & -.058 & -.035 \\
\hline $\begin{array}{l}2 \text { I am aware that the } \\
\text { clinic has EMR }\end{array}$ & -.168 & .084 & -.129 & -2.015 & .046 & -.333 & -.003 & .309 & -.166 & -.102 \\
\hline $\begin{array}{l}\text { I know more about my } \\
\text { health since EMR } \\
\text { implementation }\end{array}$ & .463 & .067 & .439 & 6.909 & .000 & .330 & .595 & .658 & .500 & .348 \\
\hline $\begin{array}{l}\text { I communicate better } \\
\text { with my health care } \\
\text { team }\end{array}$ & .566 & .080 & .493 & 7.092 & .000 & .408 & .723 & .706 & .510 & .358 \\
\hline $\begin{array}{l}\text { My prescriptions are } \\
\text { done electronically }\end{array}$ & .161 & .108 & .104 & 1.485 & .140 & -.053 & .375 & .454 & .123 & .075 \\
\hline $\begin{array}{l}\text { I get texts or email } \\
\text { messages to remind } \\
\text { me my appointments }\end{array}$ & .009 & .084 & .006 & .102 & .919 & -.157 & .174 & .348 & .009 & .005 \\
\hline
\end{tabular}

a. Dependent Variable: EMR helps me manage my care better 
Partial correlation from Table 14 above illustrated all the strength measures as predictors. It brings understanding to the reasons why certain variables correlate to each other (Green \& Salkind, 2011). Patient age, EMR knowledge, and electronic prescriptions are among the predictors counted for about $15 \%, 16 \%$, and $12 \%$ respectively. Partial correlation strength for better communication and increase selfhealth knowledge accounted for about $50 \%$, two major components in determining the provider-patient relationship. The strength of the other variables is mostly under $10 \%$ and some with even less than $1 \%$ that suggested having more or less low participatory value in the stand alone correlation. Based on the results, the linear combination suggested that better communication and increase knowledge offer more additional predictive power while age, EMR knowledge, and electronic prescriptions offer less additional predictive power. It may be due to the contributing factors in determining the effect of EMR on the provider-patient relationship and vice-versa.

\section{Post-hoc Analysis}

The partial correlation also suggested $0<r>0$ supports the research hypotheses that EHR can be significantly utilized to improve relationships among providers and patients, patient self-care engagement, and ongoing health related activities; except for patient age where $r=0$ when correlates with EMR, outweighs partially the causal relationship. 
Table 13

Bootstrap for Coefficients

\begin{tabular}{|c|c|c|c|c|c|c|}
\hline \multirow[t]{3}{*}{ Model } & \multirow[t]{3}{*}{ B } & \multicolumn{5}{|c|}{ Bootstrap $^{a}$} \\
\hline & & \multirow[t]{2}{*}{ Bias } & \multirow[t]{2}{*}{$\begin{array}{l}\text { Std. } \\
\text { Error }\end{array}$} & \multirow[t]{2}{*}{$\begin{array}{l}\text { Sig. }(2- \\
\text { tailed) }\end{array}$} & \multicolumn{2}{|c|}{$\begin{array}{l}\text { 95\% Confidence } \\
\text { Interval }\end{array}$} \\
\hline & & & & & Lower & Upper \\
\hline (Constant) & 2.084 & $\begin{array}{r}- \\
.008\end{array}$ & .398 & .006 & 1.369 & 3.059 \\
\hline Patient age & .316 & .002 & .129 & .019 & .068 & .562 \\
\hline Patient income & .046 & .005 & .081 & .635 & -.097 & .222 \\
\hline Health insurance & -.067 &. & .056 & .269 & -.179 & .026 \\
\hline Environmental exposure or habit & -.008 & .003 & .040 & .865 & -.083 & .081 \\
\hline Transportation access & -.068 &. & .051 & .218 & -.175 & .040 \\
\hline (Constant) & .035 & .036 & .211 & .865 & -.418 & .413 \\
\hline Patient age & .001 & .021 & .084 & 1.000 & -.128 & .185 \\
\hline Patient income & .086 & $\begin{array}{r}- \\
.018\end{array}$ & .067 & .250 & -.041 & .236 \\
\hline Health insurance & -.046 & .004 & .033 & .192 & -.108 & .024 \\
\hline Environmental exposure or habit & .041 & .002 & .025 & .154 & -.010 & .089 \\
\hline Transportation access & -.008 & .005 & .030 & .769 & -.067 & .059 \\
\hline $\begin{array}{l}\text { The care team addresses my health care needs } \\
\text { differently }\end{array}$ & -.050 & .024 & .060 & .506 & -.132 & .091 \\
\hline I am aware that the clinic has EMR & -.168 & .007 & .063 & .032 & -.284 & -.027 \\
\hline $\begin{array}{l}\text { I know more about my health since EMR } \\
\text { implementation }\end{array}$ & .463 & .064 & .200 & .006 & .066 & .693 \\
\hline I communicate better with my health care team & .566 & .022 & .099 & .006 & .392 & .788 \\
\hline My prescriptions are done electronically & .161 & .010 & .061 & .013 & .028 & .275 \\
\hline $\begin{array}{l}\text { I get texts or email messages to remind me my } \\
\text { appointments }\end{array}$ & .009 & .002 & .059 & .878 & -.114 & .117 \\
\hline
\end{tabular}

a. Unless otherwise noted, bootstrap results are based on 155 stratified bootstrap samples 
The 2-tailed Bootstrap for coefficients test in Table 15 above was also conducted to evaluate the overall prediction of the EHR. The statistical output shown in Table 14 demonstrates very low rate of bias in the correlations. One analysis set includes the demographic constituents and another, the patient logistical and EMR clinical characteristics. The regression equation for the demographic $R$ square $=.033$, adjusted $R$ square $=.001, F(5.149)=1.020, p<.05$ demonstrated significant proportion of the variability of the demographic constituents on the EMR and a controlling effect with $R$ square $=.637$ and adjusted $R$ square $=.609 . F(4,147)=22.7, p<0.01$. These results suggested the importance of considering the set of predictors to facilitate greater use of the EHR to meet the true needs of the underserved population.

Correlation coefficients were computed to determine either partial or linearity from excluded variables. The results of the correlation analysis from the regression output suggested some statistical significance at $p<0.01$ level with the 2-tailed test. Table 16 below indicates partial relation and statistical linearity between the set of variables determining relationship strength measure about the care team, the patient, and knowledge of EMR. Statistically: $r(155)=.295$, sig, $p<0.01,2$-tailed, therefore, $.295>$ 0 suggested nearly $30 \%$ strength measure with .90 to .97 statistical linearity. This result suggested more detailed and précised information and data collection are needed. Further research is also needed to ensure that the EHR's implementation includes a health technology model that integrates the link between the social-economic factors, the structural family dynamics, and the underserved population screening. It certainly will 
ensure that the care planning development model meets the needs of the underserved community.

Table 14

\section{Excluded Variables}

\begin{tabular}{|c|c|c|c|c|c|}
\hline \multirow[t]{2}{*}{ Model } & \multirow[t]{2}{*}{$\begin{array}{l}\text { Beta } \\
\text { In }\end{array}$} & \multirow[t]{2}{*}{$\mathrm{t}$} & \multirow[t]{2}{*}{ Sig. } & \multirow[t]{2}{*}{$\begin{array}{c}\text { Partial } \\
\text { Correlation }\end{array}$} & $\begin{array}{l}\text { Collinearity } \\
\text { Statistics }\end{array}$ \\
\hline & & & & & Tolerance \\
\hline $\begin{array}{l}\text { The care team addresses my health } \\
\text { care needs differently }\end{array}$ & $.304^{b}$ & 3.756 & .000 & .295 & .912 \\
\hline I am aware that the clinic has EMR & $.293^{b}$ & 3.751 & .000 & .295 & .974 \\
\hline $\begin{array}{l}\text { I know more about my health since } \\
\text { EMR implementation }\end{array}$ & $.656^{\mathrm{b}}$ & 10.476 & .000 & .653 & .956 \\
\hline $\begin{array}{l}\text { I communicate better with my health } \\
\text { care team }\end{array}$ & $.705^{\mathrm{b}}$ & 11.815 & .000 & .697 & .945 \\
\hline My prescriptions are done electronically & $.469^{b}$ & 6.444 & .000 & .468 & .962 \\
\hline $\begin{array}{l}\text { I get texts or email messages to remind } \\
\text { me my appointments }\end{array}$ & $.336^{\mathrm{b}}$ & 4.356 & .000 & .337 & .974 \\
\hline
\end{tabular}

a. Dependent Variable: EMR helps me manage my care better

b. Predictors in the Model: (Constant), Transportation access, Patient age, Health insurance,

Environmental exposure or habit, Patient income

\section{Conclusion}

These research findings demonstrated that technology alone would not be able to change the dynamics associated with the health care delivery and, more precisely, people's health. Several determinants of health were captured, compared, and analyzed to address the complexity, the ambivalence, the change, and the influence that might affect patient's health and patient care. The dynamics between patients and providers, patients' perspectives and health outcomes, the relationships and the functionality of the EHR were evaluated; tables and graphics were depicted in support of the findings. In this research, the assumption has been made that patients' perspectives will be significant in 
determining the effectiveness, the resourcefulness, and the greater use of the EHR. The sample effect size although somewhat significant, was considered to be a barrier against the generazibility of the research findings. The expert opinions and the pilot study supported in detail the validity of the research survey instrument.

\section{Answer to research questions}

The findings suggested that RQ1 supported the conceptual dynamic relationship between the EHR and patient's health outcomes through the use of the holistic system theory. RQ2 elaborated on best clinical outcomes that determine the effectiveness of EHR on the underserved population. RQ3 demonstrated moderate relationships between variables that support the importance of patients' perspectives as it relates to patients' health outcomes and of the EHR. RQ4 showed interesting development that may require further research while looking at the characteristics of patients who consider the impact to the EHR on their health. RQ5 demonstrated some causal relationship between variables supporting the case that the EHR can facilitate better patient-provider relationships. It also generated sets of predictions that stimulated further research questions on the implementation considerations for greater use of the EHR for the underserved community. Interpretations of these findings will be discussed in chapter 5 . Implications for social change and recommendations for future research will also be discussed in the next chapter. 


\section{Summary of the research findings}

The table listed below summarizes the findings of the study. Diagram 3 depicted the logistic interpretation of the relationship existing between the EHR and patients' health outcomes through system thinking when using holistic system theory. It, in fact, validates the research hypothesis and rejects the null hypothesis that holistic system theory has no significant effect in explaining the relationship between patients' health and their related health outcomes. There have been phenomenal research study results for implementation and the use of the EHR within the last decade. However, most supported the "one size fits all" theory for EHR implementation. Under this current holistic system theory, EHR is to be customized based on community needs-based assessment to have a successful implementation in the underserved community health clinics or health centers for the underserved community.

Table 15

Summary of research findings

\begin{tabular}{|c|c|c|c|c|c|}
\hline & RQ1 & $\mathrm{RQ2}$ & RQ3 & RQ4 & RQ5 \\
\hline Null Hypothesis & Rejects & Rejects & Rejects & Rejects & Rejects \\
\hline $\begin{array}{l}\text { Research } \\
\text { hypothesis }\end{array}$ & Supports & Supports & $\begin{array}{l}\text { Supports with } \\
\text { some } \\
\text { reservation }\end{array}$ & $\begin{array}{l}\text { Supports but not } \\
\text { consistent. } \\
\text { Contributory } \\
\text { factor } \\
\text { Predictors }\end{array}$ & Supports \\
\hline $\begin{array}{l}\text { Statistical test } \\
\text { Statistical } \\
\text { analysis }\end{array}$ & $\begin{array}{l}\text { One-sample } t \\
\text { test }\end{array}$ & $\begin{array}{l}\text { ANOVA } \\
\text {-Levene's Test of } \\
\text { Equality of } \\
\text { Variances: } p< \\
.001 \text { is less than } \\
\text { the } p \text { value of } \\
\text { significance } p=\end{array}$ & $\begin{array}{l}\text { ANOVA } \\
\text { A paired-sample } \\
t \text { test }\end{array}$ & $\begin{array}{l}\text { Multiple } \\
\text { Regression } \\
\text { Linear regression } \\
\text { analysis } \\
\text { Post hoc analysis }\end{array}$ & $\begin{array}{l}\text { Multiple } \\
\text { Regression } \\
\text { Regression } \\
\text { analysis } \\
\text { Excluded }\end{array}$ \\
\hline
\end{tabular}




\begin{tabular}{|c|c|c|c|c|c|}
\hline & & $\begin{array}{l}.05 \\
- \text { One sample } t \\
\text { test on the KUDI } \\
\text { depression scale }\end{array}$ & & & variables \\
\hline Statistical result & $\begin{array}{l}t(153)=14-92.5 \\
p<.001\end{array}$ & $\begin{array}{l}F(83,70)= \\
2.624, p<.001 \\
t(153)=14.8 \text { to } \\
95.1 . \text { when } p< \\
.01\end{array}$ & $\begin{array}{l}F(5,149)= \\
.482, p=.79 \\
\text { to } \\
F(5,149)= \\
3.68, p=.004 .\end{array}$ & $\begin{array}{l}r(155)=.094, \\
\text { sig } p<0.01,2- \\
\text { tailed } \\
R \text { square }=.001, \\
\mathrm{~F}(5.149)= \\
1.020, p<.05 \\
R \text { square }=.609 . \\
\mathrm{F}(4,147)=22.7, \\
p<0.01 .\end{array}$ & $\begin{array}{l}F(11,143)= \\
22.17, p<.001 \\
r(155)=.295, \\
\text { sig, } p<0.01,2- \\
\text { tailed, therefore, } \\
.295>0\end{array}$ \\
\hline $\begin{array}{l}\text { Statistical } \\
\text { interpretation }\end{array}$ & $\begin{array}{l}\text { Statistically } \\
\text { significant }\end{array}$ & $\begin{array}{l}\text { Statistically } \\
\text { significant when } \\
p<.01\end{array}$ & $\begin{array}{l}p<.01 \\
\text { strong level of } \\
\text { significance } \\
\text { when pairing } \\
\text { variables and co- } \\
\text { variables }\end{array}$ & $\begin{array}{l}\text { Partial relation } \\
\text { and statistical } \\
\text { linearity }\end{array}$ & $\begin{array}{l}\text { Linear } \\
\text { relationship } \\
\text { Correlational } \\
\text { strength }\end{array}$ \\
\hline $\begin{array}{l}\text { Finding } \\
\text { interpretation }\end{array}$ & $\begin{array}{l}\text { Holistic theory } \\
\text { validation for } \\
\text { understanding } \\
\text { the complexity } \\
\text { and the } \\
\text { dynamics of the } \\
\text { EHR on health }\end{array}$ & $\begin{array}{l}\text { Patient's } \\
\text { experience - a } \\
\text { significant } \\
\text { contributor to } \\
\text { clinical } \\
\text { outcomes }\end{array}$ & $\begin{array}{l}\text { Patient's } \\
\text { perspective - a } \\
\text { moderate } \\
\text { significant } \\
\text { integral factor in } \\
\text { determining the } \\
\text { impact of EHR } \\
\text { on health } \\
\text { improvement. }\end{array}$ & $\begin{array}{l}\text { Moderate to } \\
\text { high } \\
\text { predictability } \\
\text { between the } \\
\text { variables or the } \\
\text { set of variables }\end{array}$ & $\begin{array}{l}\text { Linearity in the } \\
\text { relationships } \\
\text { demonstrating } \\
\text { the use of EHR } \\
\text { to improve } \\
\text { patient-provider } \\
\text { relations to } \\
\text { facilitate patient } \\
\text { self-care } \\
\text { engagement. }\end{array}$ \\
\hline
\end{tabular}

\section{Summary}

The literature search in chapter 2 led us to believe that the EHR is a great innovation with very prodigious potential. This health technology has been quickly adopted and continues its quick adoption path with the acceptance that it improves patients' health and increases performance of health care providers. Since PPACA (2010), many regulations were designed, among them the Meaningful Use, with pressure on all health care organizations and practices to have technology infrastructure to 
coordinate care (Buntin, Burke, Hoaglin, \& Blumenthol, 2011). As demands for health technology continue to be increased, several considerations are oriented toward investments with the expectation to deliver better care, better improvement, and even better health. 


\section{Chapter 5: Discussion, Conclusions, and Recommendations}

\section{Introduction}

This chapter concentrates on the interpretations of the research findings. It also answers each research question, analyzes the findings, and evaluates the findings from the holistic system theory. Building upon the holistic framework map depicted in chapter 3 , it compares, analyzes, and evaluates variables and set of variables toward the literature search findings and within the conceptual framework discussed in Chapter 2. This chapter also combines the results with the suggestions of a comprehensive framework that is resourceful, safe, and patient-oriented. The framework will help not only meet the needs of the underserved community, but also provide long-term benefits to patients and their family while allowing them active self-care engagement, self-health management, and good health promotion. Further improvements of the conceptual model and recommendations are based on these research findings. Limitations and implications for future research and social change are also considered. While the purpose of this study is to demonstrate patients' perspectives on how the EHR impacts their health; this comprehensive study provides a worthy contribution to the great strategic initiative of redesigning health care for all Americans and of eliminating health disparities.

\section{Overview of the Study}

The EHR had made such an evolution in the history of health care within the last decade that it has become nearly impossible to talk about health care and not to elaborate on EHR. Indeed, its mandatory use since the enactment of the Accountable Care Act of 2010 had helped its spread into such a rapid adoption among in and outpatient health 
services. It becomes essential that the underserved area health centers and clinics equipped themselves with a health information technology that meets the needs of the patients they served. The purpose of this quantitative research survey design study was to determine the underserved patients' perspective about the effects of EHR on their health outcomes with respect to care coordination and health management. It also aimed at examining its relationship to patient's overall health improvement. This research study was a quantitative non-experimental design study. A research survey was conducted to determine patients' response and understanding of the impact of the EHR on their health. The Likert scaling method was used to measure the patients' judgment, attitude, knowledge, and satisfaction with the effects of the EHR on their health and health outcomes. We collected data via mail after distributing the envelopes to patients using three different rural health clinics for internal medicine health services.

\section{Key findings}

It is important to summarize the key findings and elaborate on the emerging findings that resulted from this research study. One of the key findings was the validation of the theoretical framework initiative that demonstrated the essentiality of the holistic system theory for understanding contextual changes and fundamental transformation embedded in the innovative resolution processes. Another important key finding was that clinical outcomes were a very significant contributor for determining the effectiveness of the EHR on patients' health. The patients' experience with the services provided and facilitated by the EHR in their respective health clinic servicer also accounted as much. 
Substantial to this research study were the findings that supported the entire research about underserved patients' perspectives being moderately significant integral factors in the process that determine the impact of the EHR on their health. Two other moderate significant findings were very relevant to this research study. The characteristics of patients who viewed the EHR as being beneficial to self-manage and self-engage in their health offered many opportunities to explore further their health. They also give them reason for exploring determinants of health in different groups, communities, and even cultures. There were also partial relationships and statistical predictive variables that accounted for the linearity existing between patients and providers in the findings associated with the last research question. This research explored, discussed, and interpreted all the findings in the next few pages.

\section{Discussions and interpretations of the research findings}

There has been a tremendous literature search, as seen in Chapter 2, that has been vital in the development of this research study and because of such; it is reasonable to assert that the EHR is one of the crucial elements in the history of health information technology and a valuable asset in the history of technology innovations. The mandate by the PPACA (2010) for health care organizations to be equipped with EHR that can satisfy all the meaningful use requirements was also one of the most relevant actions since the health reform. Without reservation, the EHR was found to be the ideal technology to help deal with the health reform intended to facilitate, structure, and redesign the nation's overall health care system (Frimpong et al., 2013). 
Scientific literature has demonstrated the complexity of our health care system and the holistic system was brought into this research to help understand not only the interconnections between different components of the network system but also the interplay existing between interdisciplinary care and the real-life phenomenon that may impact or sway the full potential of our health care system and health services delivery that impact all dimensions of human health. In the case of the underserved population, scientific literature has also demonstrated that this vulnerable population has even greater need for a holistic approach because of the social, economic, mental, and minimal resources that put in perspectives the dynamics associated with all these health determinants that influence their health and optimal delivery of care as intended under the provisions of the health care reform law. This research was necessary to identify determinants that measure up with the underserved culture and that influence its impact on the health of the underserved population. This research was designed to help understand the impact of the EHR from a different perspectives and identifying its use at the underserved population level and experience.

\section{Theoretical and Conceptual concept of the findings}

Innovation diffusion theory and the holistic system theory were found to be very relevant to demonstrate the characteristics of the EHR, the impact of its rapid adoption in health care. They also demonstrated in many respects, the lack of adoption where the needs are the greatest. Both theories served as the basis for creating the holistic framework map, as noted in Chapter 3, with a cooperative and collaborative approach base for designing and implementing health interventions. These theories were also 
usable for instigating and crafting health policies and for integrating health technologies interventions and even for distributing resources for better management of chronic diseases that affect the grand majority of the underserved population.

The research findings have helped comprehend further that even within the underserved population that the "one size fits all" principle would not be applicable. It is even true when considering the multiple factors associated with the complexity of health care delivery for this population. One impediment finding rested on the health IT education of the patients attending these health care centers and clinics. A moderate percentage of patients denied having any knowledge about the EHR infrastructure in their respective clinics even though they acknowledged receiving e-prescriptions and text messages from their providers. The descriptive statistics in Table 8.0 and the statistical correlation findings in Table 8.3 suggest that a much more aggressive and comprehensive approach is needed for effective change to occur to improve the health of the underserved population. This study provides a much more realistic care design and plan that reflect the true elements of care coordination, transition, management, and self-care engagement.

The concept of digitalization demonstrating the benefits of the EHR was found necessary for those with functional knowledge and adequate information on the indications and the application of the EHR at the health service level. As demonstrating in the statistical findings, patients with better education, better knowledge, and better access seem to benefit the most from the EHR. The results also demonstrated a great deal of improvements that need actions in these areas. The multiple regression analysis validated the partiality of strength and each percentage measure of strength attributed to 
each variable associated with relationships between provider and patients. These results suggested necessary action to build an underserved health care network grounded in good and appropriate care management, care coordination, and education leading to self-care engagement and self-health management.

Tables 9.1 and 9.2 showed the relevancy of these partial relationships between variables that are well suited for understanding the impact of health determinants on care delivery and health outcomes. Creswell et al. (2010) explored the micro-processes in complex environments and found that EHR can be re-organized to give deeper insights into the involved processes. Surely enough demonstrated that the EHR can be useful in guiding and identifying processes developed around the cultural and environmental functions that need to be integrated into any caring model for the underserved community or population.

The same explanation is conducive to the findings shown in Table 9.3 for the excluded variables that held up significant linearity demonstrated the partial relationship existing between these variables. Optimization of integrative care including patients' perspectives has become possible thanks to health technology progressions and evolutions. Ethnography of the EHR Creswell et al. (2010) explained, allows gaining insight from local context to even a broader social system. The exploratory findings of this study, consequently contribute to the following updated holistic framework map and subsequently to the holistic care plan. They integrate the patients' perspectives, self-care needs, and self-care engagement, health education, and self-care management. There are 
built up to improve health coordination and health transition for the underserved community.

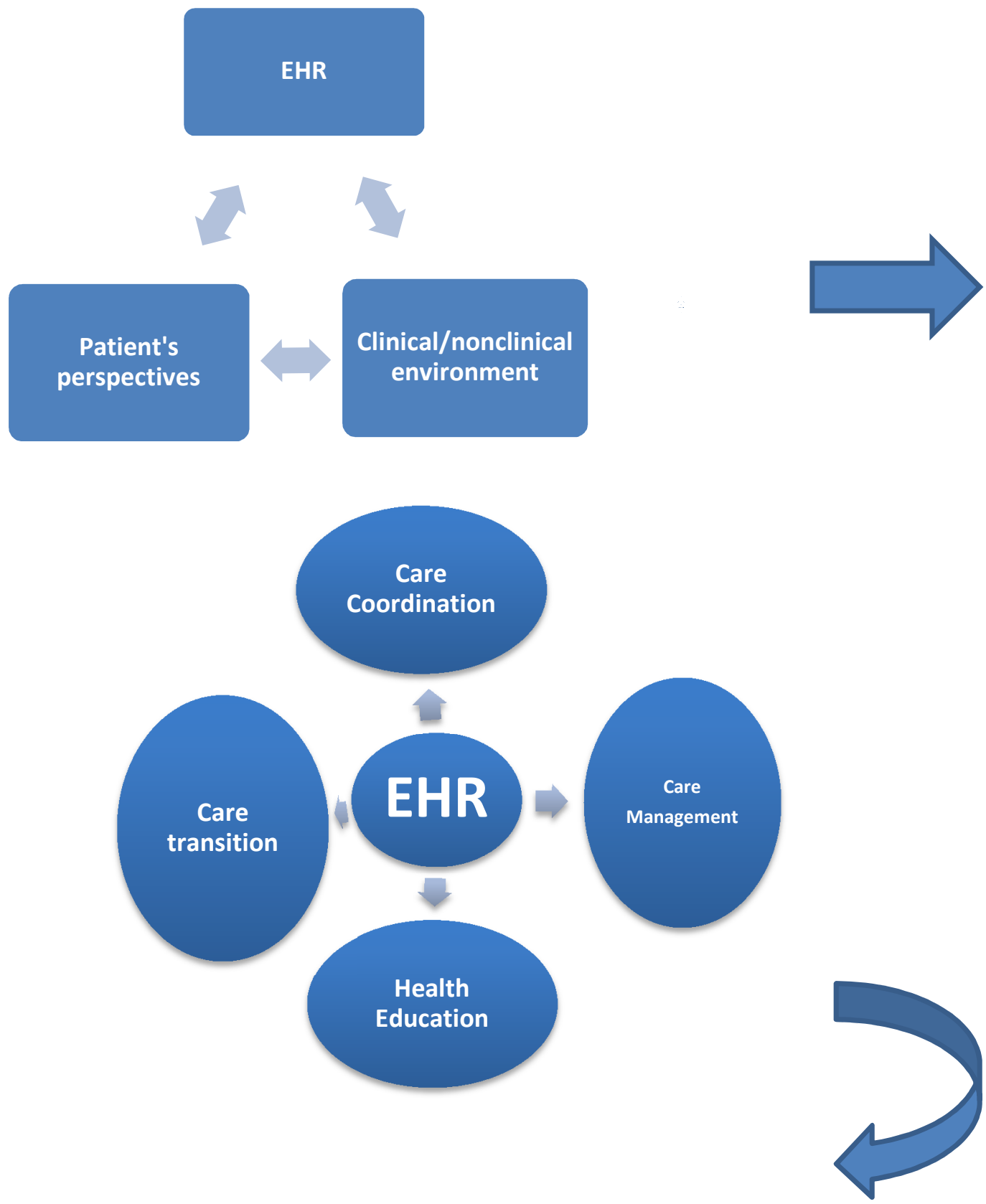




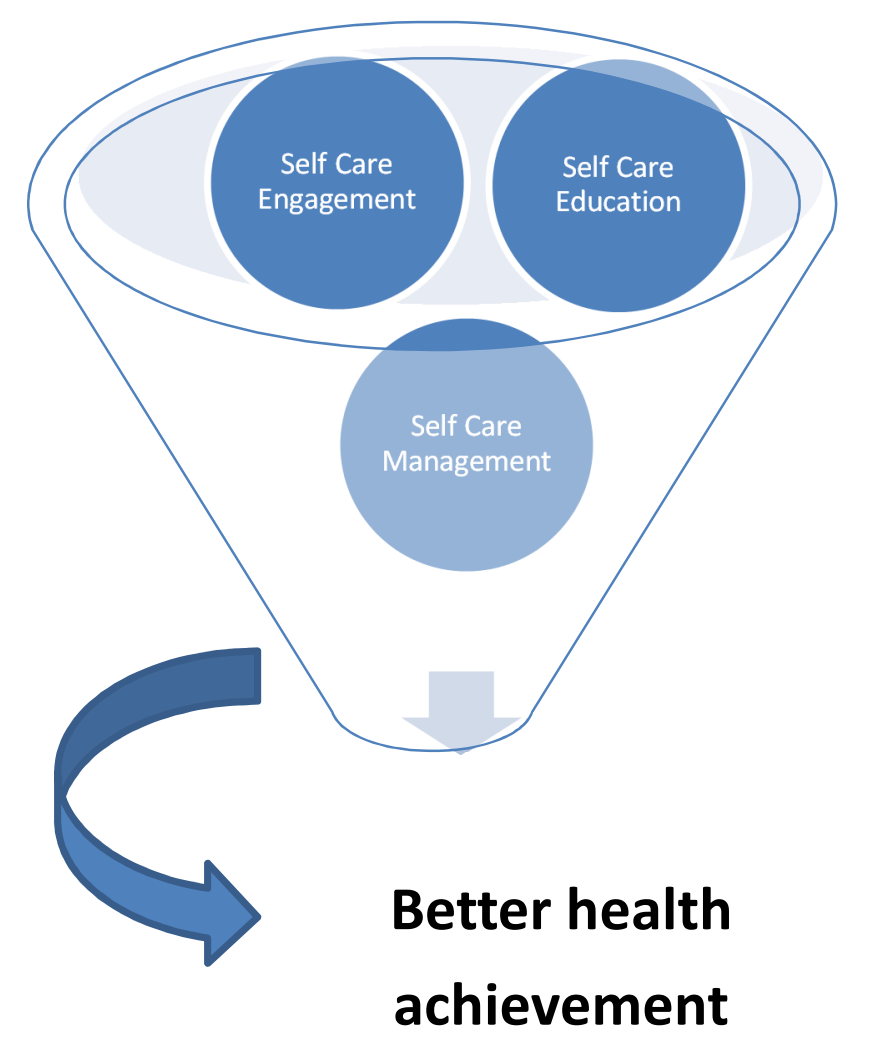

Figure 13 Wholistic Health Integration Framework.

The Wholistic Health Integration Care Plan Model shown in Table 10 is a powerful tool designed to address all different health determinants that affect the patient's world while offering not only clinical care management, but also increasing patients' self-care awareness, self-care engagement, and self-care management. This care plan tool may be used and customized for different care settings to fit the patient' care needs and may also be used as an evidence-based practice health management tool. 


\section{Limitations of the study}

The size of the survey response used in this study may limit the applicability of its findings. It was evident that the amount of time allocated to conduct the research was going to have an impact on the response size. These limitations although prevalent in the compilation of this research project, this study still made a valuable contribution to exploring further the physical and mental health needs, the cultural, and social life of the underserved community. These elements are necessary to bring effective health improvement and social lifestyle change to this community. This study still offers valuable input for putting considerable emphasis and implications of the health IT implementation to meet the community needs and life experiences. Tied to the limitations of these findings may also be the fact that the research survey collection tool, although validated for the application of this research, has not been utilized before to have insight. Also, since no validation done yet on the finding tools, it is suggested to use some form of evidence-based practice before full implementation in any clinical practice.

\section{Recommendations}

Several recommendations were depicted based on the study results. The research findings can be used to help policymakers make appropriate decisions regarding the suitable use of the EHR not only for the underserved area clinics and health centers but also for the community itself. The following suggested policies have been developed based on these findings:

Policy 1 
The EHR performance need to be evaluated using underserved community-based assessment surveys to determine its greater use and value within the underserved community and also to determine accessible resources and venues for greater community involvement.

\section{Policy 2}

The EHR should be implemented at the underserved population level according to contexts and specific interventions that meet the needs of the underserved populations to encourage self-participation and self-care engagement.

Policy 3

If the EHR is to be implemented in the underserved area clinics and health centers, its adoption rate should be increased through the community awareness, education, and participation.

Policy 4

The efficiency of the EHR in the underserved community clinics and health centers should be determined upon the health outcomes improvement of the underserved population. They should also include the decrease in sick visits, and the increase in selfcare engagement and self- health management.

Policy 5

More research should be conducted to ascertain the EHR proper implementation, proper use, and the overall population beneficial results. As information technology continues to evolve, policy makers ought to ensure that an integrative system approach that satisfies appropriate system change and response. 
It is important to understand those behavioral, psychosocial, environmental, demographical determinants other than physical and biological shape the underserved patient's health and health environment. A complete health care plan should provide enough information to ensure every aspect of the underserved patient's health is given attention. It also needs to be individually structured to reflect all the necessary elements to meet all involving and developing needs of the patient. Based on the findings of this study, it is recommended that an individual comprehensive needs assessment precedes any health or clinical interventions. These findings also recommend that an underserved community comprehensive needs assessment would be necessary before the implementation of any EHR in the underserved area clinics or health centers.

The holistic framework map and the individual disease management care plan are deeply grounded in the holistic system and innovative diffusion theories. They are an integrated health service tool and are intended to be used for extensive chronic disease management for the underserved or vulnerable population with or without health literacy problems. These two models may also be suitable for any health management system that seeks to improve health outcomes, health literacy, community and population-based care improvement, and any population-based health management and health promotion. They are also built with the perspective of making an impact on decreasing and alienating health disparities among the underserved groups of the population. These holistic framework map and care plan model are customizable with any certified information technology infrastructure in any small or large clinical practice. They are also usable as a clinical decision support tool in chronic disease management health clinics and centers. 


\section{Implications}

\section{Implications for social change}

This research has several potentials for social change. The last National Health Interview Survey report by the U.S. Department of Health and Human Services, the Centers for Disease Control and Prevention, and the National Center for Health Statistics (2012) found that $22 \%$ of Medicare and Medicaid coverage recipients consider health centers and health clinics as their usual place of health care, $12 \%$ of private insurance, and $14 \%$ of Medicare only beneficiaries. These national survey reports suggest that the research study population, although small in size, has the potential to reach a considerable amount of people. It only needs to be given the chance to apply the holistic health model and the care plan in the underserved area health care centers and clinics. The benefits of using the holistic framework and the individual care plan models will generate customized and universal approach for managing complex care, treating chronic and complex health conditions, and also give the underserved communities health care focused interventions with an enjoyable experience that not only meet their true care needs but also help them develop self-care management skills through self-care engagement and education.

This research contributes to the underserved community's health by providing means to develop health care interventions while taking into account the underserved true living experiences. This research has the potential to modify the life of the underserved community for its focus on remarkable health determinants that affect their health. These health determinants make them evincible against their efforts to engage, learn, and 
manage their health and life. Our current health care reform stressed health prevention and health maintenance. Two major elements in the Healthy People 2010 summary report are to increase the quality of life and develop long and healthy living behaviors. This research, certainly, serves as a bridge to connect with policy makers, health care officials, and health care institution by providing them with empirical evidence that supports health policies and health services implementation as well as contribution to the Healthy People 2010 efforts to eliminate health disparities in many disproportionate segments of our country (HHS, 2010).

\section{Implications for future research}

It would be incomplete to build a framework without creating a care plan model that indicates the extent and the simulation of the framework. Under this care plan, the expectations are to deliver care that produces expected health outcomes that are persuasive, measurable, and replicable. This care plan model is new and has not received any validation yet. Further research will be needed to determine its value and its validation.

The holistic framework map and the holistic care plan model building identified possible issues or problems that need to be dealt with in the course of technology implementation in underserved areas health clinics or centers and rural health clinics. It also tailored health improvement strategies and activities that are important to deal with and have an impact on complex and chronic health care management problems. The building process of these two models has also helped identify gaps in knowledge and facts necessary to build a technology around the complex needs of the underserved 
communities. It also helped identify the gaps in data toward accessible digital construct that support systemic interactions and communications for the underserved population. These are indicators that more work needs to be done in the field.

Another important approach while developing the holistic framework and care plan rested on the assurance of relevant elements affecting the patient's social, cultural and psychological needs. This research provides the health care profession a customized holistic care tool that will assist in clinical decisions. It will also provide a quality care improvement structure that is evidence-based and which may lead toward implementation of other health programs with the hope to reform health care for the underserved communities. It can be done at least one community at the time. Further research may also be needed to provide empirical evidence of the effectiveness of the holistic framework map and the holistic care plan model designed for the health management and improvement of the underserved community patients.

\section{Conclusion}

Definition of health has been reviewed several times. There is no clear consensus rather its definition should be operational, functional, mental, social, or even physical. One thing for sure is that there are many factors other than just health care affecting health itself. These factors sometimes, make it more difficult for understanding the effects of health care technologies on improving health, especially when dealing with complex health issues such as those seen in underserved communities. Evidence from this research showed that relationships among variables and covariates were explored and evaluated. They are valuable and need to be incorporated into any health model, more 
precisely into this generated holistic- integrated health framework and care plan model to meet the healthcare needs of the underserved population. With time and more evidence, validation of the care plan model will tell its benefits and impact on the health of the underserved.

As health care technology continues to expand its realm, one can remain hopeful that the EHR will get customized to reflect particular aspects that affect human health and particularly the health of the underserved. In the process of creating and improving access to care, this research managed to draw some attention to the lack of digitalization in the underserved community. It will allow the community to be part of the advanced health technology where patients can access their health information and communicate their health care needs. The service may be available but without the means to access, it is useless. This research hopes also to create avenues for more studies in that respect. Finally, this research hopes to contribute to true meaningful and satisfactory changes for the underserved communities in the near future.

In summary, the study has shown the emerging needs to go beyond treatment and clinical perspectives to integrate the underserved patients' perspectives for them to have active involvement to manage their self-care and maintain suitable self-health improvement. This work has clear implications for designing and transforming care through the EHR channels to impact health among the underserved population. This study also suggests policy level changes to impact EHR implementation to provide community-based health services. Importantly, this study authenticates the Wholistic health model and the findings explain its benefits for both providers and patients. The developing 
comprehensive and individualized care plan model is equally of importance, and professional colleagues are implored to determine its validation through evidence-based practice interventions. Future research is also beseeched to validate the greater use of the EHR for the underserved population. 


\section{References}

Adler-Milstein, J., Salzberg, C., Franz, C., Orav, E.J., Newhouse, J.P., \& Bates, D.W. (2013). Effect of EHRs on health costs: longitudinal comparative evidence from community practices. Annals of Internal Medicine, 159 (2), 97-104. doi:10.7326/00034819-159-2-201307160-00004

America's Health Rankings (2012). United Health Foundation. Retrieved from http://www.americashealthrankings.org/

Ancker, J. S., Kern, L. M., Abramson, E., \& Kaushal, R. (2012). The Triangle Model for evaluating the effect of health information technology on healthcare quality and safety. Journal of the American Medical Informatics Association, 19(1), 61-65.

Angst, C. M., \& Agarwal, R. (2009). Adoption of EHRs in the presence of privacy concerns: The elaboration likelihood model and individual persuasion. MIS quarterly, 33(2), 339-370.

Armstrong, R. A. (2014). When to use the Bonferroni correction. Ophthalmic and physiological optics, 34(5), 502-508.

Atun, R., de Jongh, T., Secci, F., Ohiri, K., \& Adeyi, O. (2010). Integration of targeted health interventions into health systems: a conceptual framework for analysis. Health Policy and Planning, 25(2), 104-111.

Baicker, K., Chandra, A., \& Skinner, J. S. (2012). Saving money or just saving lives? Improving the productivity of US health care spending. Annual Review Economics, 4(1), $33-56$. 
Banks, C., \& Sokolowski, J. (2011). Fundamentals of medical and health sciences modeling and simulation. Modeling and simulation in health sciences, 4-32.

Baum, F. (2008). The Commission on the Social Determinants of Health: reinventing health promotion for the twenty-first century? Critical Public Health, 18(4), 457-466. Blumenthal, D. (2009). Stimulating the adoption of health information technology. New England Journal of Medicine, 360(15), 1477-1479.

Blumenthal, D., \& Tavenner, M. (2010). The "meaningful use" regulation for EHRs. New England Journal of Medicine, 363(6), 501-504.

Blumenthal, D. (2010). Launching HIteCH. New England Journal of Medicine, 362(5), $382-385$.

Bombard, Y., Abelson, J., Simeonov, D., \& Gauvin, F. P. (2011). Eliciting ethical and social values in health technology assessment: A participatory approach. Social science \& medicine, 73(1), 135-144.

Bodenheimer, T. (2008). Coordinating Care- A Perilous Journey through the Health Care System. New England Journal of Medicine. 358, pp. 1064-1071

Brown, C. (2013). Media Framing of the 2009-2010 United States Health Care Reform Debate.

Buntin, M. B., Burke, M. F., Hoaglin, M. C., \& Blumenthal, D. (2011). The benefits of health information technology: a review of the recent literature shows predominantly positive results. Health Affairs, 30(3), 464-471. 
Caldwell, R. (2012): Systems thinking, organizational change and agency: a practice theory critique of Senge's learning organization. Journal of Change Management pp. 121. doi:10.1080/14697017.2011.647923

Castillo, V. H., Martínez-García, A. I., \& Pulido, J. R. G. (2010). A knowledge-based taxonomy of critical factors for adopting EHR systems by physicians: a systematic literature review. BMC medical informatics and decision making 10(1), 60.

Centers for Disease Control and Prevention. (2013). National ambulatory medical care survey: 2010 summary tables.

Centers for Medicare \& Medicaid Services (). The official web-site for the Medicare and Medicaid EHR Incentive Programs. Retrieved from http://www.cms.gov/EHRIncentivePrograms/01_Overview.aspTopOfPage Choi, N. (2011). Relationship between health service use and health information technology use among older adults: analysis of the US National Health Interview Survey. Journal of medical Internet research, 13 (2).

Clauser, Steven B., Edward H. Wagner, Erin J. Aiello Bowles, Leah Tuzzio, \& Sarah M. Greene (2011). "Improving modern cancer care through information technology." S198S207.

Cochran, W. G. (1977). Sampling techniques (3rd ed.). New York: John Wiley \& Sons. Cocks K, Torgerson DJ. (2013) Sample size calculations for pilot randomized trials: a confidence interval approach. Journal of Clinical Epidemiology. 66(2):197-201. doi: 10.1016/j.jclinepi.2012.09.002 
Congress, U. S., \& Ways and Means Committee. (2009). Health information technology for economic and clinical health (HITECH) act.

Cohen, J. (1988). Statistical power analysis for the behavioral sciences (2nd ed.).

Hillsdale, NJ: Lawrence Earlbaum Associates.

Cohen, R. A., \& Stussman, B. (2010). Health information technology use among men and women aged 18-64: early release of estimates from the National Health Interview Survey, January-June 2009. National Center for Health Statistics

Creswell J.W. (2009). Research Design: Qualitative, Quantitative and Mixed Methods Approaches. ( $3^{\text {rd }}$ ed.) Sage Publication Inc. USA

Custodio, R., Gard, A. M., \& Graham, G. (2009). Health information technology: addressing health disparity by improving quality, increasing access, and developing workforce. Journal of Health Care for the Poor and Underserved, 20(2), 301-307

Daniels, S. E., \& Walker, G. B. (2012). Lessons from the trenches: Twenty years of using systems thinking in natural resource conflict situations. Systems Research and Behavioral Science, 29(2), 104-115.

Davenport, T. H. (2013). Process innovation: reengineering work through information technology. City, State: Harvard Business Press.

De Savigny, D.; Adam T. (2009). System thinking for health system strengthening. Alliance for Health Policy and Systems Research. World Health Organization. Dearing, J. W. (2009). Applying diffusion of innovation theory to intervention development. Research on Social Work Practice, 19(5), 503-518. 
DesRoches, C. M., Campbell, E. G., Rao, S. R., Donelan, K., Ferris, T. G., Jha, A., ... \& Blumenthal, D. (2008). EHRs in ambulatory care - a national survey of physicians. New England Journal of Medicine, 359(1), 50-60.

De Savigny, D.; Adam T. (2009). System thinking for health system strengthening. Alliance for Health Policy and Systems Research. World Health Organization. Everitt B. (2006). Medical Statistics from A to Z: A Guide for Clinicians and Medical Students. ( $2^{\text {nd }}$ Ed). Cambridge, England: Cambridge University Press:

Facey, K., Boivin, A., Gracia, J., Hansen, H. P., Lo Scalzo, A., Mossman, J., \& Single, A. (2010). Patients' perspectives in health technology assessment: a route to robust evidence and fair deliberation. International journal of technology assessment in health care, 26(3), 334-340.

Fichman, R. G., Kohli, R., \& Krishnan, R. (2011). The role of information systems in healthcare: current research and future trends. Information Systems Research, 22(3), 419428.

Fisher, E. S., McClellan, M. B., Bertko, J., Lieberman, S. M., Lee, J. J., Lewis, J. L., \& Skinner, J. S. (2009). Fostering accountable health care: moving forward in Medicare. Health Affairs, 28(2), w219-w231.

Ford, E. W., Menachemi, N., \& Phillips, M. T. (2006). Predicting the adoption of EHRs by physicians: when will health care be paperless?. Journal of the American Medical Informatics Association, 13(1), 106-112.

Frankfort-Nachmias, C., \& Nachmias, D. (2008). Research methods in the social sciences (7th ed.). New York: Worth 
Frieden, T. R., Berwick, D.M. (2011). The "Million Hearts" initiative- preventing heart attacks and strokes. New England Journal of Medicine, 365 (13).

Friedell, G. H., Rubio, A., Maretzki, A., Garland, B., Brown, P., Crane, M., \& Hickman, P. (2001). Community cancer control in a rural, underserved population: the Appalachian Leadership Initiative on Cancer Project. Journal of Health Care for the Poor and Underserved, 12(1), 5-19.

Frimpong, J. A., Jackson, B. E., Stewart, L. M., Singh, K. P., Rivers, P. A., \& Bae, S. (2013). Health information technology capacity at federally qualified health centers: a mechanism for improving quality of care. BMC Health Services Research, 13(1), 35. Gagnon, M. P., Lepage-Savary, D., Gagnon, J., St-Pierre, M., Simard, C., Rhainds, M., ... \& Légaré, F. (2009). Introducing patient perspective in health technology assessment at the local level. BMC Health Services Research, 9(1), 54.

Gauvin, F. P., Abelson, J., Giacomini, M., Eyles, J., \& Lavis, J. N. (2010). “It all depends": Conceptualizing public involvement in the context of health technology assessment agencies. Social Sciences \& Medecine, 70(10), 1518-1526.

Gauvin, F. P., Abelson, J., Giacomini, M., Eyles, J., \& Lavis, J. N. (2011). Moving cautiously: Public involvement and the health technology assessment community. International Journal of Technology Assessment in Health Care, 27(01), 43-49.

Gibbons, M. C. (2011). Use of health information technology among racial and ethnic underserved communities. Perspectives in Health Information Management/AHIMA, American Health Information Management Association, 8(Winter), 1f. 
Goldzweig, C. L., Towfigh, A., Maglione, M., \& Shekelle, P. G. (2009). Costs and benefits of health information technology: new trends from the literature. Health Affairs, 28(2), w282-w293.

Gostin, L. O., Jacobson, P. D., Record, K. L., \& Hardcastle, L. E. (2010). Restoring Health to Health Reform: Integrating Medicine and Public Health to Advance the Population's Well-Being. University of Pennsylvania Law Review, 159, 1777

Granados, A. (2012). Health Technology Assessment (HTA) in a changing social and health care context. Italian Journal of Public Health, 1. Doi:

http://dx.doi.org/10.2427/6030

Grant, R., \& Greene, D. (2012). The health care home model: primary health care meeting public health goals. American Journal of Public Health, 102(6), 1096-1103.

Green, L. W., Ottoson, J., García, C., \& Robert, H. (2009). Diffusion theory and knowledge, dissemination, utilization, and integration in public health. Annual Review of Public Health, 30, 151.

Greenfield, D., \& Braithwaite, J. (2009). Developing the evidence base for accreditation of healthcare organizations: a call for transparency and innovation. Quality and Safety in Health Care, 18(3), 162-163.

Grrenhalgh, T. E. (2010). Adoption and non-adoption of a shared electronic summary record in England: a mixed method case study. British Medical Journal, 340.

Grossman, J. M., Cross, D. A., Boukus, E. R., \& Cohen, G. R. (2012). Focus on health information technology, EHRs and their financial impact: Transmitting and processing 
electronic prescriptions: experiences of physician practices and pharmacies. Journal of the American Medical Informatics Association: JAMIA, 19(3), 353.

Hafner, T., \& Shiffman, J. (2013). The emergence of global attention to health systems strengthening. Health Policy and Planning, 28(1), 41-50.

Hall, K. L., Stipelman, B. A., Eddens, K. S., Kreuter, M. W., Bame, S. I., Meissner, H. I., ... \& Fernández, M. E. (2012). Advancing collaborative research with 2-1-1 to reduce health disparities: challenges, opportunities, and recommendations. American Journal of Preventive Medicine, 43(6), S518-S528.

Halpern, R., \& Boulter, P. (2000). Population-based health care: Definitions and applications. Tufts Managed Care Institute. Retrieved from http://www.thci.org/downloads/topic11_00.pdf Hardash, J., Landegger, A., Decker, B., \& Thompson, V. (2015, March). Translating technology taxonomies to facilitate cross-industry innovation. In Aerospace Conference, 2015 (pp. 1-8). IEEE.

Harmon, M. D. (2013). The "Luntzification" of the US Health Care Debate. Electronic News, 7(3), 126-140.

Hashim, Y. A. (2010). Determining sufficiency of sample size in management survey research activities. International Journal of Organizational Management \& Entrepreneurship Development, 6(1), 119-130.

Health Resources and Services Administration (HRSA). 2009. 'Guidelines for MUA and MUP Designation', Available at: http:// bhpr.hrsa.gov/shortage/muaguide.htm 
Hernández-Ávila, J. E., Palacio-Mejía, L. S., Lara-Esqueda, A., Silvestre, E., AgudeloBotero, M., Diana, M. L., \& Parbul, A. S. (2013). Assessing the process of designing and implementing EHRs in a statewide public health system: the case of Colima, Mexico. Journal of the American Medical Informatics Association, 20(2), 238-244. Hertzog, M.A. (2008). Considerations in determining sample size in pilot studies. Research in Nursing and Health (31), 180-190.

HHS (HHS) (2010). Summary and future directions. Healthy People 2010. Retrieved from:http://www.healthypeople.gov/2010/data/midcourse/html/execsummary/future.htm Hsiao, C. J., Hing, E., Socey, T. C., \& Cai, B. (2010). Electronic medical record/EHR systems of office-based physicians: United States, 2009 and preliminary 2010 state estimates. National Center for Health Statistics

Hufstader, M., Swain, M., \& Furukawa, M. F. (2012). State Variation in E-Prescribing Trends in the United States. ONC Data Brief, 4.

Huntington, W. V., Covington, L. A., Center, P. P., Covington, L. A., \& Manchikanti, L. (2011). Patient Protection and Affordable Care Act of 2010: reforming the health care reform for the new decade. Pain Physician, 14(1), E35-E67.

Hutchinson, B., Levesque, J.F., \& Coyle, N. (2011). Primary health care in Canada: systems in motion. Milbank Quarterly, 89(2), 256-288.

Jamoom E, Beatty P, Bercovitz A, et al. Physician adoption of EHR systems: United States, (2011). NCHS data brief, no 98. Hyattsville, MD: National Center for Health Statistics. 2012. Available from http://www.cdc.gov/nchs/data/databriefs/db98.htm 
Jessen W. Highlight Health 2.0. [2010-02-20]. webcite Medicine 2.0 10-Medicine and the Second Generation of Internet-based Services.

Jha, A. K., DesRoches, C. M., Campbell, E. G., Donelan, K., Rao, S. R., Ferris, T. G., ... \& Blumenthal, D. (2009). Use of EHRs in US hospitals. New England Journal of Medicine, 360(16), 1628-1638.

Jha, A.K., Ferris, T.G., Donelan, K., DesRoches, C., Shields, A., Rosenbaum, S., \& Blumenthal, D. (2006). How common are EHRs in the United States? A summary of the evidence. 25(6), w496-w507.

Julious, S. A. (2005). Sample size of 12 per group rule of thumb for a pilot study. Pharmaceutical Statistics, 4(4), 287-291.

Kim, D. H., \& Senge, P. M. (1994). Putting systems thinking into practice. System Dynamics Review, 10(2-3), 277-290.

Kleinman, L. C., \& Dougherty, D. (2013). Assessing Quality Improvement in Health Care: Theory for Practice. Pediatrics, 131(Supplement 1), S110-S119.

Komro, K., O'Mara, R., \& Wagenaar, A. (2012). Mechanisms of Legal Effect: Perspectives from Public Health. Public Health Law Research Methods Monograph Series, Forthcoming.

Kotrlik, J. W. K. J. W., \& Higgins, C. C. H. C. C. (2001). Organizational research: Determining appropriate sample size in survey research appropriate sample size in survey research. Information Technology, Learning, and Performance Journal, 19(1), 43.

Larkin, H. (2010). Managing population health. H\&HN: Hospitals \& Health Networks, 84(10), 28-32. 
Lanham, H. J., Leykum, L. K., \& McDaniel, R. R. (2012). Same organization, same electronic health records (EHRs) system, different use: exploring the linkage between practice member communication patterns and EHR use patterns in an ambulatory care setting. Journal of the American Medical Informatics Association, 19(3), 382-391.

Légaré, F., Stacey, D., Pouliot, S., Gauvin, F. P., Desroches, S., Kryworuchko, J., ... \& Graham, I. D. (2011). Interprofessionalism and shared decision-making in primary care: a stepwise approach towards a new model. Journal of Inter-professional Care, 25(1), 18-25 Linnan, L. A. (2012). Research Collaboration with 2-1-1 to Eliminate Health Disparities. American Journal of Preventive Medicine, 43(5), 4.

López, L., Green, A. R., Tan-McGrory, A., King, R., \& Betancourt, J. R. (2011). Bridging the digital divide in health care: the role of health information technology in addressing racial and ethnic disparities. Joint Commission Journal on Quality and Patient Safety, 37(10), 437-445. Modeling the Social Determinants

Mahamoud, A.; Roche, B.; Homer, J. (2012). of Health and Simulating Short-Term and Long-Term Intervention Impacts for the City of Toronto, Canada. http://dx.doi.org/10.1016/j.socscimed.2012.06.036 Manary, M. P., Boulding, W., Staelin, R., \& Glickman, S. W. (2013). The patient experience and health outcomes. New England Journal of Medicine, 368(3), 201-203. Martin, G. P., Weaver, S., Currie, G., Finn, R., \& McDonald, R. (2012). Innovation sustainability in challenging health-care contexts: embedding clinically led change in routine practice. Health Services Management Research, 25(4), 190-199. 
Maun C. RetirementHomes.com. [2010-02-20]. webcite Maun C. Health 2.0: Take Advantage of the Technology http://www.retirementhomes.com/cgibin/forum/gforum.cgi?post $=858 ;$ sb=post_latest_reply;so=ASC;forum_view=forum_view _collapsed;page=last;guest $=3191658 \& \mathrm{t}=$ search_engine.

Moiduddin, A., \& Moore, J. (2008). The underserved and health information technology: issues and opportunities. Office of the Assistant Secretary for Planning and Evaluation and US Department of Health and Human Services Moreno-Serra, R., \& Smith, P. C. (2012). Does progress towards universal health coverage improve population health? The Lancet, 380(9845), 917-923.

Murray, C. E. (2009). Diffusion of Innovation Theory: A Bridge for the ResearchPractice Gap in Counseling. Journal of Counseling \& Development, 87(1), 108-116. Naing, L., Winn, T., \& Rusli, B. N. (2006). Practical issues in calculating the sample size for prevalence studies. Archives of Orofacial Sciences, 1(1), 9-14.

Nicol, G. E., Morrato, E. H., Johnson, M. C., Campagna, E., Yingling, M. D., Pham, V., \& Newcomer, J. W. (2011). Best practices: implementation of a glucose screening program based on diffusion of innovation theory methods. Psychiatric Services, 62(1), $12-14$.

Ortiz, A. A.; Macedo, G.; Carlos, J. (2010). A ‘Systemic Theories of Change’ Approach for Purposeful Capacity Development. IDS Bulletin. Vol. 41 3. Blackwell Publishing Ltd SN 759-5436. Available at: http://dx.doi.org/10.1111/j.1759-5436.2010.00140.x Orszag, P. R. \& Emanuel, E. J. (2010). Health care reform and cost control. New England Journal of Medicine, 363(7), 601-603. 
Overton, W. F. (2013). A new paradigm for developmental science: Relationism and relational-developmental systems. Applied Developmental Science, 17(2), 94-107.

Parente, S. T., \& McCullough, J. S. (2009). Health information technology and patient safety: Evidence from panel data. Health Affairs, 28(2), 357-360.

Patient Protection and Affordable Care Act*3022 and *10307, Pub L No. 11-148, 124 Stat 119.

People, H. (2011). Healthy People 2020. Health communication and health information technology. Retrieved on http://www. healthy people.

gov/2020/topicsobjectives2020/overview.aspx.

Porter, M. (2009). A strategy for health care reform- toward a value-based system. New England Journal of Medicine. Vol. 361 pp. 109-112 DOI: 10.1056/NEJMp0904131 Porter, M. E., Pabo, E. A., \& Lee, T. H. (2013). Redesigning primary care: a strategic vision to improve value by organizing around patients' needs. Health Affairs, 32(3), 516525.

Pourbohloul, B.1 Kieny, M-P. (2011).Complex system analysis: toward holistic approaches to health systems planning and policy. Bulletin of the World Health Organization. Vol. 89, No. 4 Geneva. Available at: http://dx.doi.org/10.1590/S004296862011000400002

Protection, P., \& Act, A. C. (2010). Public Law 111-148. Title IV, x4207, USC HR, 3590, 2010.

Salomon, R. M., Blackford, J. U., Rosenbloom, S. T., Seidel, S., Clayton, E. W., Dilts, D. M., \& Finder, S. G. (2010). Openness of patients' reporting with use of electronic 
records: psychiatric clinicians' views. Journal of the American Medical Informatics Association, 17(1), 54-60.

Shi, L; Stevens, G. (2007). The Role of Community Health Centers in Delivering Primary Care to the Underserved: Experiences of the Uninsured and Medicaid Insured. Journal of Ambulatory Care Management. Vol. 302 pp. 159-170. Original Article. Lippincott Williams \& Wilkins, Inc. DOI: 10.1097/01.JAC.0000264606.50123.6d Schiller, J. S., Lucas, J. W., Ward, B. W., \& Peregoy, J. A. (2012). Summary health statistics for US Adults: National health interview survey, 2010. Vital and Health Statistics. Series 10, Data from the National Health Survey, (252), 1-207. Shomaker, T.S. (2011). Commentary: Preparing for health care reform: ten recommendations for academic health centers. Academic Medicine, 86(5), 555-558. Rahman, M., \& Ko, M. (2012). Factors Influencing Patients' Perceptions toward Electronic Medical Record (EMR) Use: A Conceptual Model Rogers E. Diffusion of innovations. New York: Free Press, 1983.

Rosser, W. W., Colwill, J. M., Kasperski, J., \& Wilson, L. (2011). Progress of Ontario's family health team model: a patient-centered medical home. The Annals of Family Medicine, 9(2), 165-171.

Sanson-Fisher, R. W. (2004). Diffusion of innovation theory for clinical change. Medical journal of Australia, 180(6), S55.

Sarasohn-Kahn J. Social Media Strategy. [2009-09-14]. webcite Crowdsourcing Our Health—Using Social Media to Educate and Unite the Public 
http://steveradick.com/2009/03/23/crowdsourcing-our-health-\%E2\%80\%93-using-socialmedia-to-educate-and-unite-the-public/

Schoen, C., Osborn, R., Doty, M. M., Squires, D., Peugh, J., \& Applebaum, S. (2009). A survey of primary care physicians in eleven countries, 2009: perspectives on care, costs, and experiences. Health Affairs, 28(6), w1171-w1183.

Senge, P. M. (Ed.). (1994). The fifth discipline field book. Random House Digital, Inc. Serra-Sastre, V., \& McGuire, A. (2012). 11 Technology diffusion in health care: conceptual aspects and evidence. The LSE Companion to Health Policy, 177. Sheridan, S. (2012). The implementation and sustainability of EHRs. Online Journal of Nursing Informatics (OJNI), 16 (3), Available at http://ojni.org/issues/?p=1992 Shields, A. E., Shin, P., Leu, M. G., Levy, D. E., Betancourt, R. M., Hawkins, D., \& Proser, M. (2007). Adoption of health information technology in community health centers: results of a national survey. Health Affairs, 26(5), 1373-1383 Shim, J. (2010). Cultural health capital: A theoretical approach to understanding health care interactions and the dynamics of unequal treatment. Journal of Health and Social Behavior, 51(1), 1-1 5. Retrieved from the Walden Library using the MEDLINE with Full Text database.

Sittig, D. F., \& Singh, H. (2010). A new sociotechnical model for studying health information technology in complex adaptive healthcare systems. Quality and Safety in Health Care, 19(Suppl 3), i68-i74 
Street, J. M., Braunack-Mayer, A. J., Facey, K., Ashcroft, R. E., \& Hiller, J. E. (2008). Virtual community consultation? Using the literature and weblogs to link community perspectives and health technology assessment. Health Expectations, 11(2), 189-200 Swan, M. (2009). Emerging patient-driven health care models: an examination of health social networks, consumer personalized medicine and quantified selftracking. International journal of environmental research and public health, 6(2), 492525.

Swanson, R. C., Cattaneo, A., Bradley, E., Chunharas, S., Atun, R., Abbas, K. M., ... \& Best, A. (2012). Rethinking health systems strengthening: key systems thinking tools and strategies for transformational change. Health Policy and Planning, 27(suppl 4), iv54iv61.

Terry, A. L., Cejic, S., Ryan, B. L., Shadd, J. D., Stewart, M., Fortin, M., \& Thind, A. (2012). You and your EMR: the research perspective Part 4. Optimizing EMRs in primary health care practice and research. Canadian Family Physician, 58(6), 705-706. Thabane, L., Ma, J., Chu, R., Cheng, J., Ismaila, A., Rios, L.P., Robson, R., Thabane, M., Giangregorio, L. Goldsmith, C.H. A tutorial on pilot studies: the what, why and How. Medical Research Methodology, 10:1. Available at: http://www.biomedcentral.com/1471-2288/10/1 The American Recovery and Reinvestment Act (ARRA): P.L.111-5, 123 Stat. 115 (2009).

Trochim, William M. The Research Methods Knowledge Base, 2nd Edition. Internet WWW page, at URL: <http://www.socialresearchmethods.net/kb_/ (version current as of 
Trochim, W. (2000). The Research Methods Knowledge Base, 2nd Edition. Atomic Dog Publishing, Cincinnati, $\mathrm{OH}$

Van De Belt, T. H., Engelen, L. J., Berben, S. A., \& Schoonhoven, L. (2010). Definition of Health 2.0 and Medicine 2.0: a systematic review. Journal of Medical Internet research, 12(2).

Vashist, S. K., Schneider, E. M., \& Luong, J. H. (2014). Commercial smartphone-based devices and smart applications for personalized healthcare monitoring and management. Diagnostics, 4(3), 104-128.

Vedel, I., Ghadi, V., De Stampa, M., Routelous, C., Bergman, H., Ankri, J., \& Lapointe, L. (2013). Diffusion of a collaborative care model in primary care: a longitudinal qualitative study. BMC Family Practice, 14(1), 3.

Von Bertalanffy, L. (1972). The history and status of general systems theory. The Academy of Management Journal. 15 (4), pp. 407-426. Reprinted, Trends in general system theory (2004). New York: Klir, G.J. ed.

Von Bertalanffy, L. (1973). The meaning of general system theory. General system theory: Foundations, development, applications, 30-53.

Wallace, S. P. (2012). Social determinants of health inequities and healthcare in old age. Public Health for an Aging Society.

Webster, P. (2011, October 18). "Centralized, nationwide EHRs schemes under assault". Canadian Medical Association Journal, 183(15), 1105-6. 
Weiss, C.H.' \& Nunes Amaral, L.A. (2013). Envisioning sophisticated EHR through the lens of health care reform. American Journal of Respiratory and Critical Care Medicine, 188 (6), 636-638.

World Health Organization (WHO). (2008). Closing the gap in a generation - health equity through action on the social determinants of health. Retrieved from http://whqlibdoc.who.int/publications/2008/9789241563703_eng.pdf WHO Commission on the Social Determinants of Health. (2008). Closing the gap in a generation: Health equity through action on the social determinants of health. Executive summary. Geneva, Switzerland: World Health Organization.

WHO: Everybody's business: strengthening health systems to improve health outcomes: WHO's framework for action. Geneva: World Health Organization, 2007. Retrieved on September 3, 2012. Available from:

http://www.who.int/healthsystems/strategy/everybodysbusiness.pdf Wu, A. W., Snyder, C., Clancy, C. M., \& Steinwachs, D. M. (2010). Adding the patient perspective to comparative effectiveness research. Health Affairs, 29(10), 1863-1871.

Zhu, J., Brawarsky, P., Lipsitz, S., Huskamp, H., \& Haas, J. S. (2010). Massachusetts health reform and disparities in coverage, access and health status. Journal of General Internal Medicine, 25(12), 1356-62. doi: http://dx.doi.org/10.1007/s11606-010-1482 Zlabek, J. A., Wickus, J. W., \& Mathiason, M. A. (2011). Early cost and safety benefits of an inpatient EHR. Journal of the American Medical Informatics Association, 18(2), $169-172$.

Zott, C.; Amit, R. (2009). Business model design: an activity system perspective. Long 
Range Planning. DOI: 10.1016/j.lrp.2009.07.004. Available at:

http://www.elsevier.com/locate/lrp 


\section{Appendices}

Appendix A: Literature Search Engine

\begin{tabular}{|c|c|c|c|c|c|c|c|c|c|}
\hline $\begin{array}{l}\text { Author(s) last } \\
\text { name, first initial }\end{array}$ & $\begin{array}{l}\mathrm{Y} \\
\mathrm{e} \\
\mathrm{a} \\
\mathrm{r}\end{array}$ & Title of article or chapter & $\begin{array}{l}\text { R } \\
\text { ef. } \\
\text { pa } \\
\text { ge }\end{array}$ & $\begin{array}{l}\text { Journal } \\
\text { title }\end{array}$ & Database & $\begin{array}{l}\text { Lib } \\
\text { rary }\end{array}$ & $\begin{array}{l}\text { Pub } \\
\text { Date }\end{array}$ & DOI & $\begin{array}{l}\text { Keywor } \\
\text { d search }\end{array}$ \\
\hline Adler-Milstein et al & $\begin{array}{l}2 \\
0 \\
1 \\
3\end{array}$ & $\begin{array}{l}\text { Effect of EHR on health } \\
\text { costs }\end{array}$ & & $\begin{array}{l}\text { Annals of } \\
\text { Internal } \\
\text { Medicine }\end{array}$ & & & & $\begin{array}{l}\text { 10.1377/ } \\
\text { hlthaff.2 } \\
\text { 7.1.w60 }\end{array}$ & $\begin{array}{l}\text { Health } \\
\text { care cost } \\
\text { and } \\
\text { EHR }\end{array}$ \\
\hline $\begin{array}{l}\text { Ancker, J. S., Kern, } \\
\text { L. M., Abramson, } \\
\text { E., \& Kaushal, R. }\end{array}$ & $\begin{array}{l}2 \\
0 \\
1 \\
2\end{array}$ & $\begin{array}{l}\text { The Triangle Model for } \\
\text { evaluating the effect of } \\
\text { health information } \\
\text { technology on healthcare } \\
\text { quality and safety }\end{array}$ & $\begin{array}{l}\text { p. } \\
29 \\
4 \\
0 \\
45\end{array}$ & $\begin{array}{l}\text { Journal of } \\
\text { the } \\
\text { American } \\
\text { Medical } \\
\text { Informatics } \\
\text { Association }\end{array}$ & Bmj.com & $\begin{array}{l}\text { onli } \\
\text { ne }\end{array}$ & $\begin{array}{l}20-08- \\
11\end{array}$ & $\begin{array}{l}\text { 10.1136/ } \\
\text { amiagnl- } \\
2011- \\
00385\end{array}$ & $\begin{array}{l}\text { EHR } \\
\text { evaluati } \\
\text { on }\end{array}$ \\
\hline $\begin{array}{l}\text { Angs t, C. M., \& } \\
\text { Agarwal, R. }\end{array}$ & $\begin{array}{l}2 \\
0 \\
0 \\
9\end{array}$ & $\begin{array}{l}\text { Adoption of EHRs in the } \\
\text { presence of privacy } \\
\text { concerns }\end{array}$ & $\begin{array}{l}\text { p. } \\
33 \\
5 \\
8\end{array}$ & $\begin{array}{l}\text { MIS } \\
\text { Quarterly }\end{array}$ & & & & $\begin{array}{l}\text { 10.1136/ } \\
\text { amiajnl- } \\
2011- \\
000385\end{array}$ & $\begin{array}{l}\text { EHR } \\
\text { and } \\
\text { privacy }\end{array}$ \\
\hline $\begin{array}{l}\text { Baicker, K., } \\
\text { Chandra, A., \& } \\
\text { Skinner, J. S. }\end{array}$ & $\begin{array}{l}2 \\
0 \\
1 \\
2\end{array}$ & $\begin{array}{l}\text { Improving the productivity } \\
\text { of US health care spending }\end{array}$ & $\begin{array}{l}\text { P. } \\
18 \\
4 \\
1, \\
44\end{array}$ & $\begin{array}{l}\text { Annual } \\
\text { Review of } \\
\text { Economics }\end{array}$ & $\begin{array}{l}\text { Academic } \\
\text { research }\end{array}$ & $\begin{array}{l}\text { Har } \\
\text { var } \\
\text { d } \\
\text { Uni } \\
\text { ver } \\
\text { sity }\end{array}$ & & $\begin{array}{l}10.1146 \\
\text { /annure } \\
\text { v- } \\
\text { economi } \\
\text { cs- } \\
080511- \\
110942\end{array}$ & $\begin{array}{l}\text { Health } \\
\text { care cost }\end{array}$ \\
\hline Baum, F. & $\begin{array}{l}2 \\
0 \\
0 \\
8\end{array}$ & $\begin{array}{l}\text { The Commission on the } \\
\text { Social Determinants of } \\
\text { Health: reinventing health } \\
\text { promotion for the twenty- } \\
\text { first century?. }\end{array}$ & $\begin{array}{l}\text { p. } \\
44\end{array}$ & $\begin{array}{l}\text { Critical } \\
\text { Public } \\
\text { Health }\end{array}$ & $\begin{array}{l}\text { Pro Quest } \\
\text { Central }\end{array}$ & $\begin{array}{l}\text { Wal } \\
\text { den } \\
\text { Libr } \\
\text { ary }\end{array}$ & & $\begin{array}{l}10.1080 / \\
0958159 \\
6.2010 .5 \\
03266\end{array}$ & $\begin{array}{l}\text { Social } \\
\text { determin } \\
\text { ants of } \\
\text { health }\end{array}$ \\
\hline Blumenthal, D. & $\begin{array}{l}2 \\
0 \\
0 \\
9\end{array}$ & $\begin{array}{l}\text { Stimulating the adoption of } \\
\text { health information } \\
\text { technology. }\end{array}$ & $\begin{array}{l}\text { p. } \\
33 \\
4 \\
6\end{array}$ & $\begin{array}{l}\text { New } \\
\text { England } \\
\text { Journal of } \\
\text { Medicine }\end{array}$ & & $\begin{array}{l}\mathrm{Nej} \\
\mathrm{m} . \mathrm{o} \\
\mathrm{rg}\end{array}$ & & $\begin{array}{l}10.1056 / \\
\text { NEJMp0 } \\
901592\end{array}$ & $\begin{array}{l}\text { HIT } \\
\text { adoption }\end{array}$ \\
\hline $\begin{array}{l}\text { Blumenthal, D. } \\
\text {,Tavenner ,M }\end{array}$ & $\begin{array}{l}2 \\
0 \\
1 \\
0\end{array}$ & $\begin{array}{l}\text { The "meaningful use" } \\
\text { regulation for EHRs. }\end{array}$ & $\begin{array}{l}\text { p. } \\
31 \\
3 \\
5 \\
37\end{array}$ & $\begin{array}{l}\text { New } \\
\text { England } \\
\text { Journal of } \\
\text { Medicine }\end{array}$ & & $\begin{array}{l}\text { Nej } \\
\text { m.o } \\
\text { rg }\end{array}$ & & $\begin{array}{l}\text { 10.1056/NEJ } \\
\text { Mp1006114 }\end{array}$ & $\begin{array}{l}\text { Technol } \\
\text { ogy } \\
\text { adoption } \\
\text { in health } \\
\text { care }\end{array}$ \\
\hline Blumenthal, D & $\begin{array}{l}2 \\
0 \\
1 \\
0\end{array}$ & Launching HIteCH & $\begin{array}{l}\mathrm{p} . \\
35\end{array}$ & $\begin{array}{l}\text { New } \\
\text { England } \\
\text { Journal of } \\
\text { Medicine }\end{array}$ & & $\begin{array}{l}\text { Nej } \\
\text { m.o } \\
\text { rg }\end{array}$ & & $\begin{array}{l}10.1056 / \\
\text { NEJMp0 } \\
912825\end{array}$ & $\begin{array}{l}\text { Technol } \\
\text { ogy and } \\
\text { health } \\
\text { care }\end{array}$ \\
\hline $\begin{array}{l}\text { Bombard, Y., } \\
\text { Abelson, J., } \\
\text { Simeonov, D., \& } \\
\text { Gauvin, F. P }\end{array}$ & $\begin{array}{l}2 \\
0 \\
1 \\
1\end{array}$ & $\begin{array}{l}\text { Eliciting ethical and social } \\
\text { values in health technology } \\
\text { assessment }\end{array}$ & $\begin{array}{l}\text { p. } \\
41\end{array}$ & $\begin{array}{l}\text { Journal } \\
\text { Social } \\
\text { Science \& } \\
\text { Medicine }\end{array}$ & Pub Med & $\begin{array}{l}\text { Uni } \\
\text { ver } \\
\text { sity } \\
\text { of } \\
\text { Tor } \\
\text { ont } \\
\text { o }\end{array}$ & & $\begin{array}{l}10.1016 \\
\text { /jsocsci } \\
\text { med.201 } \\
1.04017\end{array}$ & $\begin{array}{l}\text { Ethics } \\
\text { and } \\
\text { health } \\
\text { technolo } \\
\text { gy }\end{array}$ \\
\hline
\end{tabular}




\begin{tabular}{|c|c|c|c|c|c|c|c|c|}
\hline Bodenheimer, $\mathrm{T}$ & $\begin{array}{l}2 \\
0 \\
0 \\
8\end{array}$ & $\begin{array}{l}\text { Coordinating Care- A } \\
\text { Perilous Journey through the } \\
\text { Health Care }\end{array}$ & $\begin{array}{l}\text { p. } \\
42 \\
4 \\
4\end{array}$ & $\begin{array}{l}\text { New } \\
\text { England } \\
\text { Journal of } \\
\text { Medicine. }\end{array}$ & $\begin{array}{l}\text { Google } \\
\text { scholar }\end{array}$ & $\begin{array}{l}\text { On } \\
\text { line }\end{array}$ & $\begin{array}{l}\text { 10.1056/ } \\
\text { NEJMp0 } \\
68155\end{array}$ & $\begin{array}{l}\text { Care } \\
\text { coordina } \\
\text { tion and } \\
\text { health } \\
\text { care }\end{array}$ \\
\hline $\begin{array}{l}\text { Castillo, V. H., } \\
\text { Martínez-García, } \\
\text { A. I., \& Pulido, J. } \\
\text { R. G. }\end{array}$ & $\begin{array}{l}2 \\
0 \\
1 \\
0\end{array}$ & $\begin{array}{l}\text { A knowledge-based } \\
\text { taxonomy of critical factors } \\
\text { for adopting EHR systems } \\
\text { by physicians: a systematic } \\
\text { literature review. }\end{array}$ & & $\begin{array}{l}\text { BMC } \\
\text { medical } \\
\text { informatics } \\
\text { and } \\
\text { decision } \\
\text { making }\end{array}$ & & & $\begin{array}{l}10.1186 / \\
1472- \\
6947- \\
10-60\end{array}$ & $\begin{array}{l}\text { Physicia } \\
\text { ns } \\
\text { adoptio } \\
\text { n and } \\
\text { HIT }\end{array}$ \\
\hline Choi, N & $\begin{array}{l}2 \\
0 \\
1 \\
1\end{array}$ & $\begin{array}{l}\text { Relationship between health } \\
\text { service use and health } \\
\text { information technology use } \\
\text { among older adults: analysis } \\
\text { of the US National Health } \\
\text { Interview Survey. }\end{array}$ & & $\begin{array}{l}\text { Journal of } \\
\text { medical } \\
\text { Internet } \\
\text { research }\end{array}$ & & & $\begin{array}{l}\text { 10.1056/ } \\
\text { NEJMsa } \\
0802005\end{array}$ & $\begin{array}{l}\text { HIT in } \\
\text { health } \\
\text { care }\end{array}$ \\
\hline $\begin{array}{l}\text { Clauser, Steven B., } \\
\text { Edward H. } \\
\text { Wagner, Erin J. } \\
\text { Aiello Bowles, } \\
\text { Leah Tuzzio, and } \\
\text { Sarah M. Greene. }\end{array}$ & $\begin{array}{l}2 \\
0 \\
1 \\
1\end{array}$ & $\begin{array}{l}\text { "Improving modern cancer } \\
\text { care through information } \\
\text { technology." }\end{array}$ & $\begin{array}{l}\mathrm{P} . \\
42\end{array}$ & $\begin{array}{l}\text { American } \\
\text { Journal of } \\
\text { Preventive } \\
\text { Medicine }\end{array}$ & & & $\begin{array}{l}10.1016 / \\
\text { j.amepre } \\
.2011 .01 \\
.014\end{array}$ & $\begin{array}{l}\text { HIT } \\
\text { improve } \\
\text { ment }\end{array}$ \\
\hline $\begin{array}{l}\text { Cohen, R. A., \& } \\
\text { Stussman, B. }\end{array}$ & $\begin{array}{l}2 \\
0 \\
1 \\
0\end{array}$ & $\begin{array}{l}\text { Health information } \\
\text { technology use among men } \\
\text { and women aged 18-64: } \\
\text { early release of estimates } \\
\text { from the National Health } \\
\text { Interview Survey, January- } \\
\text { June } 2009 \text {. }\end{array}$ & & $\begin{array}{l}\text { National } \\
\text { Center for } \\
\text { Health } \\
\text { Statistics }\end{array}$ & & & $\begin{array}{l}10.1016 / \\
\text { S0268- } \\
4012(97 \\
) 00024- \\
8\end{array}$ & $\begin{array}{l}\text { HIT } \\
\text { survey } \\
\text { in health } \\
\text { care }\end{array}$ \\
\hline $\begin{array}{l}\text { Custodio, R., Gard, } \\
\text { A. M., \& Graham, } \\
\text { G. }\end{array}$ & $\begin{array}{l}2 \\
0 \\
0 \\
9\end{array}$ & $\begin{array}{l}\text { Health information } \\
\text { technology: addressing } \\
\text { health disparity by } \\
\text { improving quality, } \\
\text { increasing access, and } \\
\text { developing workforce }\end{array}$ & & $\begin{array}{l}\text { Journal of } \\
\text { Health } \\
\text { Care for } \\
\text { the Poor } \\
\text { and } \\
\text { Underserve } \\
d\end{array}$ & & & $\begin{array}{l}10.2174 / \\
1874431 \\
1010040 \\
10195\end{array}$ & $\begin{array}{l}\text { HIT and } \\
\text { health } \\
\text { disparity }\end{array}$ \\
\hline Dearing, J. W. & $\begin{array}{l}2 \\
0 \\
0 \\
9\end{array}$ & $\begin{array}{l}\text { Applying diffusion of } \\
\text { innovation theory to } \\
\text { intervention development. }\end{array}$ & & $\begin{array}{l}\text { Research } \\
\text { on social } \\
\text { work } \\
\text { practice }\end{array}$ & & & $\begin{array}{l}\text { 10.1007/ } \\
\text { s10488- } \\
011- \\
0351-2\end{array}$ & $\begin{array}{l}\text { Innovati } \\
\text { on } \\
\text { theory }\end{array}$ \\
\hline $\begin{array}{l}\text { DesRoches, C.M., } \\
\text { Campbell, E.G., } \\
\text { Vogeli, C. Zheng, } \\
\text { J., Rao, S.R., } \\
\text { Shields, A.E. ... \& } \\
\text { Jha, A.K. }\end{array}$ & $\begin{array}{l}2 \\
0 \\
1 \\
0\end{array}$ & $\begin{array}{l}\text { EHRs' limited successes } \\
\text { suggest more targeted users }\end{array}$ & $\begin{array}{l}P . \\
8, \\
15 \\
, 3 \\
2\end{array}$ & $\begin{array}{l}\text { Health } \\
\text { Affairs }\end{array}$ & $\begin{array}{l}\text { Google } \\
\text { scholar }\end{array}$ & & & EHR \\
\hline $\begin{array}{l}\text { Facey, K., Boivin, } \\
\text { A., Gracia, J., } \\
\text { Hansen, H. P., Lo } \\
\text { Scalzo, A., } \\
\text { Mossman, J., \& } \\
\text { Single, A. }\end{array}$ & $\begin{array}{l}2 \\
0 \\
1 \\
0\end{array}$ & $\begin{array}{l}\text { Patients' perspectives in } \\
\text { health technology } \\
\text { assessment: a route to robust } \\
\text { evidence and fair } \\
\text { deliberation. }\end{array}$ & & $\begin{array}{l}\text { Internation } \\
\text { al journal } \\
\text { of } \\
\text { technology } \\
\text { assessment } \\
\text { in health } \\
\text { care }\end{array}$ & & & $\begin{array}{l}10.1016 / \\
\text { j.healthp } \\
\text { ol.2004. } \\
12.001\end{array}$ & $\begin{array}{l}\text { HIT and } \\
\text { patient's } \\
\text { perspect } \\
\text { ives }\end{array}$ \\
\hline $\begin{array}{l}\text { Fisher, E. S., } \\
\text { Bynum, J. P., }\end{array}$ & $\begin{array}{l}2 \\
0 \\
\end{array}$ & $\begin{array}{l}\text { Slowing the Growth of } \\
\text { Health Care Costs - }\end{array}$ & $\begin{array}{l}\text { p. } \\
5\end{array}$ & $\begin{array}{l}\text { New } \\
\text { England }\end{array}$ & Nej.org & & $\underline{10.1056 /}$ & \\
\hline
\end{tabular}




\begin{tabular}{|c|c|c|c|c|c|c|c|c|}
\hline Skinner, J. S. & $\begin{array}{l}0 \\
9\end{array}$ & $\begin{array}{l}\text { Lessons from Regional } \\
\text { Variation. }\end{array}$ & & $\begin{array}{l}\text { Journal of } \\
\text { Medicine. }\end{array}$ & & & $\frac{\text { NEJMp0 }}{\underline{809794}}$ & \\
\hline $\begin{array}{l}\text { Foy R, Hempel S, } \\
\text { Rubenstein L, } \\
\text { Suttorp M, Seelig } \\
\text { M, Shanman R, et } \\
\text { al }\end{array}$ & & $\begin{array}{l}\text { effect of interactive } \\
\text { communication between } \\
\text { collaborating primary care } \\
\text { physicians and specialists }\end{array}$ & & $\begin{array}{l}\text { Annals of } \\
\text { Internal } \\
\text { Medicine }\end{array}$ & & & $\begin{array}{l}10.1186 / \\
1748- \\
5908-4- \\
41\end{array}$ & $\begin{array}{l}\text { Commu } \\
\text { nication } \\
\text { and } \\
\text { collabor } \\
\text { ation in } \\
\text { primary } \\
\text { care }\end{array}$ \\
\hline $\begin{array}{l}\text { Ford, E. W., } \\
\text { Menachemi, N., \& } \\
\text { Phillips, M. T. }\end{array}$ & $\begin{array}{l}2 \\
0 \\
0 \\
6\end{array}$ & $\begin{array}{l}\text { Predicting the adoption of } \\
\text { EHRs by physicians: when } \\
\text { will health care be } \\
\text { paperless? }\end{array}$ & $\begin{array}{l}\text { p. } \\
33\end{array}$ & $\begin{array}{l}\text { Journal of } \\
\text { the } \\
\text { American } \\
\text { Medical } \\
\text { Informatics } \\
\text { Association }\end{array}$ & & & $\begin{array}{l}\text { 10.1197/ } \\
\text { jamia.M } \\
1913\end{array}$ & $\begin{array}{l}\text { HIT } \\
\text { adoptio } \\
\mathrm{n}\end{array}$ \\
\hline $\begin{array}{l}\text { Frankfort- } \\
\text { Nachmias, C., \& } \\
\text { Nachmias, D. }\end{array}$ & $\begin{array}{l}2 \\
0 \\
0 \\
8\end{array}$ & $\begin{array}{l}\text { Research methods in the } \\
\text { social sciences }\end{array}$ & $\begin{array}{l}\text { p. } \\
14\end{array}$ & & & & $\begin{array}{l}10.1177 / \\
1466138 \\
1080995 \\
86\end{array}$ & \\
\hline $\begin{array}{l}\text { Friedel, G. H., } \\
\text { Rubio, A., } \\
\text { Maretzki, A., } \\
\text { Garland, B., } \\
\text { Brown, P., Crane, } \\
\text { M., \& Hickman, P. }\end{array}$ & $\begin{array}{l}2 \\
0 \\
0 \\
1\end{array}$ & $\begin{array}{l}\text { Community cancer control } \\
\text { in a rural, underserved } \\
\text { population: the Appalachian } \\
\text { Leadership Initiative on } \\
\text { Cancer Project. }\end{array}$ & $\begin{array}{l}\mathrm{P} . \\
15\end{array}$ & $\begin{array}{l}\text { Journal of } \\
\text { health care } \\
\text { for the } \\
\text { poor and } \\
\text { underserve } \\
d\end{array}$ & & & $\begin{array}{l}10.1080 / \\
1081073 \\
0590934 \\
217\end{array}$ & $\begin{array}{l}\text { Underse } \\
\text { rved } \\
\text { commu } \\
\text { nity, } \\
\text { rural } \\
\text { health } \\
\end{array}$ \\
\hline $\begin{array}{l}\text { Frieden, T. R., } \\
\text { Berwick, D.M. }\end{array}$ & $\begin{array}{l}2 \\
0 \\
1 \\
1\end{array}$ & $\begin{array}{l}\text { The "Million Hearts" } \\
\text { initiative- preventing heart } \\
\text { attacks and strokes. }\end{array}$ & $\begin{array}{l}\text { p. } \\
46\end{array}$ & $\begin{array}{l}\text { New } \\
\text { England } \\
\text { Journal of } \\
\text { Medicine }\end{array}$ & & & $\begin{array}{l}\text { 10.1056/ } \\
\text { nejmp11 } \\
10421 \\
\text { nejm }\end{array}$ & $\begin{array}{l}\text { Improvi } \\
\text { ng } \\
\text { health }\end{array}$ \\
\hline $\begin{array}{l}\text { Gagnon, M. P., } \\
\text { Lepage-Savary, D., } \\
\text { Gagnon, J., St- } \\
\text { Pierre, M., Simard, } \\
\text { C., Rhainds, M., ... } \\
\text { \& Légaré, F. }\end{array}$ & $\begin{array}{l}2 \\
0 \\
0 \\
9\end{array}$ & $\begin{array}{l}\text { Introducing patient } \\
\text { perspective in health } \\
\text { Technology assessment at } \\
\text { the local level. }\end{array}$ & & $\begin{array}{l}B M C \\
\text { health } \\
\text { services } \\
\text { research }\end{array}$ & Bmc.org & & $\begin{array}{l}10.1186 / \\
1472- \\
6963-9- \\
54\end{array}$ & $\begin{array}{l}\text { HIT and } \\
\text { patient's } \\
\text { perspect } \\
\text { ive }\end{array}$ \\
\hline $\begin{array}{l}\text { Gauvin, F. P., } \\
\text { Abelson, J., } \\
\text { Giacomini, M., } \\
\text { Eyles, J., \& Lavis, } \\
\text { J. N. }\end{array}$ & $\begin{array}{l}2 \\
0 \\
1 \\
0\end{array}$ & $\begin{array}{l}\text { "It all depends": } \\
\text { Conceptualizing public } \\
\text { involvement in the context } \\
\text { of health technology } \\
\text { assessment agencies. }\end{array}$ & & $\begin{array}{l}\text { Social } \\
\text { science \& } \\
\text { medicine }\end{array}$ & & $\begin{array}{l}\text { Go } \\
\text { ogl } \\
\text { e } \\
\text { Sch } \\
\text { olar }\end{array}$ & $\begin{array}{l}10.1016 \\
\text { /jsocsce } \\
\text { med.01. } \\
036\end{array}$ & $\begin{array}{l}\text { HIT and } \\
\text { the } \\
\text { public }\end{array}$ \\
\hline $\begin{array}{l}\text { Gauvin, F. P., } \\
\text { Abelson, J., } \\
\text { Giacomini, M., } \\
\text { Eyles, J., \& Lavis, } \\
\text { J. N. }\end{array}$ & $\begin{array}{l}2 \\
0 \\
1 \\
1\end{array}$ & $\begin{array}{l}\text { Moving cautiously: Public } \\
\text { involvement and the health } \\
\text { technology assessment } \\
\text { community. }\end{array}$ & & $\begin{array}{l}\text { Internation } \\
\text { al journal } \\
\text { of } \\
\text { technology } \\
\text { assessment } \\
\text { in health } \\
\text { care }\end{array}$ & $\begin{array}{l}\text { Bio Med } \\
\text { Central }\end{array}$ & $\begin{array}{l}\text { Wal } \\
\text { den } \\
\text { libr } \\
\text { ary }\end{array}$ & $\begin{array}{l}10.1017 \\
\text { /s02664 } \\
6231000 \\
1200\end{array}$ & $\begin{array}{l}\text { HIT } \\
\text { assessm } \\
\text { ent }\end{array}$ \\
\hline Gibbons, M. C. & $\begin{array}{l}2 \\
0 \\
1 \\
1\end{array}$ & $\begin{array}{l}\text { Use of health information } \\
\text { technology among racial } \\
\text { and ethnic underserved } \\
\text { communities. }\end{array}$ & & $\begin{array}{l}\text { American } \\
\text { Health } \\
\text { Informatio } \\
n \\
\text { Manageme } \\
n t \\
\text { Association }\end{array}$ & & & $\begin{array}{l}10.1080 / \\
1081073 \\
0.2011\end{array}$ & \\
\hline $\begin{array}{l}\text { Goldzweig, C. L., } \\
\text { Towfigh, A., }\end{array}$ & $\begin{array}{l}2 \\
0\end{array}$ & $\begin{array}{l}\text { Costs and benefits of health } \\
\text { information technology: }\end{array}$ & & $\begin{array}{l}\text { Health } \\
\text { Affairs }\end{array}$ & $\begin{array}{l}\text { Google } \\
\text { scholar }\end{array}$ & & $\begin{array}{l}10.1377 / \\
\text { hlthaff. } 2\end{array}$ & \\
\hline
\end{tabular}




\begin{tabular}{|c|c|c|c|c|c|c|c|c|}
\hline $\begin{array}{l}\text { Maglione, M., \& } \\
\text { Shekelle, P. G. }\end{array}$ & $\begin{array}{l}0 \\
9\end{array}$ & $\begin{array}{l}\text { new trends from the } \\
\text { literature. }\end{array}$ & & & & & $\begin{array}{l}8.2 . \mathrm{w} 28 \\
2\end{array}$ & \\
\hline $\begin{array}{l}\text { Greenhalgh, T.; } \\
\text { Stramer, K.; } \\
\text { Bratan, T.; Byrne, } \\
\text { E.; Mohammad, Y.; } \\
\text { Russel, J. }\end{array}$ & $\begin{array}{l}2 \\
0 \\
0 \\
8\end{array}$ & $\begin{array}{l}\text { Introduction of shared } \\
\text { electronic records: multisite } \\
\text { case study using diffusion of } \\
\text { innovation theory. }\end{array}$ & & $\begin{array}{l}\text { British } \\
\text { Medical } \\
\text { Journal. }\end{array}$ & Bmj.org & & $\begin{array}{l}10.1136 / \\
\text { bmj.a17 } \\
86\end{array}$ & $\begin{array}{l}\text { EHR and } \\
\text { diffusion }\end{array}$ \\
\hline $\begin{array}{l}\text { Greenfield, D., \& } \\
\text { Braithwaite, J. }\end{array}$ & $\begin{array}{l}2 \\
0 \\
0 \\
9\end{array}$ & $\begin{array}{l}\text { Developing the evidence } \\
\text { base for accreditation of } \\
\text { healthcare organizations: a } \\
\text { call for transparency and } \\
\text { innovation. }\end{array}$ & & $\begin{array}{l}\text { Quality } \\
\text { and Safety } \\
\text { in Health } \\
\text { Care, }\end{array}$ & & & $\begin{array}{l}10.1136 / \\
\text { qshc. } 200 \\
9.03235 \\
9\end{array}$ & \\
\hline $\begin{array}{l}\text { Greiver, M.; } \\
\text { Barnsley, J.; } \\
\text { Glazier, R.H.; } \\
\text { Moineddin, R.; } \\
\text { Harvey, B }\end{array}$ & $\begin{array}{l}2 \\
0 \\
1 \\
1\end{array}$ & $\begin{array}{l}\text { Implementation of } \\
\text { electronic medical record: } \\
\text { theory informed qualitative } \\
\text { study. }\end{array}$ & & $\begin{array}{l}\text { Canada } \\
\text { Family } \\
\text { Physician }\end{array}$ & & $\begin{array}{l}\text { Wal } \\
\text { den }\end{array}$ & $\begin{array}{l}10.1056 / \\
\text { NEJMsa } \\
044464\end{array}$ & $\begin{array}{l}\text { EHR } \\
\text { impleme } \\
\text { ntation }\end{array}$ \\
\hline $\begin{array}{l}\text { Hysong, S. J., } \\
\text { Esquivel, A., Sittig, } \\
\text { D. F., Paul, L. A., } \\
\text { Espadas, D., Singh, } \\
\text { S., \& Singh, H. }\end{array}$ & $\begin{array}{l}2 \\
0 \\
1 \\
1\end{array}$ & $\begin{array}{l}\text { Towards successful } \\
\text { coordination of EHR based- } \\
\text { referrals: a qualitative } \\
\text { analysis. }\end{array}$ & $\begin{array}{l}\mathrm{p} . \\
44 \\
4 \\
5\end{array}$ & $\begin{array}{l}\text { Implement } \\
\text { Sci }\end{array}$ & & $\begin{array}{l}\text { Wal } \\
\text { den }\end{array}$ & $\begin{array}{l}10.1186 / \\
1748- \\
5908-6- \\
84\end{array}$ & $\begin{array}{l}\text { EHR } \\
\text { evaluati } \\
\text { on }\end{array}$ \\
\hline $\begin{array}{l}\text { Nilakanta, S., \& } \\
\text { Scamell, R. W. }\end{array}$ & $\begin{array}{l}1 \\
9 \\
9 \\
0\end{array}$ & $\begin{array}{l}\text { The effect of information } \\
\text { sources and communication } \\
\text { channels on the diffusion of } \\
\text { innovation in a data base } \\
\text { development environment. }\end{array}$ & & $\begin{array}{l}\text { Manageme } \\
\text { nt Science. }\end{array}$ & & & $\frac{\frac{10.1287 /}{\mathrm{mnsc.36.}}}{\underline{1.24}}$ & $\begin{array}{l}\text { Diffusio } \\
\mathrm{n} \text { and } \\
\text { innovati } \\
\text { on } \\
\text { theory }\end{array}$ \\
\hline $\begin{array}{l}\text { Ford, E. W., } \\
\text { Menachemi, N., \& } \\
\text { Phillips, M. T. }\end{array}$ & $\begin{array}{l}2 \\
0 \\
0 \\
6\end{array}$ & $\begin{array}{l}\text { Predicting the adoption of } \\
\text { EHRs by physicians: when } \\
\text { will health care be } \\
\text { paperless?. }\end{array}$ & & $\begin{array}{l}\text { Journal of } \\
\text { the } \\
\text { American } \\
\text { Medical } \\
\text { Informatics } \\
\text { Association }\end{array}$ & & & $\begin{array}{l}10.2196 / \\
\text { jmir.116 } \\
6\end{array}$ & $\begin{array}{l}\text { EHR } \\
\text { adoptio } \\
\mathrm{n}\end{array}$ \\
\hline $\begin{array}{l}\text { Frieden, T. R., } \\
\text { Berwick, D.M. }\end{array}$ & $\begin{array}{l}2 \\
0 \\
1 \\
1\end{array}$ & $\begin{array}{l}\text { The "Million Hearts" } \\
\text { initiative- preventing heart } \\
\text { attacks and strokes. }\end{array}$ & & $\begin{array}{l}\text { New } \\
\text { England } \\
\text { Journal of } \\
\text { Medicine }\end{array}$ & Nejm.org & & $\begin{array}{l}10.1056 / \\
\text { NEJMp1 } \\
110421\end{array}$ & $\begin{array}{l}\text { Improvi } \\
\text { ng the } \\
\text { populati } \\
\text { on } \\
\text { health }\end{array}$ \\
\hline Gibbons, M. C. & $\begin{array}{l}2 \\
0 \\
1 \\
1\end{array}$ & $\begin{array}{l}\text { Use of health information } \\
\text { technology among racial } \\
\text { and ethnic underserved } \\
\text { communities. }\end{array}$ & & $\begin{array}{l}\text { AHIMA, } \\
\text { American } \\
\text { Health } \\
\text { Informatio } \\
n \\
\text { Manageme } \\
\text { nt } \\
\text { Association }\end{array}$ & & & $\begin{array}{l}10.1080 / \\
1081073 \\
0.2011\end{array}$ & $\begin{array}{l}\text { EHR and } \\
\text { the } \\
\text { underse } \\
\text { rved } \\
\text { commu } \\
\text { nity }\end{array}$ \\
\hline $\begin{array}{l}\text { Goldzweig, C. L., } \\
\text { Towfigh, A., } \\
\text { Maglione, M., \& } \\
\text { Shekelle, P. G. }\end{array}$ & $\begin{array}{l}2 \\
0 \\
0 \\
9\end{array}$ & $\begin{array}{l}\text { Costs and benefits of health } \\
\text { information technology: } \\
\text { new trends from the } \\
\text { literature. }\end{array}$ & & $\begin{array}{l}\text { Health } \\
\text { Affairs }\end{array}$ & & & $\begin{array}{l}10.1377 / \\
\text { hlthaff.2 } \\
8.2 . w 28 \\
2\end{array}$ & $\begin{array}{l}\text { EHR } \\
\text { benefits }\end{array}$ \\
\hline $\begin{array}{l}\text { Gostin, L. O., } \\
\text { Jacobson, P. D., } \\
\text { Record, K. L., \& } \\
\text { Hardcastle, L. E. }\end{array}$ & $\begin{array}{l}2 \\
0 \\
1 \\
0\end{array}$ & $\begin{array}{l}\text { Restoring Health to Health } \\
\text { Reform: Integrating } \\
\text { Medicine and Public Health } \\
\text { to Advance the Population's } \\
\text { Well-Being. }\end{array}$ & & $\begin{array}{l}\text { U. Pa. L. } \\
\text { Rev }\end{array}$ & $\begin{array}{l}\text { Academic } \\
\text { search }\end{array}$ & $\begin{array}{l}\text { Go } \\
\text { ogl } \\
\text { e } \\
\text { Sch }\end{array}$ & $\begin{array}{l}10.1001 / \\
\text { jama.20 } \\
10.917\end{array}$ & $\begin{array}{l}\text { US and } \\
\text { health } \\
\text { reform }\end{array}$ \\
\hline
\end{tabular}




\begin{tabular}{|c|c|c|c|c|c|c|c|c|}
\hline & & & & & & olar & & \\
\hline Granados, A. & $\begin{array}{l}2 \\
0 \\
1 \\
2\end{array}$ & $\begin{array}{l}\text { Health Technology } \\
\text { Assessment (HTA) in a } \\
\text { changing social and health } \\
\text { care context. }\end{array}$ & & $\begin{array}{l}\text { Italian } \\
\text { Journal of } \\
\text { Public } \\
\text { Health }\end{array}$ & $\begin{array}{l}\text { Academic } \\
\text { search }\end{array}$ & $\begin{array}{l}\text { Go } \\
\text { ogl } \\
\text { e } \\
\text { sch } \\
\text { olar }\end{array}$ & $\begin{array}{l}10.2427 / \\
6030 ; \\
\text { NBN: } \\
\text { urn:nbn: } \\
\text { it:prex- } \\
8135 \ldots\end{array}$ & $\begin{array}{l}\text { HIT } \\
\text { assessm } \\
\text { ent }\end{array}$ \\
\hline $\begin{array}{l}\text { Green, L. W., } \\
\text { Ottoson, J., García, } \\
\text { C., \& Robert, H. }\end{array}$ & $\begin{array}{l}2 \\
0 \\
0 \\
9\end{array}$ & $\begin{array}{l}\text { Diffusion theory and } \\
\text { knowledge dissemination, } \\
\text { utilization, and integration } \\
\text { in public health. }\end{array}$ & & $\begin{array}{l}\text { Annual } \\
\text { Review of } \\
\text { Public } \\
\text { Health }\end{array}$ & $\begin{array}{l}\text { Pro Quest } \\
\text { Central }\end{array}$ & $\begin{array}{l}\text { Wal } \\
\text { den }\end{array}$ & $\begin{array}{l}10.1146 \\
\text { /annulev } \\
\text {.publhea } \\
\text { Ith.0313 } \\
08.1000 \\
49\end{array}$ & $\begin{array}{l}\text { Technol } \\
\text { ogy } \\
\text { diffusion } \\
\text { and } \\
\text { theory }\end{array}$ \\
\hline $\begin{array}{l}\text { Greenfield, D., \& } \\
\text { Braithwaite, J. }\end{array}$ & $\begin{array}{l}2 \\
0 \\
0 \\
9\end{array}$ & $\begin{array}{l}\text { Developing the evidence } \\
\text { base for accreditation of } \\
\text { healthcare organizations: a } \\
\text { call for transparency and } \\
\text { innovation. }\end{array}$ & & $\begin{array}{l}\text { Quality } \\
\text { and Safety } \\
\text { in Health } \\
\text { Care, }\end{array}$ & Medline & $\begin{array}{l}\text { Wal } \\
\text { den }\end{array}$ & $\begin{array}{l}10.1136 \\
\text { /qshc.20 } \\
09.0323 \\
59\end{array}$ & $\begin{array}{l}\text { Innovati } \\
\text { on in } \\
\text { health } \\
\text { care }\end{array}$ \\
\hline $\begin{array}{l}\text { Grossman, J. M., } \\
\text { Cross, D. A., } \\
\text { Boukus, E. R., \& } \\
\text { Cohen, G. R. }\end{array}$ & $\begin{array}{l}2 \\
0 \\
1 \\
2\end{array}$ & $\begin{array}{l}\text { Focus on health information } \\
\text { technology, EHRs and their } \\
\text { financial impact }\end{array}$ & $\begin{array}{l}\text { p. } \\
46\end{array}$ & $\begin{array}{l}\text { Journal of } \\
\text { the } \\
\text { American } \\
\text { Medical } \\
\text { Informatics } \\
\text { Association } \\
\text { :JAMIA } \\
\end{array}$ & $\begin{array}{l}\text { Academic } \\
\text { search }\end{array}$ & $\begin{array}{l}\text { Go } \\
\text { ogl } \\
\text { e } \\
\text { sch } \\
\text { olar }\end{array}$ & $\begin{array}{l}\text { 10.1136/ } \\
\text { amiajnl }\end{array}$ & $\begin{array}{l}\text { EHR } \\
\text { impact }\end{array}$ \\
\hline $\begin{array}{l}\text { Hall, K. L., } \\
\text { Stipelman, B. A., } \\
\text { Eddens, K. S., } \\
\text { Kreuter, M. W., } \\
\text { Bame, S. I., } \\
\text { Meissner, H. I., ... } \\
\text { \& Fernández, M. E. }\end{array}$ & $\begin{array}{l}2 \\
0 \\
1 \\
2\end{array}$ & $\begin{array}{l}\text { Advancing collaborative } \\
\text { research with 2-1-1 to } \\
\text { reduce health disparities: } \\
\text { challenges, opportunities, } \\
\text { and recommendations. }\end{array}$ & $\begin{array}{l}\text { P. } \\
9\end{array}$ & $\begin{array}{l}\text { American } \\
\text { journal of } \\
\text { preventive } \\
\text { medicine. }\end{array}$ & $\begin{array}{l}\text { BioMed } \\
\text { Central }\end{array}$ & $\begin{array}{l}\text { Go } \\
\text { ogl } \\
\text { e } \\
\text { Sch } \\
\text { olar }\end{array}$ & $\begin{array}{l}\text { 10.1016/ } \\
\text { j.amepre }\end{array}$ & $\begin{array}{l}\text { Reducin } \\
\text { g health } \\
\text { disparity }\end{array}$ \\
\hline $\begin{array}{l}\text { Halpern, R., \& } \\
\text { Boulter, P. }\end{array}$ & $\begin{array}{l}2 \\
0 \\
0 \\
0\end{array}$ & $\begin{array}{l}\text { Population-based health } \\
\text { care: Definitions and } \\
\text { applications. }\end{array}$ & & $\begin{array}{l}\text { Tufts } \\
\text { Managed } \\
\text { Care } \\
\text { Institute. }\end{array}$ & $\begin{array}{l}\text { Academic } \\
\text { search }\end{array}$ & $\begin{array}{l}\text { Go } \\
\text { ogl } \\
\text { e } \\
\text { sch } \\
\text { olar }\end{array}$ & $\begin{array}{l}\text { 10.1197/ } \\
\text { j.aem. } 20 \\
06.06 .04 \\
0\end{array}$ & $\begin{array}{l}\text { Health } \\
\text { care and } \\
\text { the } \\
\text { populati } \\
\text { on }\end{array}$ \\
\hline $\begin{array}{l}\text { Health Resources } \\
\text { and Services } \\
\text { Administration } \\
\text { (HRSA). }\end{array}$ & $\begin{array}{l}2 \\
0 \\
0 \\
9\end{array}$ & $\begin{array}{l}\text { "Guidelines for MUA and } \\
\text { MUP Designation", }\end{array}$ & $\begin{array}{l}\mathrm{P} . \\
16 \\
\end{array}$ & HRSA & $\begin{array}{l}\text { Academic } \\
\text { search }\end{array}$ & $\begin{array}{l}\text { We } \\
\text { bsit } \\
\text { e }\end{array}$ & $\begin{array}{l}10.1111 / \\
\text { avj.1207 } \\
5\end{array}$ & HRSA \\
\hline $\begin{array}{l}\text { Hufstader, M., } \\
\text { Swain, M., \& } \\
\text { Furukawa, M. F. }\end{array}$ & $\begin{array}{l}2 \\
0 \\
1 \\
2\end{array}$ & $\begin{array}{l}\text { State Variation in E- } \\
\text { Prescribing Trends in the } \\
\text { United States. }\end{array}$ & & $\begin{array}{l}\text { ONC Data } \\
\text { brief }\end{array}$ & $\begin{array}{l}\text { Academic } \\
\text { search }\end{array}$ & & $\begin{array}{l}10.1111 / \\
1475- \\
6773.12 \\
078\end{array}$ & \\
\hline $\begin{array}{l}\text { Hsiao, C. J., Hing, } \\
\text { E., Socey, T. C., \& } \\
\text { Cai, B. }\end{array}$ & $\begin{array}{l}2 \\
0 \\
1 \\
0\end{array}$ & $\begin{array}{l}\text { Electronic medical } \\
\text { record/EHR systems of } \\
\text { office-based physicians: } \\
\text { United States, } 2009 \text { and } \\
\text { preliminary } 2010 \text { state } \\
\text { estimates. }\end{array}$ & & $\begin{array}{l}\text { National } \\
\text { Center for } \\
\text { Health } \\
\text { Statistics }\end{array}$ & $\begin{array}{l}\text { Academic } \\
\text { search }\end{array}$ & $\begin{array}{l}\text { Wal } \\
\text { den }\end{array}$ & $\begin{array}{l}\text { doi:10.1 } \\
186 / 147 \\
1-2105- \\
12-S 12- \\
\text { S7 }\end{array}$ & $\begin{array}{l}\text { EHR and } \\
\text { primary } \\
\text { care }\end{array}$ \\
\hline $\begin{array}{l}\text { Hutchinson, B., } \\
\text { Albelson, J. \& } \\
\text { Lavis, J. }\end{array}$ & $\begin{array}{l}2 \\
0 \\
1 \\
1\end{array}$ & $\begin{array}{l}\text { Primary health care in } \\
\text { Canada }\end{array}$ & & & & & & \\
\hline
\end{tabular}




\begin{tabular}{|c|c|c|c|c|c|c|c|c|c|}
\hline $\begin{array}{l}\text { Jamoon E., Beatty, } \\
\text { P. Bercovitz, A, et } \\
\text { al }\end{array}$ & \begin{tabular}{l|}
2 \\
0 \\
1 \\
1
\end{tabular} & $\begin{array}{l}\text { Physician adoption of EHR } \\
\text { systems }\end{array}$ & $\begin{array}{l}\text { p. } \\
42\end{array}$ & $\begin{array}{l}\text { National } \\
\text { Center for } \\
\text { Health } \\
\text { Statistics }\end{array}$ & $\begin{array}{l}\text { Academic } \\
\text { search }\end{array}$ & $\begin{array}{l}\text { Wal } \\
\text { den }\end{array}$ & $\begin{array}{l}\frac{\text { http: }: / \mathrm{w}}{\text { ww.cdc }} \\
. \text { gov/nc } \\
\underline{\text { hs/data/ }} \\
\text { databrie } \\
\text { fs/db98 } \\
. \text { htm }\end{array}$ & $\begin{array}{l}10.1007 / \\
\text { s11606- } \\
012- \\
2324-x\end{array}$ & \\
\hline $\begin{array}{l}\text { Jessen W. } \\
\text { Highlight Health }\end{array}$ & $\begin{array}{l}2 \\
0 \\
1 \\
0\end{array}$ & $\begin{array}{l}\text { Medicine and the Second } \\
\text { Generation of Internet-based } \\
\text { Services }\end{array}$ & $\begin{array}{l}\text { p. } \\
26\end{array}$ & & $\begin{array}{l}\text { Google } \\
\text { scholar }\end{array}$ & $\frac{\underline{w e b}}{\underline{\text { cite }}}$ & & $\begin{array}{l}10.2196 / \\
\text { jmir.135 } \\
0 .\end{array}$ & $\begin{array}{l}\text { HIT } \\
\text { assessm } \\
\text { ent }\end{array}$ \\
\hline $\begin{array}{l}\text { Jha, A. K., } \\
\text { DesRoches, C. M., } \\
\text { Campbell, E. G., } \\
\text { Donelan, K., Rao, } \\
\text { S. R., Ferris, T. G., } \\
\text { ․ \& Blumenthal, } \\
\text { D. }\end{array}$ & $\begin{array}{l}2 \\
0 \\
0 \\
9\end{array}$ & $\begin{array}{l}\text { Use of EHRs in US } \\
\text { hospitals. }\end{array}$ & $\begin{array}{l}\text { p. } \\
33 \\
36\end{array}$ & $\begin{array}{l}\text { New } \\
\text { England } \\
\text { Journal of } \\
\text { Medicine }\end{array}$ & $\begin{array}{l}\text { Academic } \\
\text { search }\end{array}$ & & & $\begin{array}{l}10.1056 / \\
\text { NEJMsa } \\
0900592\end{array}$ & $\begin{array}{l}\text { EHR and } \\
\text { hospital } \\
\mathrm{s}\end{array}$ \\
\hline $\begin{array}{l}\text { Kleinman, L. C., \& } \\
\text { Dougherty, D. }\end{array}$ & $\begin{array}{l}2 \\
0 \\
1 \\
3 \\
\end{array}$ & $\begin{array}{l}\text { Assessing Quality } \\
\text { Improvement in Health } \\
\text { Care: Theory for Practice. }\end{array}$ & & & $\begin{array}{l}\text { Academic } \\
\text { search }\end{array}$ & $\begin{array}{l}\text { Wal } \\
\text { den } \\
\text { Lib } \\
\text { rary }\end{array}$ & & $\begin{array}{l}10.1056 / \\
\text { NEJM19 } \\
9301283 \\
280406\end{array}$ & $\begin{array}{l}\text { Health } \\
\text { care } \\
\text { improve } \\
\text { ment } \\
\end{array}$ \\
\hline $\begin{array}{l}\text { Komro, K., } \\
\text { O'Mara, R., } \\
\text { \&Wagenaar, A. }\end{array}$ & $\begin{array}{l}2 \\
0 \\
1 \\
2\end{array}$ & $\begin{array}{l}\text { Mechanisms of Legal } \\
\text { Effect: Perspectives from } \\
\text { Public Health. Public Health } \\
\text { Law. }\end{array}$ & $\begin{array}{l}\text { p. } \\
47 \\
50\end{array}$ & $\begin{array}{l}\text { Public } \\
\text { Health } \\
\text { Law } \\
\text { Research. }\end{array}$ & $\begin{array}{l}\text { ProQuest } \\
\text { Central }\end{array}$ & $\begin{array}{l}\text { Wal } \\
\text { den } \\
\text { Lib } \\
\text { rary }\end{array}$ & & & $\begin{array}{l}\text { Health } \\
\text { and law }\end{array}$ \\
\hline Larkin, $\mathrm{H}$. & $\begin{array}{l}2 \\
0 \\
1 \\
0\end{array}$ & $\begin{array}{l}\text { Managing the population's } \\
\text { health. }\end{array}$ & & $\begin{array}{l}\text { H\&HN: } \\
\text { Hospitals } \\
\text { \& Health } \\
\text { Networks }\end{array}$ & $\begin{array}{l}\text { ProQuest } \\
\text { Central }\end{array}$ & $\begin{array}{l}\text { Wal } \\
\text { den } \\
\text { Lib } \\
\text { rary }\end{array}$ & & & $\begin{array}{l}\text { Populati } \\
\text { on and } \\
\text { health }\end{array}$ \\
\hline Linnan, L. A. & $\begin{array}{l}2 \\
0 \\
1 \\
2\end{array}$ & $\begin{array}{l}\text { Research Collaboration with } \\
2-1-1 \text { to Eliminate Health } \\
\text { Disparities. }\end{array}$ & & $\begin{array}{l}\text { American } \\
\text { Journal of } \\
\text { Preventive } \\
\text { Medicine }\end{array}$ & $\begin{array}{l}\text { Science } \\
\text { Direct }\end{array}$ & & & $\begin{array}{l}10.1016 / \\
\text { j.amepre } \\
.2012 .09 \\
.025 \\
\end{array}$ & $\begin{array}{l}\text { Health } \\
\text { disparity } \\
\text { and } \\
\text { research }\end{array}$ \\
\hline $\begin{array}{l}\text { Mahamoud, A.; } \\
\text { Roche, B.; Homer, } \\
\text { J. }\end{array}$ & \begin{tabular}{l|}
2 \\
0 \\
1 \\
2
\end{tabular} & $\begin{array}{c}\text { Modeling the Social } \\
\text { Determinants of Health and } \\
\text { Simulating Short-Term and } \\
\text { Long-Term Intervention } \\
\text { Impacts for the City of } \\
\text { Toronto, Canada. } \\
\end{array}$ & & $\begin{array}{l}\text { Social } \\
\text { Sciences } \\
\text { and } \\
\text { Medicine }\end{array}$ & $\begin{array}{l}\text { Academic } \\
\text { search }\end{array}$ & & & $\begin{array}{l}10.1016 \\
\text { /j.socsci } \\
\text { med.201 } \\
2.06 .036\end{array}$ & \\
\hline $\begin{array}{l}\text { López, L., Green, } \\
\text { A. R., Tan- } \\
\text { McGrory, A., King, } \\
\text { R., \& Betancourt, J. } \\
\text { R. }\end{array}$ & $\begin{array}{l}2 \\
0 \\
1 \\
1\end{array}$ & $\begin{array}{l}\text { Bridging the digital divide } \\
\text { in health care: the role of } \\
\text { health information } \\
\text { technology in addressing } \\
\text { racial and ethnic disparities. }\end{array}$ & $\begin{array}{l}\mathrm{P} . \\
15 \\
, 3 \\
2, \\
48 \\
5 \\
51\end{array}$ & $\begin{array}{l}\text { Joint } \\
\text { Commissio } \\
n \text { Journal } \\
\text { on Quality } \\
\text { and Patient } \\
\text { Safety, }\end{array}$ & $\begin{array}{l}\text { Academic } \\
\text { search }\end{array}$ & $\begin{array}{l}\mathrm{JC} \\
\mathrm{We} \\
\text { bsit } \\
\mathrm{e}\end{array}$ & $\begin{array}{l}\text { Oct } \\
2011\end{array}$ & & $\begin{array}{l}\text { HIT and } \\
\text { health } \\
\text { disparity }\end{array}$ \\
\hline $\begin{array}{l}\text { Manary, M. P., } \\
\text { Boulding, W., } \\
\text { Staelin, R., \& } \\
\text { Glickman, S. W. }\end{array}$ & $\begin{array}{l}2 \\
0 \\
1 \\
3\end{array}$ & $\begin{array}{l}\text { The patient experience and } \\
\text { health outcomes. }\end{array}$ & & $\begin{array}{l}\text { New } \\
\text { England } \\
\text { Journal of } \\
\text { Medicine }\end{array}$ & Nejm.org & $\begin{array}{l}\text { Onl } \\
\text { ine }\end{array}$ & & $\begin{array}{l}10.1056 / \\
\text { NEJMp1 } \\
211775\end{array}$ & $\begin{array}{l}\text { EHR and } \\
\text { patient } \\
\text { satisfact } \\
\text { ion }\end{array}$ \\
\hline $\begin{array}{l}\text { Martin, G. P., } \\
\text { Weaver, S., Currie, } \\
\text { G., Finn, R., \& } \\
\text { McDonald, R. }\end{array}$ & $\begin{array}{l}2 \\
0 \\
1 \\
2\end{array}$ & $\begin{array}{l}\text { Innovation sustainability in } \\
\text { challenging health-care } \\
\text { contexts: embedding } \\
\text { clinically led change in }\end{array}$ & & $\begin{array}{l}\text { Health } \\
\text { Services } \\
\text { Manageme } \\
n t\end{array}$ & $\begin{array}{l}\text { Academic } \\
\text { search }\end{array}$ & $\begin{array}{l}\text { Onl } \\
\text { ine }\end{array}$ & & $\begin{array}{l}10.1177 / \\
0951484 \\
8124742 \\
46 \\
\end{array}$ & $\begin{array}{l}\text { Health } \\
\text { care } \\
\text { challeng } \\
\mathrm{e}\end{array}$ \\
\hline
\end{tabular}




\begin{tabular}{|c|c|c|c|c|c|c|c|c|}
\hline & & routine practice. & & Research & & & & \\
\hline Maun C. & $\begin{array}{l}2 \\
0 \\
1 \\
0\end{array}$ & $\begin{array}{l}\text { Take Advantage of the } \\
\text { Technology }\end{array}$ & $\begin{array}{l}\mathrm{P} . \\
12\end{array}$ & $\underline{\text { webcite }}$ & $\begin{array}{l}\text { Academic } \\
\text { search }\end{array}$ & $\begin{array}{l}\text { onli } \\
\text { ne }\end{array}$ & & \\
\hline $\begin{array}{l}\text { Moiduddin, A., \& } \\
\text { Moore, J. }\end{array}$ & $\begin{array}{l}2 \\
0 \\
0 \\
8\end{array}$ & $\begin{array}{l}\text { The underserved and health } \\
\text { information technology: } \\
\text { issues and opportunities. }\end{array}$ & & US HHS & $\begin{array}{l}\text { Academic } \\
\text { search }\end{array}$ & $\begin{array}{l}\text { web } \\
\text { site }\end{array}$ & $\begin{array}{l}10.1136 / \\
\text { bmj.330. } \\
7491.58 \\
1 .\end{array}$ & $\begin{array}{l}\text { HIT and } \\
\text { underse } \\
\text { rved } \\
\text { populati } \\
\text { on }\end{array}$ \\
\hline Murray, C. E. & $\begin{array}{l}2 \\
0 \\
0 \\
9\end{array}$ & $\begin{array}{l}\text { Diffusion of Innovation } \\
\text { Theory: A Bridge for the } \\
\text { Research-Practice Gap in } \\
\text { Counseling. }\end{array}$ & $\begin{array}{l}\text { p. } \\
40\end{array}$ & $\begin{array}{l}\text { Journal of } \\
\text { Counseling } \\
\text { and } \\
\text { Developme } \\
\text { nt }\end{array}$ & $\begin{array}{l}\text { Google } \\
\text { Scholar }\end{array}$ & $\begin{array}{l}\text { Onl } \\
\text { ine }\end{array}$ & $\begin{array}{l}10.1002 / \\
\text { j.1556- } \\
6678.20 \\
09 . t b 005 \\
56 . x\end{array}$ & $\begin{array}{l}\text { Diffusio } \\
\mathrm{n} \text { and } \\
\text { innovati } \\
\text { on } \\
\text { theory }\end{array}$ \\
\hline $\begin{array}{l}\text { Nicol, G. E., } \\
\text { Morrato, E. H., } \\
\text { Johnson, M. C., } \\
\text { Campagna, E., } \\
\text { Yingling, M. D., } \\
\text { Pham, V., \& } \\
\text { Newcomer, J. W. }\end{array}$ & $\begin{array}{l}2 \\
0 \\
1 \\
1\end{array}$ & $\begin{array}{l}\text { Best practices: } \\
\text { implementation of a glucose } \\
\text { screening program based on } \\
\text { diffusion of innovation } \\
\text { theory methods. }\end{array}$ & $\begin{array}{l}\text { p. } \\
37 \\
40\end{array}$ & $\begin{array}{l}\text { Psychiatric } \\
\text { Services }\end{array}$ & $\begin{array}{l}\text { Journal of } \\
\text { Clinical } \\
\text { Psychiatry }\end{array}$ & $\begin{array}{l}\text { Go } \\
\text { ogl } \\
\text { e } \\
\text { sch } \\
\text { olar }\end{array}$ & $\begin{array}{l}10.1176 / \\
\text { appi.ps.6 } \\
2.1 .12\end{array}$ & $\begin{array}{l}\text { Diffusio } \\
\mathrm{n} \\
\text { innovati } \\
\text { on } \\
\text { theory }\end{array}$ \\
\hline $\begin{array}{l}\text { Ortiz, A. A.; } \\
\text { Macedo, G.; } \\
\text { Carlos, J. }\end{array}$ & $\begin{array}{l}2 \\
0 \\
1 \\
0\end{array}$ & $\begin{array}{l}\text { A ‘Systemic Theories of } \\
\text { Change' Approach for } \\
\text { Purposeful Capacity } \\
\text { Development. }\end{array}$ & $\begin{array}{l}\text { P. } \\
34\end{array}$ & $\begin{array}{l}\text { IDS } \\
\text { Bulletin. }\end{array}$ & & & $\begin{array}{l}10.1111 \\
/ \mathrm{j} .1759- \\
5436.20 \\
10.0014 \\
0 . x\end{array}$ & \\
\hline $\begin{array}{l}\text { Orszag, P. R., \& } \\
\text { Emanuel, E. J. }\end{array}$ & $\begin{array}{l}2 \\
0 \\
1 \\
0\end{array}$ & $\begin{array}{l}\text { Health care reform and } \\
\text { cost control }\end{array}$ & $\begin{array}{l}\text { p. } \\
5\end{array}$ & $\begin{array}{l}\text { New } \\
\text { England } \\
\text { Journal of } \\
\text { Medicine, }\end{array}$ & & & & \\
\hline Porter, M. & $\begin{array}{l}2 \\
0 \\
0 \\
9\end{array}$ & $\begin{array}{l}\text { A strategy for health care } \\
\text { reform- toward a value- } \\
\text { based system. }\end{array}$ & $\begin{array}{l}\text { p. } \\
5\end{array}$ & $\begin{array}{l}\text { New } \\
\text { England } \\
\text { Journal of } \\
\text { Medicine. }\end{array}$ & & & $\begin{array}{l}\text { 10.1056/ } \\
\text { NEJMp0 } \\
904131\end{array}$ & \\
\hline $\begin{array}{l}\text { Pourbohloul, B.1 } \\
\text { Kieny, M-P. }\end{array}$ & $\begin{array}{l}2 \\
0 \\
1 \\
1\end{array}$ & $\begin{array}{l}\text { Complex system analysis: } \\
\text { toward holistic approaches } \\
\text { to health systems planning } \\
\text { and policy. }\end{array}$ & $\begin{array}{l}\text { p. } \\
13 \\
2 \\
8, \\
37\end{array}$ & & $\begin{array}{l}\frac{\text { http://dx.do }}{\text { i.org/10.159 }} \\
\underline{0 / \mathrm{S} 0042-} \\
\underline{968620110} \\
\underline{00400002}\end{array}$ & & $\begin{array}{l}10.1590 \\
\text { /S0042- } \\
9686201 \\
1000400 \\
002 \\
\end{array}$ & \\
\hline $\begin{array}{l}\text { Parente, S. T., \& } \\
\text { McCullough, J. S. }\end{array}$ & $\begin{array}{l}2 \\
0 \\
0 \\
9\end{array}$ & $\begin{array}{l}\text { Health information } \\
\text { technology and patient } \\
\text { safety: Evidence from panel } \\
\text { data. }\end{array}$ & & $\begin{array}{l}\text { Health } \\
\text { Affairs }\end{array}$ & & & $\begin{array}{l}10.1377 \\
\text { /hlthaff. } \\
28.2 .357\end{array}$ & $\begin{array}{l}\text { HIT and } \\
\text { safety }\end{array}$ \\
\hline $\begin{array}{l}\text { Salomon, R. M., } \\
\text { Blackford, J. U., } \\
\text { Rosenbloom, S. T., } \\
\text { Seidel, S., Clayton, } \\
\text { E. W., Dilts, D. M., } \\
\text { \& Finder, S. G. }\end{array}$ & $\begin{array}{l}2 \\
0 \\
1 \\
0\end{array}$ & $\begin{array}{l}\text { Openness of patients' } \\
\text { reporting with use of } \\
\text { electronic records: } \\
\text { psychiatric clinicians' views. }\end{array}$ & & $\begin{array}{l}\text { Journal of } \\
\text { the } \\
\text { American } \\
\text { Medical } \\
\text { Informatics } \\
\text { Associatio } \\
\mathrm{n},\end{array}$ & $\begin{array}{l}\text { Academic } \\
\text { search }\end{array}$ & $\begin{array}{l}\text { Go } \\
\text { ogl } \\
\text { e } \\
\text { sch } \\
\text { olar }\end{array}$ & $\begin{array}{l}\text { 10.1197/ } \\
\text { jamia.M } \\
3341 .\end{array}$ & $\begin{array}{l}\text { EHR and } \\
\text { physicia } \\
\text { ns' } \\
\text { perspect } \\
\text { ives }\end{array}$ \\
\hline $\begin{array}{l}\text { Rahman, M., \& Ko, } \\
\text { M. }\end{array}$ & $\begin{array}{l}2 \\
0 \\
1 \\
2\end{array}$ & $\begin{array}{l}\text { Factors Influencing } \\
\text { Patients' Perceptions toward } \\
\text { Electronic }\end{array}$ & & $\begin{array}{l}\text { Medical } \\
\text { Record } \\
\text { (EMR) } \\
\text { use: A }\end{array}$ & $\begin{array}{l}\text { Academic } \\
\text { search }\end{array}$ & $\begin{array}{l}\text { Go } \\
\text { ogl } \\
\text { e } \\
\text { sch }\end{array}$ & $\begin{array}{l}10.5539 / \\
\text { ass.v8n1 } \\
3 \mathrm{p} 201\end{array}$ & $\begin{array}{l}\text { EHR and } \\
\text { patients' } \\
\text { perspect } \\
\text { ives }\end{array}$ \\
\hline
\end{tabular}




\begin{tabular}{|c|c|c|c|c|c|c|c|c|c|}
\hline & & & & $\begin{array}{l}\text { Conceptual } \\
\text { Model }\end{array}$ & & olar & & & \\
\hline $\begin{array}{l}\text { Rosser, W. W., } \\
\text { Colwill, J. M., } \\
\text { Kasperski, J., \& } \\
\text { Wilson, L. }\end{array}$ & $\begin{array}{l}2 \\
0 \\
1 \\
1\end{array}$ & $\begin{array}{l}\text { Progress of Ontario's family } \\
\text { health team model: a } \\
\text { patient-centered medical } \\
\text { home. }\end{array}$ & & $\begin{array}{l}\text { The Annals } \\
\text { of Family } \\
\text { Medicine }\end{array}$ & & & & $\begin{array}{l}10.1370 / \\
\text { afm.122 } \\
8 .\end{array}$ & $\begin{array}{l}\text { Medical } \\
\text { home } \\
\text { model }\end{array}$ \\
\hline $\begin{array}{l}\text { Sanson-Fisher, R. } \\
\text { W. }\end{array}$ & $\begin{array}{l}2 \\
0 \\
0 \\
4\end{array}$ & $\begin{array}{l}\text { Diffusion of innovation } \\
\text { theory for clinical change }\end{array}$ & $\begin{array}{l}\text { P. } \\
13\end{array}$ & $\begin{array}{l}\text { Medical } \\
\text { journal of } \\
\text { Australia, }\end{array}$ & & & & $\begin{array}{l}10.1002 / \\
\text { jclp }\end{array}$ & $\begin{array}{l}\text { Diffusio } \\
\mathrm{n} \text { and } \\
\text { innovati } \\
\text { on } \\
\text { theory }\end{array}$ \\
\hline $\begin{array}{l}\text { Sarasohn-Kahn J. } \\
\text { Social Media } \\
\text { Strategery. }\end{array}$ & $\begin{array}{l}2 \\
0 \\
0 \\
9\end{array}$ & $\begin{array}{l}\text { Crowdsourcing Our } \\
\text { Health-Using Social } \\
\text { Media to Educate and Unite } \\
\text { the Public }\end{array}$ & $\begin{array}{l}\text { p. } \\
26\end{array}$ & $\underline{\text { Webcite }}$ & $\begin{array}{l}\text { Academic } \\
\text { search }\end{array}$ & $\begin{array}{l}\text { Go } \\
\text { ogl } \\
\text { e } \\
\text { sch } \\
\text { olar }\end{array}$ & & $\begin{array}{l}10.2196 / \\
\text { jmir. } 7.1 \text {. } \\
\text { e1 }\end{array}$ & \\
\hline $\begin{array}{l}\text { Schoen, C., } \\
\text { Osborn, R., Doty, } \\
\text { M. M., Squires, D., } \\
\text { Peugh, J., \& } \\
\text { Applebaum, S. }\end{array}$ & $\begin{array}{l}2 \\
0 \\
0 \\
9\end{array}$ & $\begin{array}{l}\text { A survey of primary care } \\
\text { physicians in eleven } \\
\text { countries, 2009: } \\
\text { perspectives on care, costs, } \\
\text { and experiences. }\end{array}$ & $\begin{array}{l}\text { p. } \\
28\end{array}$ & $\begin{array}{l}\text { Health } \\
\text { Affairs }\end{array}$ & & & & $\begin{array}{l}10.1377 / \\
\text { hlthaff.2 } \\
\text { 8.1.w1 }\end{array}$ & $\begin{array}{l}\text { Primary } \\
\text { care } \\
\text { survey }\end{array}$ \\
\hline $\begin{array}{l}\text { Serra-Sastre, V., \& } \\
\text { McGuire, A. }\end{array}$ & $\begin{array}{l}2 \\
0 \\
1 \\
2\end{array}$ & $\begin{array}{l}\text { Technology diffusion in } \\
\text { health care: conceptual } \\
\text { aspects and evidence. }\end{array}$ & & $\begin{array}{l}\text { The LSE } \\
\text { Companion } \\
\text { to Health } \\
\text { Policy }\end{array}$ & $\begin{array}{l}\text { Academic } \\
\text { search }\end{array}$ & $\begin{array}{l}\text { Go } \\
\text { ogl } \\
\mathrm{e} \\
\text { sch } \\
\text { olar }\end{array}$ & & & $\begin{array}{l}\text { HIT and } \\
\text { health } \\
\text { care }\end{array}$ \\
\hline Shi, L; Stevens, G. & $\begin{array}{l}2 \\
0 \\
0 \\
7\end{array}$ & $\begin{array}{l}\text { The Role of Community } \\
\text { Health Centers in Delivering } \\
\text { Primary Care to the } \\
\text { Underserved: Experiences } \\
\text { of the Uninsured and } \\
\text { Medicaid Insured. }\end{array}$ & & $\begin{array}{l}\text { Journal of } \\
\text { Ambulator } \\
y \text { Care } \\
\text { Manageme } \\
n t .\end{array}$ & $\begin{array}{l}\text { ProQuest } \\
\text { Central }\end{array}$ & $\begin{array}{l}\text { Wal } \\
\text { den }\end{array}$ & & $\begin{array}{l}10.1097 / \\
01 . J A C . \\
0000264 \\
606.501 \\
23.6 \mathrm{~d}\end{array}$ & \\
\hline $\begin{array}{l}\text { Shields, A. E., } \\
\text { Shin, P., Leu, M. } \\
\text { G., Levy, D. E., } \\
\text { Betancourt, R. M., } \\
\text { Hawkins, D., \& } \\
\text { Proser, M. }\end{array}$ & $\begin{array}{l}2 \\
0 \\
0 \\
7\end{array}$ & $\begin{array}{l}\text { Adoption of health } \\
\text { information technology in } \\
\text { community health centers: } \\
\text { results of a national survey. }\end{array}$ & & $\begin{array}{l}\text { Health } \\
\text { Affairs }\end{array}$ & & & & $\begin{array}{l}\frac{10.1111 /}{\mathrm{j} .1475-} \\
\frac{6773.20}{10.0111} \\
\underline{3 . \mathrm{x}}\end{array}$ & $\begin{array}{l}\text { Primary } \\
\text { care } \\
\text { survey }\end{array}$ \\
\hline Shim, J. & $\begin{array}{l}2 \\
0 \\
1 \\
0\end{array}$ & $\begin{array}{l}\text { Cultural health capital: A } \\
\text { theoretical approach to } \\
\text { understanding health care } \\
\text { interactions and the } \\
\text { dynamics of unequal } \\
\text { treatment. }\end{array}$ & & $\begin{array}{l}\text { Journal of } \\
\text { Health and } \\
\text { Social } \\
\text { Behavior }\end{array}$ & MEDLINE & $\begin{array}{l}\text { Wal } \\
\text { den } \\
\text { Lib } \\
\text { rary }\end{array}$ & & $\begin{array}{l}10.1177 / \\
0022146 \\
5103835 \\
01\end{array}$ & $\begin{array}{l}\text { Health } \\
\text { care and } \\
\text { inequalit } \\
y\end{array}$ \\
\hline $\begin{array}{l}7 . \\
\text { Sittig, D. F., \& } \\
\text { Singh, H. }\end{array}$ & $\begin{array}{l}2 \\
0 \\
1 \\
0\end{array}$ & $\begin{array}{l}\text { A new sociotechnical model } \\
\text { for studying health } \\
\text { information technology in } \\
\text { complex adaptive healthcare } \\
\text { systems. }\end{array}$ & & $\begin{array}{l}\text { Quality } \\
\text { and Safety } \\
\text { in Health } \\
\text { Care }\end{array}$ & $\begin{array}{l}7 \\
\text { MEDLINE }\end{array}$ & $\begin{array}{l}\text { Wal } \\
\text { den } \\
\text { Lib } \\
\text { rary }\end{array}$ & & $\begin{array}{l}10.1136 / \\
\text { qshc. } 201 \\
0.04208 \\
5\end{array}$ & $\begin{array}{l}\text { HIT and } \\
\text { health } \\
\text { care }\end{array}$ \\
\hline $\begin{array}{l}\text { Street,J.M.,Braunac } \\
\text { k-Mayer, A. J., } \\
\text { Facey, K., } \\
\text { Ashcroft, R. E., \& } \\
\text { Hiller, J. E. }\end{array}$ & $\begin{array}{l}2 \\
0 \\
0 \\
8\end{array}$ & $\begin{array}{l}\text { Virtual community } \\
\text { consultation? Using the } \\
\text { literature and weblogs to } \\
\text { link community } \\
\text { perspectives and health } \\
\text { technology assessment. }\end{array}$ & & $\begin{array}{l}\text { Health } \\
\text { Expectatio } \\
n s\end{array}$ & $\begin{array}{l}\text { Pro Quest } \\
\text { Central }\end{array}$ & $\begin{array}{l}\text { Wal } \\
\text { den }\end{array}$ & $\begin{array}{l}10.23 .0 \\
7\end{array}$ & $\begin{array}{l}10.1111 \\
\text { /g.3013 } \\
69- \\
7625 .- \\
2007.00 \\
484 . x\end{array}$ & $\begin{array}{l}\text { Commu } \\
\text { nity- } \\
\text { based } \\
\text { health }\end{array}$ \\
\hline $\begin{array}{l}\text { Swanson, R. } \\
\text { C.,Cattaneo,A.,Bra }\end{array}$ & 2 & $\begin{array}{l}\text { Rethinking health systems } \\
\text { strengthening: key systems }\end{array}$ & & $\begin{array}{l}\text { Health } \\
\text { Policy and }\end{array}$ & & & & $\begin{array}{l}10.1093 / \\
\text { heapol/c }\end{array}$ & Health \\
\hline
\end{tabular}




\begin{tabular}{|c|c|c|c|c|c|c|c|c|}
\hline $\begin{array}{l}\text { dley,E.,Chunharas, } \\
\text { S.,Atun, R., } \\
\text { Abbas,K.M., ... \& } \\
\text { Best, A. }\end{array}$ & $\begin{array}{l}0 \\
1 \\
2\end{array}$ & $\begin{array}{l}\text { thinking tools and strategies } \\
\text { for transformational change. }\end{array}$ & & Planning & & & zs090 & $\begin{array}{l}\text { system } \\
\text { transfor } \\
\text { mation }\end{array}$ \\
\hline $\begin{array}{l}\text { Terry, A. L.,Cejic, } \\
\text { S.,Ryan,B. L., } \\
\text { Shadd, } \\
\text { J.D.,Stewart,M.,For } \\
\text { tin,M.,\&Thind, A }\end{array}$ & $\begin{array}{l}2 \\
0 \\
1 \\
2\end{array}$ & $\begin{array}{l}\text { You and your EMR: the } \\
\text { research perspective Part } 4 . \\
\text { Optimizing EMRs in } \\
\text { primary health care practice } \\
\text { and research. }\end{array}$ & $\begin{array}{l}\text { p. } \\
47 \\
49\end{array}$ & $\begin{array}{l}\text { Canadian } \\
\text { Family } \\
\text { Physician }\end{array}$ & $\begin{array}{l}\text { Canadian } \\
\text { Family } \\
\text { Physician }\end{array}$ & $\begin{array}{l}\text { Ato } \\
\text { mic } \\
\text { Do } \\
\text { g } \\
\text { Pub } \\
\text { lish } \\
\text { ing }\end{array}$ & & $\begin{array}{l}\text { EHR and } \\
\text { primary } \\
\text { care }\end{array}$ \\
\hline Trochim, W. M. & $\begin{array}{l}2 \\
0 \\
0 \\
0\end{array}$ & $\begin{array}{l}\text { The Research Methods } \\
\text { Knowledge Base }\end{array}$ & & & $\begin{array}{l}\text { socialresear } \\
\text { chmethods. } \\
\text { net }\end{array}$ & & $\begin{array}{l}10.1371 / \\
\text { journal.p } \\
\text { bio.0040 } \\
105 .\end{array}$ & $\begin{array}{l}\text { Researc } \\
\text { h } \\
\text { method } \\
\text { ology }\end{array}$ \\
\hline $\begin{array}{l}\text { Van De Belt, T. H., } \\
\text { Engelen,L. J., } \\
\text { Berben, } \\
\text { S.A.,\&Schoonhove } \\
\text { n, L. }\end{array}$ & $\begin{array}{l}2 \\
0 \\
1 \\
0\end{array}$ & $\begin{array}{l}\text { Health and Medicine: a } \\
\text { systematic review. }\end{array}$ & $\begin{array}{l}\text { P. } \\
31\end{array}$ & $\begin{array}{l}\text { Journal of } \\
\text { MedicaI } \\
\text { Internet } \\
\text { Research. }\end{array}$ & & $\begin{array}{l}\text { Aca } \\
\text { de } \\
\text { mic } \\
\text { sear } \\
\text { ch }\end{array}$ & $\begin{array}{l}10.1080 / \\
1081073 \\
0.2011\end{array}$ & \\
\hline \multirow[t]{3}{*}{ Wallace, S. P. } & $\begin{array}{l}2 \\
0 \\
1 \\
2 \\
\end{array}$ & $\begin{array}{l}\text { Social determinants of } \\
\text { health inequities and } \\
\text { healthcare in old age }\end{array}$ & $\begin{array}{l}\text { p. } \\
50\end{array}$ & & & $\begin{array}{l}\text { Wal } \\
\text { den }\end{array}$ & $\begin{array}{l}10.2105 / \\
\text { AJPH.2 } \\
006.085 \\
530\end{array}$ & \\
\hline & & & & & & & & $\begin{array}{l}\text { Health } \\
\text { and } \\
\text { medicin } \\
\mathrm{e}\end{array}$ \\
\hline & $\begin{array}{l}2 \\
0 \\
1 \\
2\end{array}$ & & & & & & & $\begin{array}{l}\text { Health } \\
\text { inequity }\end{array}$ \\
\hline $\begin{array}{l}\text { World Health } \\
\text { Organization(WHO } \\
\text { ) }\end{array}$ & $\begin{array}{l}2 \\
0 \\
0 \\
8\end{array}$ & $\begin{array}{l}\text { Closing the gap in a } \\
\text { generation }\end{array}$ & & $\begin{array}{l}\text { WHO } \\
\text { Bulletin }\end{array}$ & $\begin{array}{l}\text { http://whqli } \\
\text { bdoc.who.i } \\
\text { nt/publicati } \\
\underline{\text { ons/2008/9 } / 9241563} \\
7892415 \text { eng.pd } \\
\text { f }\end{array}$ & $\begin{array}{l}\text { On } \\
\text { line }\end{array}$ & & $\begin{array}{l}\text { World } \\
\text { health } \\
\text { organiza } \\
\text { tion } \\
\text { survey }\end{array}$ \\
\hline $\begin{array}{l}\text { World Health } \\
\text { Organization(WHO } \\
\text { ) }\end{array}$ & $\begin{array}{l}2 \\
0 \\
0 \\
7\end{array}$ & $\begin{array}{l}\text { Everybody's business: } \\
\text { strengthening health } \\
\text { systems to improve health } \\
\text { outcomes }\end{array}$ & & $\begin{array}{l}\text { Geneva: } \\
\text { World } \\
\text { Health } \\
\text { Organizati } \\
\text { on }\end{array}$ & $\begin{array}{l}\frac{\text { http://www. }}{\text { who.int } / \text { hea }} \\
\text { lthsystems/s } \\
\text { trategy/ever } \\
\text { ybodysbusi } \\
\text { ness.pdf }\end{array}$ & $\begin{array}{l}\text { onli } \\
\text { ne }\end{array}$ & & \\
\hline $\begin{array}{l}\text { Wu,A.W.,Snyder, } \\
\text { C.,ClancyC.M.,\&St } \\
\text { einwachs, D. M. }\end{array}$ & $\begin{array}{l}2 \\
0 \\
1 \\
0\end{array}$ & $\begin{array}{l}\text { Adding the patient } \\
\text { perspective to comparative } \\
\text { effectiveness research. }\end{array}$ & & $\begin{array}{l}\text { Health } \\
\text { Affairs }\end{array}$ & & $\begin{array}{l}\text { Aca } \\
\text { de } \\
\text { mic } \\
\text { sear } \\
\text { ch }\end{array}$ & $\begin{array}{l}10.1377 / \\
\text { hlthaff.2 } \\
012.076 \\
4\end{array}$ & \\
\hline $\begin{array}{l}\text { Zhu,J.,Brawarsky,P } \\
\text {.,Lipsitz,S.,Huskam } \\
\text { p, H.,\& Haas, J. S. }\end{array}$ & $\begin{array}{l}2 \\
0 \\
1 \\
0\end{array}$ & & & $\begin{array}{l}\text { Journal of } \\
\text { General } \\
\text { Internal } \\
\text { Medicine }\end{array}$ & & & $\begin{array}{l}10.1007 \\
\text { /s11606- } \\
010- \\
1482\end{array}$ & \\
\hline Zott, C.; Amit, R. & 2 & $\begin{array}{l}\text { Business model design: an } \\
\text { activity system perspective }\end{array}$ & p. & $\begin{array}{l}\text { Long } \\
\text { Range }\end{array}$ & $\begin{array}{l}\text { http://www. } \\
\text { elsevier.co }\end{array}$ & $\begin{array}{l}\text { Aca } \\
\text { de }\end{array}$ & $\begin{array}{l}10.1016 / \\
\text { j.lrp.200 }\end{array}$ & \\
\hline
\end{tabular}




\begin{tabular}{|c|c|c|c|c|c|c|c|c|}
\hline & $\begin{array}{l}0 \\
0 \\
9\end{array}$ & & 13 & Planning. & $\underline{\mathrm{m} / \text { locate/lrp }}$ & $\begin{array}{l}\text { mic } \\
\text { sear } \\
\text { ch }\end{array}$ & 9.07 .004 & \\
\hline $\begin{array}{l}\text { Zlabek,J.A.,Wickus } \\
\text {, J.W.,\& } \\
\text { Mathiason, M. A. }\end{array}$ & $\begin{array}{l}2 \\
0 \\
1 \\
1\end{array}$ & $\begin{array}{l}\text { Early cost and safety } \\
\text { benefits of an inpatient } \\
\text { EHR. }\end{array}$ & $\begin{array}{l}\text { p. } \\
46\end{array}$ & $\begin{array}{l}\text { Journal of } \\
\text { the } \\
\text { American } \\
\text { Medical } \\
\text { Informatics } \\
\text { Association }\end{array}$ & $\begin{array}{l}\text { Academic } \\
\text { research }\end{array}$ & & & $\begin{array}{l}\text { EHR and } \\
\text { cost }\end{array}$ \\
\hline
\end{tabular}




\section{Appendix B: Letter of invitation to Pilot Study}

\section{Dear Sir/Madam:}

You are invited to participate in a small study or pilot study by reading the enclosed survey questionnaire and responding to the separate form. The purpose of this pilot study is to assess the level of clarity, understanding, and difficulty of the enclosed survey questionnaire. Your participation will bring valuable information for conducting a larger scale study. Your participation is also voluntary.

The result of this pilot study will help assess the feasibility of the enclosed survey questionnaire that will be utilized in a larger scale study. This project is a pre-requisite of a larger research project that is needed to fulfill a partial requirement for my $\mathrm{PhD}$ degree in Health Services and Health Sciences. The primary reason of the main study is to determine the impact of the EHRs on the health of the underserved community. The feasibility criteria are based on the understanding rate of the enclosed survey questionnaire. A rate of $70 \%$ or higher is needed to carry on with the main study or a rate of 50-69\% will determine if the survey questionnaire will need closed monitoring. A rate of less than $50 \%$ will require modifications of the survey questionnaire.

Thank you for your time and assistance

Mirna Lexima

Email: Mirna.lexima@waldenu.edu

Ph.: 571-332-8353 


\section{Appendix C: Pilot Study instrument}

Please read the enclosed survey questionnaire before responding to the questions below. Put an $\mathrm{X}$ in the appropriate blue box to show your answers:

\begin{tabular}{|c|c|c|c|c|}
\hline $\begin{array}{l}\text { The information } \\
\text { written in the } \\
\text { survey } \\
\text { questionnaire is } \\
\text { clear and easy to } \\
\text { read }\end{array}$ & Agree & mostly agree & $\begin{array}{l}\text { very much } \\
\text { agree }\end{array}$ & Disagree \\
\hline $\begin{array}{l}\text { The questions } \\
\text { from the survey } \\
\text { questionnaire } \\
\text { are easy to } \\
\text { understand }\end{array}$ & Agree & Mostly agree & $\begin{array}{l}\text { Very much } \\
\text { agree }\end{array}$ & Disagree \\
\hline $\begin{array}{l}\text { The wordiness } \\
\text { of the survey } \\
\text { questionnaire } \\
\text { was too difficult } \\
\text { to understand }\end{array}$ & Disagree & Mostly disagree & $\begin{array}{l}\text { Definitely } \\
\text { disagree }\end{array}$ & Agree \\
\hline $\begin{array}{l}\text { The overall level } \\
\text { of difficulty is }\end{array}$ & Minimal & Mostly minimal & Very minimal & Not minimal \\
\hline $\begin{array}{l}\text { The overall level } \\
\text { of } \\
\text { understanding } \\
\text { is }\end{array}$ & Appropriate & $\begin{array}{l}\text { Mostly } \\
\text { appropriate }\end{array}$ & $\begin{array}{l}\text { Very } \\
\text { appropriate }\end{array}$ & Not appropriate \\
\hline
\end{tabular}




\section{Appendix D: Partial survey instrument for the pilot study}

\section{Patient experience}

Please put an $\mathbf{X}$ where the definition matches your personal experience as a patient and customer.

\begin{tabular}{|c|c|c|c|c|c|}
\hline & $\begin{array}{l}\text { Strongly } \\
\text { agree }\end{array}$ & Agree & $\begin{array}{l}\text { Strongly } \\
\text { disagree }\end{array}$ & Disagree & Neutral \\
\hline $\begin{array}{l}\text { My experience with the health clinic has been } \\
\text { better during my last few visits }\end{array}$ & & & & & \\
\hline $\begin{array}{l}\text { I notice changes in the way the care team } \\
\text { addresses my health care needs during my last } \\
\text { few visits in the clinic. }\end{array}$ & & & & & \\
\hline $\begin{array}{l}\text { I am aware that the health center/clinic has } \\
\text { electronic medical record to help coordinate and } \\
\text { manage my care better and faster }\end{array}$ & & & & & \\
\hline $\begin{array}{l}\text { I know more about my health condition compare } \\
\text { to before the implementation of the EHR. }\end{array}$ & & & & & \\
\hline $\begin{array}{l}\text { The EHR helps me communicate better with my } \\
\text { doctor and the other staff in the clinic }\end{array}$ & & & & & \\
\hline The EHR helps me manage my care better & & & & & \\
\hline $\begin{array}{l}\text { My doctor sends my prescriptions electronically } \\
\text { for me }\end{array}$ & & & & & \\
\hline $\begin{array}{l}\text { I get calls or text messages to remind me of my } \\
\text { appointment }\end{array}$ & & & & & \\
\hline $\begin{array}{l}\text { I prefer to communicate via email with my doctor } \\
\text { about my health care such as my lab results, } \\
\text { questions about my health and my medicines. }\end{array}$ & & & & & \\
\hline $\begin{array}{l}\text { I have a computer or a digital phone that allows } \\
\text { me to receive text messages, alerts, and email } \\
\text { from my doctor. }\end{array}$ & & & & & \\
\hline $\begin{array}{l}\text { I have a health care team and I can reach out to } \\
\text { anyone in my care team or the designated contact } \\
\text { person in my care team anytime via email, phone, } \\
\text { or text messages }\end{array}$ & & & & & \\
\hline $\begin{array}{l}\text { I don't have a care team but I can reach my doctor } \\
\text { or the nurse when I have questions related to my }\end{array}$ & & & & & \\
\hline
\end{tabular}




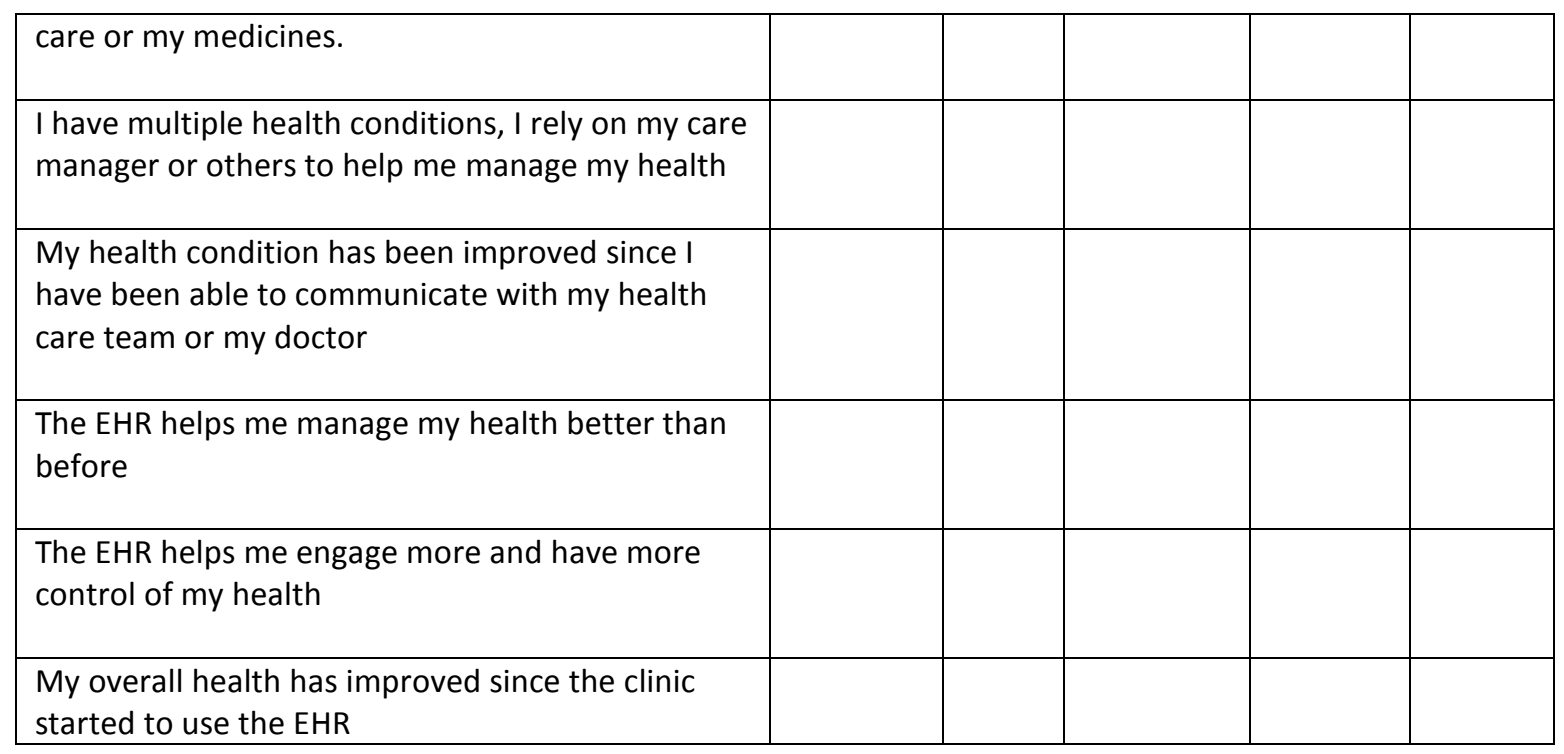




\section{Appendix E: Letter of invitation- Main study}

EHR and underserved patients' health

Dear sir/madam,

I am currently enrolled in a research project addressing the impact of the EHR on patients attending underserved area health clinics or community health centers. The project examines how the EHR improves the health of the underserved community. The study is performed as a partial fulfillment of the requirement for my $\mathrm{PhD}$ degree in health services with a focus in health care administration at Walden University under the supervision of Dr. Ronald Hudak.

Your participation in this project will provide useful information on this topic. You are required to be between the ages of 18 and up to be qualified for participation. You will need to complete the enclosed questionnaire; that should take about 20 to 30 minutes. The questionnaire includes some background information, health services information, and a satisfaction survey. Your participation is strictly voluntary and will not involve any harm. You may also decide to stop at any time or decline your participation for any reasons at any time during the study. The data collected from this project are confidential and will be used only for the research purposes. The information from this questionnaire is anonymous and will remain as such throughout the project.

I do thank you for your time and assistance.

Mirna Lexima

Tel : 571-332-8353

Email: mirna.lexima@waldenu.edu 


\title{
Appendix F: Research Survey instrument
}

\author{
Wholistic Health Integration Power Tool
}

\section{Background characteristics}

Please circle the box that best describes you or your needs

\begin{tabular}{|c|c|c|c|c|c|c|c|}
\hline Race & Black & White & $\begin{array}{l}\text { Hispanic/Lati } \\
\text { no/ or } \\
\text { Spanish } \\
\text { origin }\end{array}$ & Asian & & & \\
\hline Age & $18-29$ & $30-49$ & $50-69$ & $70-89$ & $90+$ & & \\
\hline Sex & Male & Female & & & & & \\
\hline Income & Working & Not working & homeless & $\begin{array}{l}\text { Live with } \\
\text { family/frie } \\
\text { nd }\end{array}$ & & & \\
\hline Status & Citizen & $\begin{array}{l}\text { Documente } \\
\text { d resident }\end{array}$ & $\begin{array}{l}\text { Non- } \\
\text { documented } \\
\text { resident }\end{array}$ & $\begin{array}{l}\text { Church } \\
\text { affiliation }\end{array}$ & $\begin{array}{l}\text { No church } \\
\text { affiliation }\end{array}$ & & \\
\hline $\begin{array}{l}\text { Insurance } \\
\text { coverage }\end{array}$ & Private & Medicaid & Medicare & $\begin{array}{l}\mathrm{HMO} / \mathrm{CHIP} \\
\mathrm{S}\end{array}$ & Self-pay & Charity & $\begin{array}{l}\text { othe } \\
r\end{array}$ \\
\hline $\begin{array}{l}\text { Disease/diagn } \\
\text { osis }\end{array}$ & 1 & $1-2$ & $2-3$ & $4-5$ & $5-6$ & $7+$ & \\
\hline $\begin{array}{l}\text { Exposure/habi } \\
\mathrm{t}\end{array}$ & $\begin{array}{l}\text { Domesti } \\
\text { c } \\
\text { violence }\end{array}$ & $\begin{array}{l}\text { Substance } \\
\text { abuse }\end{array}$ & $\begin{array}{l}\text { Street } \\
\text { violence }\end{array}$ & Tobacco & Alcohol & $\begin{array}{l}\text { Illegal } \\
\text { drugs }\end{array}$ & \\
\hline Transportation & Own car & $\begin{array}{l}\text { Public } \\
\text { transportati } \\
\text { on }\end{array}$ & $\begin{array}{l}\text { Special } \\
\text { transportatio } \\
\mathrm{n}\end{array}$ & $\begin{array}{l}\text { By } \\
\text { arrangeme } \\
\text { nt only }\end{array}$ & $\begin{array}{l}\text { Walk to } \\
\text { appointme } \\
\text { nt }\end{array}$ & & \\
\hline $\begin{array}{l}\text { Digitalization } \\
\text { own /access }\end{array}$ & $\begin{array}{l}\text { Comput } \\
\text { er }\end{array}$ & Cell phone & Laptop & $\begin{array}{l}\text { Internet } \\
\text { service }\end{array}$ & Email & $\begin{array}{l}\text { Text } \\
\text { messag } \\
\text { es }\end{array}$ & $\begin{array}{l}\text { non } \\
\text { e }\end{array}$ \\
\hline
\end{tabular}

\section{Health service characteristics}

Preventive health services available and last time used. Please put an $\mathbf{X}$ if service is available and the last time you used these health services

\begin{tabular}{|l|l|l|l|l|l|l|l|}
\hline Health services & Available & $\begin{array}{l}\text { Not- } \\
\text { available }\end{array}$ & $\begin{array}{l}\text { Used } \\
\text { within a } \\
\text { year }\end{array}$ & $\begin{array}{l}\text { Over 1 } \\
\text { year }\end{array}$ & $\begin{array}{l}2 \\
\text { Years } \\
\text { ago }\end{array}$ & $\begin{array}{l}3-4 \\
\text { years } \\
\text { ago }\end{array}$ & $\begin{array}{l}5 \text { years } \\
\text { or more }\end{array}$ \\
\hline Internal Medicine & & & & & & & \\
\hline Primary care & & & & & & & \\
\hline Pediatrics & & & & & & & \\
\hline Reproductive health & & & & & & & \\
\hline Infectious disease & & & & & & & \\
\hline Mental health & & & & & & & \\
\hline Dental health & & & & & & & \\
\hline Health education & & & & & & & \\
\hline
\end{tabular}




\begin{tabular}{|l|l|l|l|l|l|l|l|}
\hline Urgent care & & & & & & & \\
\hline Immunization & & & & & & & \\
\hline Radiography & & & & & & & \\
\hline Substance abuse & & & & & & & \\
\hline $\begin{array}{l}\text { Chronic disease } \\
\text { management }\end{array}$ & & & & & & & \\
\hline
\end{tabular}

The following questions are from the SF36 Health Survey instrument used with permission from OPTUM Insight.

INSTRUCTIONS: This set of questions asks for your views about your health. This information will help keep track of how you feel and how well you are able to do your usual activities. Answer every question by marking the answer as indicated. If you are unsure about how to answer a question please give the best answer you can.

1. In general, would you say your health is: (Please tick one box.) Excellent $\square$ Very Good $\square$ Good $\square$ Fair $\square$ Poor $\square$

2. Compared to one year ago, how would you rate your health in general now? (Please tick one box.)

Much better than one year ago $\square$ Somewhat better now than one year ago $\square$ About the same as one year ago $\square$ Somewhat worse now than one year ago $\square$ Much worse now than one year ago

3. During the past 4 weeks, have you had any of the following problems with your work or other regular daily activities as a result of your physical health?

(Please circle one number on each line.) Yes (1) No (2)

3(a) Cut down on the amount of time you spent on work or other activities 12

3(b) Accomplished less than you would like 12

3(c) Were limited in the kind of work or other activities 12

3(d) Had difficulty performing the work or other activities (for example, it took extra effort) 12

4. During the past 4 weeks, have you had any of the following problems with your work or other regular daily activities as a result of any emotional problems (e.g. feeling depressed or anxious)?

(Please circle one number on each line.) Yes (1) No (2)

4(a) Cut down on the amount of time you spent on work or other activities 12

4(b) Accomplished less than you would like 12

4(c) Didn't do work or other activities as carefully as usual 12 
5. During the past 4 weeks, to what extent has your physical health or emotional problems interfered with your normal social activities with family, friends, neighbors, or groups? (Please tick one box.)

Not at all $\square$ Slightly $\square$ Moderately $\square$ Quite a bit $\square$ Extremely

6. How much physical pain have you had during the past 4 weeks? (Please tick one box.) None $\square$ Very mild $\square$ Mild $\square$ Moderate $\square$ Severe $\square$ Very Severe $\square$

7. During the past 4 weeks, how much did pain interfere with your normal work (including both work outside the home and housework)? (Please tick one box.) Not at all $\square$ A little bit $\square$ Moderately $\square$ Quite a bit $\square$ Extremely $\square$

8. During the past 4 weeks, how much of the time has your physical health or emotional problems interfered with your social activities (like visiting with friends, relatives etc.) (Please tick one box.)

All of the time $\square$ Most of the time $\square$ Some of the time $\square$ A little of the time $\square$ None of the time $\square$

9. How TRUE or FALSE is each of the following statements for you ?

(Please circle one number on each line.)

1-Definitely True $\quad$ 2- Mostly True $\quad 3$-Don't Know 4-Mostly False $\quad$ 5-Definitely False

11(a) I seem to get sick a little easier than other people 12345

11(b) I am as healthy as anybody I know 12345

11(c) I expect my health to get worse 12345

11(d) My health is excellent 12345

\section{Patient experience}

Please put an $\mathbf{X}$ where the definition matches your personal experience as a patient and customer.

\begin{tabular}{|l|l|l|l|l|l|}
\hline & $\begin{array}{l}\text { Strongly } \\
\text { agree }\end{array}$ & Agree & $\begin{array}{l}\text { Strongly } \\
\text { disagree }\end{array}$ & Disagree & Neutral \\
\hline $\begin{array}{l}\text { My experience with the health clinic has been } \\
\text { better during my last few visits }\end{array}$ & & & & & \\
\hline $\begin{array}{l}\text { I notice changes in the way the care team } \\
\text { addresses my health care needs during my last } \\
\text { few visits in the clinic. }\end{array}$ & & & & & \\
\hline $\begin{array}{l}\text { I am aware that the health center/clinic has } \\
\text { electronic medical record to help coordinate and } \\
\text { manage my care better and faster }\end{array}$ & & & & & \\
\hline
\end{tabular}




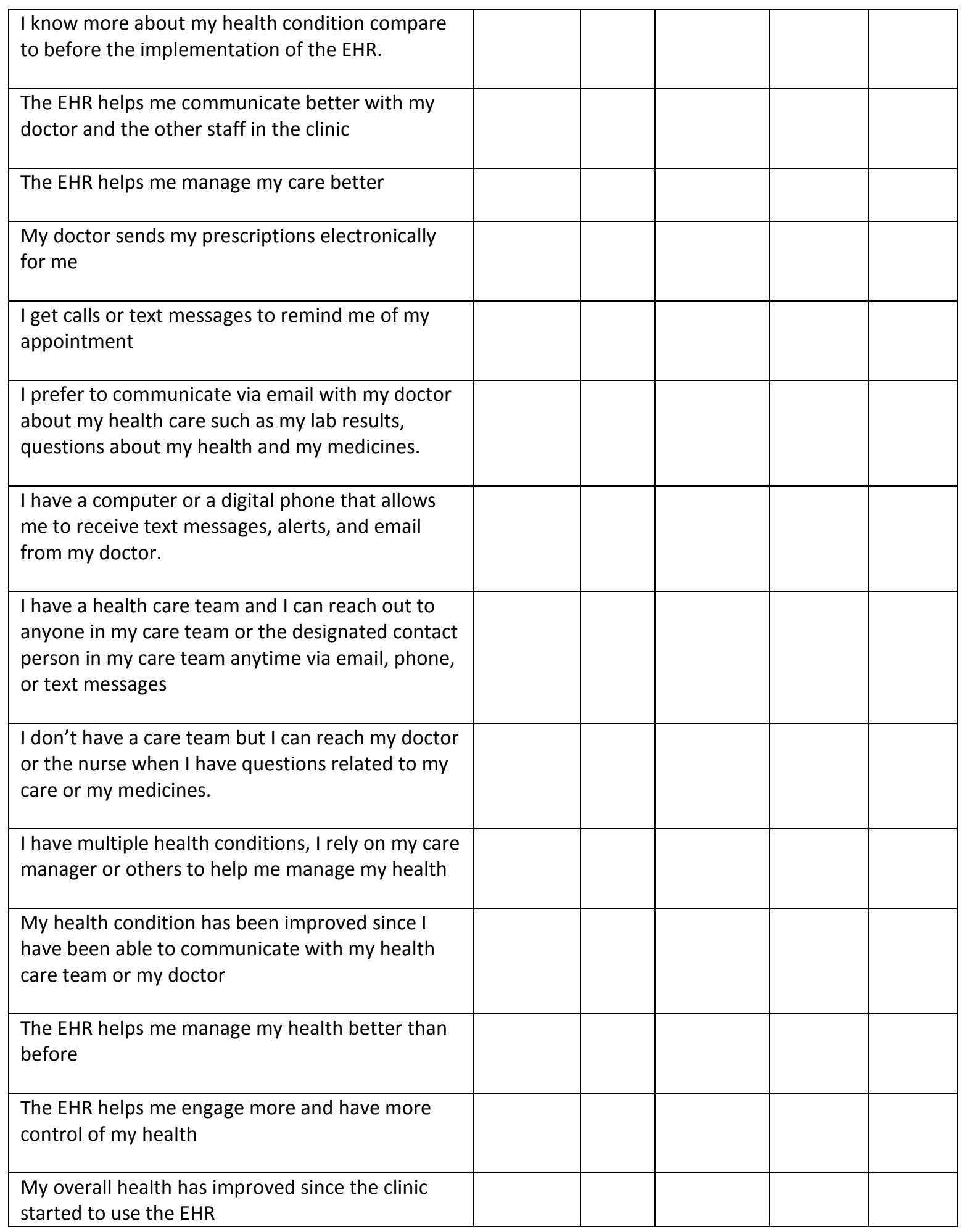




\title{
Appendix G Permission for using SF-36 survey
}

\author{
icense Number: OM021457 \\ infectiva Date: $\quad 11101 / 13$ \\ fcansee Name: Mirna Lexima \\ kensee Address: 7005 Ben Franklin Rd Springfield, VA 22150 \\ pproved Purpose: Non-commercial academic research and/or thesis - Unfunded Student
}

Study Name: Determining Underserved Patients' Perspectives on how the Electronic Health R Improves their Health

Study Type: Thesis/Dissertation Study

erapeutic Area: Wellness \& Lifestyle

yalty Fee: $\quad$ None, because this License is granted in support of the non-commercial Approved Purpose

Ier Definitions: As indicated on Appendix B "License Agreement - Details", including without limitation: Licens Surveys, Modes, Fees, Administrations, Services, Approved Languages and (if applicable) Lis Term

insee accepts and agrees to the terms of this Non-Commercial License Agreement (the "Agreement") from se of Grants and Scholarly Research (OGSR) of Optuminsight Life Sciences, Inc. (f/k/a QualityMe rporated) ("Optuminsight") as of the Effective Date.

ect to the terms of this Agreement, including the Optuminsight Non-Commercial License Terms and Conditi thed as Appendix A: Optuminsight grants to Licensee, and Licensee accepts, a non-exclusive, non-transfera assignable, non-sublicensable worldwide license to use, solely for the Approved Purpose and during the Lice 1. the Licensed Surveys in the authorized Modes and Approved Languages indicated on Appendix B an nister the Licensed Surveys only up to the approved number of Administrations (and to make up to such nun act reproductions of the Licensed Surveys necessary to support such Administrations) in any combination of fic Licensed Surveys and Approved Languages and Modes and to use any related software provider ninsight.

alized terms used in this Agreement shall have the meanings assigned to them above, or in Appendices $A$ ched hereto. Appendices A and B attached hereto are incorporated into and made a part of this Agreeme poses.

UTED, as of the Effective Date, by the duly authorized representatives as set forth below.

Insight Life Sciences, Inc. insight]

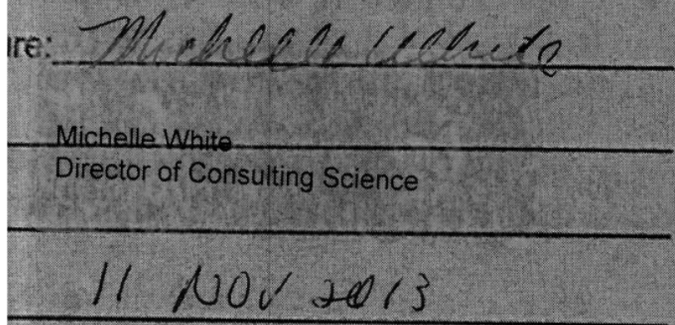

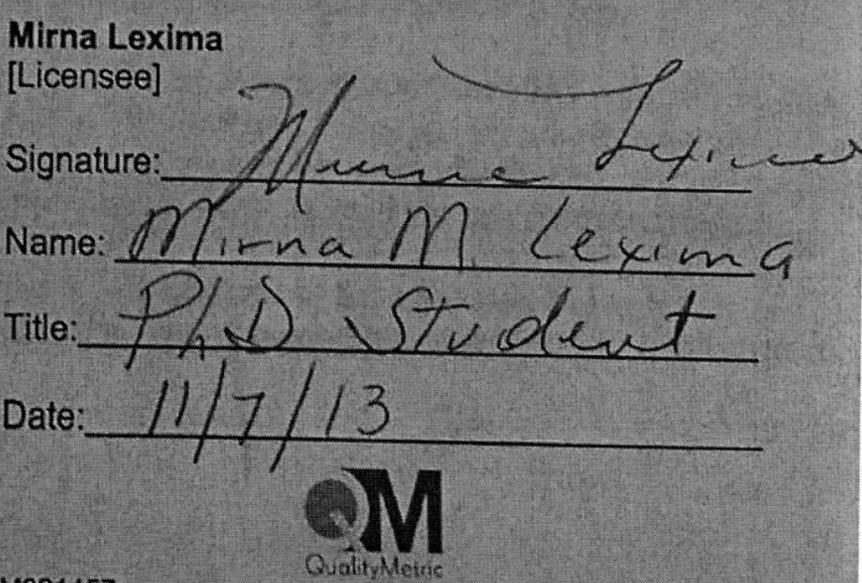

an Optumlnsight company 


\section{Appendix H: Descriptive statistics}

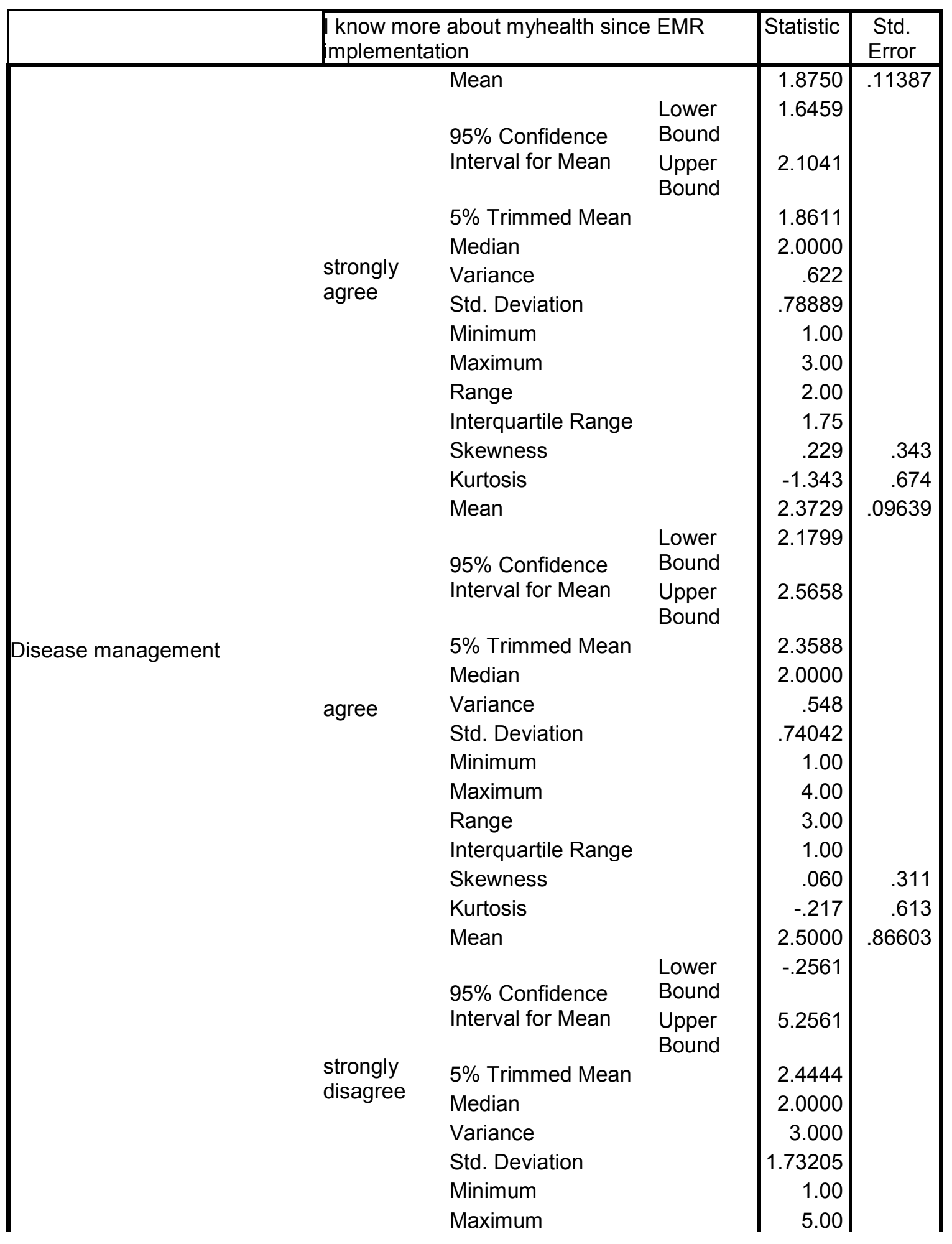




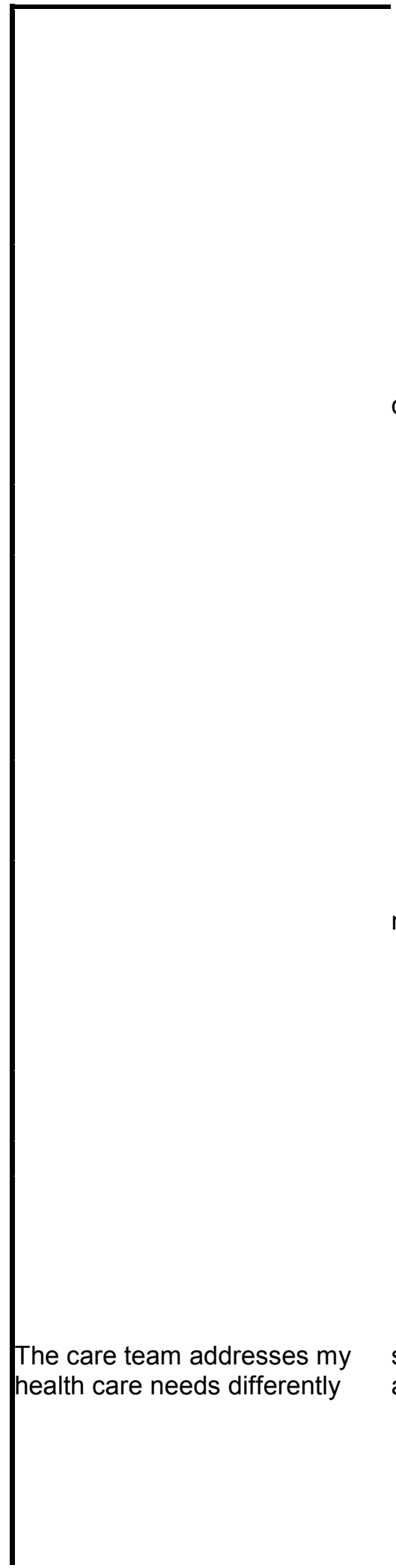

$\begin{array}{ll} & \text { Range } \\ \text { Interquartile Range } & \text { Skewness } \\ & \text { Kurtosis } \\ & \text { Mean } \\ & 95 \% \text { Confidence } \\ \text { Interval for Mean } \\ \\ \\ \text { 5\% Trimmed Mean } \\ \text { Median } \\ \text { Variance } \\ \text { Std. Deviation } \\ \text { Minimum } \\ \text { Maximum } \\ \text { Range } \\ \text { Interquartile Range } \\ \text { Skewness } \\ \text { Kurtosis } \\ \text { Mean }\end{array}$

\begin{tabular}{|c|c|c|}
\hline & 4.00 & \\
\hline & 3.00 & \\
\hline & 1.540 & 1.014 \\
\hline & 2.889 & 2.619 \\
\hline & 1.8333 & .16667 \\
\hline $\begin{array}{l}\text { Lower } \\
\text { Bound }\end{array}$ & 1.4665 & \\
\hline Upper & 2.2002 & \\
\hline Bound & 18148 & \\
\hline & $\begin{array}{l}1.8140 \\
2.0000\end{array}$ & \\
\hline & .333 & \\
\hline & .57735 & \\
\hline & 1.00 & \\
\hline & 3.00 & \\
\hline & 2.00 & \\
\hline & .75 & \\
\hline & -.063 & .637 \\
\hline & .655 & 1.232 \\
\hline & 2.1724 & .13195 \\
\hline $\begin{array}{l}\text { Lower } \\
\text { Bound }\end{array}$ & 1.9021 & \\
\hline Upper & 2.4427 & \\
\hline & 2.1533 & \\
\hline & 2.0000 & \\
\hline & .505 & \\
\hline & .71058 & \\
\hline & 1.00 & \\
\hline & 4.00 & \\
\hline & 3.00 & \\
\hline & 1.00 & \\
\hline & .378 & .434 \\
\hline & .471 & .845 \\
\hline & 1.9792 & .22179 \\
\hline Lower & 1.5330 & \\
\hline Bound & & \\
\hline Upper & 2.4254 & \\
\hline Bound & 1.8657 & \\
\hline & 1.0000 & \\
\hline & 2.361 & \\
\hline & 1.53664 & \\
\hline & 1.00 & \\
\hline & 5.00 & \\
\hline & 4.00 & \\
\hline & 1.00 & \\
\hline
\end{tabular}




\begin{tabular}{|c|c|c|c|c|}
\hline & Skewness & & 1.358 & .343 \\
\hline & Kurtosis & & .168 & .674 \\
\hline & Mean & & 2.2203 & 14316 \\
\hline & & Lower & 1.9338 & \\
\hline & 95\% Confidence & Bound & & \\
\hline & Interval for Mean & Upper & 2.5069 & \\
\hline & $5 \%$ Trimmed Mean & & 2.1337 & \\
\hline & Median & & 2.0000 & \\
\hline agree & Variance & & 1.209 & \\
\hline & Std. Deviation & & 1.09965 & \\
\hline & Minimum & & 1.00 & \\
\hline & Maximum & & 5.00 & \\
\hline & Range & & 4.00 & \\
\hline & Interquartile Range & & .00 & \\
\hline & Skewness & & 1.637 & .311 \\
\hline & Kurtosis & & 2.081 & .613 \\
\hline & Mean & & 2.7500 & 85391 \\
\hline & & Lower & .0325 & \\
\hline & 95\% Confidence & Bound & & \\
\hline & Interval for Mean & Upper & 5.4675 & \\
\hline & $5 \%$ Trimmed Mean & & 2.7222 & \\
\hline & Median & & 2.5000 & \\
\hline $\begin{array}{l}\text { strongly } \\
\text { disagree }\end{array}$ & Variance & & 2.917 & \\
\hline & Std. Deviation & & 1.70783 & \\
\hline & Minimum & & 1.00 & \\
\hline & Maximum & & 5.00 & \\
\hline & Range & & 4.00 & \\
\hline & Interquartile Range & & 3.25 & \\
\hline & Skewness & & .753 & 1.014 \\
\hline & Kurtosis & & .343 & 2.619 \\
\hline & Mean & & 3.8333 & .29729 \\
\hline & & Lower & 3.1790 & \\
\hline & 95\% Confidence & Bound & & \\
\hline & Interval for Mean & $\begin{array}{l}\text { Upper } \\
\text { Bound }\end{array}$ & 4.4877 & \\
\hline & $5 \%$ Trimmed Mean & & 3.8704 & \\
\hline & Median & & 4.0000 & \\
\hline disagree & Variance & & 1.061 & \\
\hline & Std. Deviation & & 1.02986 & \\
\hline & Minimum & & 2.00 & \\
\hline & Maximum & & 5.00 & \\
\hline & Range & & 3.00 & \\
\hline & Interquartile Range & & 1.50 & \\
\hline & Skewness & & -.810 & .637 \\
\hline & Kurtosis & & -.022 & 1.232 \\
\hline & Mean & & 4.0000 & .24815 \\
\hline & & Lower & 3.4917 & \\
\hline neutral & 95\% Confidence & Bound & & \\
\hline & Interval for Mean & $\begin{array}{l}\text { Upper } \\
\text { Bound }\end{array}$ & 4.5083 & \\
\hline
\end{tabular}




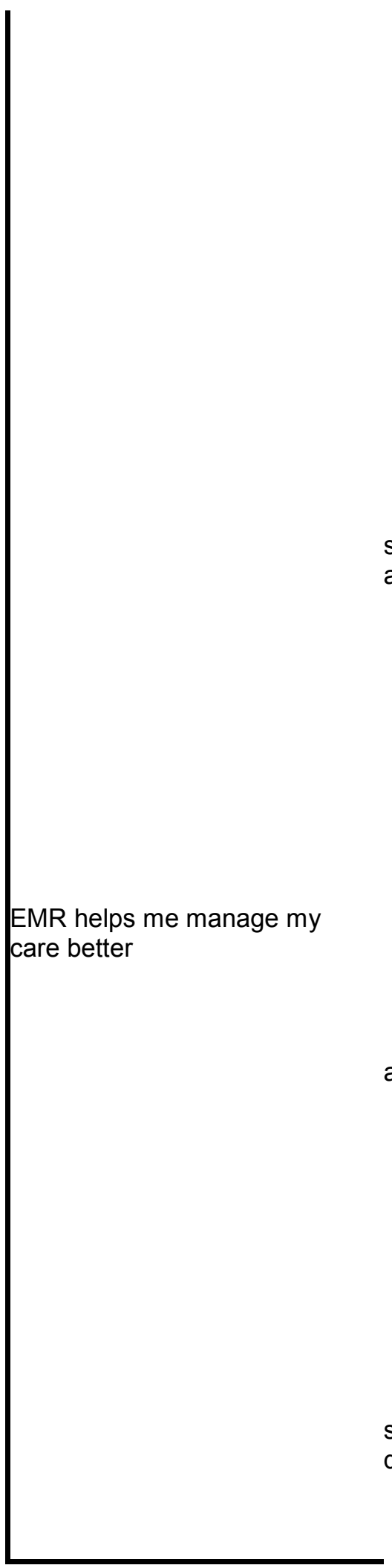

5\% Trimmed Mean

Median

Variance

Std. Deviation

Minimum

Maximum

Range

Interquartile Range

Skewness

Kurtosis

Mean

strongly

agree

strongly

disagree
95\% Confidence

Interval for Mean

5\% Trimmed Mean

Median

Variance

Std. Deviation

Minimum

Maximum

Range

Interquartile Range

Skewness

Kurtosis

Mean

95\% Confidence

Interval for Mean

$5 \%$ Trimmed Mean

Median

Variance

Std. Deviation

Minimum

Maximum

Range

Interquartile Range

Skewness

Kurtosis

Mean

95\% Confidence Interval for Mean

5\% Trimmed Mean

Median

\begin{tabular}{|c|c|}
\hline 4.0939 & \\
\hline 5.0000 & \\
\hline 1.786 & \\
\hline 1.33631 & \\
\hline 1.00 & \\
\hline 5.00 & \\
\hline 4.00 & \\
\hline 2.00 & \\
\hline-.868 & .434 \\
\hline-.824 & .845 \\
\hline 1.5208 & 17101 \\
\hline 1.1768 & \\
\hline 1.8649 & \\
\hline 1.3565 & \\
\hline 1.0000 & \\
\hline 1.404 & \\
\hline 1.18483 & \\
\hline 1.00 & \\
\hline 5.00 & \\
\hline 4.00 & \\
\hline .00 & \\
\hline 2.391 & .343 \\
\hline 4.489 & .674 \\
\hline 2.3220 & .15749 \\
\hline 2.0068 & \\
\hline 2.6373 & \\
\hline 2.2467 & \\
\hline 2.0000 & \\
\hline 1.463 & \\
\hline 1.20974 & \\
\hline 1.00 & \\
\hline 5.00 & \\
\hline 4.00 & \\
\hline .00 & \\
\hline 1.401 & .311 \\
\hline .931 & .613 \\
\hline 4.5000 & .50000 \\
\hline 2.9088 & \\
\hline 6.0912 & \\
\hline 4.5556 & \\
\hline 5.0000 & \\
\hline
\end{tabular}




\begin{tabular}{|c|c|c|c|c|}
\hline & Variance & & 1.000 & \\
\hline & Std. Deviation & & 1.00000 & \\
\hline & Minimum & & 3.00 & \\
\hline & Maximum & & 5.00 & \\
\hline & Range & & 2.00 & \\
\hline & Interquartile Range & & 1.50 & \\
\hline & Skewness & & -2.000 & 1.014 \\
\hline & Kurtosis & & 4.000 & 2.619 \\
\hline & Mean & & 3.8333 & .34451 \\
\hline & & Lower & 3.0751 & \\
\hline & 95\% Confidence & Bound & & \\
\hline & Interval for Mean & $\begin{array}{l}\text { Upper } \\
\text { Bound }\end{array}$ & 4.5916 & \\
\hline & $5 \%$ Trimmed Mean & & 3.9259 & \\
\hline & Median & & 4.0000 & \\
\hline disagree & Variance & & 1.424 & \\
\hline & Std. Deviation & & 1.19342 & \\
\hline & Minimum & & 1.00 & \\
\hline & Maximum & & 5.00 & \\
\hline & Range & & 4.00 & \\
\hline & Interquartile Range & & .75 & \\
\hline & Skewness & & -1.547 & .637 \\
\hline & Kurtosis & & 2.283 & 1.232 \\
\hline & Mean & & 3.9310 & .28044 \\
\hline & & Lower & 3.3566 & \\
\hline & 95\% Confidence & Bound & & \\
\hline & Interval for Mean & $\begin{array}{l}\text { Upper } \\
\text { Bound }\end{array}$ & 4.5055 & \\
\hline & $5 \%$ Trimmed Mean & & 4.0345 & \\
\hline & Median & & 5.0000 & \\
\hline neutral & Variance & & 2.281 & \\
\hline & Std. Deviation & & 1.51023 & \\
\hline & Minimum & & 1.00 & \\
\hline & Maximum & & 5.00 & \\
\hline & Range & & 4.00 & \\
\hline & Interquartile Range & & 3.00 & \\
\hline & Skewness & & -.877 & .434 \\
\hline & Kurtosis & & -1.066 & .845 \\
\hline
\end{tabular}

a. Disease management is constant when I know more about my health since EMR implementation $=11.00$. It has been omitted.

b. The care team addresses my health care needs differently is constant when I know more about myhealth since EMR implementation $=11.00$. It has been omitted.

c. EMR helps me manage my care better is constant when I know more about my health since EMR implementation $=11.00$. It has been omitted. 


\section{Appendix I: Table 1}

\begin{tabular}{|c|c|c|c|}
\hline \multicolumn{4}{|c|}{\begin{tabular}{|c|c|} 
Correlations \\
\end{tabular}} \\
\hline \multirow[t]{24}{*}{ Pearson Correlation } & \multirow[t]{6}{*}{$\begin{array}{l}\text { EMR helps me manage my care } \\
\text { better }\end{array}$} & $\begin{array}{l}\text { EMR helps me manage } \\
\text { my care better }\end{array}$ & 1.000 \\
\hline & & $\begin{array}{l}\text { The care team addresses } \\
\text { my health care needs } \\
\text { differently }\end{array}$ & .317 \\
\hline & & $\begin{array}{l}\text { I know more about my } \\
\text { health since EMR } \\
\text { implementation }\end{array}$ & .658 \\
\hline & & $\begin{array}{l}\text { I communicate better with } \\
\text { my health care team }\end{array}$ & .706 \\
\hline & & $\begin{array}{l}\text { My prescriptions are done } \\
\text { electronically }\end{array}$ & .454 \\
\hline & & $\begin{array}{l}\text { I get texts or email } \\
\text { messages to remind me } \\
\text { my appointments }\end{array}$ & .348 \\
\hline & \multirow[t]{6}{*}{$\begin{array}{l}\text { The care team addresses my health } \\
\text { care needs differently }\end{array}$} & $\begin{array}{l}\text { EMR helps me manage } \\
\text { my care better }\end{array}$ & .317 \\
\hline & & $\begin{array}{l}\text { The care team addresses } \\
\text { my health care needs } \\
\text { differently }\end{array}$ & 1.000 \\
\hline & & $\begin{array}{l}\text { I know more about my } \\
\text { health since EMR } \\
\text { implementation }\end{array}$ & .439 \\
\hline & & $\begin{array}{l}\text { I communicate better with } \\
\text { my health care team }\end{array}$ & .410 \\
\hline & & $\begin{array}{l}\text { My prescriptions are done } \\
\text { electronically }\end{array}$ & .300 \\
\hline & & $\begin{array}{l}\text { I get texts or email } \\
\text { messages to remind me } \\
\text { my appointments }\end{array}$ & .324 \\
\hline & \multirow[t]{6}{*}{$\begin{array}{l}\text { I know more about my health since } \\
\text { EMR implementation }\end{array}$} & $\begin{array}{l}\text { EMR helps me manage } \\
\text { my care better }\end{array}$ & .658 \\
\hline & & $\begin{array}{l}\text { The care team addresses } \\
\text { my health care needs } \\
\text { differently }\end{array}$ & .439 \\
\hline & & $\begin{array}{l}\text { I know more about my } \\
\text { health since EMR } \\
\text { implementation }\end{array}$ & 1.000 \\
\hline & & $\begin{array}{l}\text { I communicate better with } \\
\text { my health care team }\end{array}$ & .522 \\
\hline & & $\begin{array}{l}\text { My prescriptions are done } \\
\text { electronically }\end{array}$ & .358 \\
\hline & & $\begin{array}{l}\text { I get texts or email } \\
\text { messages to remind me } \\
\text { my appointments }\end{array}$ & .296 \\
\hline & \multirow[t]{6}{*}{$\begin{array}{l}\text { I communicate better with my health } \\
\text { care team }\end{array}$} & $\begin{array}{l}\text { EMR helps me manage } \\
\text { my care better }\end{array}$ & .706 \\
\hline & & $\begin{array}{l}\text { The care team addresses } \\
\text { my health care needs } \\
\text { differently }\end{array}$ & .410 \\
\hline & & $\begin{array}{l}\text { I know more about my } \\
\text { health since EMR } \\
\text { implementation }\end{array}$ & .522 \\
\hline & & $\begin{array}{l}\text { I communicate better with } \\
\text { my health care team }\end{array}$ & 1.000 \\
\hline & & $\begin{array}{l}\text { My prescriptions are done } \\
\text { electronically }\end{array}$ & .540 \\
\hline & & $\begin{array}{l}\text { I get texts or email } \\
\text { messages to remind me }\end{array}$ & .427 \\
\hline
\end{tabular}




\begin{tabular}{|c|c|c|c|}
\hline & & my appointments & \\
\hline & $\begin{array}{l}\text { My prescriptions are done } \\
\text { electronically }\end{array}$ & $\begin{array}{l}\text { EMR helps me manage } \\
\text { my care better }\end{array}$ & .454 \\
\hline & & $\begin{array}{l}\text { The care team addresses } \\
\text { my health care needs } \\
\text { differently }\end{array}$ & .300 \\
\hline & & $\begin{array}{l}\text { I know more about my } \\
\text { health since EMR } \\
\text { implementation }\end{array}$ & .358 \\
\hline & & $\begin{array}{l}\text { I communicate better with } \\
\text { my health care team }\end{array}$ & .540 \\
\hline & & $\begin{array}{l}\text { My prescriptions are done } \\
\text { electronically }\end{array}$ & 1.000 \\
\hline & & $\begin{array}{l}\text { I get texts or email } \\
\text { messages to remind me } \\
\text { my appointments }\end{array}$ & .561 \\
\hline & $\begin{array}{l}\text { I get texts or email messages to } \\
\text { remind me my appointments }\end{array}$ & $\begin{array}{l}\text { EMR helps me manage } \\
\text { my care better }\end{array}$ & .348 \\
\hline & & $\begin{array}{l}\text { The care team addresses } \\
\text { my health care needs } \\
\text { differently }\end{array}$ & .324 \\
\hline & & $\begin{array}{l}\text { I know more about my } \\
\text { health since EMR } \\
\text { implementation }\end{array}$ & .296 \\
\hline & & $\begin{array}{l}\text { I communicate better with } \\
\text { my health care team }\end{array}$ & .427 \\
\hline & & $\begin{array}{l}\text { My prescriptions are done } \\
\text { electronically }\end{array}$ & .561 \\
\hline & & $\begin{array}{l}\text { I get texts or email } \\
\text { messages to remind me } \\
\text { my appointments }\end{array}$ & 1.000 \\
\hline Sig. (1-tailed) & $\begin{array}{l}\text { EMR helps me manage my care } \\
\text { better }\end{array}$ & $\begin{array}{l}\text { EMR helps me manage } \\
\text { my care better }\end{array}$ & . \\
\hline & & $\begin{array}{l}\text { The care team addresses } \\
\text { my health care needs } \\
\text { differently }\end{array}$ & .000 \\
\hline & & $\begin{array}{l}\text { I know more about my } \\
\text { health since EMR } \\
\text { implementation }\end{array}$ & .000 \\
\hline & & $\begin{array}{l}\text { I communicate better with } \\
\text { my health care team }\end{array}$ & .000 \\
\hline & & $\begin{array}{l}\text { My prescriptions are done } \\
\text { electronically }\end{array}$ & .000 \\
\hline & & $\begin{array}{l}\text { I get texts or email } \\
\text { messages to remind me } \\
\text { my appointments }\end{array}$ & .000 \\
\hline & $\begin{array}{l}\text { The care team addresses my health } \\
\text { care needs differently }\end{array}$ & $\begin{array}{l}\text { EMR helps me manage } \\
\text { my care better }\end{array}$ & .000 \\
\hline & & $\begin{array}{l}\text { The care team addresses } \\
\text { my health care needs } \\
\text { differently }\end{array}$ & . \\
\hline & & $\begin{array}{l}\text { I know more about my } \\
\text { health since EMR } \\
\text { implementation }\end{array}$ & .000 \\
\hline & & $\begin{array}{l}\text { I communicate better with } \\
\text { my health care team }\end{array}$ & .000 \\
\hline & & $\begin{array}{l}\text { My prescriptions are done } \\
\text { electronically }\end{array}$ & .000 \\
\hline & & $\begin{array}{l}\text { I get texts or email } \\
\text { messages to remind me } \\
\text { my appointments }\end{array}$ & .000 \\
\hline & $\begin{array}{l}\text { I know more about my health since } \\
\text { EMR implementation }\end{array}$ & $\begin{array}{l}\text { EMR helps me manage } \\
\text { my care better }\end{array}$ & .000 \\
\hline & & The care team addresses & .000 \\
\hline
\end{tabular}




\begin{tabular}{|c|c|c|c|}
\hline & & $\begin{array}{l}\text { my health care needs } \\
\text { differently }\end{array}$ & \\
\hline & & $\begin{array}{l}\text { I know more about my } \\
\text { health since EMR } \\
\text { implementation }\end{array}$ & . \\
\hline & & $\begin{array}{l}\text { I communicate better with } \\
\text { my health care team }\end{array}$ & .000 \\
\hline & & $\begin{array}{l}\text { My prescriptions are done } \\
\text { electronically }\end{array}$ & .000 \\
\hline & & $\begin{array}{l}\text { I get texts or email } \\
\text { messages to remind me } \\
\text { my appointments }\end{array}$ & .000 \\
\hline & $\begin{array}{l}\text { I communicate better with my health } \\
\text { care team }\end{array}$ & $\begin{array}{l}\text { EMR helps me manage } \\
\text { my care better }\end{array}$ & .000 \\
\hline & & $\begin{array}{l}\text { The care team addresses } \\
\text { my health care needs } \\
\text { differently }\end{array}$ & .000 \\
\hline & & $\begin{array}{l}\text { I know more about my } \\
\text { health since EMR } \\
\text { implementation }\end{array}$ & .000 \\
\hline & & $\begin{array}{l}\text { I communicate better with } \\
\text { my health care team }\end{array}$ & . \\
\hline & & $\begin{array}{l}\text { My prescriptions are done } \\
\text { electronically }\end{array}$ & .000 \\
\hline & & $\begin{array}{l}\text { I get texts or email } \\
\text { messages to remind me } \\
\text { my appointments }\end{array}$ & .000 \\
\hline & $\begin{array}{l}\text { My prescriptions are done } \\
\text { electronically }\end{array}$ & $\begin{array}{l}\text { EMR helps me manage } \\
\text { my care better }\end{array}$ & .000 \\
\hline & & $\begin{array}{l}\text { The care team addresses } \\
\text { my health care needs } \\
\text { differently }\end{array}$ & .000 \\
\hline & & $\begin{array}{l}\text { I know more about my } \\
\text { health since EMR } \\
\text { implementation }\end{array}$ & .000 \\
\hline & & $\begin{array}{l}\text { I communicate better with } \\
\text { my health care team }\end{array}$ & .000 \\
\hline & & $\begin{array}{l}\text { My prescriptions are done } \\
\text { electronically }\end{array}$ & . \\
\hline & & $\begin{array}{l}\text { I get texts or email } \\
\text { messages to remind me } \\
\text { my appointments }\end{array}$ & .000 \\
\hline & $\begin{array}{l}\text { I get texts or email messages to } \\
\text { remind me my appointments }\end{array}$ & $\begin{array}{l}\text { EMR helps me manage } \\
\text { my care better }\end{array}$ & .000 \\
\hline & & $\begin{array}{l}\text { The care team addresses } \\
\text { my health care needs } \\
\text { differently }\end{array}$ & .000 \\
\hline & & $\begin{array}{l}\text { I know more about my } \\
\text { health since EMR } \\
\text { implementation }\end{array}$ & .000 \\
\hline & & $\begin{array}{l}\text { I communicate better with } \\
\text { my health care team }\end{array}$ & .000 \\
\hline & & $\begin{array}{l}\text { My prescriptions are done } \\
\text { electronically }\end{array}$ & .000 \\
\hline & & $\begin{array}{l}\text { I get texts or email } \\
\text { messages to remind me } \\
\text { my appointments }\end{array}$ & $\cdot$ \\
\hline $\mathrm{N}$ & $\begin{array}{l}\text { EMR helps me manage my care } \\
\text { better }\end{array}$ & $\begin{array}{l}\text { EMR helps me manage } \\
\text { my care better }\end{array}$ & 155 \\
\hline & & $\begin{array}{l}\text { The care team addresses } \\
\text { my health care needs } \\
\text { differently }\end{array}$ & 155 \\
\hline & & $\begin{array}{l}\text { I know more about my } \\
\text { health since EMR }\end{array}$ & 155 \\
\hline
\end{tabular}




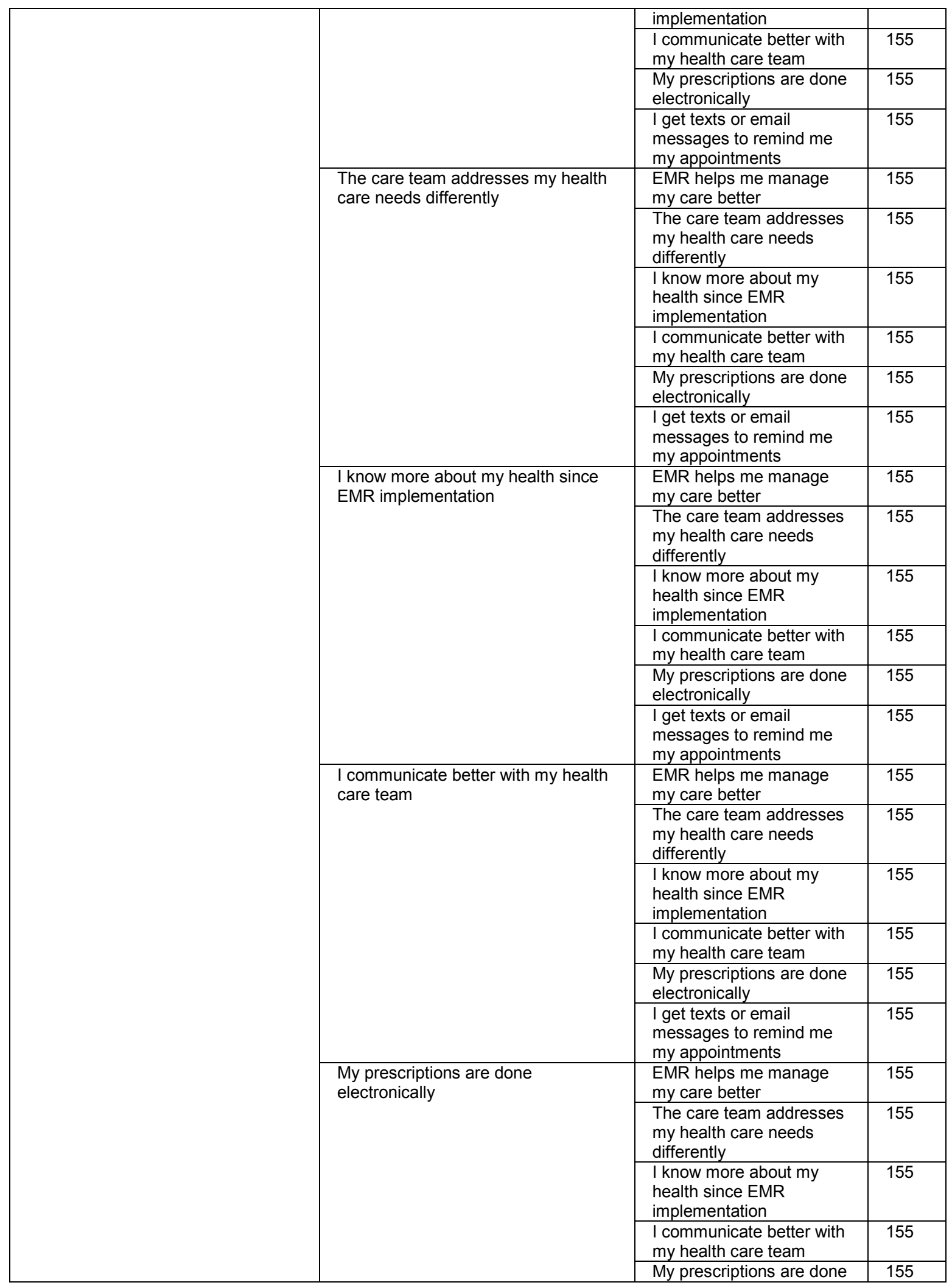




\begin{tabular}{|c|c|c|c|c|}
\hline & & & electronically & \\
\hline & & & $\begin{array}{l}\text { I get texts or email } \\
\text { messages to remind me } \\
\text { my appointments }\end{array}$ & 155 \\
\hline & & $\begin{array}{l}\text { I get texts or email messages to } \\
\text { remind me my appointments }\end{array}$ & $\begin{array}{l}\text { EMR helps me manage } \\
\text { my care better }\end{array}$ & 155 \\
\hline & & & $\begin{array}{l}\text { The care team addresses } \\
\text { my health care needs } \\
\text { differently }\end{array}$ & 155 \\
\hline & & & $\begin{array}{l}\text { I know more about my } \\
\text { health since EMR } \\
\text { implementation }\end{array}$ & 155 \\
\hline & & & $\begin{array}{l}\text { I communicate better with } \\
\text { my health care team }\end{array}$ & 155 \\
\hline & & & $\begin{array}{l}\text { My prescriptions are done } \\
\text { electronically }\end{array}$ & 155 \\
\hline & & & $\begin{array}{l}\text { I get texts or email } \\
\text { messages to remind me } \\
\text { my appointments }\end{array}$ & 155 \\
\hline $\begin{array}{l}\text { Bootstrap for } \\
\text { Pearson }\end{array}$ & Bias & $\begin{array}{l}\text { EMR helps me manage my care } \\
\text { better }\end{array}$ & $\begin{array}{l}\text { EMR helps me manage } \\
\text { my care better }\end{array}$ & .000 \\
\hline Correlations & & & $\begin{array}{l}\text { The care team addresses } \\
\text { my health care needs } \\
\text { differently }\end{array}$ & .005 \\
\hline & & & $\begin{array}{l}\text { I know more about my } \\
\text { health since EMR } \\
\text { implementation }\end{array}$ & -.011 \\
\hline & & & $\begin{array}{l}\text { I communicate better with } \\
\text { my health care team }\end{array}$ & .006 \\
\hline & & & $\begin{array}{l}\text { My prescriptions are done } \\
\text { electronically }\end{array}$ & .003 \\
\hline & & & $\begin{array}{l}\text { I get texts or email } \\
\text { messages to remind me } \\
\text { my appointments }\end{array}$ & -.001 \\
\hline & & $\begin{array}{l}\text { The care team addresses my health } \\
\text { care needs differently }\end{array}$ & $\begin{array}{l}\text { EMR helps me manage } \\
\text { my care better }\end{array}$ & .005 \\
\hline & & & $\begin{array}{l}\text { The care team addresses } \\
\text { my health care needs } \\
\text { differently }\end{array}$ & .000 \\
\hline & & & $\begin{array}{l}\text { I know more about my } \\
\text { health since EMR } \\
\text { implementation }\end{array}$ & .009 \\
\hline & & & $\begin{array}{l}\text { I communicate better with } \\
\text { my health care team }\end{array}$ & .000 \\
\hline & & & $\begin{array}{l}\text { My prescriptions are done } \\
\text { electronically }\end{array}$ & .002 \\
\hline & & & $\begin{array}{l}\text { I get texts or email } \\
\text { messages to remind me } \\
\text { my appointments }\end{array}$ & .001 \\
\hline & & $\begin{array}{l}\text { I know more about my health since } \\
\text { EMR implementation }\end{array}$ & $\begin{array}{l}\text { EMR helps me manage } \\
\text { my care better }\end{array}$ & -.011 \\
\hline & & & $\begin{array}{l}\text { The care team addresses } \\
\text { my health care needs } \\
\text { differently }\end{array}$ & .009 \\
\hline & & & $\begin{array}{l}\text { I know more about my } \\
\text { health since EMR } \\
\text { implementation }\end{array}$ & .000 \\
\hline & & & $\begin{array}{l}\text { I communicate better with } \\
\text { my health care team }\end{array}$ & .008 \\
\hline & & & $\begin{array}{l}\text { My prescriptions are done } \\
\text { electronically }\end{array}$ & .007 \\
\hline & & & $\begin{array}{l}\text { I get texts or email } \\
\text { messages to remind me } \\
\text { my appointments }\end{array}$ & .006 \\
\hline
\end{tabular}




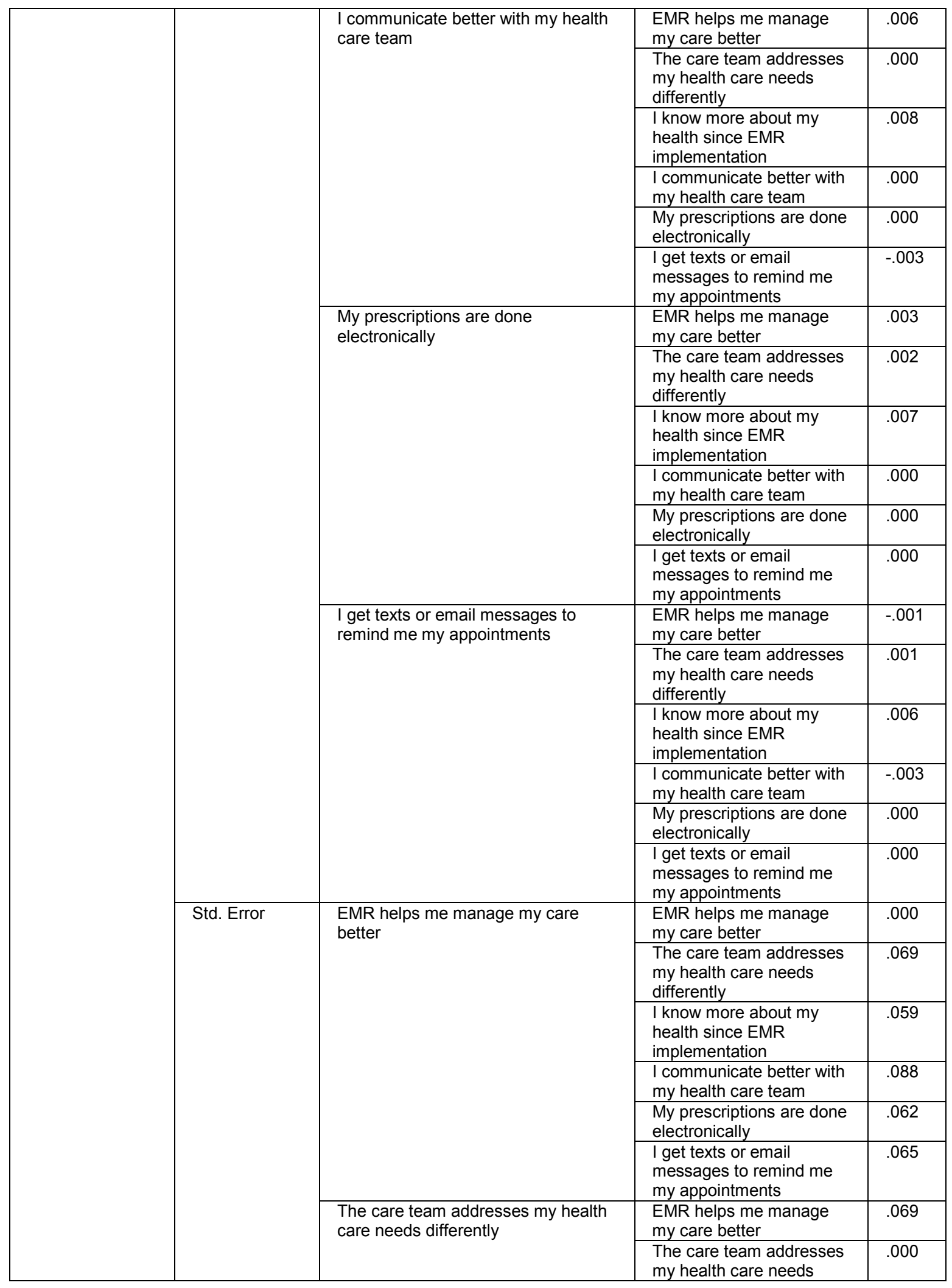




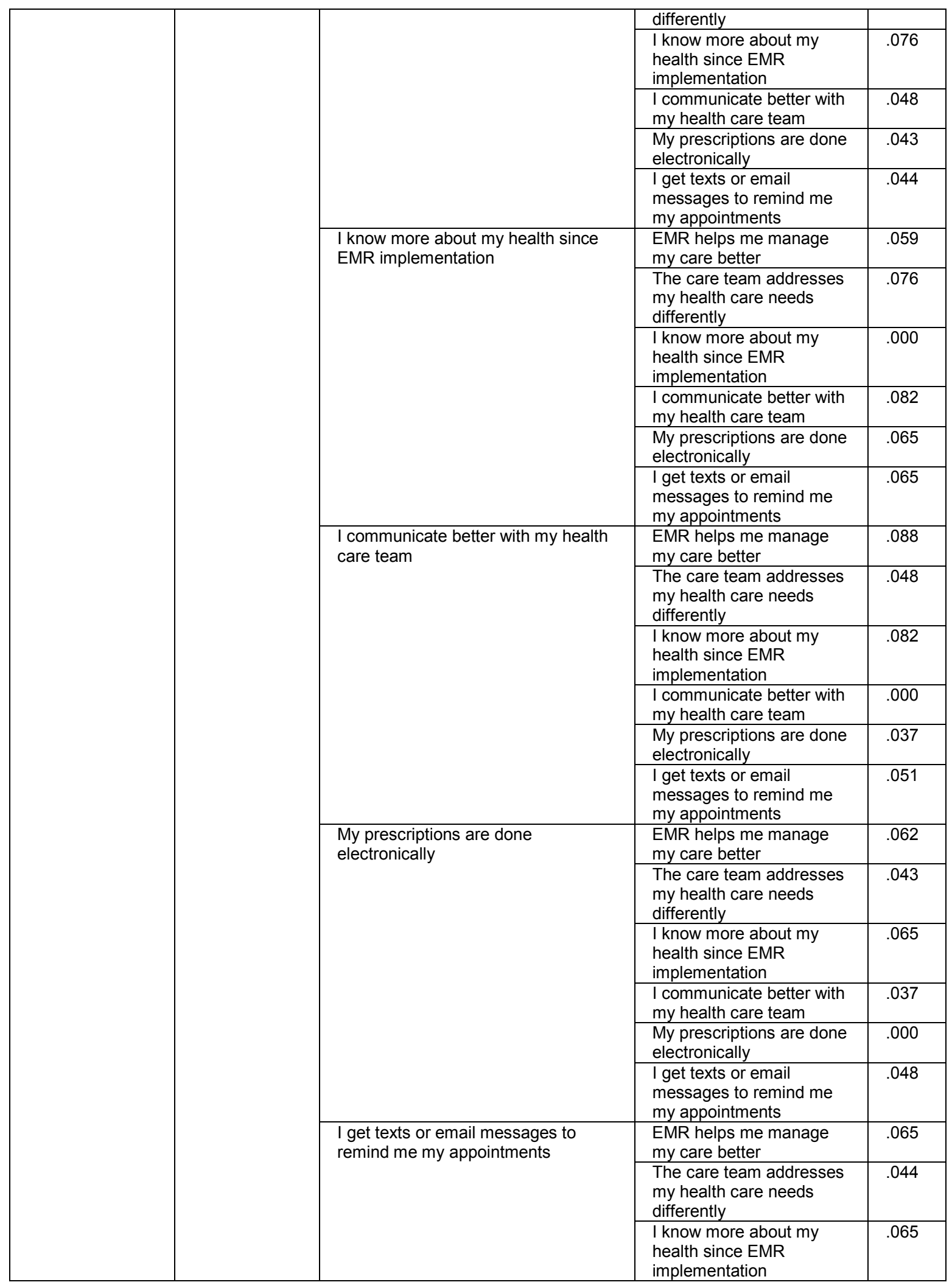




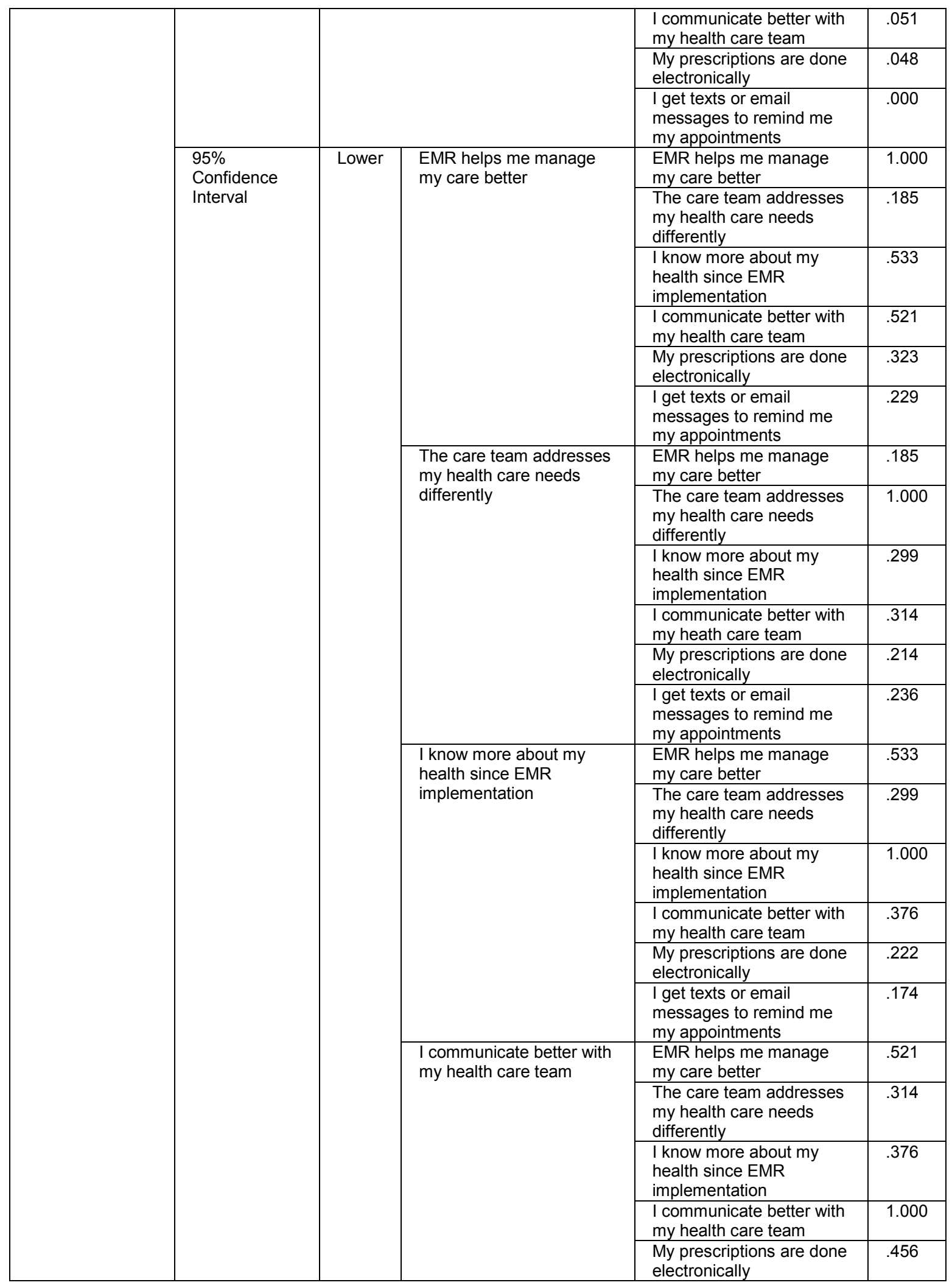




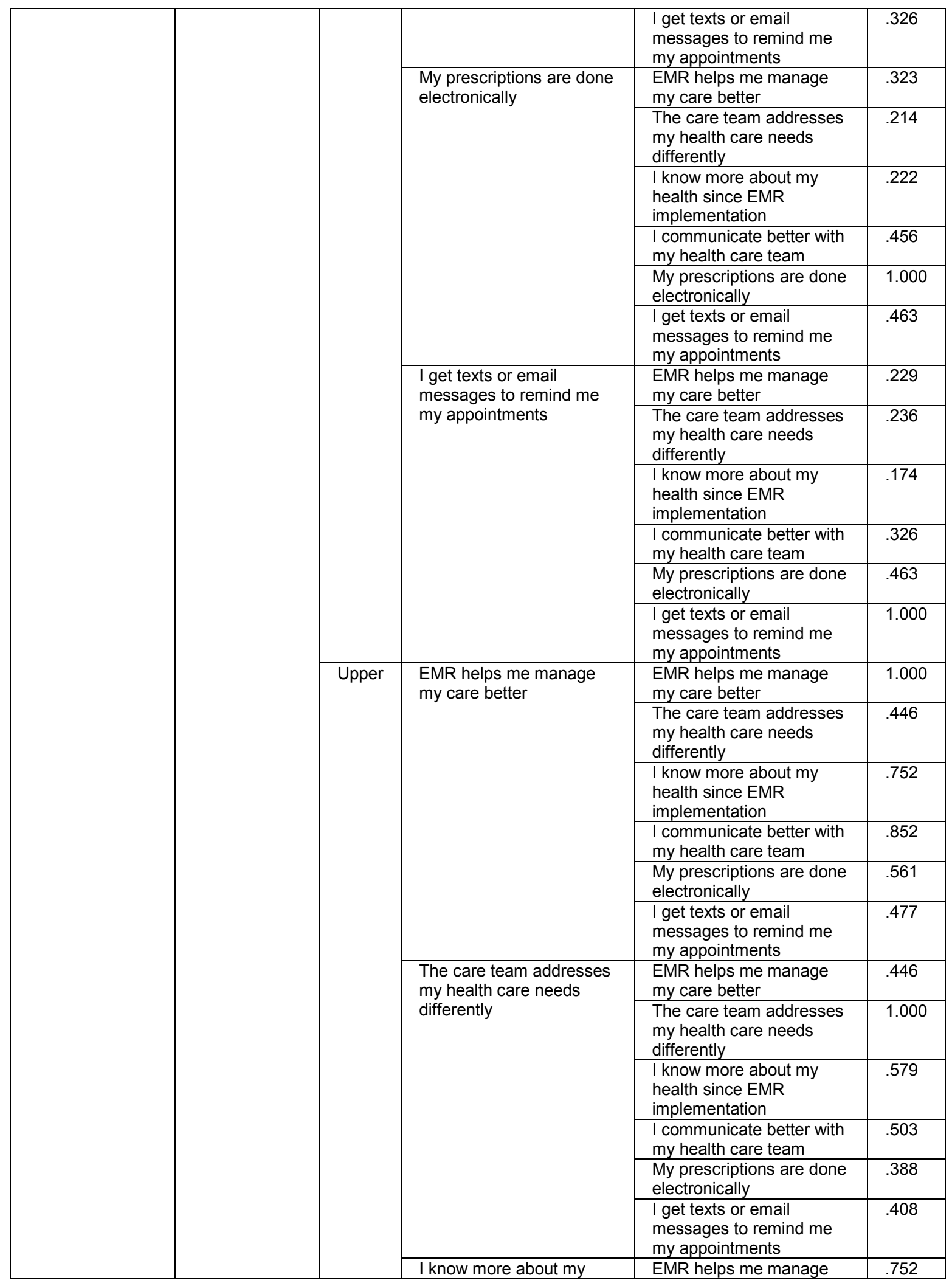




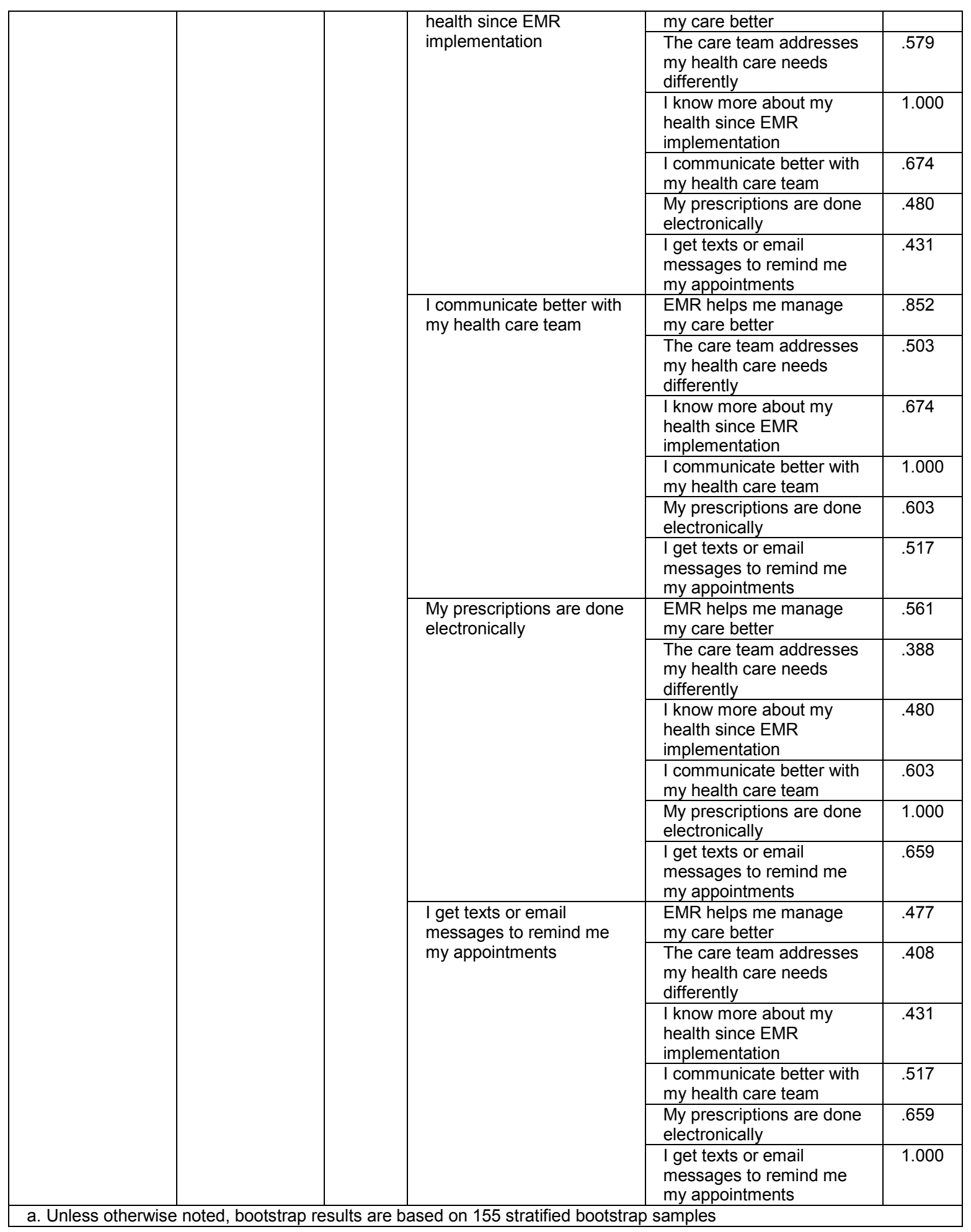




\section{Appendix J: Descriptive Statistics}

Table J1.

\begin{tabular}{|c|c|c|c|c|c|c|c|c|c|}
\hline \multicolumn{10}{|c|}{ Descriptive Statistics } \\
\hline & & \multirow[t]{2}{*}{$\mathrm{N}$} & \multirow[t]{2}{*}{ Mean } & \multirow{2}{*}{$\begin{array}{c}\text { Std. } \\
\text { Deviatio } \\
n\end{array}$} & \multirow[t]{2}{*}{$\begin{array}{l}\text { Std. } \\
\text { Error }\end{array}$} & \multicolumn{2}{|c|}{$\begin{array}{l}\text { 95\% Confidence } \\
\text { Interval for Mean }\end{array}$} & \multirow[t]{2}{*}{$\begin{array}{c}\text { Minimu } \\
\mathrm{m}\end{array}$} & \multirow[t]{2}{*}{$\begin{array}{c}\text { Maximu } \\
\mathrm{m}\end{array}$} \\
\hline & & & & & & $\begin{array}{l}\text { Lower } \\
\text { Bound }\end{array}$ & $\begin{array}{l}\text { Upper } \\
\text { Bound }\end{array}$ & & \\
\hline \multirow[t]{7}{*}{ Patient age } & $\begin{array}{l}\text { comput } \\
\text { er }\end{array}$ & 18 & $\begin{array}{r}2.555 \\
6\end{array}$ & .98352 & .23182 & 2.0665 & 3.0447 & 1.00 & 4.00 \\
\hline & $\begin{array}{l}\text { cell } \\
\text { phone }\end{array}$ & 60 & $\begin{array}{r}2.500 \\
0\end{array}$ & .89253 & .11523 & 2.2694 & 2.7306 & 1.00 & 4.00 \\
\hline & laptop & 1 & $\begin{array}{r}1.000 \\
0\end{array}$ & . & & . & . & 1.00 & 1.00 \\
\hline & $\begin{array}{l}\text { internet } \\
\text { service }\end{array}$ & 1 & $\begin{array}{r}4.000 \\
0\end{array}$ & . & & . & . & 4.00 & 4.00 \\
\hline & all & 73 & $\begin{array}{r}2.246 \\
6\end{array}$ & .87846 & .10282 & 2.0416 & 2.4515 & 1.00 & 4.00 \\
\hline & 8.00 & 2 & $\begin{array}{r}2.500 \\
0\end{array}$ & 2.12132 & $\begin{array}{r}1.5000 \\
0\end{array}$ & $\begin{array}{r}- \\
16.559 \\
3\end{array}$ & $\begin{array}{r}21.559 \\
3\end{array}$ & 1.00 & 4.00 \\
\hline & Total & $\begin{array}{r}15 \\
5\end{array}$ & $\begin{array}{r}2.387 \\
1\end{array}$ & .92151 & .07402 & 2.2409 & 2.5333 & 1.00 & 4.00 \\
\hline \multirow[t]{7}{*}{ Health insurance } & $\begin{array}{l}\text { comput } \\
\text { er }\end{array}$ & 18 & $\begin{array}{r}2.277 \\
8 \\
\end{array}$ & .95828 & .22587 & 1.8012 & 2.7543 & 1.00 & 4.00 \\
\hline & $\begin{array}{l}\text { cell } \\
\text { phone }\end{array}$ & 60 & $\begin{array}{r}2.400 \\
0\end{array}$ & 1.19604 & .15441 & 2.0910 & 2.7090 & 1.00 & 7.00 \\
\hline & laptop & 1 & $\begin{array}{r}5.000 \\
0\end{array}$ & . & & & . & 5.00 & 5.00 \\
\hline & $\begin{array}{l}\text { internet } \\
\text { service }\end{array}$ & 1 & $\begin{array}{r}3.000 \\
0 \\
\end{array}$ & . & . & . & . & 3.00 & 3.00 \\
\hline & all & 73 & $\begin{array}{r}2.054 \\
8\end{array}$ & 1.41314 & .16540 & 1.7251 & 2.3845 & 1.00 & 8.00 \\
\hline & 8.00 & 2 & $\begin{array}{r}1.000 \\
0\end{array}$ & .00000 & .00000 & 1.0000 & 1.0000 & 1.00 & 1.00 \\
\hline & Total & $\begin{array}{r}15 \\
5\end{array}$ & $\begin{array}{r}2.225 \\
8\end{array}$ & 1.29709 & .10418 & 2.0200 & 2.4316 & 1.00 & 8.00 \\
\hline \multirow{7}{*}{$\begin{array}{l}\text { Number of health } \\
\text { conditions/diagno } \\
\text { sis }\end{array}$} & $\begin{array}{l}\text { comput } \\
\text { er }\end{array}$ & 18 & $\begin{array}{r}2.833 \\
3 \\
\end{array}$ & 1.58114 & .37268 & 2.0471 & 3.6196 & 1.00 & 7.00 \\
\hline & $\begin{array}{l}\text { cell } \\
\text { phone }\end{array}$ & 60 & $\begin{array}{r}2.016 \\
7 \\
\end{array}$ & .92958 & .12001 & 1.7765 & 2.2568 & 1.00 & 5.00 \\
\hline & laptop & 1 & $\begin{array}{r}1.000 \\
0\end{array}$ & & & & . & 1.00 & 1.00 \\
\hline & $\begin{array}{l}\text { internet } \\
\text { service }\end{array}$ & 1 & $\begin{array}{r}3.000 \\
0 \\
\end{array}$ & & & & . & 3.00 & 3.00 \\
\hline & all & 73 & $\begin{array}{r}1.808 \\
2 \\
\end{array}$ & .82761 & .09686 & 1.6151 & 2.0013 & 1.00 & 4.00 \\
\hline & 8.00 & 2 & $\begin{array}{r}1.500 \\
0 \\
\end{array}$ & .70711 & .50000 & $\begin{array}{r}- \\
4.8531 \\
\end{array}$ & 7.8531 & 1.00 & 2.00 \\
\hline & Total & $\begin{array}{r}15 \\
5\end{array}$ & $\begin{array}{r}2.006 \\
5\end{array}$ & 1.02245 & .08213 & 1.8442 & 2.1687 & 1.00 & 7.00 \\
\hline \multirow[t]{2}{*}{$\begin{array}{l}\text { Disease } \\
\text { management }\end{array}$} & $\begin{array}{l}\text { comput } \\
\text { er }\end{array}$ & 18 & $\begin{array}{r}2.333 \\
3 \\
\end{array}$ & .84017 & .19803 & 1.9155 & 2.7511 & 1.00 & 4.00 \\
\hline & cell & 59 & 2.237 & .70317 & .09154 & 2.0540 & 2.4205 & 1.00 & 3.00 \\
\hline
\end{tabular}




\begin{tabular}{|c|c|c|c|c|c|c|c|c|c|}
\hline & phone & & 3 & & & & & & \\
\hline & laptop & 1 & $\begin{array}{r}3.000 \\
0\end{array}$ & & . & . & . & 3.00 & 3.00 \\
\hline & $\begin{array}{l}\text { internet } \\
\text { service }\end{array}$ & 1 & $\begin{array}{r}3.000 \\
0 \\
\end{array}$ & & . & . & . & 3.00 & 3.00 \\
\hline & all & 73 & $\begin{array}{r}1.917 \\
8 \\
\end{array}$ & .75927 & 08887 & 1.7407 & 2.0950 & 1.00 & 4.00 \\
\hline & 8.00 & 2 & $\begin{array}{r}3.500 \\
0\end{array}$ & 2.12132 & $\begin{array}{r}1.5000 \\
0\end{array}$ & $\begin{array}{r}- \\
15.559 \\
3 \\
\end{array}$ & $\begin{array}{r}22.559 \\
3\end{array}$ & 2.00 & 5.00 \\
\hline & Total & $\begin{array}{r}15 \\
4 \\
\end{array}$ & $\begin{array}{r}2.123 \\
4\end{array}$ & .79482 & .06405 & 1.9968 & 2.2499 & 1.00 & 5.00 \\
\hline \multirow{7}{*}{$\begin{array}{l}\text { The care team } \\
\text { addresses my } \\
\text { health care needs } \\
\text { differently }\end{array}$} & $\begin{array}{l}\text { comput } \\
\text { er }\end{array}$ & 18 & $\begin{array}{r}2.944 \\
4 \\
\end{array}$ & 1.55193 & .36579 & 2.1727 & 3.7162 & 1.00 & 5.00 \\
\hline & $\begin{array}{l}\text { cell } \\
\text { phone }\end{array}$ & 60 & $\begin{array}{r}2.350 \\
0 \\
\end{array}$ & 1.42407 & 18385 & 1.9821 & 2.7179 & 1.00 & 5.00 \\
\hline & laptop & 1 & $\begin{array}{r}2.000 \\
0 \\
\end{array}$ & & . & & . & 2.00 & 2.00 \\
\hline & $\begin{array}{l}\text { internet } \\
\text { service }\end{array}$ & 1 & $\begin{array}{r}5.000 \\
0 \\
\end{array}$ & & . & . & . & 5.00 & 5.00 \\
\hline & all & 73 & $\begin{array}{r}2.712 \\
3 \\
\end{array}$ & 1.60277 & 18759 & 2.3384 & 3.0863 & 1.00 & 5.00 \\
\hline & 8.00 & 2 & $\begin{array}{r}2.000 \\
0 \\
\end{array}$ & .00000 & .00000 & 2.0000 & 2.0000 & 2.00 & 2.00 \\
\hline & Total & $\begin{array}{r}15 \\
5 \\
\end{array}$ & $\begin{array}{r}2.600 \\
0\end{array}$ & 1.52724 & .12267 & 2.3577 & 2.8423 & 1.00 & 5.00 \\
\hline \multirow{7}{*}{$\begin{array}{l}\text { EMR helps me } \\
\text { manage my care } \\
\text { better }\end{array}$} & $\begin{array}{l}\text { comput } \\
\text { er }\end{array}$ & 18 & $\begin{array}{r}2.388 \\
9 \\
\end{array}$ & 1.46082 & .34432 & 1.6624 & 3.1153 & 1.00 & 5.00 \\
\hline & $\begin{array}{l}\text { cell } \\
\text { phone }\end{array}$ & 60 & $\begin{array}{r}2.433 \\
3 \\
\end{array}$ & 1.48856 & .19217 & 2.0488 & 2.8179 & 1.00 & 5.00 \\
\hline & laptop & 1 & $\begin{array}{r}2.000 \\
0 \\
\end{array}$ & & . & & . & 2.00 & 2.00 \\
\hline & $\begin{array}{l}\text { internet } \\
\text { service }\end{array}$ & 1 & $\begin{array}{r}4.000 \\
0 \\
\end{array}$ & 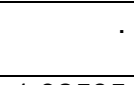 & 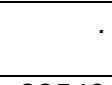 & . & . & 4.00 & 4.00 \\
\hline & all & 73 & $\begin{array}{r}2.767 \\
1 \\
\end{array}$ & 1.92585 & .22540 & 2.3178 & 3.2165 & 1.00 & 11.00 \\
\hline & 8.00 & 2 & $\begin{array}{r}3.000 \\
0\end{array}$ & 2.82843 & $\begin{array}{r}2.0000 \\
0\end{array}$ & $\begin{array}{r}- \\
22.412 \\
4\end{array}$ & $\begin{array}{r}28.412 \\
4\end{array}$ & 1.00 & 5.00 \\
\hline & Total & $\begin{array}{r}15 \\
5 \\
\end{array}$ & $\begin{array}{r}2.600 \\
0 \\
\end{array}$ & 1.70789 & 13718 & 2.3290 & 2.8710 & 1.00 & 11.00 \\
\hline \multirow{7}{*}{$\begin{array}{l}\text { My overall health } \\
\text { has improved } \\
\text { since the clinic } \\
\text { started with the } \\
\text { electronic health } \\
\text { record }\end{array}$} & $\begin{array}{l}\text { comput } \\
\text { er }\end{array}$ & 18 & $\begin{array}{r}2.888 \\
9 \\
\end{array}$ & 1.77859 & .41922 & 2.0044 & 3.7734 & 1.00 & 5.00 \\
\hline & $\begin{array}{l}\text { cell } \\
\text { phone }\end{array}$ & 60 & $\begin{array}{r}2.733 \\
3 \\
\end{array}$ & 1.47138 & 18995 & 2.3532 & 3.1134 & 1.00 & 5.00 \\
\hline & laptop & 1 & $\begin{array}{r}4.000 \\
0 \\
\end{array}$ & & . & & . & 4.00 & 4.00 \\
\hline & $\begin{array}{l}\text { internet } \\
\text { service }\end{array}$ & 1 & $\begin{array}{r}5.000 \\
0 \\
\end{array}$ & & & & . & 5.00 & 5.00 \\
\hline & all & 73 & $\begin{array}{r}3.068 \\
5 \\
\end{array}$ & 1.74267 & 20396 & 2.6619 & 3.4751 & 1.00 & 5.00 \\
\hline & 8.00 & 2 & $\begin{array}{r}1.500 \\
0 \\
\end{array}$ & .70711 & .50000 & $\begin{array}{r}- \\
4.8531\end{array}$ & 7.8531 & 1.00 & 2.00 \\
\hline & Total & $\begin{array}{r}15 \\
5 \\
\end{array}$ & $\begin{array}{r}2.916 \\
1 \\
\end{array}$ & 1.63943 & .13168 & 2.6560 & 3.1763 & 1.00 & 5.00 \\
\hline
\end{tabular}

Appendix K: One Way ANOVA One-Sample Statistics

\begin{tabular}{|l|l|l|l|}
\hline \multirow{2}{*}{ Statistic } & \multicolumn{3}{|c|}{ Bootstrap $^{\mathrm{a}}$} \\
\cline { 2 - 4 } & Bias & Std. & $95 \%$ Confidence \\
\hline
\end{tabular}




\begin{tabular}{|c|c|c|c|c|c|c|}
\hline \multirow{3}{*}{ Digitalization access } & \multirow[b]{3}{*}{$\mathrm{N}$} & \multirow[b]{3}{*}{154} & & \multirow[t]{2}{*}{ Error } & \multicolumn{2}{|c|}{ Interval } \\
\hline & & & & & \multirow[t]{2}{*}{ Lower } & \multirow[t]{2}{*}{ Upper } \\
\hline & & & & & & \\
\hline & Mean & 4.3506 & .0000 & .0000 & 4.3506 & 4.3506 \\
\hline & $\begin{array}{l}\text { Std. } \\
\text { Deviation }\end{array}$ & 2.64336 & .00000 & .00000 & 2.64336 & 2.64336 \\
\hline & $\begin{array}{l}\text { Std. Error } \\
\text { Mean }\end{array}$ & .21301 & & & & \\
\hline \multirow[t]{4}{*}{ Disease management } & $\mathrm{N}$ & 154 & & & & \\
\hline & Mean & 2.1234 & -.0014 & .0279 & 2.0714 & 2.1753 \\
\hline & $\begin{array}{l}\text { Std. } \\
\text { Deviation }\end{array}$ & .79482 & .00204 & .02123 & .74579 & .83509 \\
\hline & $\begin{array}{l}\text { Std. Error } \\
\text { Mean }\end{array}$ & .06405 & & & & \\
\hline \multirow[t]{4}{*}{ general health status } & $\mathrm{N}$ & 154 & & & & \\
\hline & Mean & 2.3312 & .0111 & .0503 & 2.2468 & 2.4486 \\
\hline & $\begin{array}{l}\text { Std. } \\
\text { Deviation }\end{array}$ & .96376 & $.00304^{-}$ & .02751 & .90056 & 1.01742 \\
\hline & $\begin{array}{l}\text { Std. Error } \\
\text { Mean }\end{array}$ & .07766 & & & & \\
\hline \multirow[t]{4}{*}{ Limitations from typical activities } & $\mathrm{N}$ & 154 & & & & \\
\hline & Mean & 2.2078 & -.0004 & .0317 & 2.1299 & 2.2727 \\
\hline & $\begin{array}{l}\text { Std. } \\
\text { Deviation }\end{array}$ & .75559 & .00114 & .01553 & .72278 & .78517 \\
\hline & $\begin{array}{l}\text { Std. Error } \\
\text { Mean }\end{array}$ & .06089 & & & & \\
\hline \multirow[t]{4}{*}{ Physical pain during the last 4 weeks } & $\mathrm{N}$ & 154 & & & & \\
\hline & Mean & 2.3117 & -.0026 & .0535 & 2.2072 & 2.4168 \\
\hline & $\begin{array}{l}\text { Std. } \\
\text { Deviation }\end{array}$ & 1.24470 & .00532 & .03803 & 1.15078 & 1.31036 \\
\hline & $\begin{array}{l}\text { Std. Error } \\
\text { Mean }\end{array}$ & .10030 & & & & \\
\hline \multirow[t]{4}{*}{ The care team addresses my health care needs differently } & $\mathrm{N}$ & 154 & & & & \\
\hline & Mean & 2.6039 & .0028 & .0860 & 2.4351 & 2.7993 \\
\hline & $\begin{array}{l}\text { Std. } \\
\text { Deviation }\end{array}$ & 1.53145 & $.00170^{-}$ & .03470 & 1.45085 & 1.60871 \\
\hline & $\begin{array}{l}\text { Std. Error } \\
\text { Mean }\end{array}$ & .12341 & & & & \\
\hline \multirow[t]{4}{*}{ The health service is better than before } & $\mathrm{N}$ & 154 & & & & \\
\hline & Mean & 2.2143 & -.0020 & .0693 & 2.0773 & 2.3831 \\
\hline & $\begin{array}{l}\text { Std. } \\
\text { Deviation }\end{array}$ & 1.43242 & $\begin{array}{r}- \\
.00686\end{array}$ & .04535 & 1.33767 & 1.51770 \\
\hline & $\begin{array}{l}\text { Std. Error } \\
\text { Mean }\end{array}$ & .11543 & & & & \\
\hline \multirow[t]{4}{*}{ I know more about my health since EMR implementation } & $\mathrm{N}$ & 154 & & & & \\
\hline & Mean & 2.4935 & -.0002 & .0882 & 2.3300 & 2.6830 \\
\hline & $\begin{array}{l}\text { Std. } \\
\text { Deviation }\end{array}$ & 1.62596 & .00814 & .11831 & 1.42329 & 1.87571 \\
\hline & $\begin{array}{l}\text { Std. Error } \\
\text { Mean }\end{array}$ & .13102 & & & & \\
\hline \multirow[t]{4}{*}{ EMR helps me manage my care better } & $\mathrm{N}$ & 154 & & & & \\
\hline & Mean & 2.6039 & .0071 & .0909 & 2.4345 & 2.7928 \\
\hline & $\begin{array}{l}\text { Std. } \\
\text { Deviation }\end{array}$ & 1.71277 & .00345 & .10662 & 1.52024 & 1.94086 \\
\hline & $\begin{array}{l}\text { Std. Error } \\
\text { Mean }\end{array}$ & .13802 & & & & \\
\hline \multirow[t]{4}{*}{ I prefer email for my lab results, and questions about my health } & $\mathrm{N}$ & 154 & & & & \\
\hline & Mean & 3.0130 & -.0090 & .2934 & 2.5562 & 3.6800 \\
\hline & $\begin{array}{l}\text { Std. } \\
\text { Deviation }\end{array}$ & 4.26873 & .48004 & 1.72873 & 1.51229 & 7.00544 \\
\hline & $\begin{array}{l}\text { Std. Error } \\
\text { Mean }\end{array}$ & .34398 & & & & \\
\hline \multirow[t]{4}{*}{ I have multiple health conditions, I rely on others to help me } & $\mathrm{N}$ & 154 & & & & \\
\hline & Mean & 3.4805 & -.0138 & .2439 & 3.0974 & 4.0142 \\
\hline & $\begin{array}{l}\text { Std. } \\
\text { Deviation }\end{array}$ & 3.62493 & .35756 & 1.39259 & 1.50160 & 5.86457 \\
\hline & $\begin{array}{l}\text { Std. Error } \\
\text { Mean }\end{array}$ & .29211 & & & & \\
\hline
\end{tabular}




\begin{tabular}{|c|c|c|c|c|c|c|}
\hline \multirow[t]{4}{*}{ The emr helps me manage my health better than before } & $\mathrm{N}$ & 154 & & & & \\
\hline & Mean & 3.0130 & .0015 & .2186 & 2.6281 & 3.4162 \\
\hline & $\begin{array}{l}\text { Std. } \\
\text { Deviation }\end{array}$ & 4.19303 & .29053 & 1.48982 & 1.53608 & 5.70987 \\
\hline & $\begin{array}{l}\text { Std. Error } \\
\text { Mean }\end{array}$ & .33788 & & & & \\
\hline \multirow{4}{*}{$\begin{array}{l}\text { The emr helps me engage more and have more control of my } \\
\text { health }\end{array}$} & $\mathrm{N}$ & 154 & & & & \\
\hline & Mean & 2.7013 & .0027 & .0818 & 2.5514 & 2.8766 \\
\hline & $\begin{array}{l}\text { Std. } \\
\text { Deviation }\end{array}$ & 1.57650 & .00327 & .02539 & 1.52518 & 1.62427 \\
\hline & $\begin{array}{l}\text { Std. Error } \\
\text { Mean }\end{array}$ & .12704 & & & & \\
\hline \multirow{4}{*}{$\begin{array}{l}\text { My overall health has improved since the clinic started with the } \\
\text { electronic health record }\end{array}$} & $\mathrm{N}$ & 154 & & & & \\
\hline & Mean & 2.9221 & .0008 & .0830 & 2.7651 & 3.1110 \\
\hline & $\begin{array}{l}\text { Std. } \\
\text { Deviation }\end{array}$ & 1.64310 & $.00453^{-}$ & .02378 & 1.58985 & 1.67930 \\
\hline & $\begin{array}{l}\text { Std. Error } \\
\text { Mean }\end{array}$ & .13240 & & & & \\
\hline
\end{tabular}




\section{Appendix L: The Bootstrap for coefficients}

\section{Bootstrap for Coefficients}

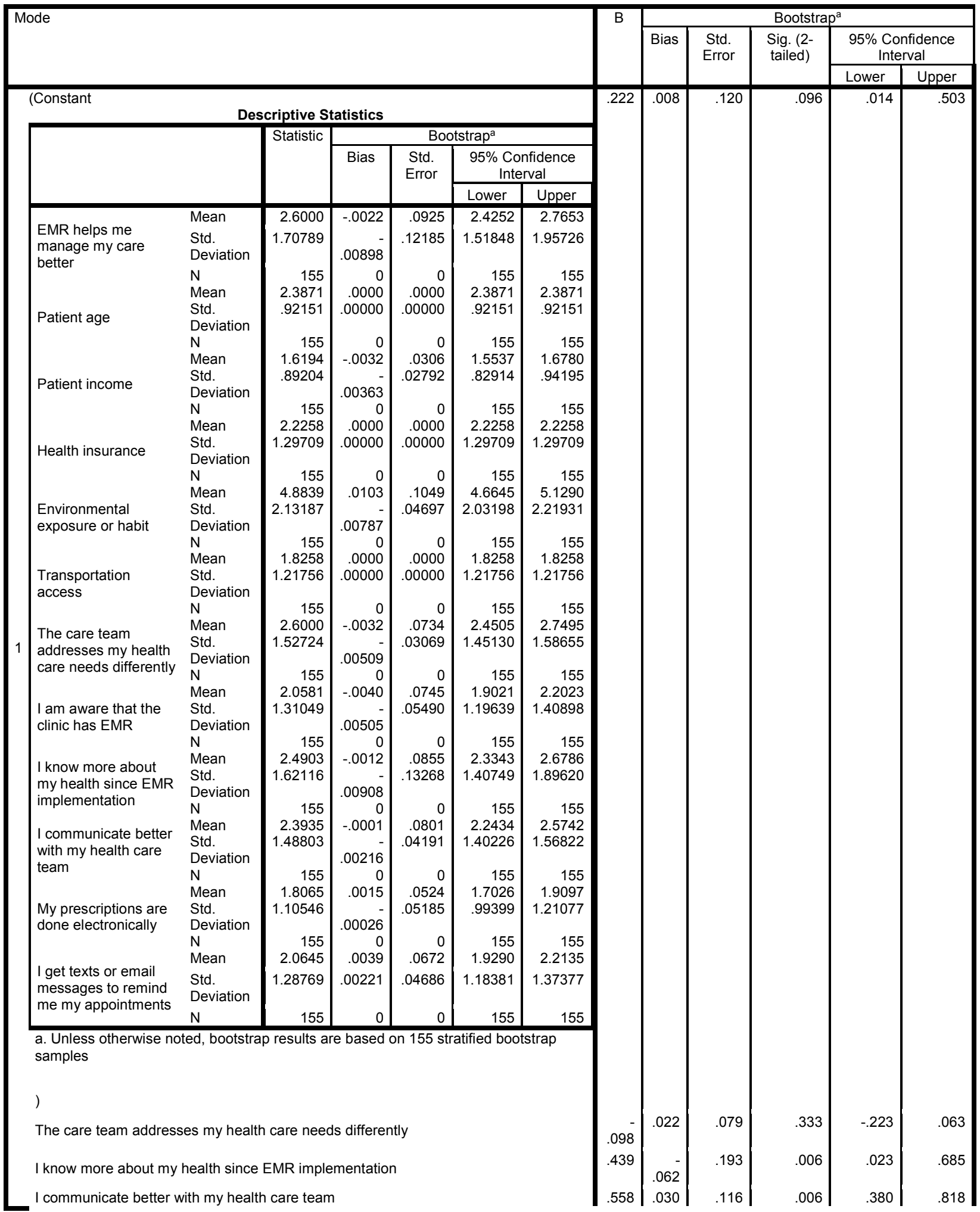


My prescriptions are done electronically

I get texts or email messages to remind me my appointments

\begin{tabular}{l|l}
.097 & .007 \\
.014 & \\
& .00
\end{tabular}

.007
-
.002

.052
.054

.064
.840

-.021
-.099

.199
.116

a. Unless otherwise noted, bootstrap results are based on 155 stratified bootstrap samples

\section{Appendix M: Holistic Health Integration Care Plan Model}

Table M1.

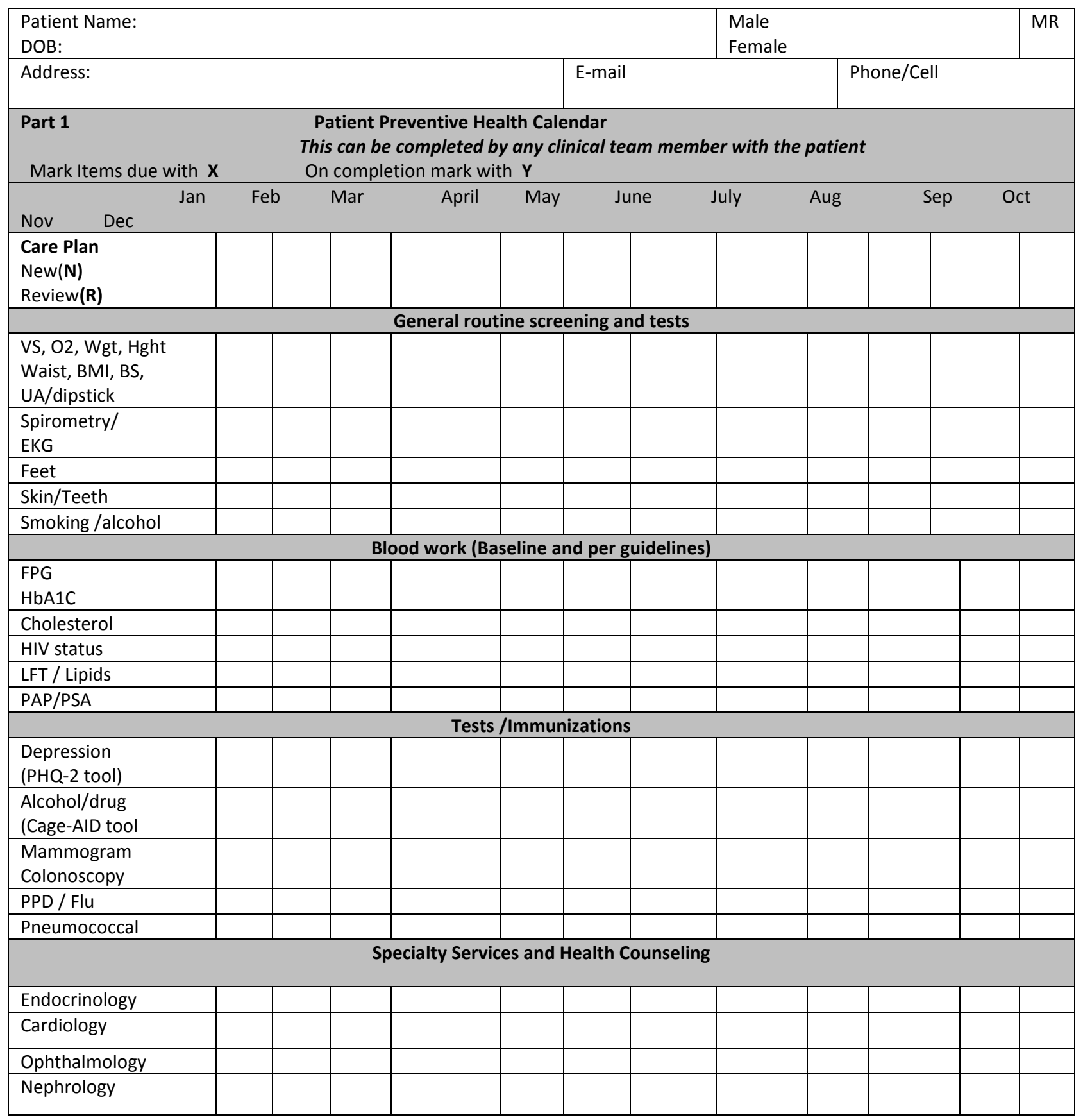




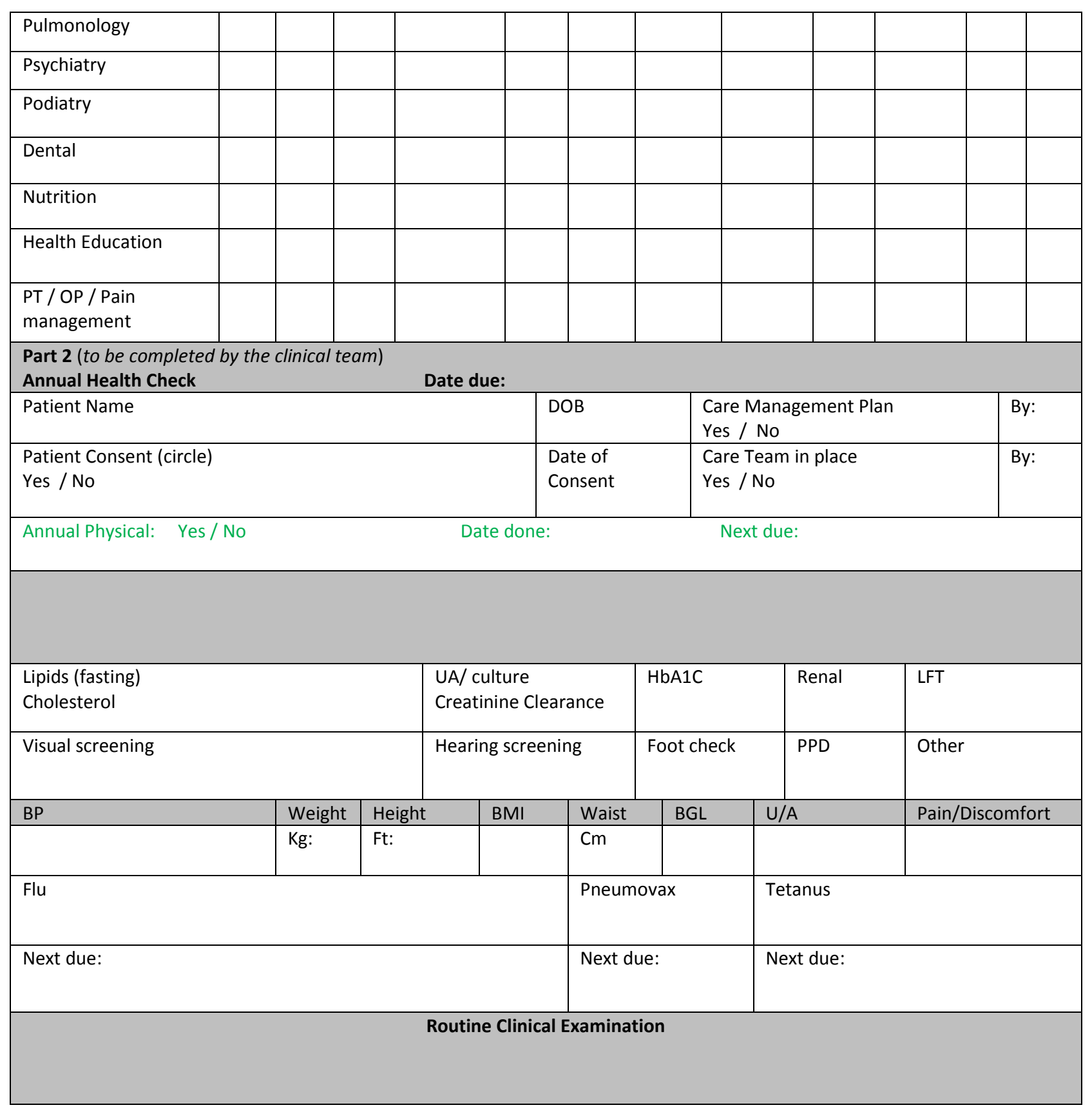


Eyes

Skin

Oral health

Cardiovascular

Respiratory

Abdominal

Gastrointestinal

Musculoskeletal

Neurological

Renal / Urological

Feet : Pulses

$\mathrm{N} /$ Abnormal

(Yes/No) : R L Both

Skin Integrity

Medications (Review and New)

Discharge plan

Referrals made (Please circle)

Cardiologist Ophthalmologist

Nephrologists Mental Health

Social Worker/ Case Management

Medication Management

Nutrition Management

Weight Management

Dr.'s Name

Dr.'s signature

Date

Transportation arrangement needs:

Next visit plan (to be done with patient)

Additional issues and concerns 


\begin{tabular}{|l|l|l|}
\hline \multicolumn{2}{|l|}{ Part 3 Pertinent Visit Summary } \\
\hline \multicolumn{2}{|l|}{ Please ensure that all health related issues are listed and all medications are updated } \\
\hline Risks Factors & Adherence to treatment & \\
\hline A & Diet/Nutrition & \\
\hline D & Alcohol/Substance Abuse & \\
\hline A & Physical Activity & \\
\hline P & Typical stressors / concerns & Social / Economic Situations \\
\hline T
\end{tabular}

\begin{tabular}{|l|l|l|l|}
\hline \multicolumn{3}{|c|}{ Personal Health Goals (to be done with patient) } \\
\hline & & & \\
\hline & & & \\
\hline & & & \\
\hline & & & \\
\hline
\end{tabular}

\begin{tabular}{|l|l|l|l|l|l|l|l|l|}
\hline Waist & Weight & BMI & BP & HbA1C & Cholesterol & Feet & Immunizations & Behavioral change \\
\hline & & & & & & & & \\
\hline & & & & & & & & \\
\hline $\begin{array}{l}\text { Part 4 Evidence-based Care } \\
\text { Chronic Disease Care Plan Review (To be completed by Care Team Manager) }\end{array}$ \\
\begin{tabular}{|l|l|l|l|l|} 
Year 1 \\
Clinical goals and Indicators
\end{tabular} \\
\begin{tabular}{|l|l|l|l|l|l|} 
Date due: \\
progress notes to complete \\
BP
\end{tabular} & Waist & Weight & BMI & HbA1C & Cholesterol & Immunizations & $\begin{array}{l}\text { Hospitalizations /ER } \\
\text { visits }\end{array}$ \\
\hline
\end{tabular}




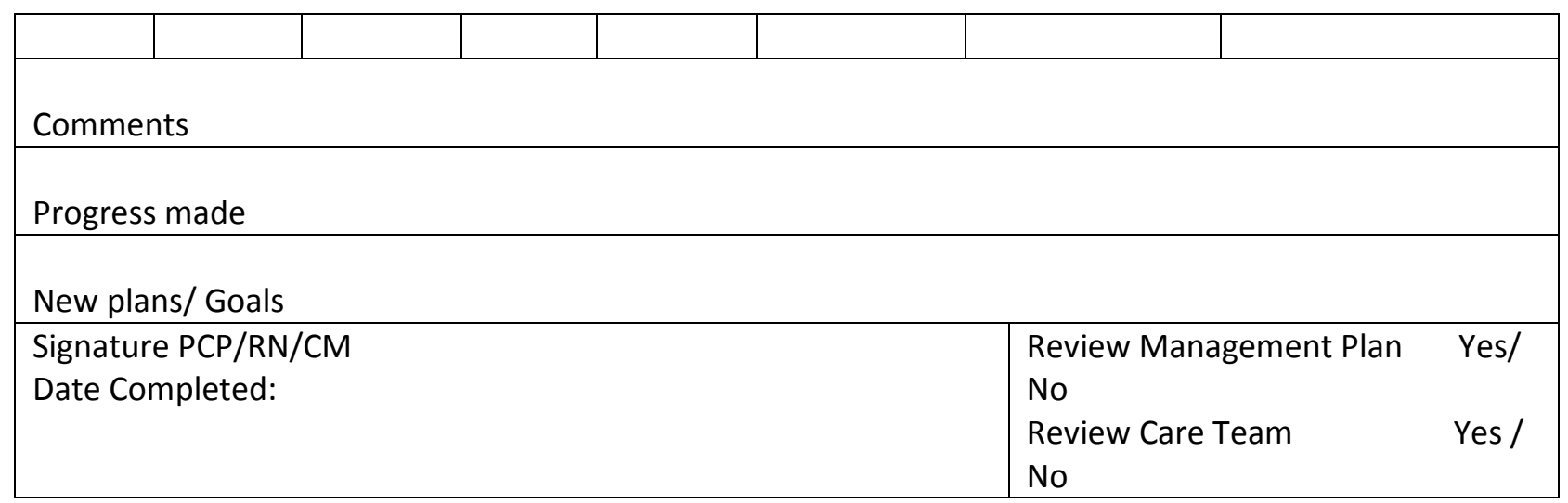

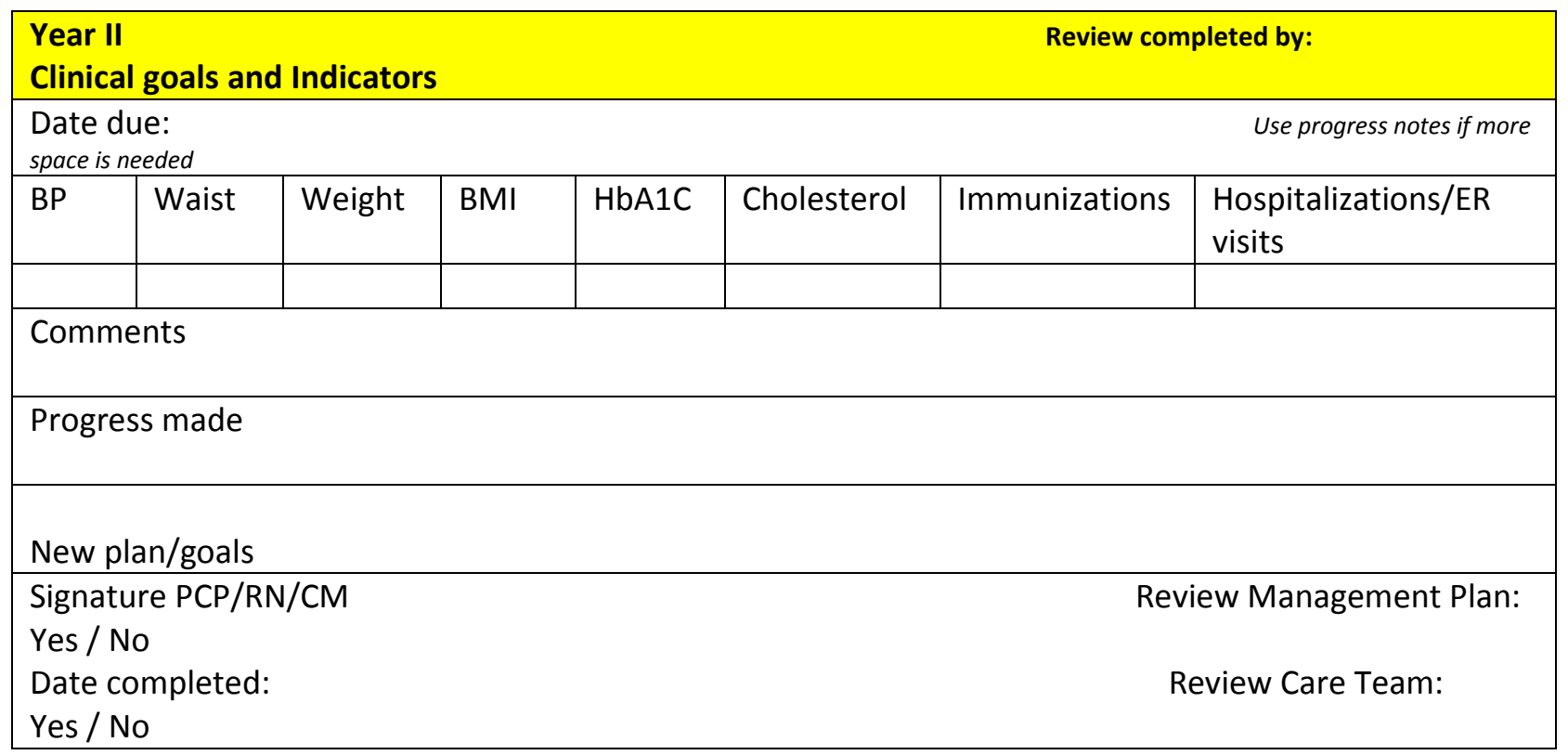

\begin{tabular}{|c|c|c|c|c|c|c|c|}
\hline \multicolumn{8}{|c|}{$\begin{array}{l}\text { Part V } \\
\text { Clinical Goals and Indicators }\end{array}$} \\
\hline \multicolumn{5}{|c|}{ Date Due } & \multicolumn{3}{|c|}{ Use progress notes for additional information } \\
\hline BP & Waist & Weight & BMI & $\mathrm{HbA1C}$ & Cholesterol & Immunizations & $\begin{array}{l}\text { Hospitalizations/ER } \\
\text { visits }\end{array}$ \\
\hline \multicolumn{8}{|c|}{ Comments } \\
\hline \multicolumn{8}{|c|}{ Progress made } \\
\hline \multicolumn{8}{|c|}{ New Plans/ Goals } \\
\hline \multicolumn{8}{|c|}{ Recommendations } \\
\hline \multicolumn{5}{|c|}{$\begin{array}{l}\text { Signature PCP/RN/CM } \\
\text { Yes / No }\end{array}$} & \multicolumn{3}{|c|}{ Review Management Plan: } \\
\hline
\end{tabular}


Date completed:

Review Care Team:

Yes / No 